
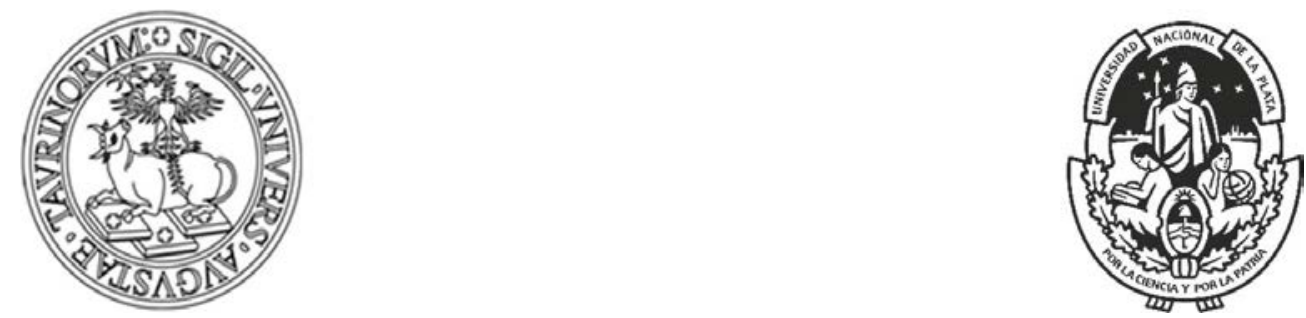

Università degli Studi di Torino

Doctoral School of Sciences and Innovative Technologies

PhD Programme in Chemical and Materials Sciences

University of La Plata

Faculty of Exact Sciences, Department of Chemistry

PhD in Exact Sciences, Chemistry Area

\title{
Obtaining Magnetic Nanoparticles as low-cost photocatalysts for water treatments
}

\author{
Francisca Aparicio
}

Supervisors:

Prof. Giuliana Magnacca

Prof. Daniel O. Mártire

Prof. Luciano Carlos 



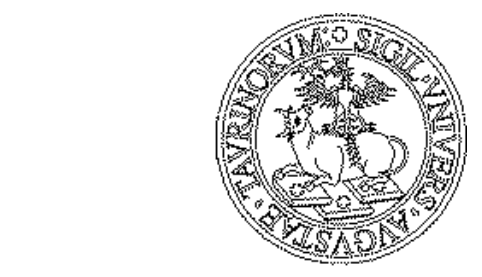

\section{Università degli Studi di Torino}

Doctoral School of Sciences and Innovative Technologies

PhD Programme in Chemical and Materials Sciences XXIX cycle

\section{Obtaining Magnetic Nanoparticles as low-cost photo catalysts for water treatments}

$\begin{array}{ll}\text { Candidate: } & \text { Francisca Aparicio } \\ \text { Supervisor: } & \text { Prof. Giuliana Magnacca }\end{array}$

Jury Members: $\quad$ Prof. Enzo Laurenti

University of Turin

Department of Chemistry

Prof. Marìa Giulia Faga

CNR, Italy

Prof. Gustavo Ruiz

University of La Plata

Department of Chemistry

Prof. M. Gabriela Lagorio

University of Buenos Aires

Department of Inorganic, Analytical and Physical Chemistry

Head of the Doctoral School: Prof. Massimo Maffei

PhD Programme Coordinator: Prof. Mario Chiesa 



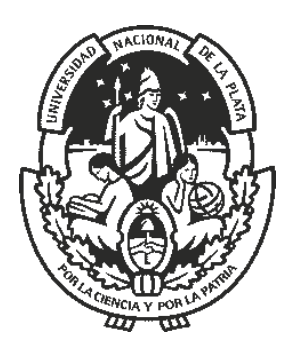

\section{UNIVERSIDAD NACIONAL DE LA PLATA}

FACULTAD DE CIENCIAS EXACTAS

DEPARTAMENTO DE QUÍMICA

Trabajo de Tesis Doctoral:

Obtención de Nanomateriales magnéticos como fotosensibilizadores de bajo costo para tratamiento de aguas

Tesista: Lic. Francisca Aparicio

Directores: Dr. Daniel O. Mártire-Dr. Luciano Carlos

Año: 2019 

Se aprende en la cuna se aprende en la cama se aprende en la puerta de un hospital Se aprende de golpe se aprende de a poco $y$ a veces se aprende recién al final ${ }^{1}$.

\footnotetext{
${ }^{1}$ "It is learned in the cradle/it is learned in bed/it is learned at the door of a hospital/It is learned all at once, /It is learned little by little/and sometimes it is learned only at the end." - Jorge Drexler "Polvo de Estrellas"
} 



\section{Index}

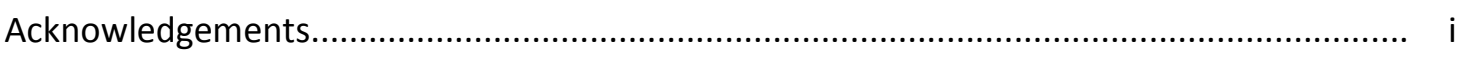

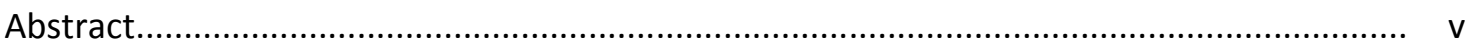

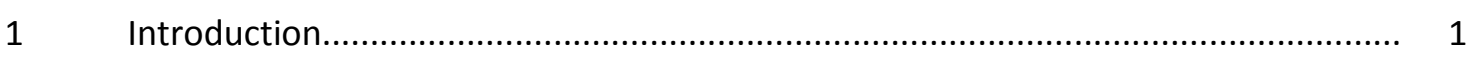

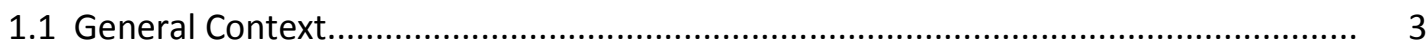

AOPs: Advanced Oxidation Processes. Photocatalysis for water treatment.

Photocatalysis with magnetic nanomaterials................................................................ 3

Iron Oxides as photocatalysts......................................................................... 8

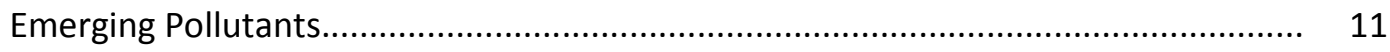

BBS: origin and chemical structure. Potential applications....................................... 13

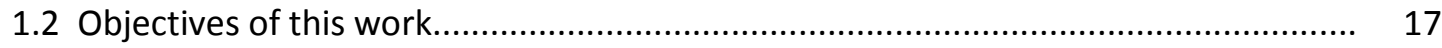

1.3 Appendix: Waste to Energy Biorefineries............................................................. $\quad 19$

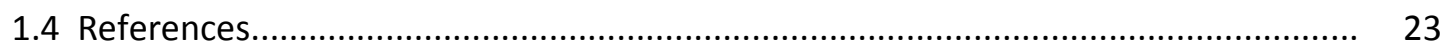

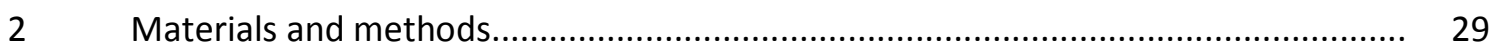

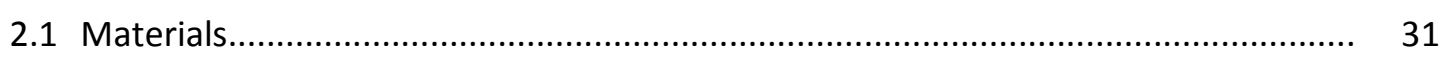

2.2 Preparation of magnetic nanocomposites.......................................................... 35

2.3 Characterization Techniques......................................................................... 37

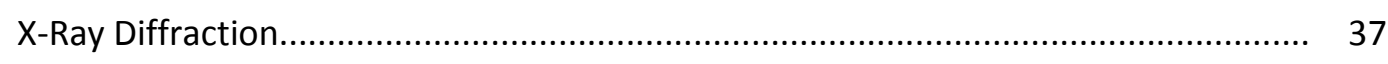

X-Ray Absorption Spectroscopy (XRS) ............................................................. 38

Fourier Transform Infrared Spectroscopy (FT-IR) ............................................... 40

Atomic Absorption Spectroscopy (AAS) ................................................................ 41

Elemental Analysis - CHONS determination.............................................................. 41

Diffuse Reflectance Spectroscopy (DRS) ............................................................ 42

Thermogravimetric Analysis (TGA) ....................................................................... 44

Specific Surface Area.......................................................................................... 44

Magnetic Properties.......................................................................................... 46

High Resolution Transmission Electron Microscopy (HR-TEM)................................. 47

Electronic Paramagnetic Resonance (EPR)....................................................... 48

Laser Flash Photolysis (LFP) ........................................................................... $\quad 50$

2.4 Photochemical Experiments..................................................................................... 53

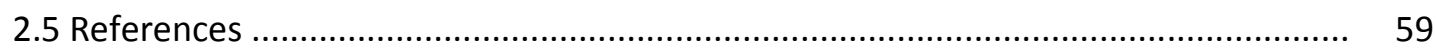

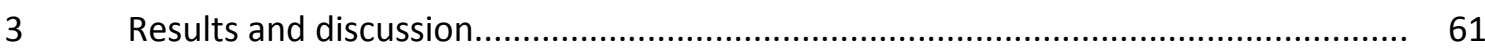

3.1 Physicochemical Characterizations ....................................................................... 63 


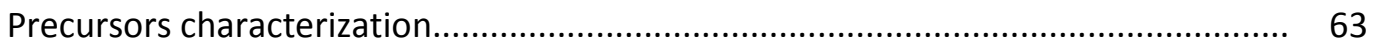

Magnetic Nanocomposites................................................................................. 69

3.2 UV-Visible Light Absorption Spectroscopy............................................................ 109

3.3 Transients Characterization and ROS generation.................................................. 117

Transient Absorption Spectroscopy ................................................................... 117

Electronic Paramagnetic Resonance...................................................................... 129

3.4 Appendix: Preparation and characterization of auxiliary materials.......................... 137

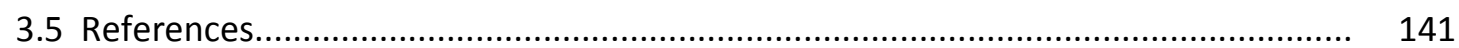

$4 \quad$ Carbamazepine photodegradation................................................................ 147

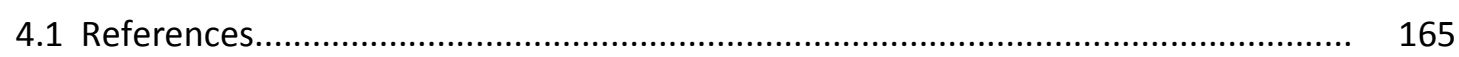

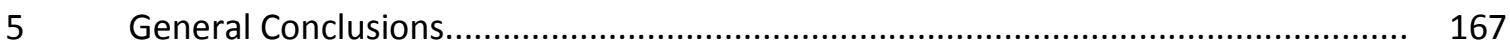

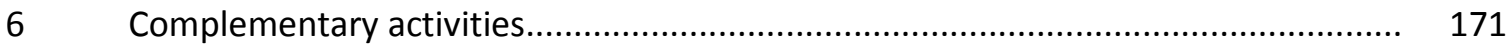




\section{Acknowledgements}

Taking a doctorate means learning on how to investigate, learning on how to research as a daily task, getting an own way of working. I owe a huge part of that learning to my supervisors Daniel and Lucho. Each one with his own imprint, but both of them with admirable professional and human qualities. Thanks to them for their generosity to share their experiences, for the effort to overcome times and distances; for their understanding on that this process demands specific efforts for everyone; for accompanying me in the moments when I doubted of myself, for giving me the necessary confidence to be able to fulfill this objective. For their impeccable commitment and dedication.

To my colleagues of (ex)LEAR: Belu, Lau Gomez, Juaqui, Emi, Lu, Darlin, Damián, Darío, Lau Dittler, Colo, Gaby, Lau Dell'Arciprete, Hernán, Paula, Janina, Lu Rossi, Mónica, Juanjo, Crischu, Fabio, Vale. Daily sharing spice up any human bond and exposes us in ways we would never suspect. Getting friendships of all this is something that I never would have imagined, and that I appreciate infinitely. To the guys of AOPs group (Andrés, Eli, Bruno, Fede, Seba) and the rest of the first floor of the INIFTA (Eugenia, Paula, Ale, Iván, Chino), for all the talks and moments shared. Among other people of INIFTA who helped me and accompanied me during this time in a thousand ways, I would like to especially mention Martín Mizrahi, for the XANES measurements and his invaluable help, predisposition and patience; to Leandro Andrini, for his listening and his contributions to the visualization of the senses of our doing as scientists; and to Agustín Iborra, for his friendship.

To the Italian side, for the possibility of learning with them. Especially Giuliana Magnacca, for her warmth and confidence to receive me at UniTo. To Roberto, Flavia, Marco, Luca, Miche, Martini, Pavlò, Razieh, Chiara, Enzo and Gloria, for their company in each stay. And Valentina Crocellà, and the guys of the Center for Nanostructured Interfaces and Surfaces, for their help on the measures and preparation of the materials. To have the possibility of knowing different ways of working and see different realities to 
develop our tasks meant an expansion of my perception, and led me to verify that beyond those differences, what drives us all is the same.

To the staff of the Physical Chemistry course of the FCE - UNLP, for sharing the beautiful task of teaching. I learned a lot about physical chemistry during the thesis, and a large part I owe to work as a teacher with them.

To the Cátedra Libre de Ciencia, Política y Sociedad of the UNLP, for their work bringing much-needed debates about the scientific work.

To Victoria Gallegos and Sol Represa. Friends and colleagues. Working with friends is one of the most beautiful things that happened to me in these years.

To my friends, those from La Plata and those from beyond. Those I have met at the faculty, with whom we have continued to meet at this stage. And also, those I have found all around different corners of this wonderful city, that we learned how to become our home. To all of them: thanks for making me see that the multiplicity of ways of understanding life, enriches our ways of being in the world.

Finally, I appreciate having the opportunity to do this thesis work. And that involves many more actors than I was able to see at the beginning of this process. I would not have even thought about working on scientific research, if not for two high school teachers who showed us this world and encouraged us to dare. The task of teachers of elementary and high schools in the formation of the subjectivity of girls that can be foreshadowed as scientific workers is extremely necessary. And scarce. I greatly appreciate having met with women who showed me that we can do it. I would not have been able to study at the Universidad Nacional de La Plata if not for the Public Education system of our country. To all those who had stand for years, dedicating hours of their time to carry out discussions and concrete actions to guarantee access to education. Each contribution of each person to sustain the Public University is invaluable, and it is what has made it possible for many of us to make this portion of our formation. And not only to form professionals but actual political actors of our society. The Public, secular, free, cogoverned University is an experience of integral formation. 
The R\&D system of our country is also supported by public funds. I have had the privilege of accessing a Ph.D scholarship in the year 2015, granted by the National Council for Scientific and Technical Research (CONICET). A historical year for our country in terms of R\&D investment: to this day, it was the year in which the largest investment was destined to this area, and that was reflected in the fact that 2015 was the year with the largest number of Ph.D scholarships awarded (1796 just by CONICET throughout the national territory). Four years from that, the situation has changed drastically: the public policies on R\&D of the latter government have been a disrespect for the sector and the entire population. I am very proud to belong to this generation of scholars and $R \& D$ workers.

To my family, for having always been a support and a stimulus for growth, I thank you all very especially. To my sister, with whom this new stage brought us closer, and also revealed her as a friend. And to Luz, with whom life brought us together in the construction of a home, for their company and patience, especially in the last part of this work. 



\section{Abstract}

Heterogeneous photocatalytic processes have attracted massive attention as potentially efficient, environmentally friendly and low cost methods for water purification. However, some limitations regarding to recovery and reuse of the photocatalysts have inhibited their application in real systems. This issue can be overcome providing magnetic properties to the photocatalysts allowing an efficient separation and recovery with an external magnetic field. In this work, magnetic nanocomposites were developed to be used as photocatalysts in photochemical treatments for the degradation of pollutants from wastewater. Carbon coated iron and copper oxides nanocomposites were prepared by using the precursor method under different conditions. Soluble substances isolated from urban biowaste were used as carbon sources in the synthesis procedure. The composition, texture, structure and morphology of the nanocomposites were thoroughly characterized by Fourier transform infrared spectroscopy (FT-IR), X-ray diffraction (XRD), $X$-ray absorption spectroscopy (XRS), elemental analysis, nitrogen $\left(\mathrm{N}_{2}\right)$ sorption analysis, thermogravimetric analysis (TGA), high resolution transmission electron microscopy (HR-TEM), UV-Vis diffuse reflectance spectroscopy (DRS) and vibrating sample magnetometer (VSM). The capacity of the as-prepared nanocomposites for the generation of reactive species under UVA light was evaluated by laser flash photolysis (LFP) experiments and by the electronic paramagnetic resonance (EPR) spin-trap technique. Their photocatalytic activities were tested by using carbamazepine (CBZ) as model of an emerging pollutant (EP), under UVA light by varying different parameters including composition and concentration of the photocatalysts. The as-prepared nanocomposites showed a strong dependence of their photocatalytic activity on the synthesis conditions. Particularly, nanocomposites obtained with the lower organic matter content and pyrolyzed at 600 and $800{ }^{\circ} \mathrm{C}$ yielded the highest photocatalytic activities for the CBZ degradation. In summary, this Thesis reports the methods of preparation of magnetic photocatalysts with environmental applications, revalorizing solid urban wastes as the carbon sources necessary for the synthesis of the precursor complexes. The use of products obtained from urban wastes for making photocatalysts for the treatment of wastewaters is expected to contribute to the sustainability of these procedures. 

1 Introduction 



\subsection{General Context}

\section{AOPs: Advanced Oxidation Processes. Photocatalysis for water treatment.Photocatalysis with magnetic nanomaterials}

The uncontrolled dumping of industrial and municipal waste into rivers and lakes is causing serious problems to the water resources of several regions, endangering in many cases the equilibrium of different ecosystems and the health of population. Despite the important achievements in the search for greater efficiency and productivity of the chemical processes that are used today, the treatment of industrial effluents containing organic pollutants is still a serious problem to be solved. On the other hand, the problem generated by water pollution has made the control of waste increasingly demanding and led to more restrictive regulations on the permitted content of hazardous compounds in industrial and municipal discharges. Thus, the incorporation of new technologies for the purification of wastewater from many industries is essential. In recent decades, this fact has driven the development of new decontamination technologies, with the aim of providing economically viable alternatives that enable an effective degradation of the pollutants.

Water contaminated by human activity can, in general, be processed efficiently by biological treatment plants, by adsorption with activated carbon or other adsorbents, by membrane processes or by conventional chemical treatments (thermal oxidation, chlorination, etc.). However, in some cases where the water is contaminated with substances refractory to conventional methods, these procedures are inadequate to reach the concentration levels required by law for the subsequent use of the treated effluent. In these cases, the use of the so-called Advanced Oxidation Processes (AOPs) results an alternative that may solve this issue. AOPs are based on physicochemical processes that produce deep changes in the structure of chemical species (Litter, 1999). Most of these processes involve the oxidation of the contaminants mediated by powerful transitory species, mainly the hydroxyl radical $\left(\mathrm{HO}^{\circ}\right)$. Some AOPs, such as heterogeneous photocatalysts, can also produce reducing agents, allowing the degradation of contaminants that are difficult to oxidize, e.g. some metal ions or halogenated 
compounds. AOPs are also especially useful as "pre-treatment" before a biological treatment or as a "post-treatment" process to improve the quality of the water before its discharge into the receiving bodies.

Regarding the methodology to generate hydroxyl radicals, AOPs can be divided into chemical, electro-chemical, sono-chemical and photochemical processes (Babuponnusami \& Muthukumar, 2014). Conventional AOPs can be also classified as homogeneous and heterogeneous processes, depending on whether they take place in a single phase or they make use of a heterogeneous catalyst like metal supported catalysts, carbon materials or semiconductors such as $\mathrm{TiO}_{2}$ (Oliveira et al., 2014). Also, AOPs are usually divided into non-photochemical and photochemical processes, as listed inTable 1.1

Table 1.1: Advanced Oxidation Technologies and other related processes ${ }^{a}$

\begin{tabular}{ll}
\hline \multicolumn{1}{c}{ Non-photochemical processes } & \multicolumn{1}{c}{ Photochemical processes } \\
\hline Alkaline ozonation $\left(\mathrm{O}_{3} / \mathrm{OH}^{-}\right)$ & Water photolysis in vacuum ultraviolet (VUV) \\
Ozonation with hydrogen peroxide $\left(\mathrm{O}_{3} / \mathrm{H}_{2} \mathrm{O}_{2}\right)$ & $\mathrm{UV} /$ hydrogen peroxide \\
Fenton and related processes $\left(\mathrm{Fe}^{2+} / \mathrm{H}_{2} \mathrm{O}_{2}\right)$ & $\mathrm{UV} / \mathrm{O}_{3}$ \\
Electrochemical oxidation & Photo-Fenton and related processes \\
Y-Radiolysis and electron-beam treatment & UV-periodate \\
Activated persulfate & UV-persulfate \\
Non-thermal plasma & Heterogeneous photocatalysis \\
Electrohydraulic discharge-ultrasound & \\
Oxidation in sub/and supercritical water & \\
Zero-valent iron & \\
Ferrate $\left(\mathrm{K}_{2} \mathrm{FeO}{ }_{4}, \mathrm{Fe}(\mathrm{VI})\right)$
\end{tabular}

atitter, 1999; Guerra-Rodríguez et al., 2018

The high efficiency of AOPs is supported on thermodynamic and kinetic grounds, due to the participation of radicals, mainly hydroxyl $\left(\mathrm{HO}^{\circ}\right)$ and sulfate radicals $\left(\mathrm{SO}_{4}{ }^{-}\right)$. For instance, the hydroxyl radical can attack virtually all organic compounds and it reacts $10^{6}-10^{12}$ times more rapidly than alternative oxidants such as $\mathrm{O}_{3}$. In Table 1.2 , it can be 
observed that, hydroxyl $\left(\mathrm{HO}^{\circ}\right)$ and sulfate radicals $\left(\mathrm{SO}_{4}{ }^{\circ}\right)$ are among the most energetic oxidant agents.

Table 1.2: Oxidation potential of commonly used oxidants ${ }^{a}$

\begin{tabular}{cc}
\hline Oxidant & Oxidation potential (V) \\
\hline Fluorine $\mathrm{F}_{2}$ & 3.0 \\
Hydroxyl radical $\mathrm{OH}^{-}$ & 2.8 \\
Sulfate radical $\mathrm{SO}_{4}{ }^{-}$ & $2.5-3.1$ \\
Ozone $\mathrm{O}_{3}$ & 2.1 \\
Persulfate $\mathrm{S}_{2} \mathrm{O}_{8}^{2-}$ & 2.1 \\
Peroxymonosulfate $\mathrm{HSO}_{5}^{-}$ & 1.8 \\
Hydrogen peroxide $\mathrm{H}_{2} \mathrm{O}_{2}$ & 1.8 \\
Permanganate $\mathrm{MnO}_{4}^{-}$ & 1.7 \\
Chlorine dioxide $\mathrm{ClO}_{2}$ & 1.5 \\
Chlorine $\mathrm{Cl}_{2}$ & 1.4
\end{tabular}

J. Wang \& Wang, 2018

Heterogeneous photocatalysis has rapidly emerged as the most attractive AOP in recent years for the destruction of organic, inorganic, and microbial pollutants due to a number of advantages, such as its versatile nature in terms of the variety of pollutants that can be removed, the potential to completely mineralize organic pollutants, the ability to use solar radiation in some cases to reduce the operational costs, and its capacity of being reused in several treatment cycles (Byrne et al., 2018). Heterogeneous photocatalysis can be defined as the acceleration of photoreactions in the presence of a catalyst. One of the first works of investigation in this field goes back to principles of the decade of 1970, when the first publications on water-splitting with $\mathrm{TiO}_{2}$ appeared. Since then, different aspects of the technique have been investigated, as well as several applications developed. Perhaps one of the most interesting applications is the purification of air and water where contaminants are present at low concentrations.

The basic principle that underlies the process of photocatalysis is the physicalchemistry of semiconductors. The conductivity is explained as the mobility of the charge 
carriers (i.e., electrons) between the valence band (VB) and the conduction band (CB). An intermediate situation, between metals and insulators is found in the semiconductors, where $d$ orbitals are involved. These materials have an unfilled VB, but the separation between levels is not large, and electrons can be promoted through the application of energy, which gives place to the phenomenon of conductivity. The separation between the VB and $C B$ is called the band gap, and this difference in energy is a property of the material.

Fig. 1.1 shows the bandgap energy and band edge positions of common semiconductor oxides and semiconductor sulfides, along with selected redox potentials (Wu et al., 2015).

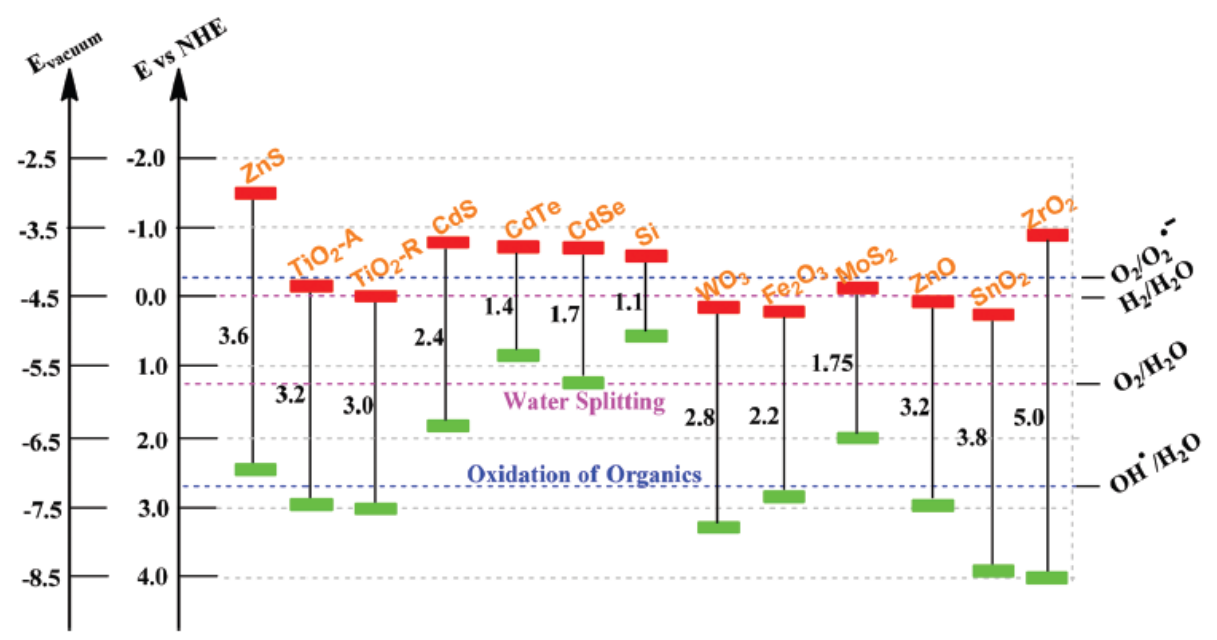

Fig. 1.1: Band gap energy, $V B$ and $C B$ for a range of semiconductors on a potential scale $(V)$ vs. the normal hydrogen electrode (NHE).

Electromagnetic radiation can promote the transfer of electrons, if the energy of the radiation is equal to or greater than the separation between bands. When an electron $\left(\mathrm{e}^{-}\right)$is excited and promoted to the $\mathrm{CB}$, a hole $\left(\mathrm{h}^{+}\right)$is generated in the VB (reaction 1$)$. After the pair $\mathrm{e}^{-} / \mathrm{h}^{+}$is generated, a number of processes can follow, such as: the recombination of electrons and holes (reaction 2) releasing heat; the reaction of holes with hydroxyl ions or water molecules adsorbed to the material surface to yield hydroxyl radicals (reaction $3)$; the reduction of molecular oxygen mediated by electrons to yield superoxide radical 
anions (reaction 4), and the reduction of hydroxyl radicals to yield hydroxyl ions (reaction 5) (Braun et al., 2002).

$$
\begin{aligned}
& \mathrm{SC} \rightarrow \mathrm{h}^{+}+\mathrm{e}^{-} \\
& \mathrm{h}^{+}+\mathrm{e}^{-} \rightarrow \text { heat } \\
& \mathrm{h}^{+}+\mathrm{OH}^{-}\left(\text {or } \mathrm{H}_{2} \mathrm{O}\right) \rightarrow \mathrm{HO}^{\circ} \\
& \mathrm{e}^{-}+\mathrm{O}_{2} \rightarrow \mathrm{O}_{2}^{--} \\
& \mathrm{e}^{-}+\mathrm{HO}^{-} \rightarrow \mathrm{OH}^{-}
\end{aligned}
$$

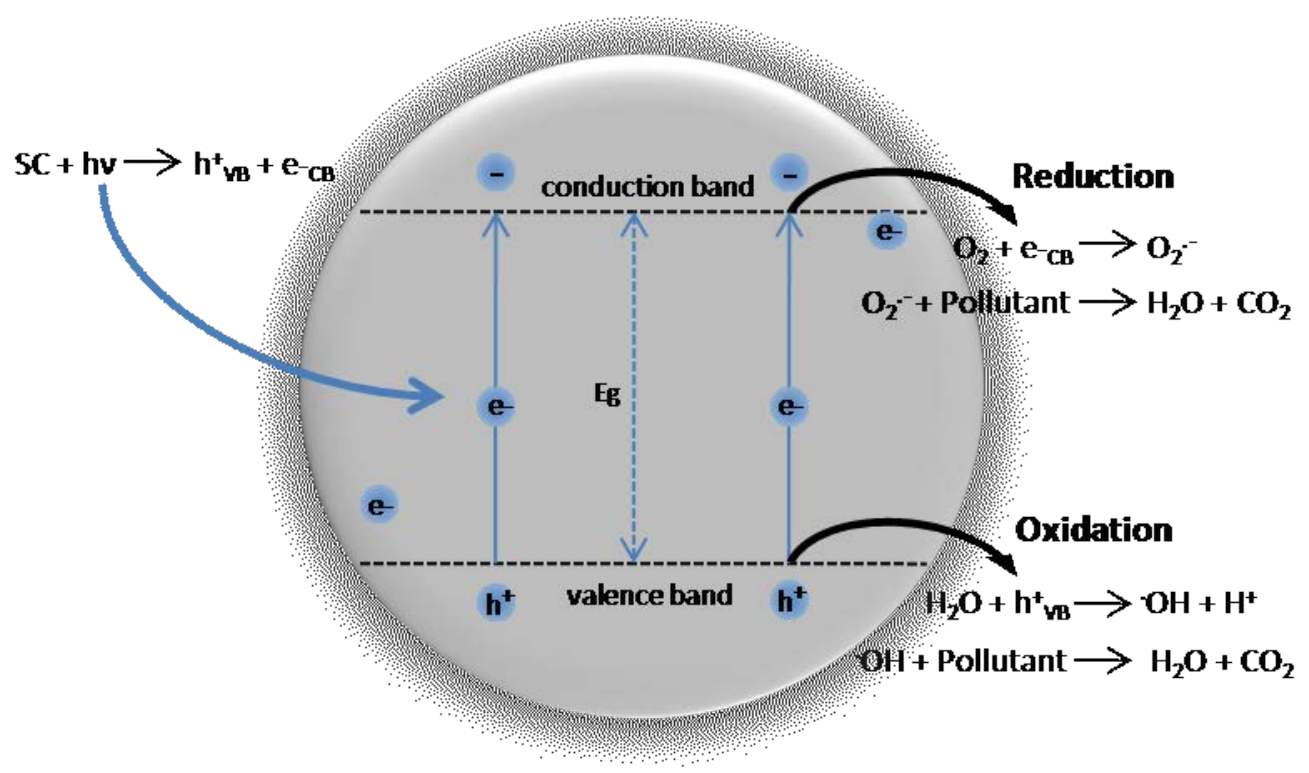

Fig. 1.2: Scheme of the generation of ROS by a semiconductor photocatalyst

In the presence of adsorbed water, the electrons are transferred from the water molecule to the holes to produce highly reactive oxygen species (ROS), such as $\mathrm{HO}^{\circ}$, superoxide anion radicals $\left(\mathrm{O}_{2}{ }^{--}\right)$, hydroperoxyl radical $\left(\mathrm{HO}_{2}{ }^{-}\right)$, that can react with organic compounds, degrading them into $\mathrm{CO}_{2}, \mathrm{H}_{2} \mathrm{O}$ and short chain organic acids (a scheme of these processes is depicted in Fig. 1.2). $\mathrm{HO}^{\circ}$ radicals play an important role in the initiation of oxidation reactions. This pathway is known as indirect oxidation to differentiate it from 
the direct oxidation produced by the holes. In order to guarantee the occurrence of reactions (3) and (4), the oxidation potential of the hydroxyl radicals $\left(\mathrm{E}_{0}\left(\mathrm{H}_{2} \mathrm{O} / \mathrm{HO}^{\circ}\right)=2.8 \mathrm{~V}\right.$ vs. $\mathrm{NHE})$ and the reduction potential of the superoxide radicals $\left(\mathrm{E}_{0}\left(\mathrm{O}_{2} / \mathrm{O}_{2}{ }^{-{ }^{-}}\right)=-0.28 \mathrm{~V}\right.$ vs. NHE), must lie well within the band gap. This means that the redox potential of the VB holes must be sufficiently positive to produce hydroxyl radicals and the CB electrons must be sufficiently negative to produce superoxide radicals (Vinu \& Madras, 2010). The bandgap energy and band edge positions of $\mathrm{TiO}_{2}, \mathrm{ZnO}, \mathrm{SnO}_{2}, \mathrm{Fe}_{2} \mathrm{O}_{3}, \mathrm{WO}_{3}$ and $\mathrm{ZrO}_{2}$ (see Fig. 1.1) are relatively good. Such semiconductor materials are used in photocatalysis due to their inherently filled VB and empty CB.

The efficiency of a photocatalyst depends on the competence between different transfer processes involving electrons and holes and their deactivation by recombination. In this context, there are intrinsic and extrinsic parameters to the photocatalyst that affect the kinetics and mechanisms of photocatalytic reactions in aqueous media. The crystallographic phase, the exposed crystalline face, the crystallite size and the presence of dopants, impurities, vacancies and different surface states can be included as the intrinsic factors. The surrounding environment and the photocatalytic conditions, $\mathrm{pH}$ of the solution, type of pollutant and its initial concentration, the presence of impurities in the system, the intensity of the light, the dosage of the catalyst and the flow rate are some of the extrinsic parameters (Pang et al., 2016).

\section{Iron Oxides as photocatalysts}

The most studied system to be used as a photocatalyst for water treatments has been $\mathrm{TiO}_{2}$. The major drawback for these photocatalysts is related to its relatively wide band gap energy, (i.e. $3.2 \mathrm{eV}$ for anatase and $3.02 \mathrm{eV}$ for rutile (Pang, et al., 2016)). In order to promote more efficient utilization of solar light, the development of visible light active or narrow band gap semiconductors as photocatalyts has attracted extensive attention. In this context, iron oxides with appropriate valence state and chemical compositions can be considered as high promising photocatalysts owing to their narrow band gap energies and low toxicity. It has been reported that iron oxide could absorb and 
utilize about $40 \%$ of the incident solar spectra (Zhang et al., 2010). However, its photocatalytic efficiency still depends on other factors, such as particle size, aggregates size in suspension, crystalline phase, crystallinity and other structural parameters (Gumy et al., 2008). In addition, magnetic iron oxides have the advantage that can be easily separated from the water body by applying a magnetic field, thus allowing the recuperation and reutilization of the catalyst.

Iron oxides can be obtained in several phases such as hematite $\left(\alpha-\mathrm{Fe}_{2} \mathrm{O}_{3}\right)$, maghemite $\left(\nu-\mathrm{Fe}_{2} \mathrm{O}_{3}\right)$, and magnetite $\left(\mathrm{Fe}_{3} \mathrm{O}_{4}, \mathrm{Fe}(\mathrm{II}) \mathrm{Fe}(\mathrm{III})_{2} \mathrm{O}_{4}\right)$, depending upon the synthesis method and conditions (Nisticò, 2017). Since both magnetite and maghemite present the same crystal organization(Wu et al., 2015) (see Fig. 1.3), and magnetite is sensitive to oxidation (Laurent et al., 2008) maghemite is assumed as a ferrous-deficient magnetite, obtained through topotactic oxidation of magnetite's Fe(II) ions into Fe(III) (Dronskowski, 2001), (Cesano et al., 2015). A different form of $\mathrm{Fe}_{2} \mathrm{O}_{3}$ is hematite $\left(\alpha-\mathrm{Fe}_{2} \mathrm{O}_{3}\right)$, which crystallizes in the rhombohedral lattice system, and has the same crystal structure as corundum (Wu, Jiang, et al., 2015)(see Fig. 1.3).

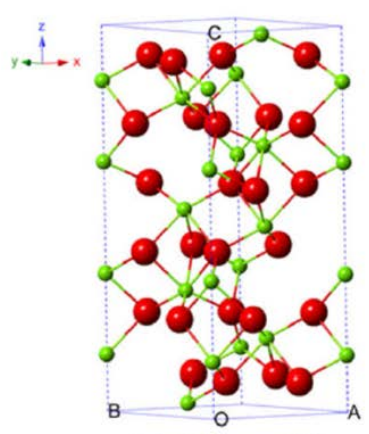

(a) Hematite Rhombohedral, $\mathrm{R} \overline{3} \mathrm{c}$

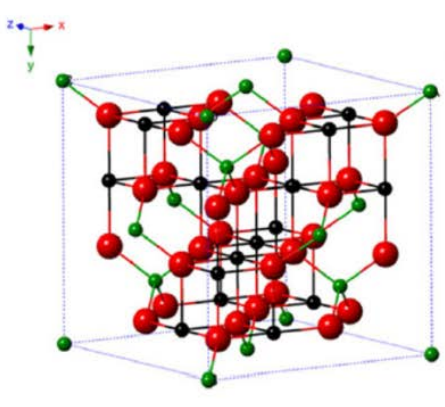

(b) Magnetite cubic, Fd3m

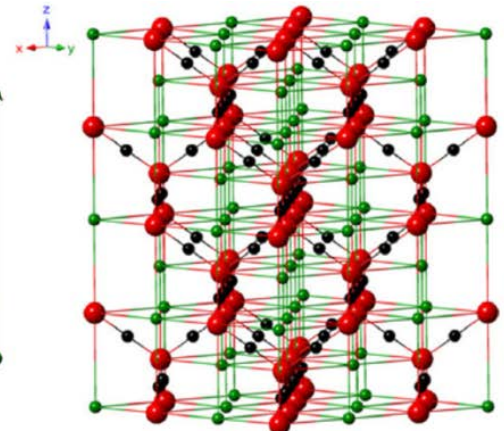

(c) Maghemite Cubic, $\mathrm{P} 4,32 / T$ tragonal, $\mathrm{P}_{1}, 2,2$

Fig. 1.3: Crystal structure and crystallographic data of hematite (a), magnetite (b), and maghemite (c). Legend: Fe(II) (black), Fe(III) (green), and O (red) (Wu, 2015)

There are various methods to synthesize magnetic iron oxide nanoparticles: co-precipitation of Fe ions in alkaline solutions, thermal decomposition of iron precursor (in organic solution or the dried complex-precursor treatment), and also hydrothermal, 
solvothermal and microemulsion methods (Alibeigi \& Vaezi, 2008, Wang, 2014, Deng et al., 2015, Kumar et al., 2013).

In addition, pure iron oxide exhibits a very short excited state lifetime, a short hole diffusion length and high recombination rate of photo-generated electron-hole pairs. Numerous efforts have been focused to improve the photocatalytic activity of iron oxide magnetic particles, such as doping with various metal or non-metal ions, incorporation of noble metals, as well as synthesis of composites with other photocatalysts to generate magnetic photocatalytic heterostructures. These heterostructures offer synergetic enhancement to the catalytic activity due to the suppressed recombination rate and promoted transportation rate of photo-generated charge carriers (Cong et al., 2014). On the other hand, it has been demonstrated that bimetallic copper and nanostructured iron materials have unique photocatalytic and magnetic properties. Kang and Wang prepared $\mathrm{Cu}-\mathrm{Fe}_{2} \mathrm{O}_{3} / \mathrm{Fe}$ photocatalysts for the degradation of methylene blue (Kang \& Wang, 2013). The nanomaterials consisted of bimetallic nanoparticles encapsulated in a carbon matrix, obtained by carbonization of $\mathrm{Fe}^{3+}$ and $\mathrm{Cu}^{2+}-\beta$-cyclodextrin (CD) complexes. More recently, different $\mathrm{Fe} / \mathrm{Cu}$ materials were prepared to be used as catalysts or photocatalysts. For example, $\mathrm{Cu}$ ferrites $\left(\mathrm{CuFe}_{2} \mathrm{O}_{4}\right)$ were prepared by a polymer precursor method at different temperatures and were used as catalysts in Fenton-like processes for the degradation of methylene blue (Naseriet al., 2013). The authors reported that when the temperature increased, the catalytic performance was reduced, which was attributed to the increase in particle size and the decrease in the number of surface -OH groups. Copper ferrites were also used as Fenton catalysts for the degradation of gallic acid (Dang et al., 2016). Other authors have prepared several ferrites $\left(\mathrm{MFe}_{2} \mathrm{O}_{4}\right.$ with $\mathrm{M}=\mathrm{Cu}$, $\mathrm{Co}$ and $\left.\mathrm{Zn}\right)$ and found that copper ferrite exhibited the best catalytic activity for the photodegradation of methylene blue in the presence of $\mathrm{H}_{2} \mathrm{O}_{2}$ under visible light (photo-Fenton process) (Sahaet al., 2016).

The coating with inorganic material such as silica, carbon and polymer can protect the magnetic particles from un-wanted degradation, whereas the use of organic material such as surfactants or polymers, enhance the particles dispersion. Several different synthesis strategies were published in recent years involving the use of diverse carbon 
sources, the application of several synthesis methods, resulting in a broad field of materials with different properties (Lu et al., 2007).

\section{Emerging Pollutants}

Because of the modern lifestyle, which includes the consumption of a wide variety of chemical products (pharmaceutical drugs, beauty products, recreational drugs, etc.), a new type of contamination has been established. This contamination is due to the socalled emerging pollutants. Emerging pollutants (EPs) are defined as synthetic or naturally occurring chemicals that are not commonly monitored in the environment but which have the potential to enter the environment and cause known or suspected adverse ecological and (or) human health effects (Geissen et al., 2015). This group of chemical substances are detected in fresh waters as a result of human activities. Perfluorinated compounds, pharmaceuticals, hormones, endocrine disruptors, disinfection byproducts, sunscreens, flame retardants, algal toxins, dioxane, pesticides and their degradation byproducts or nanomaterials are considered within this group (Petrovic \& Barceló, 2006), (Richardson, 2012).

In some countries, drugs are sold almost as much as pesticides (Fatta-Kassinos et al., 2011), even without a prescription. Among other types of emerging pollutants, pharmaceutical drugs have special features, which include polymorphism, its introduction into the environment after human metabolism, its chemically complex structure, and the fact that they can be ionized and have multiple ionization sites (Klaus, 2007). Pharmaceutical drugs have been detected in a wide variety of water samples, including wastewater flows, surface water and groundwater; with concentrations that generally vary from nanograms to micrograms per liter. Even though these compounds are commercialized after long and detailed researches on their structure, composition, and effects on human health, the exposure to long-term low doses is unknown, as well as their effect on the environment (World Health Organization, 2012). There are only a few 
studies of exposure at low doses compared to prolonged exposure, or when they are present in mixtures (Fatta-Kassinos et al., 2011).

After the application and/or ingestion, many medicines are excreted without having undergone metabolic modifications; others are metabolized. Consequently, they enter sewage through sewer systems, either in their original or metabolized form. In municipal wastewater treatment plants, incomplete removal or partial mineralization could take place, causing these compounds to end up in the environment.

The first studies that reported the existence of drugs in wastewater date back to the 1980s. In these pioneering works performed with samples taken in the United Kingdom, the presence of trichlorethylene, tetrachlorethylene and $p$-dichlorobenzene was reported in groundwater (Fielding et al., 1981) and several pharmaceutical products (caffeine, aspirin, morphine, among others) in wastewater, rivers and purified water (Richardson \& Bowron, 1985). From that moment, numerous studies have confirmed the existence of pharmaceutical compounds and their metabolites in aquatic matrices, sediments, soils and sludge, all around the world. In Argentina, the main effort has been made in the detection of agro-toxics that enter the environment through the irrigation water of agricultural activities. But information about the concentrations of EPs in aquatic environments of the country, their fate and behavior are incipient and fragmentary or non-existent. Researchers at the Centro de Investigaciones del Medioambiente (CIM, UNLP-CONICET) have carried out specific monitoring studies in six localities, with different degrees of urbanization, from the provinces of Buenos Aires and Córdoba. They have determined the prevalence and range of concentrations of four drugs in the effluents of primary treatment plants (Elorriagaet al., 2013).

The EP chosen in this thesis as a model to test the photocatalytic properties of the synthetized nanophotocatalysts is the psychiatric drug carbamazepine (Fig. 1.4), $5 \mathrm{H}-$ dibenzo[b,f]azepine-5-carboxamide, that passes sewage treatment plants relatively unchanged and hence can be found in many rivers and streams (Mcdowell et al., 2005). For instance, in Argentina carbamazepine was found in municipal wastewaters discharging 
into fresh and estuarine waters from areas with varying degrees of urbanization at concentrations in the range $0.2-2.3 \mu \mathrm{gL}^{-1}$ (Elorriaga et al., 2013b).

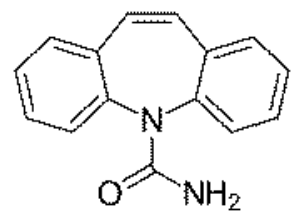

Fig. 1.4: Chemical structure of Carbamazepine

\section{BBS: origin and chemical structure. Potential applications}

Bio-Based Substances (BBS-GC, where GC stands for green compost) are supramolecular aggregates made of organic macromolecules with a highly branched and complex lignin-derived structure. Such substances are isolated from urban composted biowastes after more than 180 days of composting from the process lines of ACEA Pinerolese Industriale S.p.A. waste treatment plant in Pinerolo, Italy (ACEA, 2019). The process is an advanced system that comprises specific technological facilities, developed by Acea. The final products of the plant represent the biowastes types produced by a population of 2.9 million spread over a $13,732 \mathrm{~km}^{2}$ area, with $30 \%$ people living in one large metropolitan area and the rest distributed over other 564 small municipalities. More details about the operation of the plant and treatment of urban solid waste in Argentina are given in the Appendix "Waste to Energy Biorefineries", at the end of this section.

Because of the starting material complexity (i.e., urban public park trimming and home gardening residues), BBS-GC contain several functional groups (BBS-GC chemical structure and functionalities are fully reported in Materials and Methods chapter). These substances are new materials of biological origin with quite complex chemical composition, which could be defined as biopolymers having multiple randomly assembled repeating units. They are mixtures of molecules differing in molecular weight $\left(M_{W}\right)$ and organic moieties representing the memory of fats, proteins, polysaccharides and lignin contained in the sourcing refuse matter which is not completely mineralized by 
biodegradation. The chemical structure of BBS cannot be assessed as accurately as those of synthetic molecules. Also, the sourcing material and the type of treatment were found to significantly affect the chemical composition and properties of BBS. We have focused on CVT270, the name is an acronym used to indicate that it is obtained after 270 days of composting urban public park trimming and home gardening residues exclusively. The proposed structure of CVT270 is shown in Fig. 1.5.

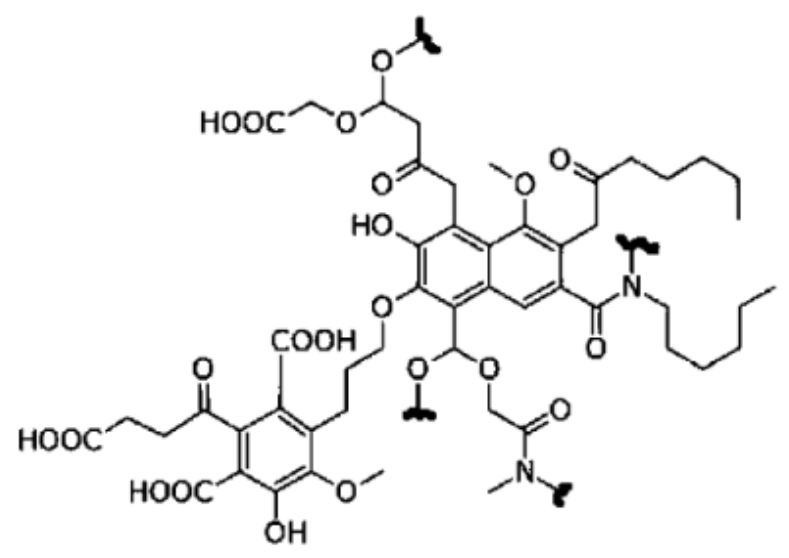

Fig. 1.5: proposed structure of a molecular fragment of BBS-GC CVT270 (from Montoneri et al., 2010)

The physico-chemical properties of BBS and their capacity of generating reactive species upon photoexcitation were investigated as part of the projects Biochemenergy (Mainero et al., 2011), EnvironBOS (CORDIS, 2015) and MAT4TREAT (UniTo, 2015). Their use in different technological applications was proposed: as templates for microporous materials' sol-gel synthesis (Boffa et al., 2010), as detergents or auxiliaries in textile dying because of their surfactant-like behavior in water solutions (Savarinoet al., 2010), as immobilizing agents for enzymes to prepare biocatalysts, among others. Since BBS have a similar behavior to that of humic acids regarding to the production of reactive species under irradiation in aqueous suspensions (Bianco Prevot et al., 2011), they were also tested as photosensitizing agents to be used in water treatments (Gomis et al., 2013) (Carlos, et al., 2012). Also, BBS were used as carbon sources for the preparation of carboncoated magnet-sensitive nanoparticles, which were tested as nanoadsorbents for the 
removal of organic and inorganic pollutants from waters (Magnacca et al., 2014; Nisticò et al., 2018a; Magnacca et al., 2018; Nisticò et al., 2018b). 



\subsection{Objectives of this work:}

The objective of this Ph.D. thesis is to enhance the available knowledge on the development of magnetic nanophotocatalysts to be used in photochemical methods for the degradation of pollutants from wastewater. Special emphasis will be laid on the use of substances extracted from urban composted biowaste as green precursors for the synthesis of the magnetic nanomaterials.

Specific objectives are:

- To prepare magnetic iron and copper nanocomposites with various coatings extracted from biowaste materials by using the precursor method under different conditions.

- To perform physicochemical characterizations of the obtained nanocomposites by Fourier transform infrared spectroscopy (FT-IR), X-ray diffraction (XRD), X-ray absorption spectroscopy (XRS), elemental analysis, nitrogen $\left(\mathrm{N}_{2}\right)$ sorption analysis, thermogravimetric analysis (TGA), transmission electronmicroscopy (TEM), UV-Vis diffuse reflectance spectroscopy (DRS) and vibrating sample magnetometer (VSM).

- To investigate the ability to generate reactive species under UVA light by laser flash photolysis (LFP) experiments and by electronic paramagnetic resonance (EPR) spintrapping technique.

- To investigate the photocatalytic activity of the prepared nanocomposites for the degradation of an emerging contaminant, carbamazepine, under UVA light by varying different parameters including composition and concentration of the photocatalysts. 



\subsection{Appendix: Waste to Energy Biorefineries}

\section{Acea plant: organic fraction as source of energy and soil conditioner}

The plant operated by ACEA Pinerolese, in North West Italy, is an example of integrated waste treatment processes. Its installation is designed to optimize energy and material recovery through the concerted operation of four plant sections treating all types of urban bio-wastes by anaerobic and aerobic microbial digestion. It is in the Italian town Pinerolo, in the region of Piedmont, and accepts waste from a third of the population of the Turin area (roughly 800.000 inhabitants). The factory has its own developments for treating the organic fraction of municipal solid waste and has made an affordable experience in term of anaerobic digestion.

The plant contains four sections: two for the treatment of solid wastes by anaerobic and aerobic digestion, the third one for treating wastewaters and the last one being a landfill area equipped for biogas collection. These four sections are interconnected to maximize biogas and compost yields from bio-waste, thus minimizing bio-refuse disposal to landfill. The key technological feature of the plant is the configuration, which integrates the four processes. Compared to the four processes run in separate plants, the integrated design allows the achievement of several desirable objectives, like the less surface area needed per treated bio-waste ton or the possibility to easily control the odor emission.

The bio-organic humid fraction is obtained from the raw bio-organic municipal solid waste, by separate source collection (mostly organic humid refuse recovered from town bins). The biogas released from the anaerobic digestion is transferred to a storage tank where the biogas streams coming from the other two sections are also flown in. The digestate from the anaerobic digester is sieved to remove residual non-biodegradable scraps (such as wood and nut shells), then treated in a dewatering station by a filter press to separate the solid material from the process water. The anaerobic digester is monitored for temperature, pressure, quality and production rate of biogas, and the solid matter is then transferred to the aerobic section. 
The aerobic digestion process takes place essentially in two phases, namely bioxidation and maturing. In the first bioxidation phase, the mass is cleansed by means of a traditional air flowing system through the basement. This is the active microbial biodegradation phase, taking place over about 28 days. During this time intensive exothermic bio-reactions occur. The ligno-cellulosic organic matter, not converted to biogas in the anaerobic process, is partially mineralized and partially converted to humic matter ((Centemero, 2006); (Montoneri et al., 2008)). Due to the intense carbon dioxide and water evolution, and consequent odor emission, the area is closed and equipped with a gas collection system connected to a bio-filter. In this phase occurs the major part of the carbon and nitrogen mineralization. The residual organic matter, mostly lignin-humus, is rather recalcitrant to microbial degradation. Thus, the second maturing phase occurring over about 7-8 weeks, is characterized by slow bioreactions and no significant gas evolution rate. During this time the compost product becomes enriched with humic substances and acquires more stability. The aerobic section processes basically three types of refuse: organic raw urban refuse, green residues and sewage. These are mixed in various ratios, depending on the level of heavy metal contents.

Also, the biogas produced in the anaerobic section is used to cover the energy consumption of the plant, produce hot water and the exceeding energy is sold for external use.

\section{Treatment of urban solid waste in Argentina}

In Argentina, the situation regarding to the urban solid waste is complex and inhomogeneous along the territory. The responsibility of the recollection of urban solid wastes belongs to municipal governments. In 2005 the Ministry of Health and Ambient designed a National Strategy for Urban Solid Wastes (USW), which was considered as the very beginning of the management of USW. In its first stages it was responsible of the elaboration of a database and statistics of the situation regarding USW in the different provinces. In this document, the production of compost from urban wastes is recommended. Although the most populated areas (Buenos Aires, Córdoba and Rosario) have facilities to compost production, the main production takes place in smaller cities 
(from 2,000 to 10,000 inhabitants). On the other hand, all municipalities with more than 500,000 inhabitants use the sanitary landfill method as final deposition; and other cities with 10,000 to 500,000 inhabitants still use the open-air waste disposal (González, 2011). The lack of public policies to manage this situation, poor infrastructure and investments, no appropriate legislation and population growth without urbanization planning need to be attended to assure the development of healthy societies, and reduce the ambient impact on air, earth and aquatic resources.

To this end, some initiatives have been recently implemented. The company CEAMSE (created by the states of Buenos Aires province and the city of Buenos Aires to manage the wastes of the metropolitan area) has recently opened a 500 hectares plant over a land-fill field of more than 61 million tons of wastes. It receives 15,500 tons of urban wastes daily. The $13 \%$ of these wastes are then processed to yield biogas, from which electrical energy to feed circa 25,000 houses is obtained; as well as irrigation water from the aerobic digestion and filtering of leached liquids. The complex also receives exhausted tires and residues from public trimming to make granulated rubber and fertilized compost, respectively. 



\subsection{References}

ACEA. (2019). IL POLO ECOLOGICO ACEA PINEROLESE - TRATTAMENTO RIFIUTI ORGANICI - Acea Pinerolese. Retrieved March 19, 2019, from https://www.aceapinerolese.it/ambiente/ilpolo-ecologico-acea-pinerolese-trattamento-rifiuti-organici/

Alibeigi, S., \& Vaezi, M. R. (2008). Phase transformation of iron oxide nanoparticles by varying the molar ratio of Fe2+:Fe3+. Chemical Engineering and Technology, 31(11), 1591-1596. http://doi.org/10.1002/ceat.200800093

Babuponnusami, A., \& Muthukumar, K. (2014). A review on Fenton and improvements to the Fenton process for wastewater treatment. Journal of Environmental Chemical Engineering. http://doi.org/10.1016/j.jece.2013.10.011

Bianco Prevot, A., Avetta, P., Fabbri, D., Laurenti, E., Marchis, T., Perrone, D. G., ... Boffa, V. (2011). Waste-derived bioorganic substances for light-induced generation of reactive oxygenated species. ChemSusChem, 4(1), 85-90. http://doi.org/10.1002/cssc.201000237

Boffa, V., Perrone, D. G., Montoneri, E., Magnacca, G., Bertinetti, L., Garlasco, L., \& Mendichi, R. (2010). A waste-derived biosurfactant for the preparation of templated silica powders. ChemSusChem, 3(4), 445-452. http://doi.org/10.1002/cssc.200900205

Braun, A. M., Schwarz, P. F., Dürr, H., Turro, N. J., Wahab, A.-M. A. A., \& Bossmann, S. H. (2002). A New Method To Determine the Generation of Hydroxyl Radicals in Illuminated TiO 2 Suspensions . The Journal of Physical Chemistry B, 101(36), 7127-7134. http://doi.org/10.1021/jp971315c

Byrne, C., Subramanian, G., \& Pillai, S. C. (2018). Recent advances in photocatalysis for environmental applications. Journal of Environmental Chemical Engineering, 6(3), 35313555. http://doi.org/10.1016/j.jece.2017.07.080

Carlos, L., Mártire, D. O., Gonzalez, M. C., Gomis, J., Bernabeu, A., Amat, A. M., \& Arques, A. (2012). Photochemical fate of a mixture of emerging pollutants in the presence of humic substances. Water Research, 46, 4732-4740. http://doi.org/10.1016/j.watres.2012.06.022

Centemero. (2006). Composting in Italy, key indicators (Vol. 1993).

Cesano, F., Fenoglio, G., Carlos, L., \& Nisticò, R. (2015). One-step synthesis of magnetic chitosan polymer composite films. Applied Surface Science, 345, 175-181. http://doi.org/10.1016/j.apsusc.2015.03.154

Cong, Y., Chen, M., Xu, T., Zhang, Y., \& Wang, Q. (2014). Tantalum and aluminum co-doped iron oxide as a robust photocatalyst for water oxidation. Applied Catalysis B: Environmental, 147, 733-740. http://doi.org/10.1016/j.apcatb.2013.10.009

CORDIS, E. C.-. (2019). ENVIRONBOS Report Summary. Retrieved March 19, 2019, from https://cordis.europa.eu/project/rcn/99136/reporting/en

Dang, H. T., Nguyen, T. M. T., Nguyen, T. T., Thi, S. Q., Tran, H. T., Tran, H. Q., \& Le, T. K. (2016). Magnetic CuFe2O4Prepared by Polymeric Precursor Method as a Reusable Heterogeneous 
Fenton-like Catalyst for the Efficient Removal of Methylene Blue. Chemical Engineering Communications, 203(9), 1260-1268. http://doi.org/10.1080/00986445.2016.1174858

Deng, Y., Qi, D., Deng, C., Zhang, X., \& Zhao, D. (2015). Adsorption of bovine serum albumin on superparamagnetic composite microspheres with a Fe $3 \mathrm{O} 4$ /SiO 2 core and mesoporous SiO 2 shell. RSC Advances, 5(126), 103760-103766. http://doi.org/10.1039/c5ra21773c

Dronskowski, R. (2001). The little maghemite story: A classic functional material. Advanced Funtional Materials, 11(1), 27-29. http://doi.org/10.1002/1616-3028(200102)11:1<27::AIDADFM27>3.0.CO;2-X

Elorriaga, Y., Marino, D. J., Carriquiriborde, P., \& Ronco, A. E. (2013a). Human pharmaceuticals in wastewaters from urbanized areas of Argentina. Bulletin of Environmental Contamination and Toxicology, 90, 397-400. http://doi.org/10.1007/s00128-012-0919-x

Elorriaga, Y., Marino, D. J., Carriquiriborde, P., \& Ronco, A. E. (2013b). Human pharmaceuticals in wastewaters from urbanized areas of Argentina. Bulletin of Environmental Contamination and Toxicology, 90, 397-400. http://doi.org/10.1007/s00128-012-0919-x

Fatta-Kassinos et al. (2011). Pharmaceutical residues in environmental waters and wastewater: Current state of knowledge and future research. Analytical and Bioanalytical Chemistry. http://doi.org/10.1007/s00216-010-4300-9

Fielding, M., Gibson, T. M., \& James, H. A. (1981). Levels of trichloroethylene, tetrachloroethylene and p-dichlorobenzene in ground waters. Environmental Technology Letters, 2, 545-550. http://doi.org/10.1080/09593338009384086

Geissen, V., Mol, H., Klumpp, E., Umlauf, G., Nadal, M., van der Ploeg, M., ... Ritsema, C. J. (2015). Emerging pollutants in the environment: A challenge for water resource management. International Soil and Water Conservation Research, 3(1), 57-65. http://doi.org/10.1016/j.iswcr.2015.03.002

Gomis, J., Vercher, R. F., Amat, A. M., Mártire, D. O., González, M. C., Bianco Prevot, A., ... Carlos, L. (2013). Application of soluble bio-organic substances (SBO) as photocatalysts for wastewater treatment: Sensitizing effect and photo-Fenton-like process. Catalysis Today, 209, 176-180. http://doi.org/10.1016/j.cattod.2012.08.036

González, L. (2011). Residuos Solidos Urbanos Argentina: situación actual y perspectivas futuras (1a ed.). Buenos aires.

Guerra-Rodríguez, S., Rodríguez, E., Singh, D. N., \& Rodríguez-Chueca, J. (2018). Assessment of sulfate radical-based advanced oxidation processes for water and wastewater treatment: A review. Water (Switzerland), 10(12). http://doi.org/10.3390/w10121828

Gumy, D., Giraldo, S. A., Rengifo, J., \& Pulgarin, C. (2008). Effect of suspended TiO2 physicochemical characteristics on benzene derivatives photocatalytic degradation. Applied Catalysis B: Environmental, 78 (1-2), 19-29. http://doi.org/10.1016/j.apcatb.2007.08.007

Kang, H., \& Wang, H. P. (2013). Preparation of Magnetic Recoverable Nanosize $\mathrm{Cu}-\mathrm{Fe}_{2} \mathrm{O}_{3} / \mathrm{Fe}$ Photocatalysts, 47 (13), 7380-7387. 
Klaus, K. (2007). Pharmaceuticals in the Environment ( PIE ) (3rd Ed., Vol. 42).

Kumar, S. R., Raja, M. M., Mangalaraj, D., Viswanathan, C., \& Ponpandian, N. (2013). Surfactant free solvothermal synthesis of monodispersed 3D hierarchical $\mathrm{Fe} 304$ microspheres. Materials Letters, 110, 98-101. http://doi.org/10.1016/j.matlet.2013.08.005

Laurent, S., Forge, D., Port, M., Roch, A., Robic, C., Vander Elst, L., \& Muller, R. N. (2008). Magnetic iron oxide nanoparticles: Synthesis, stabilization, vectorization, physicochemical characterizations and biological applications. Chemical Reviews, 108(6), 2064-2110. http://doi.org/10.1021/cr068445e

Litter, M. I. (1999). Heterogeneous photocatalysis: Transition metal ions in photocatalytic systems. Applied Catalysis B: Environmental, 23(2-3), 89-114. http://doi.org/10.1016/S09263373(99)00069-7

Lu, A. H., Salabas, E. L., \& Schüth, F. (2007). Magnetic nanoparticles: Synthesis, protection, functionalization, and application. Angewandte Chemie - International Edition, 46(8), 12221244. http://doi.org/10.1002/anie.200602866

Magnacca, G., Allera, A., Montoneri, E., Celi, L., Benito, D. E., Gagliardi, L. G., \& Carlos, L. (2014). Novel magnetite nanoparticles coated with waste sourced bio- based substances as sustainable and renewable adsorbing materials. ACS Sustainable Chemistry and Engineering, 2(6), 1518-1524. http://doi.org/10.1021/sc500213j

Magnacca, G., Guerretta, F., Vizintin, A., Benzi, P., Valsania, M. C., \& Nisticò, R. (2018). Preparation, characterization and environmental/electrochemical energy storage testing of low-cost biochar from natural chitin obtained via pyrolysis at mild conditions. Applied Surface Science, 427, 883-893. http://doi.org/10.1016/j.apsusc.2017.07.277

Mainero, D., Montoneri, E., Boffa, V., \& Montoneri, C. (2011). New Perspective From Organic Fraction Treatment : Renewable Energy and Chemicals.

McDowell, D. C., Huber, M. M., Wagner, M., Von Gunten, U., \& Ternes, T. A. (2005). Ozonation of carbamazepine in drinking water: Identification and kinetic study of major oxidation products. Environmental Science and Technology, 39(20), 8014-8022. http://doi.org/10.1021/es050043|

Montoneri, E., Boffa, V., Quagliotto, P. L., Mendichi, R., Chierotti, M. R., Gobetto, R., \& Medana, C. (2008). Humic acid-like matter isolated from green urban wastes. Part I: Structur and surfactant properties. BioResources, 3(1), 123-141. http://doi.org/10.15376/BIORES.3.1.123141

Montoneri, E., Boffa, V., Savarino, P., Perrone, D. G., Montoneri, C., Mendichi, R., ... Kiran, S. (2010). Behavior and properties in aqueous solution of biopolymers isolated from urban refuse. Biomacromolecules, 11(11), 3036-3042. http://doi.org/10.1021/bm1008662

Naseri, M. G., Saion, E. B., Ahangar, H. A., \& Shaari, A. H. (2013). Fabrication, characterization, and magnetic properties of copper ferrite nanoparticles prepared by a simple, thermal-treatment method. Materials Research Bulletin, 48(4), 1439-1446. http://doi.org/10.1016/j.materresbull.2012.12.039 
Nisticò, R. (2017). Magnetic materials and water treatments for a sustainable future. Research on Chemical Intermediates, 43(12), 6911-6949. http://doi.org/10.1007/s11164-017-3029-x

Nisticò, R., Celi, L. R., Bianco Prevot, A., Carlos, L., Magnacca, G., Zanzo, E., \& Martin, M. (2018a). Sustainable magnet-responsive nanomaterials for the removal of arsenic from contaminated water. Journal of Hazardous Materials, 342, 260-269. http://doi.org/10.1016/j.jhazmat.2017.08.034

Nisticò, R., Cesano, F., Franzoso, F., Magnacca, G., Scarano, D., Funes, I. G., ... Parolo, M. E. (2018b). From biowaste to magnet-responsive materials for water remediation from polycyclic aromatic hydrocarbons. Chemosphere, 202, 686-693. http://doi.org/10.1016/j.chemosphere.2018.03.153

Oliveira, C., Alves, A., \& Madeira, L. M. (2014). Treatment of water networks (waters and deposits) contaminated with chlorfenvinphos by oxidation with Fenton's reagent. Chemical Engineering Journal, 241, 190-199. http://doi.org/10.1016/j.cej.2013.12.026

Pang, Y. L., Lim, S., Ong, H. C., \& Chong, W. T. (2016). Research progress on iron oxide-based magnetic materials: Synthesis techniques and photocatalytic applications. Ceramics International, 42(1), 9-34. http://doi.org/10.1016/j.ceramint.2015.08.144

Petrovic, M., \& Barceló, D. (2006). Liquid chromatography-mass spectrometry in the analysis of emerging environmental contaminants. Analytical and Bioanalytical Chemistry, 385(3), 422424. http://doi.org/10.1007/s00216-006-0450-1

Richardson, M. L., \& Bowron, J. M. (1985). The fate of pharmaceutical chemicals in the aquatic environment. Journal of Pharmacy and Pharmacology, 37(1), 1-12. http://doi.org/10.1111/j.2042-7158.1985.tb04922.x

Richardson, S. D. (2012). Environmental mass spectrometry: Emerging contaminants and current issues. Analytical Chemistry, 84(2), 747-778. http://doi.org/10.1021/ac202903d

Saha, M., Mukherjee, S., Kumar, S., Dey, S., \& Gayen, A. (2016). Albumin matrix assisted wet chemical synthesis of nanocrystalline MFe2O4(M $=\mathrm{Cu}$, Co and $\mathrm{Zn}$ ) ferrites for visible light driven degradation of methylene blue by hydrogen peroxide. RSC Advances, 6(63), 5812558136. http://doi.org/10.1039/c6ra04825k

Savarino, P., Montoneri, E., Musso, G., \& Boffa, V. (2010). Biosurfactants from urban wastes for detergent formulation: Surface activity and washing performance. Journal of Surfactants and Detergents, 13(1), 59-68. http://doi.org/10.1007/s11743-009-1133-7

UniTo. (2015). MAT4TREAT. Retrieved from http://www.mat4treat.unito.it/

Vinu, R., \& Madras, G. (2010). Environmental remediation by photocatalysis. Journal of the Indian Institute of Science, 90(2), 189-230.

Wang, D., Yang, P., \& Zhu, Y. (2014). Growth of Fe3O4 nanoparticles with tunable sizes and morphologies using organic amine. Materials Research Bulletin, 49, 514-520. http://doi.org/10.1016/j.materresbull.2013.09.019

Wang, J., \& Wang, S. (2018). Activation of persulfate (PS) and peroxymonosulfate (PMS) and 
application for the degradation of emerging contaminants. Chemical Engineering Journal, 334, 1502-1517. http://doi.org/10.1016/j.cej.2017.11.059

World Health Organization. (2012). Treatment technologies for removal of pharmaceuticals from water.

Wu, W., Jiang, C., \& Roy, V. A. L. (2015). Recent progress in magnetic iron oxide-semiconductor composite nanomaterials as promising photocatalysts. Nanoscale, 7(1), 38-58. http://doi.org/10.1039/c4nr04244a

Wu, W., Wu, Z., Yu, T., Jiang, C., \& Kim, W. S. (2015). Recent progress on magnetic iron oxide nanoparticles: Synthesis, surface functional strategies and biomedical applications. Science and Technology of Advanced Materials, 16(2), 023501. http://doi.org/10.1088/1468$6996 / 16 / 2 / 023501$

Zhang, Z., Hossain, M. F., \& Takahashi, T. (2010). Self-assembled hematite ( $\alpha$-Fe2O3) nanotube arrays for photoelectrocatalytic degradation of azo dye under simulated solar light irradiation. Applied Catalysis B: Environmental, 95, 423-429. http://doi.org/10.1016/j.apcatb.2010.01.022 

2 Materials \& Methods 



\subsection{Materials}

All chemical substances were used as received (except the contrary is indicate) and are listed in Table 2.1.

Table 2.1: List of used chemical reagents

\begin{tabular}{|c|c|c|}
\hline IUPAC denomination & Formula & Purity/ supplier \\
\hline Ferric chloride & $\mathrm{FeCl}_{3} \times 6 \mathrm{H}_{2} \mathrm{O}$ & 98\%, Sigma Aldrich \\
\hline Copper sulfate & $\mathrm{CuSO}_{4}$ & $\geq 99.0 \%$, Sigma Aldrich \\
\hline Nickel (II) nitrate & $\mathrm{Ni}\left(\mathrm{NO}_{3}\right)_{2} \times 6 \mathrm{H}_{2} \mathrm{O}$ & 98\%, Sigma Aldrich \\
\hline Cobalt (II) nitrate & $\mathrm{Co}\left(\mathrm{NO}_{3}\right)_{2} \times 6 \mathrm{H}_{2} \mathrm{O}$ & 98\%, Sigma Aldrich \\
\hline Potassium bromide & $\mathrm{KBr}$ & FT-IR grade, Sigma Aldrich \\
\hline Barium sulfate & $\mathrm{BaSO}_{4}$ & Reagent Plus, Sigma Aldrich \\
\hline Graphite & C & powder, $<20 \mu \mathrm{m}$, synthetic \\
\hline Sodium nitrate & $\mathrm{Na}\left(\mathrm{NO}_{3}\right)$ & $\begin{array}{c}\text { ACS reagent, } \geq 99.0 \% \text {, Sigma } \\
\text { Aldrich }\end{array}$ \\
\hline Potassium permanganate & $\mathrm{KMnO}_{4}$ & Pro-analysis, Cicarelli \\
\hline Hydrazine & $\mathrm{N}_{2} \mathrm{H}_{4}$ & $\begin{array}{c}\text { ca. } 80 \% \text { hydrazine } \\
\text { monohydratesolution, Aldrich }\end{array}$ \\
\hline $\begin{array}{c}\text { 5,5-dimethyl-1-pyrroline-N- } \\
\text { oxide }\end{array}$ & DMPO & $\geq 97.0 \%$, Sigma Aldrich \\
\hline Potassium thiocyanate & $\mathrm{KSCN}$ & $\begin{array}{c}\text { ACS reagent, } \geq 99.0 \% \text {, Sigma } \\
\text { Aldrich }\end{array}$ \\
\hline $\begin{array}{c}\text { Methylviologen dichloride } \\
\text { hydrate (Paraquat dichloride) } \\
\text { 1,1'-Dimethyl-4,4'- } \\
\text { bipyridinium dichloride }\end{array}$ & $\mathrm{C}_{12} \mathrm{H}_{14} \mathrm{Cl}_{2} \mathrm{~N}_{2} \cdot \mathrm{xH}_{2} \mathrm{O}$ & 98\% Sigma Aldrich \\
\hline $\begin{array}{c}\text { Triethanolamine (TEOA) } \\
2,2^{\prime}, 2^{\prime \prime}-\text { Trihydroxi-trietilamina }\end{array}$ & $\mathrm{C}_{12} \mathrm{H}_{14} \mathrm{Cl}_{2} \mathrm{~N}_{2} \cdot \mathrm{xH}_{2} \mathrm{O}$ & $\geq 99.5 \%$, Sigma Aldrich \\
\hline
\end{tabular}




\begin{tabular}{|c|c|c|}
\hline $\begin{array}{c}\text { Triethylamine (TEA) } \\
\text { 2,2',2"-Nitrilotri(ethan-1-ol) }\end{array}$ & $\mathrm{N}\left(\mathrm{CH}_{2} \mathrm{CH}_{2} \mathrm{OH}\right)_{3}$ & $\begin{array}{c}\text { 98\% Reagent Grade, Sigma } \\
\text { Aldrich }\end{array}$ \\
\hline Hydrogen peroxide & $\mathrm{H}_{2} \mathrm{O}_{2}$ & $30 \%$ Cicarelli \\
\hline Sodium azide & $\mathrm{NaN}_{3}$ & $\begin{array}{c}\text { Reagent Plus, 99.5\% Sigma } \\
\text { Aldrich }\end{array}$ \\
\hline Isopropyl alcohol & $\mathrm{C}_{3} \mathrm{H}_{8} \mathrm{O}$ & ACS reagent, $\geq 99.5 \%$ \\
\hline Furfuryl alcohol & $\mathrm{C}_{5} \mathrm{H}_{6} \mathrm{O}_{2}$ & Sigma Aldrich 98\% \\
\hline Methanol & $\mathrm{CH}_{4} \mathrm{O}$ & $\begin{array}{l}\text { 98\% / HPLC grade Sigma } \\
\text { Aldrich }\end{array}$ \\
\hline Ethanol & $\mathrm{C}_{2} \mathrm{H}_{6} \mathrm{O}$ & $96^{\circ}$ Purocol \\
\hline Nitric acid & $\mathrm{HNO}_{3}$ & ACS 70\% Sigma Aldrich \\
\hline Sulfuric acid & $\mathrm{H}_{2} \mathrm{SO}_{4}$ & ACS 95-98\% Sigma Aldrich \\
\hline Phosphoric acid & $\mathrm{H}_{3} \mathrm{PO}_{4}$ & 85 wt. $\%$ in $\mathrm{H}_{2} \mathrm{O}$, Sigma Aldrich \\
\hline Sodium hydroxide & $\mathrm{NaOH}$ & $\begin{array}{l}\text { reagent grade, } \geq 98 \% \text {, pellets } \\
\text { (anhydrous) }\end{array}$ \\
\hline Ammonium hydroxide & $\mathrm{NH}_{4} \mathrm{OH}$ & $\begin{array}{l}\text { puriss. p.a. } 28 \% \text { aqueous } \\
\text { solution, Sigma Aldrich }\end{array}$ \\
\hline $\begin{array}{c}\text { Carbamazepine } \\
\text { 5H-dibenzo[b,f]azepine-5- } \\
\text { carboxamide }\end{array}$ & $\mathrm{C}_{15} \mathrm{H}_{12} \mathrm{~N}_{2} \mathrm{O}$ & $\begin{array}{l}\text { Isolated from commercial pills } \\
\text { (see below for the } \\
\text { experimental procedure) }\end{array}$ \\
\hline BBS /BBS-GC & & $\begin{array}{c}\text { Provided by ACEA Pinerolese, } \\
\text { S.A. (Pinerolo, Italy) }\end{array}$ \\
\hline
\end{tabular}

Isolation of CBZ was made from commercial pills (Bagó, $200 \mathrm{mg}$ ). Briefly, 25 pills were grounded in a mortar. The solid was suspended in $100 \mathrm{~mL}$ of distilled water (a milky suspension remains) and transferred to a separating funnel. An extraction with three portions of $30 \mathrm{~mL}$ of $\mathrm{CH}_{2} \mathrm{Cl}_{2}$ was performed. The organic phases were decanted and collected in a round flask. The solvent was evaporated, and the solid was recrystallized from $\mathrm{MeOH}$. It was allowed to dry in a stove until constant weight. 
Isolation of BBS-GC was performed similarly to previously reported procedures (Montoneri et al., 2009) by treating 50 g of green compost with $1 \mathrm{~L}$ of $6 \mathrm{M} \mathrm{NaOH}$ water solution under stirring at $60{ }^{\circ} \mathrm{C}$ for $4 \mathrm{~h}$. The reaction mixture was then separated by centrifugation. The separated liquid phase was concentrated, and different fractions were separated through a lab-scale ultrafiltration unit equipped with a membrane (molar mass cut-off $5 \mathrm{KDa}$ ). The retentate fraction was then dried at $60^{\circ} \mathrm{C}$ for $24 \mathrm{~h}$. The BBS-GC thus obtained was about $20-30 \%$ in mass of the starting compost. Before using, it is necessary to grind the BBS-GC pellets. Solubility maximum is $100 \mathrm{~g} \cdot \mathrm{L}^{-1}$ in water, dissolving is achieved by heating at about $60{ }^{\circ} \mathrm{C}$. Solutions are stable for one week at different temperatures (tests conducted at $4^{\circ} \mathrm{C}, 25^{\circ} \mathrm{C}$ and $40^{\circ} \mathrm{C}$ ) in water of hardness $\leq 40^{\circ} \mathrm{F}$. Chemical composition is detailed in Table 2.2 (Nisticò et al. 2018).

Table 2.2: BBS-GC chemical composition and functional groups

\begin{tabular}{|c|c|c|c|c|c|c|}
\hline \multicolumn{7}{|c|}{ Metal analysis } \\
\hline Si (\%) & $\mathrm{Fe}(\%)$ & $\mathrm{Al}(\%)$ & $\operatorname{Mg}(\%)$ & $\mathrm{Ca}(\%)$ & $\mathrm{K}(\%)$ & $\mathrm{Na}(\%)$ \\
\hline $12.14 \pm 0.07$ & $1.03 \pm 0.02$ & $0.59 \pm 0.01$ & $1.67 \pm 0.25$ & $4.86 \pm 0.61$ & $1.18 \pm 0.07$ & $0.06 \pm 0.01$ \\
\hline \multicolumn{7}{|c|}{ Microelements } \\
\hline $\mathrm{Cu}$ (ppm) & $\mathrm{Ni}(p p m)$ & Zn (ppm) & $\mathrm{Cr}(p p m)$ & $\mathrm{Pb}$ (ppm) & Cd (ppm) & $\mathrm{Hg}$ (ppm) \\
\hline $73 \pm 1$ & $100 \pm 3$ & $157 \pm 13$ & $49 \pm 1$ & $43 \pm 2$ & $<0.02$ & $<0.02$ \\
\hline \multicolumn{4}{|c|}{ General characteristics } & \multicolumn{3}{|c|}{$\begin{array}{l}\text { Characteristics in aqueous solution } \\
\qquad\left(3 g . \mathrm{L}^{-1}\right)\end{array}$} \\
\hline $\begin{array}{l}\text { Moisture } \\
\text { (\%) }\end{array}$ & $\begin{array}{l}\text { Ashes } \\
(\%)\end{array}$ & $\begin{array}{c}C \\
(\%)\end{array}$ & $\begin{array}{l}N \\
(\%)\end{array}$ & $\mathrm{pH}$ & $\begin{array}{l}\text { Conductivity } \\
(\mu S / \mathrm{cm})\end{array}$ & $\begin{array}{c}\text { Surface } \\
\text { tension } \\
(\mathrm{N} / \mathrm{m})\end{array}$ \\
\hline 3.69 & 31.2 & $39.94 \pm 0.35$ & $4.82 \pm 0.14$ & 9.02 & 429 & 56.8 \\
\hline \multicolumn{7}{|c|}{ Concentration values as mole fraction of total $\mathrm{C}$ for functional groups and $\mathrm{C}$ types in by } \\
\hline \multicolumn{7}{|c|}{ NMR analysis ${ }^{a}$} \\
\hline Aliph & NR & $\mathrm{COOH}$ & OR & $\mathrm{Ph}$ & $\mathrm{PhOH}$ & Kt \\
\hline 0.31 & 0.07 & 0.12 & 0.20 & 0.16 & 0.06 & 0.02 \\
\hline
\end{tabular}

a'Legends: aliph = aliphatic groups, $\mathrm{NR}=$ amino groups, $\mathrm{COOH}=$ carboxylic acids, $\mathrm{OR}=$ alkoxy groups, $\mathrm{Ph}=$ aromatic phenyl groups, $\mathrm{PhOH}=$ phenoxy groups, $\mathrm{Kt}=$ ketones . 



\subsection{Preparation of magnetic nanocomposites}

The nanocomposite preparation was made following the precursor method ((Kang \& Wang 2013,Naseri et al. 2011). In this work, BBS were used as complexing agents of the metals. Briefly, BBS pellets were grinded and solubilized in deionized water at the desired concentration. A solution containing both $\mathrm{Fe}^{3+}$ and $\mathrm{M}^{2+}$ salts (where $\mathrm{M}^{2+}$ stand for $\mathrm{Cu}^{2+}$, $\mathrm{Ni}^{2+}$ and $\left.\mathrm{Co}^{2+}\right)$ was added to the BBS solution. The mixture was stirred in a closed beaker at room temperature for $24 \mathrm{~h}$. Then, the mixture was centrifuged $10 \mathrm{~min}$ at $4000 \mathrm{rpm}$ and the separated solid was dried in an oven at $60^{\circ} \mathrm{C}$ until constant weight. To obtain the nanocomposites, the dried solid (precursor) were subjected to a thermal treatment. The pyrolysis of the precursors was carried out in a tubular furnace, at a rate of $2{ }^{\circ} \mathrm{C} \min ^{-1}$

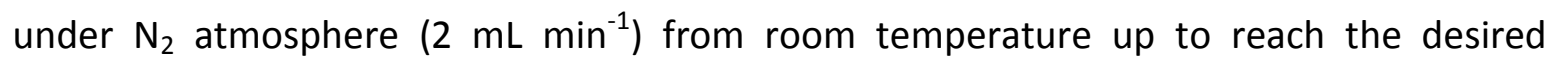
temperature. After that, in order to eliminate all the undesired soluble and non-magnetic products, the materials were washed three times with deionized water. In all the washing steps, the solid was separated from the supernatant with the aid of a magnet. Finally, the obtained solid was dried in a vacuum oven at $70{ }^{\circ} \mathrm{C}$ for several hours and then stored at room temperature. Different materials were obtained by varying: (a) the amount of BBS (5-50 $\left.\mathrm{g} \mathrm{L}^{-1}\right)$ in the precursor's preparation. Considering that BBS contains $39.4 \%$ of carbon (Nisticò et al., 2018), the variation of BBS content in the synthesis can be expressed as $\left.\mathrm{n}(\mathrm{C}) /\left[\mathrm{n}\left(\mathrm{Fe}^{3+}\right)+\mathrm{n}\left(\mathrm{M}^{2+}\right)\right]\right)$, where $\mathrm{n}$ is the number of moles. (b) The nature of divalent metal ion $\left(\mathrm{Cu}^{2+}, \mathrm{Ni}^{2+}, \mathrm{Co}^{2+}\right)$. (c) The final temperature of thermal treatment $\left(300-800{ }^{\circ} \mathrm{C}\right)$.

Table 2.3 summarizes the details of the experimental conditions used for obtaining the precursors and nanocomposites. 
Table 2.3: Experimental conditions used for the synthesis of the nanocomposites

\begin{tabular}{|c|c|c|c|c|c|c|c|}
\hline $\begin{array}{l}\text { Sample } \\
\text { code }\end{array}$ & $\begin{array}{c}\text { Precursor } \\
\text { code }\end{array}$ & $\begin{array}{l}\text { Metallic } \\
\text { ions }\end{array}$ & $\begin{array}{l}{[\mathrm{BBS}]} \\
\left(\mathrm{g} \mathrm{L}^{-1}\right)\end{array}$ & $\begin{array}{l}{\left[\mathrm{Fe}^{3+}\right]} \\
(\mathrm{M})\end{array}$ & $\begin{array}{l}{\left[\mathrm{M}^{2+}\right]} \\
(\mathrm{M})\end{array}$ & $\frac{\mathrm{n}(\mathrm{C})}{\mathrm{n}\left(F e^{3+}\right)+\mathrm{n}\left(M^{2+}\right)}$ & $\begin{array}{c}\text { Final Temperature } \\
\qquad\left({ }^{\circ} \mathrm{C}\right)\end{array}$ \\
\hline $\mathrm{FeCu} 400 / 1$ & PFeCu-1 & $\mathrm{Cu}^{2+}-\mathrm{Fe}^{3+}$ & 5 & 0.15 & 0.15 & 1 & 400 \\
\hline $\mathrm{FeCu} 400 / 2$ & PFeCu-2 & $\mathrm{Cu}^{2+}-\mathrm{Fe}^{3+}$ & 5 & 0.15 & 0.15 & 1.6 & 400 \\
\hline $\mathrm{FeCu} 400 / 3$ & PFeCu-3 & $\mathrm{Cu}^{2+}-\mathrm{Fe}^{3+}$ & 30 & 0.15 & 0.15 & 5.5 & 400 \\
\hline $\mathrm{FeCu} 400 / 4$ & PFeCu-4 & $\mathrm{Cu}^{2+}-\mathrm{Fe}^{3+}$ & 30 & 0.15 & 0.15 & 11 & 400 \\
\hline $\mathrm{FeCu} 400 / 5$ & PFeCu-5 & $\mathrm{Cu}^{2+}-\mathrm{Fe}^{3+}$ & 50 & 0.10 & 0.10 & 23 & 400 \\
\hline FeCu300/1 & PFeCu-1 & $\mathrm{Cu}^{2+}-\mathrm{Fe}^{3+}$ & 5 & 0.15 & 0.15 & 1 & 300 \\
\hline FeCu300/3 & PFeCu-3 & $\mathrm{Cu}^{2+}-\mathrm{Fe}^{3+}$ & 30 & 0.15 & 0.15 & 5.5 & 300 \\
\hline FeCu300/5 & PFeCu-5 & $\mathrm{Cu}^{2+}-\mathrm{Fe}^{3+}$ & 50 & 0.10 & 0.10 & 23 & 300 \\
\hline FeCu600/1 & PFeCu-1 & $\mathrm{Cu}^{2+}-\mathrm{Fe}^{3+}$ & 5 & 0.15 & 0.15 & 1 & 600 \\
\hline FeCu800/1 & PFeCu-1 & $\mathrm{Cu}^{2+}-\mathrm{Fe}^{3+}$ & 5 & 0.15 & 0.15 & 1 & 800 \\
\hline $\mathrm{FeCo600/1}$ & PFeCo-1 & $\mathrm{Co}^{2+}-\mathrm{Fe}^{3+}$ & 5 & 0.15 & 0.15 & 1 & 600 \\
\hline FeNi600/1 & PFeNi-1 & $\mathrm{Ni}^{2+}-\mathrm{Fe}^{3+}$ & 5 & 0.15 & 0.15 & 1 & 600 \\
\hline
\end{tabular}




\subsection{Characterization Techniques}

\section{X-Ray Diffraction}

X-Ray diffraction assays were performed to determine the crystal phases present in each nanocomposite. Crystalline solids consist of regular arrays of atoms, ions or molecules with interatomic spacing on the order of $100 \mathrm{pm}$. The diffraction phenomenon occurs when the wavelength of the incident light is on the same order of magnitude as the spacing of the grating. A finely ground crystalline powder contains a very large number of small crystals, known as crystallites, which are oriented randomly to one another. If such a sample is placed in the path of a monochromatic X-ray beam, diffraction will occur from planes in those crystallites which happen to be oriented at the correct angle to fulfill the Bragg condition (Eq. 2.1):

$$
2 d \operatorname{sen} \theta=n \lambda \quad(\text { Eq. 2.1) }
$$

Here, $d$ is the interplanar distance, $\theta$ is the incident angle, $n$ a natural number and $\lambda$ is the wavelength of the radiation. Because of the periodic nature of the internal structure, it is possible for crystals to act as a three-dimensional diffraction gratings to light of a suitable wavelength. The primary use of the Bragg law is for the determination of the spacing between the layers in the lattice; for once the angle $\theta_{h k l}$ corresponding to a reflection has been determined, $d_{h k l}$ may readily be calculated (see Fig. 2.1) (Smart and Moore, 2005).

\section{Experimental set-up}

X-ray diffraction (XRD) patterns were recorded by using an X'Pert PRO MPD diffractometer from PANalytical, equipped with Cu anode $(\lambda=1.54 \AA$ ) , working at $45 \mathrm{kV}$ and $40 \mathrm{~mA}$ in Bragg-Brentano geometry in a flat or capillary sample-holder. The XRD pattern acquisition was performed in the $2 \theta$ range of $5-70^{\circ}$ with $0.02^{\circ}$ interval steps, $70 \mathrm{~s} \mathrm{step}^{-1}$ to improve the signal-to-noise ratio. The analysis of the XRD diffraction patterns was made with the X'Pert High Score Software. 


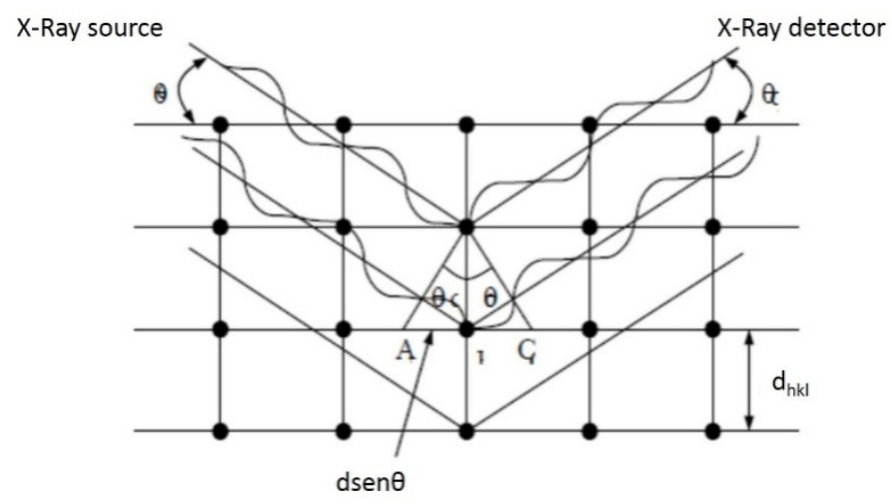

Fig. 2.1: Bragg reflection from a set of crystal planes with a spacing $d_{\text {hkl }}$ (taken from Smart and Moore, 2005)

\section{X-Ray Absorption Spectroscopy (XRS)}

In order to identify the chemical speciation of the metals contained in our nanomaterials XRS was performed. This group of related techniques was developed in the early 1970s and is widely used at synchrotron facilities. Regardless of the complexity of the sample, the XRS signal comes from all the atoms of a single element as selected by the $X$-ray energy. Structural information provided with these techniques can be obtained from mineral, non-crystalline solids or adsorbed phases. The acronym XAS covers both X-ray absorption near edge structure (XANES) and extended X-ray absorption fine structure (EXAFS) spectroscopies. XANES can be used to determine the valence state and coordination geometry, whereas EXAFS can be used to determine the local molecular structure of an element within a sample (Smart and Moore 2005). For most systems the application of XRD and XRS is complementary, since XRS gives information of the immediate environment of the selected element, within $6 \AA$, and its theory and interpretation does not rely on any assumption of symmetry or periodicity.

$\mathrm{X}$-ray absorption occurs when an atom acquires all the energy of an X-ray photon, which is used to excite electrons into an unoccupied higher energy state or into the continuum, where the electron is no longer associated with the atom. The promotion of an electron into a higher energy state by X-ray absorption is short lived. Within approximately a femtosecond, the core hole generated is filled by an electron that decays from a higher energy orbital. The transition is accompanied by relaxation processes that 
can be in the form of fluorescence radiation, Auger electron or secondary electron or photon production. X-Ray absorption spectroscopy involves measuring the X-ray absorption coefficient $\mu$ as a function of X-ray energy. The coefficient $\mu$ is the probability for an X-ray to be absorbed by a sample and is a function of the incident X-ray energy. The probability for absorption increases sharply when the incident X-ray energy has the same energy that is required to excite an electron to an unoccupied energy level. These steps in the absorption coefficient are termed absorption edges. Each element has a specific set of absorption edges at the binding energies of its electrons (Leng, 2008). The energy of a specific edge increases as the atomic number of the element increases. This is because elements with larger atomic numbers have more positively charged nuclei, and therefore, electrons in a given atomic orbital are more strongly attracted.

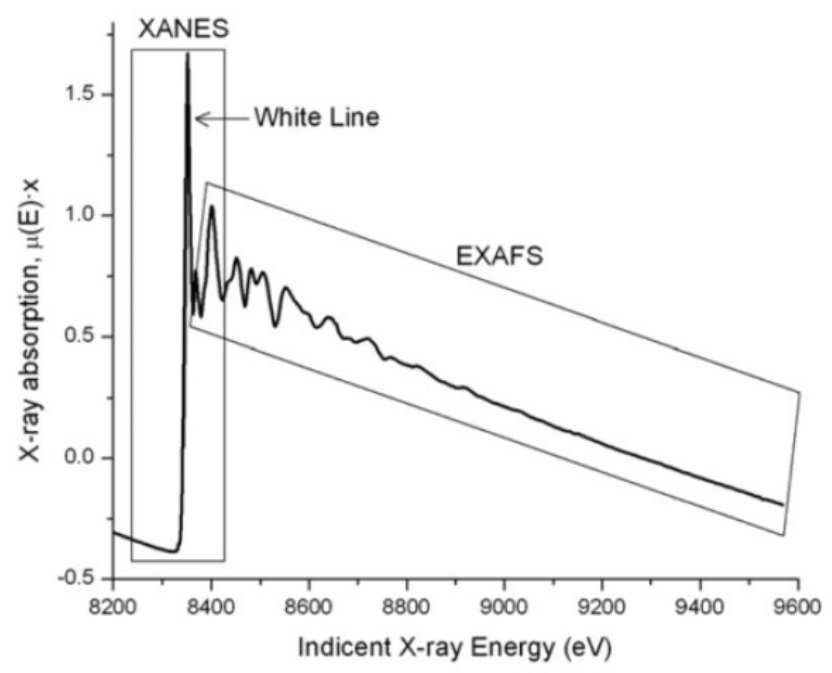

Fig. 2.2: X-Ray absorption spectrum with XANES and EXAFS regions highlighted, as well as the white line (Kelly et al. 2008)

A typical X-Ray absorption spectrum is recorded from approximately $200 \mathrm{eV}$ below to $1000 \mathrm{eV}$ above the absorption edge of interest. The part of the spectrum near the absorption edge (ranging from approximately -50 to $+200 \mathrm{eV}$ relative to the edge energy) corresponds to the XANES region. The shape of the absorption edge is related to the 
density of states available for the excitation of the photoelectron. Therefore, the binding geometry and the oxidation state of the atom modify the XANES part of the spectrum. The change in the oxidation state is usually accompanied by a change in centro-symmetry, which will affect the features of the absorption edge: a pre-edge peak could appear. The intensity of pre-edge peaks depends not only on the amount of the species that generates it, but also on the symmetry of the coordinated atom. It could be used to quantify the relative proportions of the element in different oxidation states (Kelly et al. 2008).

The EXAFS part of a spectrum is the normalized oscillatory part of the absorption

coefficient above the absorption edge to approximately $1000 \mathrm{eV}$ or higher. This region is used to determine local molecular bonding environments of elements. It contains information on the types and number of atoms in coordination with absorber atoms, their interatomic distances, and the degree of local molecular bonding disorder.

\section{Experimental Set-up}

XANES experiments at the Fe, Cu, Co and Ni K-edges (7112 eV, $7709 \mathrm{eV}, 8333 \mathrm{eV}$ and 8979 $\mathrm{eV}$, respectively) were measured at room temperature using a $\mathrm{Si}(111)$ single channel-cut crystal monochromator in transmission mode. Ionization chambers were used to detect the incident and transmitted flux through the sample. A third ionization chamber was used to simultaneously measure a metallic sheet of the element that is being studied to be used as a reference. The appropriate amount of material for optimum measurements was calculated by the program XAFSMASS (Klementiev, 2012). The powder was mixed with boron nitride in a mortar and pressed into pellets of $7 \mathrm{~mm}$ diameter. The final XANES spectra were obtained after background subtraction and normalization to the post-edge intensity using the ATHENA software part of the DEMETER (Ravel \& Newville, 2005). The XANES spectra of samples have been analyzed by linear combination fitting of the experimental data from reference compounds using ATHENA program.

\section{Fourier Transform Infrared Spectroscopy (FT-IR)}

FT-IR spectroscopy was used to identify the different functional groups present on the surface of the nanocomposites. This technique is based upon the absorption of infrared radiation at specific wavelengths as it passes through a sample. FT-IR spectroscopy harness the interference of radiation between two beams to yield an 
interferogram: a signal produced as a function of the change of pathlength between the two beams. The infrared spectrum of the sample is obtained by applying the inverse Fourier-transformation calculation on the interferogram (Griffiths \& De Haseth, 2006).

\section{Experimental Set-up}

FT-IR spectra were obtained by using a Bruker Vector 22 spectrophotometer equipped with Globar source and DTGS detector. The spectra were recorded in transmission mode with 128 scans at $4 \mathrm{~cm}^{-1}$ resolution in the $4000-400 \mathrm{~cm}^{-1}$ range. Samples were previously dispersed in $\mathrm{KBr}$ previously dehydrated at $105^{\circ} \mathrm{C}(1: 40$ weight ratio) and pelletized.

\section{Atomic Absorption Spectroscopy (AAS)}

AAS was used to analyze the metal content in the precursor materials employed for the synthesis of the nanocomposites. This technique uses absorption spectrometry to evaluate the concentration of an analyte in a sample based on Lambert-Beer's law. The components in the sample are converted into atoms or ionized atoms in the atomizer. Here, the electrons of the atoms or ions can be promoted to higher orbitals for an instant by absorbing an amount of energy (i.e., photons of a certain wavelength). This amount of energy (or wavelength) refers specifically to an electron transition in an element, and in general, each wavelength corresponds to a single element. Single-element or multielement hollow cathode lamps are commonly used as emission sources to achieve good sensitivity and spectral resolution.

\section{Experimental Set-up}

AAS spectra were obtained by using a Perkin Elmer A200 atomic absorption spectrophotometer. Air-acetylene flame were used for the AAS analysis. Prior to the analysis, the samples were filtered with a Nylon $0.45 \mu \mathrm{m}$ filter and acidified with $\mathrm{HNO}_{3}$ (3 \%wt).

\section{Elemental Analysis - CHONS determination}

Quantitative determination of nitrogen, carbon, hydrogen, sulfur and oxygen, was carried out in order to obtain more precision on the characterization of the prepared materials. An analyzer that operates with the dynamic flash combustion (modified Dumas 
Method) of the sample for CHNS determination, with the system operating in pyrolysis mode was used. The resulted gases (Nitrogen and nitrogen oxide in $\mathrm{N}_{2}-$ Carbon in $\mathrm{CO}_{2}-$ Hydrogen in $\mathrm{H}_{2} \mathrm{O}$ - Sulfur in $\mathrm{SO}_{2}$ ) are carried by a helium (or argon) flow to a gas chromatographic column that provides the separation of the gases, which are finally detected by a thermal conductivity detector (TCD). The instrument must first be calibrated by analyzing a material that is pure and has a known composition, amino acid methionine is usually used a reference material.

\section{Experimental Setup}

Elemental composition of the solids was determined using a ThermoFlash EA 1112 CHNS$\mathrm{O}$ analyzer. Two replicas were performed, and values were presented as $\%$ mass mean value \pm SD (standard deviation).

\section{Diffuse Reflectance Spectroscopy (DRS)}

DRS was used to study optical properties of the materials. For solid materials, besides the transmission and absorption, the dispersion of electromagnetic radiation is important. Thus, a UV-Visible spectrophotometer equipped with an integrating sphere is needed to collect the analyzer and reference beam. The analyzer beam is reflected by the sample (a fraction is absorbed) and the reference beam is reflected by a $\mathrm{BaSO}_{4}$ standard. Both beams are collected and compared (Eq. 2.2) to obtain the fraction of reflected radiation:

$$
R(\lambda)=\frac{I_{r}(\lambda)}{I(\lambda)}
$$

Where $I_{r}(\lambda)$ and $I(\lambda)$ are the wavelength-dependent light intensities obtained for the analyzer and reference beams, respectively. With suitable experimental set up, there is no transmitted radiation by the sample (i.e. infinitely thickness of very compacted powder samples), and in that case the radiation transfer theory must be considered, leading to the well-known Kubelka-Munk theory. The Kubelka-Munk model uses an effective scattering coefficient $S$ and an effective absorption coefficient $K$ to describe the optical properties of a compact powder sample (Hernandez-Ramirez, 2016). Then, the Kubelka-Munk (K-M) 
function, $F\left(R_{\infty}\right)$, is related to the apparent absorption $(K)$ and the apparent scattering coefficient (S) by:

$$
F\left(R_{\infty}\right)=\frac{\left(1-R_{\infty}\right)^{2}}{2 R_{\infty}}=\frac{K}{S}
$$

Where $R_{\infty}=R_{\text {sample }} / R_{\text {standard, }}$ and it is the equivalent of the Lambert-Beer law for dilute species measured by diffuse reflectance experiments: $F\left(R_{\infty}\right)=\varepsilon C / s$, where $\varepsilon$ is the molar absorptivity and $\mathrm{C}$ the concentration. For such powder infinitely thick samples, the optical band gap can be easily calculated from Tauc' plots (Tauc, 1968): $(F(R \infty))^{2}$ vs. $h v$ for a direct gap or $\left(F\left(R_{\infty}\right)\right)^{1 / 2}$ vs. $h v$ for indirect gap ${ }^{1}$. From such plots, Eg is calculated as the point at which a linear extrapolation of the previous plots crosses the energy axis at $F\left(R_{\infty}\right)=0$.

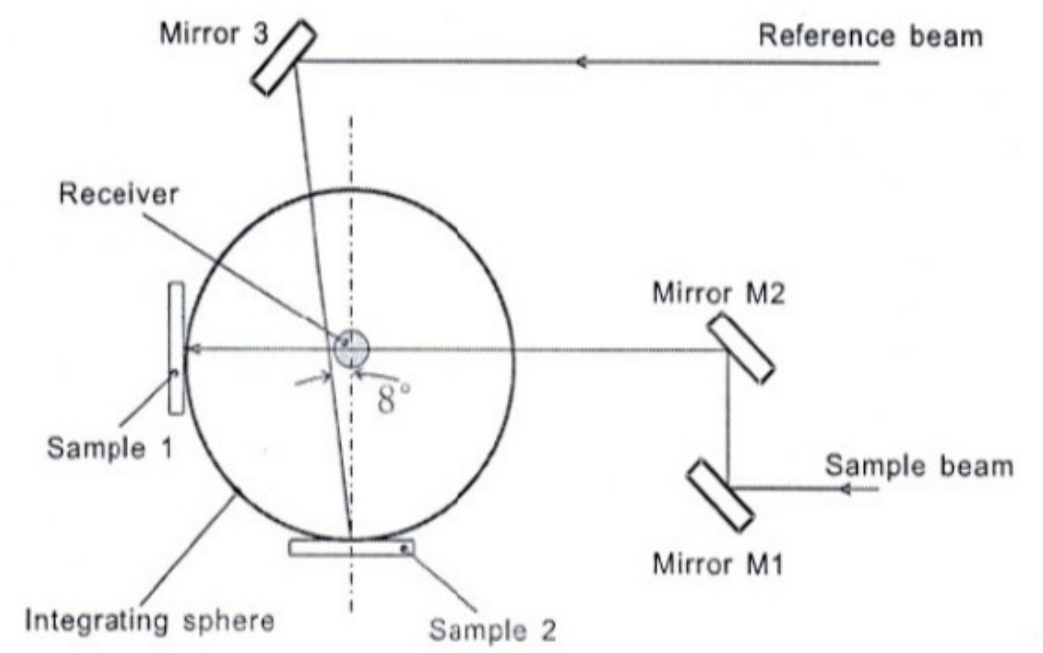

Fig. 2.3: scheme of the used integrating sphere accessory (taken from PG Instruments Limited T90+ spectrophotometer user's manual)

\footnotetext{
${ }^{1} \mathrm{~A}$ direct absorption process occurs when a photon is absorbed by the crystal with the creation of an electron and a hole. In an indirect absorption process, the transition also requires the creation of a phonon (Kittel, 2004).
} 
Experimental Set-up

Diffuse Reflectance spectra (DRS) of powder solid samples were recorded at room temperature with a double beam PG Instruments Limited T90+ spectrophotometer, equipped with an integration sphere IS19-1. The solids were mixed with $\mathrm{BaSO}_{4}$ in a weight ratio 1:5, the mixture was placed onto the sample holder and pressed to obtain a flat surface.

\section{Thermogravimetric Analysis (TGA)}

TGA was used to assess the organic matter content in the samples. This technique measures the absolute amount and rate of change in weight of a sample as either functions of time or temperature in a controlled environment. From TGA a wide range of properties can be measured such as thermal stability, oxidative stability, and sometimes the composition of multi-component systems. The measurement can be run in either a reactive or non-reactive atmosphere. Reactive atmospheres include corrosive, oxidizing and reducing gases, whereas non-reactive atmospheres include an inert gas, such as Ar or $\mathrm{N}_{2}$. TGA curves are plotted as mass change expressed in percent versus temperature or time (Leng, 2008).

\section{Experimental Set-up}

Thermo-Gravimetric Analysis (TGA) was carried out by means of a TA Q600 (TA Instruments). TGA tests were performed to monitor the organic matrix degradation and iron oxides phase transitions. The thermal analysis was performed with a heating ramp of $10{ }^{\circ} \mathrm{C} / \mathrm{min}$ from $\mathrm{RT}$ to $800^{\circ} \mathrm{C}$ in air.

\section{Specific Surface Area}

Nitrogen adsorption isotherms are generally determined by the volumetric method and provide the basis for the various standard procedures proposed for the determination of surface area $\left(A_{s}\right)$. The relationship between the quantity adsorbed and the equilibrium pressure of the gas, at constant temperature is known as the adsorption isotherm. Many adsorbents of high surface area are porous. Pores are classified according to their sizes: macropores, width exceeding $50 \mathrm{~nm}$; micropores width not exceeding about $2 \mathrm{~nm}$; and 
mesopores, width between 2 and $50 \mathrm{~nm}$. The micropore filling may be regarded as a primary physisorption process, whereas in mesopores the process takes place in different stages: monolayer-multilayer adsorption and capillary condensation. The last process is usually accompanied by hysteresis (Hiemenz, 2004).

The specific surface area of the samples was determined by applying the BET model to the adsorption isotherm of $\mathrm{N}_{2}$ at $77 \mathrm{~K}$. The BET model describes the volume of gas adsorbed at different values of relative pressure with respect to the bulk vapor pressure $p^{0}\left(x=p / p^{0}\right)$ in terms of two parameters: $V_{m}$ the total volume of gas adsorbed at monolayer; and C: a parameter related to the enthalpy (heat) of adsorption of the first adsorbed layer.

The BET equation requires a linear relation between $\frac{1}{V} \frac{x}{(x-1)}$ and $\mathrm{x}$ (Eq. 2.4). The range of linearity is restricted to a limit part of the isotherm $\left(0.05-0.30 p / p^{0}\right)$

$$
\frac{1}{V} \frac{x}{(x-1)}=\frac{c-1}{c V_{m}} x+\frac{1}{c V_{m}} \quad \text { with } \mathrm{x}=\mathrm{p} / \mathrm{p}^{0} \quad \text { (Eq. 2.4) }
$$

The $V_{m}$ parameter allows the calculus of the specific surface area $\left(A_{s}\right)$ by knowing with high accuracy the molecular cross-section area $\sigma^{\circ}$ of the gas employed $0.162 \mathrm{~nm}^{2}$ for $\mathrm{N}_{2}$ at $\left.77 \mathrm{~K}\right)$, and applying Eq. 2.5:

$$
A_{S}=\frac{V_{m} N_{A} \sigma^{\circ}}{22.414} \quad \text { (Eq. 2.5) }
$$

Where $\mathrm{N}_{\mathrm{A}}$ is the Avogadro constant.

Experimental Set-up:

For the present work, $\mathrm{N}_{2}$ adsorption-desorption experiments at $77 \mathrm{~K}$ were carried out by means of an ASAP 2020 gas volumetric instrument (Micrometrics) to determine the specific surface area (BET model). When possible, the BJH model was used to study the pore distribution. Samples were pretreated for several hours at $150{ }^{\circ} \mathrm{C}$ in order to remove undesired atmospheric gaseous contaminants adsorbed on powder surface and/or pores. 


\section{Magnetic Properties}

Magnetic properties of the nanocomposites were evaluated by using a Vibrating Sample Magnetometer (VSM).The VSM is a sensitive and versatile instrument for the study of magnetic moments of different magnetic materials as a function of magnetic field and temperature.

In the VSM method, a magnetic material is first magnetized by a uniform field created between the electric magnet's poles. This causes the sample to generate its own magnetic field. The sample is sinusoidally vibrated, inducing thus an electric current in suitably placed sensing coils. The resulting voltage induced in the sensing coils is proportional to the magnetic moment of the sample (Borin \& Baffa, 2005).

The most common parameters extracted from the hysteresis loop that are used to characterize the magnetic properties of permanent magnet materials (shown in Fig. 2.4) include: the saturation magnetization $M_{s}$, the remanence $M_{r}$, and the coercivity $H_{c}$ (ASTM International, 2015).

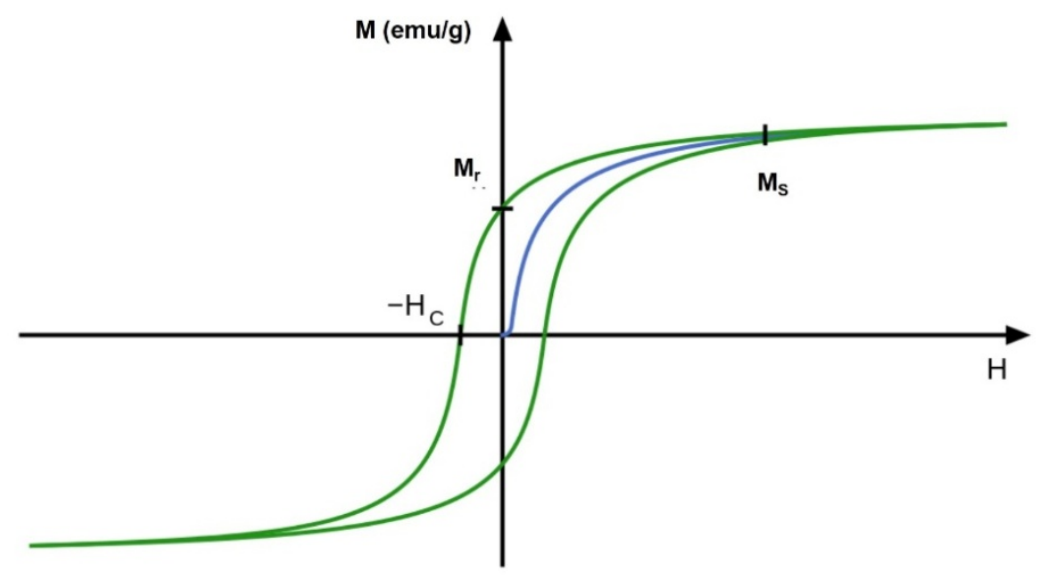

Fig. 2.4: Typical magnetization hysteresis loop. $M_{S}$ stands for saturation magnetization; $M_{r}$ for remnant magnetization and $\mathrm{H}_{\mathrm{C}}$ for coercivity

\section{Experimental Set-up}

Hysteresis loops were recorded with a LakeShore 7404 vibrating sample magnetometer. The hysteresis loop of the samples was registered at room temperature $\left(25^{\circ} \mathrm{C}\right)$. The magnetic field was cycled between $-20,000$ and 20,000 Oe. 


\section{High Resolution Transmission Electron Microscopy (HR-TEM)}

HR-TEM was used to evaluate the morphology and structure of the nanocomposites at a nanometric level. In TEM, the sample is subjected to a high intensity beam of electrons. The energy of this beam determines the wavelength of electrons and wavelength largely determines the resolution of the microscope, thus the acceleration voltage determines the resolution to a large extent. To achieve a high resolution, the microscopes usually operate under an acceleration voltage greater than $100 \mathrm{kV}$. In practice, $200 \mathrm{kV}$ is commonly used and meets most resolution requirements. Depending on the instrument, a resolution of $0.1 \mathrm{~nm}$ can be achieved. As the electrons pass through the sample, the obtained images are of the bulk structure; crystal defects such as phase boundaries, shear planes, etc. can be seen.

The instrument can be operated to select either the direct beam (bright field image) or the diffracted beam (dark field image). There are several modes of operation that can be used in TEM: image modes of amplitude contrast (mass-density and diffraction modes) and phase contrast. In the amplitude contrast modes, only the change in the amplitude of transmitted electrons is used. Mass-density and diffraction modes both generate images by electron scattering. Contrast relies on deflection of electrons from their primary transmission direction when they pass through the sample. The contrast is generated when there is a difference in the number of electrons being scattered away from the transmitted beam. Mass-density contrast exists in all types of materials. It is the main mechanism for image formation for non-crystalline materials such as amorphous polymers and biological specimens. HR-TEM, on the other hand, generates phase contrast images, as shown in Fig. 2.5. They are formed by (at least) two beams: the transmitted beam and a diffraction beam. A crystalline material with a periodic lattice structure generates a phase difference between the transmitted and diffracted beams. The recombination of those beams will generate an interference pattern with periodic darkbright changes on the image plane: an interference pattern is a fringe type that reveals the periodic nature of a crystal (Leng, 2008). 


\section{Experimental Set up}

Micrographs were obtained using a JEOL JEM 3010 instrument (300 kV) equipped with a $\mathrm{LaB}_{6}$ filament. For the specimen preparation, a few drops of nanoparticles water suspensions were poured on holed carbon-coated copper grids and left to dry before analyses. The as obtained images were analyzed with ImageJ software in order to obtain interplanar distances of crystalline regions, sizes and morphological features of the samples.

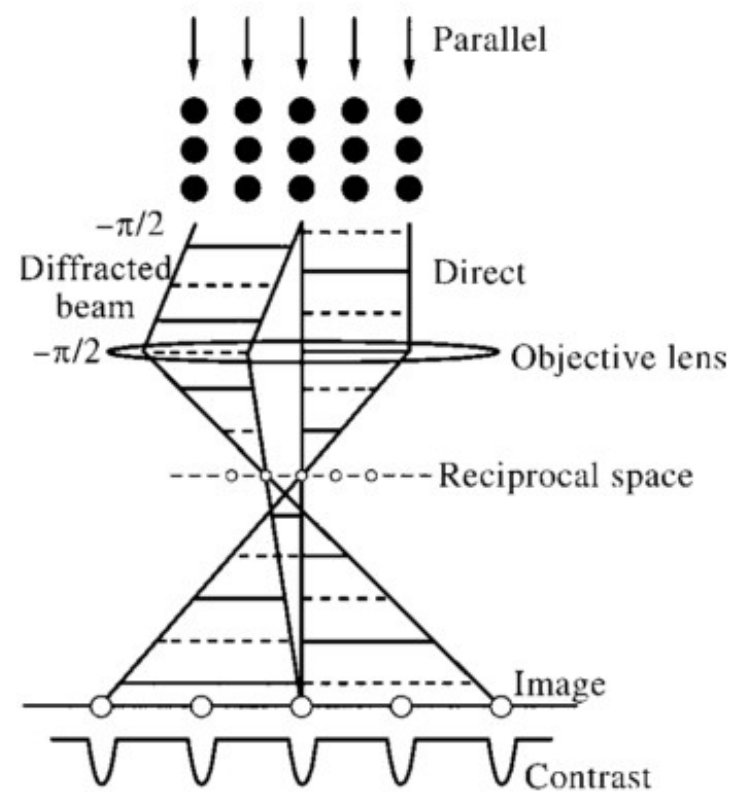

Fig. 2.5: Phase contrast formation from a crystalline specimen. Phase difference is generated by crystal diffraction and objective lenses. This results in a phase difference of $-\pi$ between the direct and transmitted beams (image taken from (Leng, 2008)

\section{Electronic Paramagnetic Resonance (EPR)}

The EPR technique was used to assess the formation of $\mathrm{HO}^{\bullet}$ radical from aqueous dispersion of the nanocomposites under UVA irradiation. EPR is a powerful spectroscopic tool for the investigation of chemical species with unpaired electrons like radicals or transition metal ions with partially filled $d$-orbitals. This non-destructive technique allows the in-situ study of structures and dynamics of such species involved in numerous chemical and biochemical reactions. EPR involves the interaction of electromagnetic radiation, usually in the microwave region ( $X$-band, $8-10 \mathrm{GHz}$ ), with the paramagnetic 
material in a magnetic field. The EPR spectrum is characterized by several parameters, which give information about the nature of the paramagnetic centers and their surroundings. In this work, the identification of short-lived free radicals, such as $\mathrm{HO}^{\bullet}$ radicals, was carried out by EPR spin-trapping technique. A spin trap is a diamagnetic compound, which is introduced into the system without perturbing it and reacts rapidly and specifically with a transient free radical to form a stable radical (radical-adduct) recognized from its EPR signal. The spin trap used, the spin-adduct formed, and its typical signal are shown in Fig. 2.6

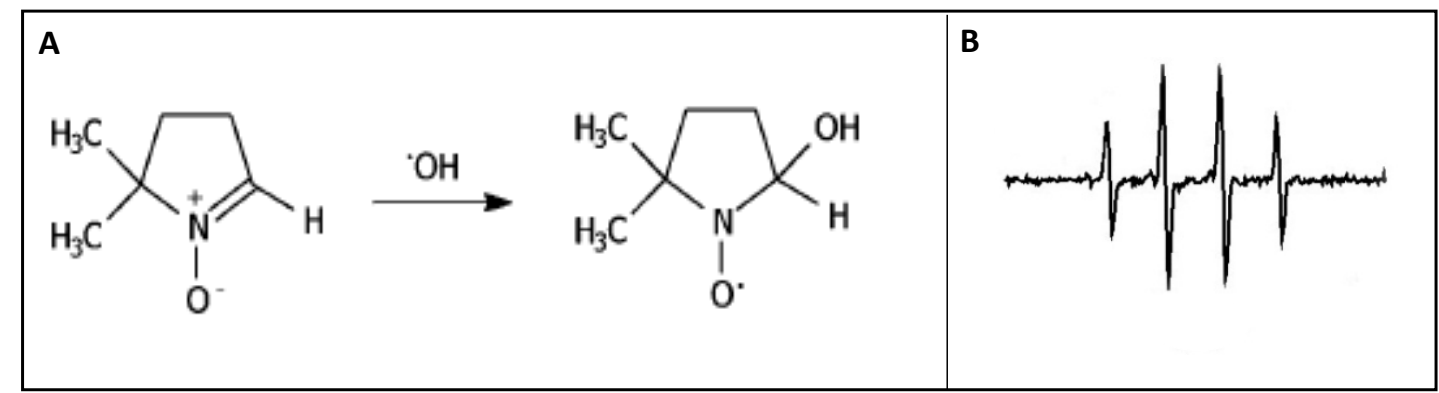

Fig. 2.6: Formation ofspin-adduct DMPO-OH (A) and its typical EPR spectrum: a 1:2:2:1 quartet, with a 14.8 G hyperfine splitting constant

\section{Experimental Set-up}

EPR spectra were registered at room temperature with a Bruker ESR 300E spectrometer operating at X-band and equipped with a flat quartz EPR cell. The acquisition parameters were as follows: Frequency of $9.69 \mathrm{GHz}, 5.024 \mathrm{~mW}$ of microwave power, center field $3475 \mathrm{G}$, sweep width $80 \mathrm{G}$, number of scans 40 , receiver gain $1 \times 10^{5}$, modulation amplitude $0.43 \mathrm{G}$, conversion time 40.960 ms. 5,5-dimethyl-1-pyrroline-N-oxide (DMPO) was employed as trapping agent for hydroxyl radicals $\left(\mathrm{HO}^{\circ}\right)$ detection. The experimental procedure for the analysis of $\mathrm{HO}^{\circ}$ radical by EPR technique was as follows: $5 \mathrm{~mL}$ of aqueous dispersion of samples $\left(500 \mathrm{mgL}^{-1}\right)$ were placed in Pyrex closed cells and irradiated, under continuous stirring, with a $1500 \mathrm{~W}$ xenon lamp (Solarbox, Co. Fo. Megra, Milan, Italy) equipped with a $340 \mathrm{~nm}$ or $310 \mathrm{~nm}$ cut-off filter. Then, $0.97 \mu \mathrm{L}$ of DMPO were added to the cell after $1 \mathrm{~h}$ of irradiation, and the EPR spectra were recorded immediately after irradiation. 


\section{Laser Flash Photolysis (LFP)}

Laser Flash Photolysis is a very powerful technique that allows the study of transient species such as excited states, radicals and solvated electrons produced by the interaction between radiation and the substrate. The method consists of the irradiation of a sample with a very short high intensity flash of light, and the monitoring of the resulting changes in light absorption. The analyzing light source provides a continuous beam which passes through the sample. A monochromator is used to select wavelengths at which the transmission of the sample is scanned by the photodetector that converts changes in light intensity to electrical signals, which are displayed on an oscilloscope. Then, the transmission changes are normally converted into optical densities. In spectral regions where the absorption of the transient and original material overlap a difference spectrum is obtained, the change in optical density observed being (Eq. 2.6):

$$
\Delta O D=\left(\epsilon_{t}-\epsilon_{G}\right) c l \quad \text { Eq. } 2.6
$$

Where $\varepsilon_{\mathrm{G}}$ and $\varepsilon_{\mathrm{t}}$ are the extinction coefficients of the ground state and the transient, respectively; $c$ is the concentration of ground state converted to transient and $I$ is the optical path length. Pulsed lasers as sources of radiation allow time resolutions of even picoseconds $\left(10^{-12} \mathrm{~s}\right)$. Electronically excited states and free radicals are the most common intermediates detectable by LFP. Another important species usually detected is the solvated electron $\mathrm{e}_{\mathrm{aq}}^{-}$. 


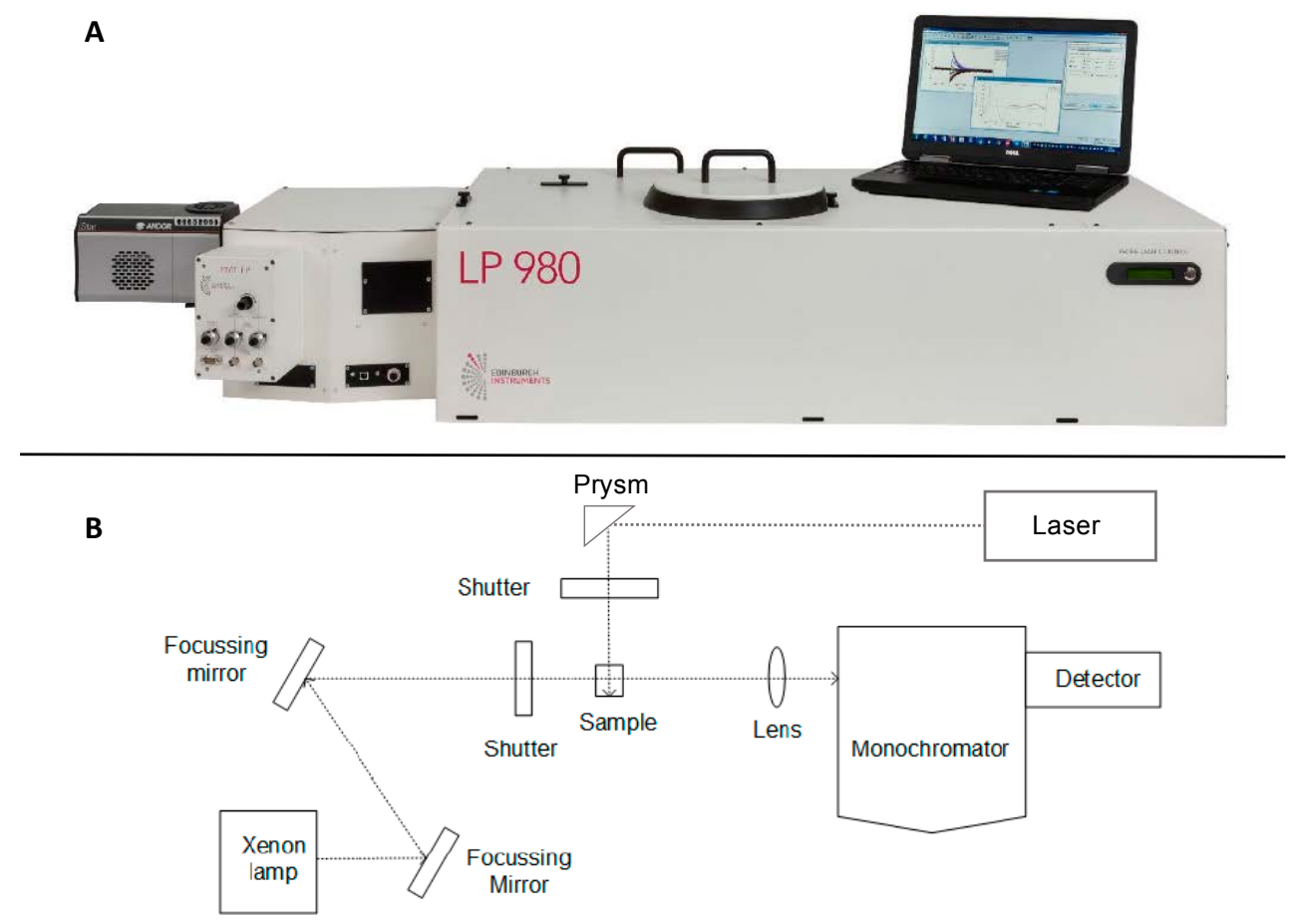

2.7: LFP system (A) and scheme of the experimental arrange (B)

\section{Experimental Set up}

An LP980 laser flash-photolysis from Edinburgh instruments was employed. The third harmonic (355 nm) of a Continuum Surelite Nd:YAG laser (20 ns FWHM) was employed as excitation source. Since several species contribute to the absorption traces, a global analysis of the transient absorption data was carried out. Decay-associated difference spectra (DADS) were performed with the free software Glotaran (Snellenburg et al., 2012). Suspensions of the nanocomposites (500 mg. $\mathrm{L}^{-1}$ ) were prepared, and the absorbance adjusted to $\lambda^{355}=0.2$. Different quenchers were added to the suspensions to study their effect: KSCN, TEA, TEOA. 



\subsection{Photochemical Experiments}

Carbamazepine (CBZ), an antiepileptic drug, was selected as a model emerging pollutant to test the photocatalytic activity of the synthesized nanocomposites. Photochemical experiments were carried out in a $200 \mathrm{~mL}$ glass reactor placed in the center of Rayonet RPR- reactor equipped with 8 lamps with a maximum emission centered at $300 \mathrm{~nm}$ and eventually at 350nm and $8 \mathrm{~W}$ of power (Fig. 2.8). The photon flux per unit volume sample $\left(P_{0}\right)$ was measured using potassium ferrioxalate as actinometer. For the $300 \mathrm{~nm}$ centered lamps was $8.7 \times 10^{-7}$ Einstein $\mathrm{s}^{-1} \mathrm{~L}^{-1}$ (details of the actinometry are outlined below) and for the $350 \mathrm{~nm}$ centered lamps was $3.5 \times 10^{-5}$ Einstein $\mathrm{s}^{-1} \mathrm{~L}^{-1}$ (García Einschlaget al., 2002).

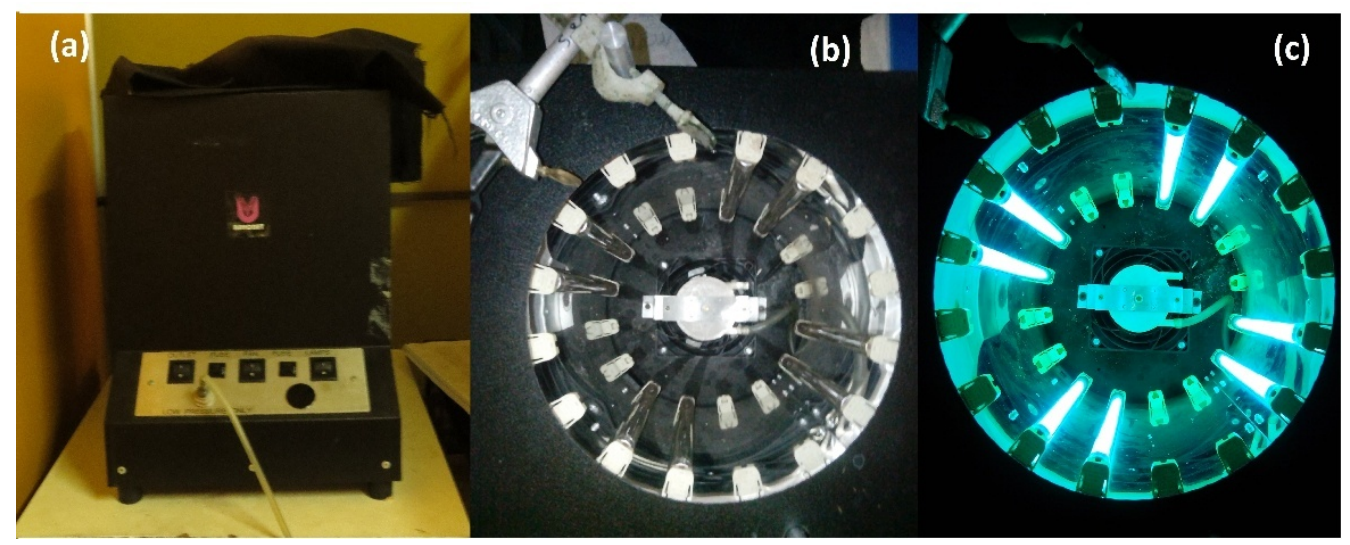

Fig. 2.8: Rayonet reactor photographs: front view(a), and top view with the $300 \mathrm{~nm}$ lamps (b) and with the $350 \mathrm{~nm}$ emission lamps (c)

In all the experiments, the initial concentration of CBZ was $2 \mathrm{mg} \mathrm{L}^{-1}$ and the initial concentrations of the nanocomposites ranged from 0.62 to $1.25 \mathrm{mg} \mathrm{L}^{-1}$. The aqueous suspensions were irradiated for $6 \mathrm{~h}$ under constant stirring, and $2 \mathrm{~mL}$ aliquots were taken at different times to determine the remnant CBZ concentration by HPLC. The withdrawn samples were placed in $5 \mathrm{~mL}$ flasks. The supernatant was magnetically separated from the nanocomposites using a neodymium magnet and, then filtered with $0.45 \mathrm{~mm}$ nylon filters before the HPLC analysis. A Hewlett-Packard TI series 1050 HPLC system with autosampler and multi-wavelength detection system; equipped with a C18 Restek Pinnacle II 
(particle size $5 \mu \mathrm{m}, 2.1 \mathrm{~mm}$, id250 mm) was used to quantify CBZ. The elution conditions were: mobile phase composed of $75 / 25(\mathrm{v} / \mathrm{v})$ methanol and an aqueous solution $(0.1 \%$

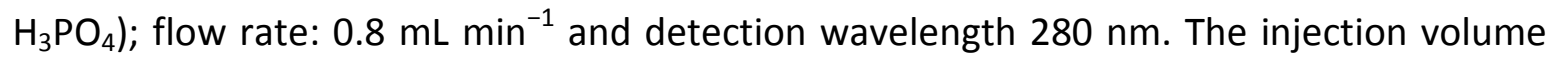
was $25 \mu \mathrm{L}$ with a re-equilibration time of $2 \mathrm{~min}$.

Control experiments were also performed: without irradiation (adsorption experiments), and direct photolysis of the CBZ (absence of the nanocomposites). All these control experiments were performed under the same experimental conditions.

Actinometry of the lamps

In order to evaluate the radiation that reaches the solution placed in the reactor, an actinometry was performed using $\mathrm{K}_{3} \mathrm{Fe}\left(\mathrm{C}_{2} \mathrm{O}_{4}\right)_{3} \cdot 3 \mathrm{H}_{2} \mathrm{O}$ that in the presence of UV radiation participates in the following global photochemical reaction:

$$
2 \mathrm{Fe}\left(\mathrm{C}_{2} \mathrm{O}_{4}\right)_{3} \stackrel{\mathrm{hv}}{\longrightarrow} 2 \mathrm{Fe}^{2+}+\mathrm{CO}_{2}+5 \mathrm{C}_{2} \mathrm{O}_{4}{ }^{2-}
$$

Potassium ferrioxalate is one of the most practical actinometers used to evaluate radiation intensities between 200 and $500 \mathrm{~nm}$. The quantum yield of $\mathrm{Fe}^{+2}$ ion production $\left(\Phi_{\mathrm{Ac}, \lambda}\right)$ has a practically constant value of 1.24 in the range between 200 and $360 \mathrm{~nm}$, then decreases to a value of 0.86 to $509 \mathrm{~nm}$ (Table 3.2). The incident photon velocity $\left(\mathrm{P}_{0}\right)$ defined as the total number of photons entering the solution per unit time and unit volume can be calculated for a polychromatic lamp by means of equation 2.7 (García Einschlag, 2002):

$$
P_{o}=\frac{\left(\frac{d\left[F e^{2+}\right]}{d t}\right)}{\sum_{i} p_{i}\left(1-10^{-A_{i}}\right) \phi_{A c, i}}
$$

The subscript $i$ refers to small finite intervals of wavelength, the sum of all the intervals covers the region of $\lambda$ between 200 and $500 \mathrm{~nm}, \mathrm{~d}\left[\mathrm{Fe}^{+2}\right] / \mathrm{dt}$ is the rate of formation of $\mathrm{Fe}^{+2}$ (calculated from the slope of the graph $\left[\mathrm{Fe}^{+2}\right]$ vs. time), $p_{i}$ is the probability function of the photon emission of the lamp (the total integral of the emission 
of the lamp is equal to 1$), A_{i}$ is the mean absorbance of the solution and $\Phi_{A c, i}$ is the overall quantum performance of the actinometer used in this case (potassium ferrioxalate) in the wavelength interval $i$.

To ensure the absorption of all the radiation by the actinometric solution, a $0.02 \mathrm{M}$ solution of potassium ferrioxalate was used whose $\mathrm{pH}$ was adjusted to a value of 3.0 with $\mathrm{HClO}_{4}$. The absorbance of this solution for an optical path of $1 \mathrm{~cm}$ is greater than 2 between 200 and $480 \mathrm{~nm}$. Under these conditions the term $\left(1-10^{-A i}\right)$ within the sum of the equation 3.8 is reduced to 1 over the entire range of wavelengths studied. The flow of radiation entering the reactor was determined as follows:

1) $200 \mathrm{~mL}$ of the aforementioned solution was placed in the reactor.

2) The lamps were switched on.

3) Samples were taken from the reactor at 1 minute intervals.

4) The samples were placed in contact with the 1,10-phenanthroline solution. The concentration of ferrous ions formed during the photolysis of ferrioxlate was determined by the colorimetric method $o$-phenantroline.

5) The solution was irradiated for a maximum of 5 minutes to avoid ferrioxalate consumption greater than $10 \%$.

Table 2.4: Quantum yield of the formation of $\mathrm{Fe}^{2+}$ (extracted from Braun et al., Photochemical technology, 1991. Wiley, Chichester.

\begin{tabular}{ccc|ccc}
\hline$\lambda(\mathrm{nm})$ & Concentration $(\mathrm{M})$ & $\Phi_{\mathrm{Ac}, \lambda}$ & $\lambda(\mathrm{nm})$ & Concentration $(\mathrm{M})$ & $\Phi_{\mathrm{Ac}, \lambda}$ \\
\hline 254 & $6 \times 10^{-3}$ & 1.25 & 405 & $6 \times 10^{-3}$ & 1.14 \\
$297-302$ & $6 \times 10^{-3}$ & 1.24 & 406.7 & $6 \times 10^{-3}$ & 1.19 \\
313 & $6 \times 10^{-3}$ & 1.24 & 416 & $6 \times 10^{-3}$ & 1.12 \\
334 & $6 \times 10^{-3}$ & 1.23 & 436 & $6 \times 10^{-3}$ & 1.11 \\
358 & $6 \times 10^{-3}$ & 1.25 & 436 & $1.5 \times 10^{-1}$ & 1.01 \\
$361-366$ & $6 \times 10^{-3}$ & 1.21 & 457.9 & $1.5 \times 10^{-1}$ & 0.84 \\
$365-366$ & $6 \times 10^{-3}$ & 1.21 & 468 & $1.5 \times 10^{-1}$ & 0.92 \\
$365-366$ & $1.5 \times 10^{-1}$ & 1.20 & 480 & $1.5 \times 10^{-1}$ & 0.94 \\
392 & $6 \times 10^{-3}$ & 1.13 & 509 & $1.5 \times 10^{-1}$ & 0.86 \\
\hline \multicolumn{5}{r}{}
\end{tabular}


The analysis of the $\mathrm{Fe}^{+2}$ concentration in the samples was carried out using the colorimetric method of modified $o$-(Phen). The basis of the method is based on the formation of a stable red-orange complex between $\mathrm{Fe}^{+2}$ and (Phen). The complex formation reaction is shown below:

$$
\mathrm{Fe}^{2+}+3 \text { Phen } \stackrel{\mathrm{H}+}{\longrightarrow} \mathrm{Fe}(\text { Phen })_{3}{ }^{2+}+3 \mathrm{H}^{+}
$$

The equilibrium constant for this reaction is $2.5 \times 10^{6}$ at $25^{\circ} \mathrm{C}$. The quantitative formation of the complex is observed in the range of $\mathrm{pH}$ between 2 and 9 . The complex formed absorbs radiation in the visible region with a maximum absorption at $510 \mathrm{~nm}$. Since the absorption of light by the complex follows the Lambert-Beer law and considering that neither Fe ${ }^{+2}$ nor Phen absorb appreciably at $510 \mathrm{~nm}$, the absorbance of the solution at 510 $\mathrm{nm}$ can be used to determine the concentration of the complex and in this way the concentration of $\mathrm{Fe}^{+2}$ in the sample.

The solutions used were:

(a) $0.018 \mathrm{M}$ Phen, to achieve complete dissolution, the solution was magnetically stirred and heated to a temperature not higher than $60^{\circ} \mathrm{C}$ for $30 \mathrm{~min}$.

(b) $0.7 \mathrm{M}$ Sodium Acetate

(c) $\mathrm{Fe}\left(\mathrm{SO}_{4}\right) \cdot 6 \mathrm{H}_{2} \mathrm{O} 0.001 \mathrm{M}$,

Procedure: Solutions of Phen and sodium acetate were mixed in equal proportions. $1 \mathrm{~mL}$ of the mixture was placed in a test tube, then an aliquot of $1 \mathrm{~mL}$ of sample was added to the test tube and the complex was allowed to develop for $1 \mathrm{~min}$. Next, the spectra of the solutions were measured in a range between 400 and $600 \mathrm{~nm}$. The cells used were $1 \mathrm{~cm}$ of optical path. Prior to the $\mathrm{Fe}^{+2}$ analyses, a calibration curve was made with a solution of $\mathrm{Fe}\left(\mathrm{SO}_{4}\right) \cdot 6 \mathrm{H}_{2} \mathrm{O}$. The molar extinction coefficient of the complex at $510 \mathrm{~nm}\left(\varepsilon_{510}{ }^{\mathrm{FePh} 3}\right)$ was determined to be $11428 \mathrm{~L} \mathrm{~mol}^{-1} \mathrm{~cm}^{-1}$ (Carlos, 2008).

The concentration profile obtained for $\mathrm{Fe}^{+2}$ is shown in Figure 2.9. Using the value of the slope calculated by linear fitting on Figure 2.9 (dotted line) and using intervals of 
$0.37 \mathrm{~nm}$ in equation 3.8 , an incident intensity of $8.7 \times 10^{-7}$ Eins s $^{-1} \mathrm{~L}^{-1}\left(\mathrm{P}_{0}\right)$ was estimated in the reactor used for the range of 300 to $500 \mathrm{~nm}$.

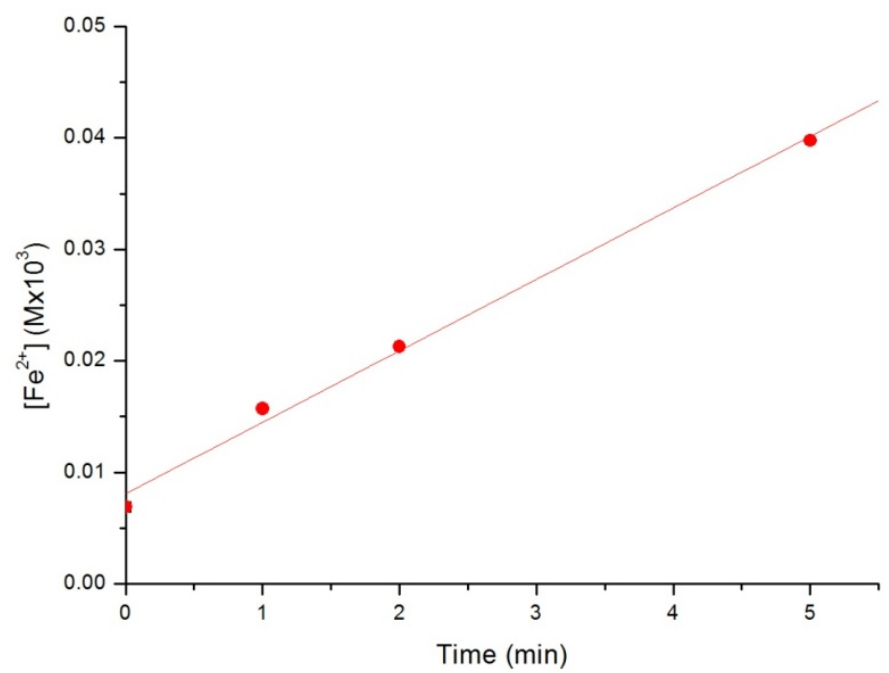

Fig. 2.9: Profile of concentration of $\mathrm{Fe}^{+2}$ obtained during the actinometry using a solution $0.2 \mathrm{M}$ of $\mathrm{K}_{3} \mathrm{Fe}\left(\mathrm{C}_{2} \mathrm{O}_{4}\right)_{3} \cdot 3 \mathrm{H}_{2} \mathrm{O}$. 



\subsection{References}

ASTM International. (2015). ASTM A340 - Standard Terminology of Symbols and Definitions Relating to Magnetic Testing. ASTM International. https://doi.org/10.1520/A034003AR11.Part

Borin, J. F., \& Baffa, O. (2005). Measuring magnetic properties of ferromagnetic materials. American Journal of Physics, 66(5), 449-452. https://doi.org/10.1119/1.19074

Carlos, L. (2008). Degradación de contaminantes empleando tecnologías de oxidación avanzada: Procesos Fenton y foto-Fenton. UNLP.

García Einschlag, F. S., Carlos, L., Capparelli, A. L., Braun, A. M., \& Oliveros, E. (2002). Degradation of nitroaromatic compounds by the UV- $\mathrm{H} 2 \mathrm{O} 2$ process using polychromatic radiation sources. $\begin{array}{llll}\text { Photochemical and Photobiological } & \text { Sciences, }\end{array}$ https://doi.org/10.1039/b203152c

Griffiths, P. R., \& De Haseth, J. A. (2006). Fourier Transform Infrared Spectrometry: Second Edition. Fourier Transform Infrared Spectrometry: Second Edition. https://doi.org/10.1002/047010631X

Hernandez-Ramirez, A. (2016). Photocatalytic semiconductors. (A. Hernández-Ramírez \& I. Medina-Ramírez, Eds.). Springer. https://doi.org/10.1007/978-3-319-10999-2

Hiemenz, P. C. and R. (2004). Principles of colloid and surface chemistry. Journal of Colloid and Interface Science (3rd ed., Vol. 70). https://doi.org/10.1016/0021-9797(79)90045-6

Kang, H., \& Wang, H. P. (2013). Preparation of Magnetic Recoverable Nanosize Cu - Fe $203 / \mathrm{Fe}$ Photocatalysts, 47(13), 7380-7387.

Kelly, S. D., HESTERBERG, D., RAVEL, B., ULERY, A. L., \& RICHARD DREES, L. (2008). Analysis of Soils and Minerals Using X-ray Absorption Spectroscopy, (5), 387-463. https://doi.org/10.2136/sssabookser5.5.c14

Kittel, C. (2004). Introduction to Solid State Physics. In Introduction to Solid State Physics (8th ed., pp. 185-220).

Klementiev, $\quad$ K. $\quad$ V. $\quad$ (2012). XAFSmass. $\quad$ Retrieved from www.cells.es/Beamlines/CLAESS/software/xafsmass.html

Leng, Y. (2008). MATERIALS CHARACTERIZATION Introduction to Microscopic andSpectroscopic Methods. (John Wiley \& Sons, Ed.).

Montoneri, E., Boffa, V., Savarino, P., Perrone, D. G., Musso, G., Mendichi, R., ... Gobetto, R. (2009). Biosurfactants from urban green waste. ChemSusChem, 2(3), 239-247. https://doi.org/10.1002/cssc.200800199

Naseri, M. G., Saion, E. B., Hashim, M., Shaari, A. H., \& Ahangar, H. A. (2011). Synthesis and characterization of zinc ferrite nanoparticles by a thermal treatment method. Solid State Communications, 151(14-15), 1031-1035. https://doi.org/10.1016/j.ssc.2011.04.018 
Nisticò, R., Cesano, F., Franzoso, F., Magnacca, G., Scarano, D., Funes, I. G., ... Parolo, M. E. (2018). From biowaste to magnet-responsive materials for water remediation from polycyclic aromatic hydrocarbons. Chemosphere, 202, 686-693. https://doi.org/10.1016/j.chemosphere.2018.03.153

Ravel, B., \& Newville, M. (2005). ATHENA, ARTEMIS, HEPHAESTUS: Data analysis for X-ray absorption spectroscopy using IFEFFIT. In Journal of Synchrotron Radiation. https://doi.org/10.1107/S0909049505012719

Smart, Lesley and Moore, E. (2005). Solid state chemistry: an introduction (3rd ed.). https://doi.org/10.1007/978-1-4899-6830-2

Snellenburg, J. J., Laptenok, S. P., Seger, R., Mullen, K. M., \& van Stokkum, I. H. M. (2012). Glotaran : A Java-based graphical user interface for the R package TIMP. Journal of Statistical Software, 49(3), 1-2. https://doi.org/10.18637/jss.v049.i03

Tauc, J. (1968). Optical properties and electronic structure of amorphous Ge and Si. Materials Research Bulletin, 3(1), 37-46. https://doi.org/10.1016/0025-5408(68)90023-8 
3 Results and discussion 



\subsection{Physicochemical Characterizations}

\section{Precursors characterization}

As a first step, the physicochemical characterization of the precursors was carried out to obtain information on their structures and compositions. This is key to understanding the changes that precursors will undergo after the thermal treatment. In this section results from precursors PFeCu-1, PFeCu-3 and PFeCu- 5 will be discussed.

X-Ray diffraction patterns of BBS and the three precursors are shown in Fig. 3.1.1 and Fig. 3.1.2, respectively. No relevant reflections are observed from BBS since its XRD pattern presents only one broad amorphous contribution centered at ca. $2 \theta=25$ and few negligible signals due to its ash content. On the other hand, precursors show a few peaks that could be assigned to unreacted salts of $\mathrm{FeCl}_{3} \times 6 \mathrm{H}_{2} \mathrm{O}$ and $\mathrm{CuSO}_{4}$ (ICDD card numbers 00-001-0132 and 00-001-0620, respectively). The weak intensity of the signals suggests that only a negligible amount of unreacted salts is present in the precursors, whereas the most part of the metal ions formed complexes with the organic matter. In addition, the continuous increase of the signal with the decrease of $2 \theta$ suggests the presence of amorphous organic matter.

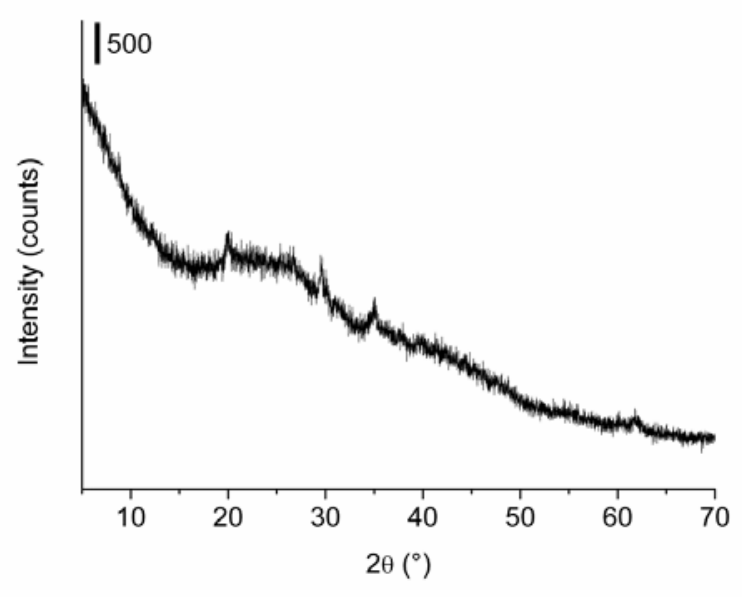

Fig. 3.1.1: XRD pattern of neat BBS 


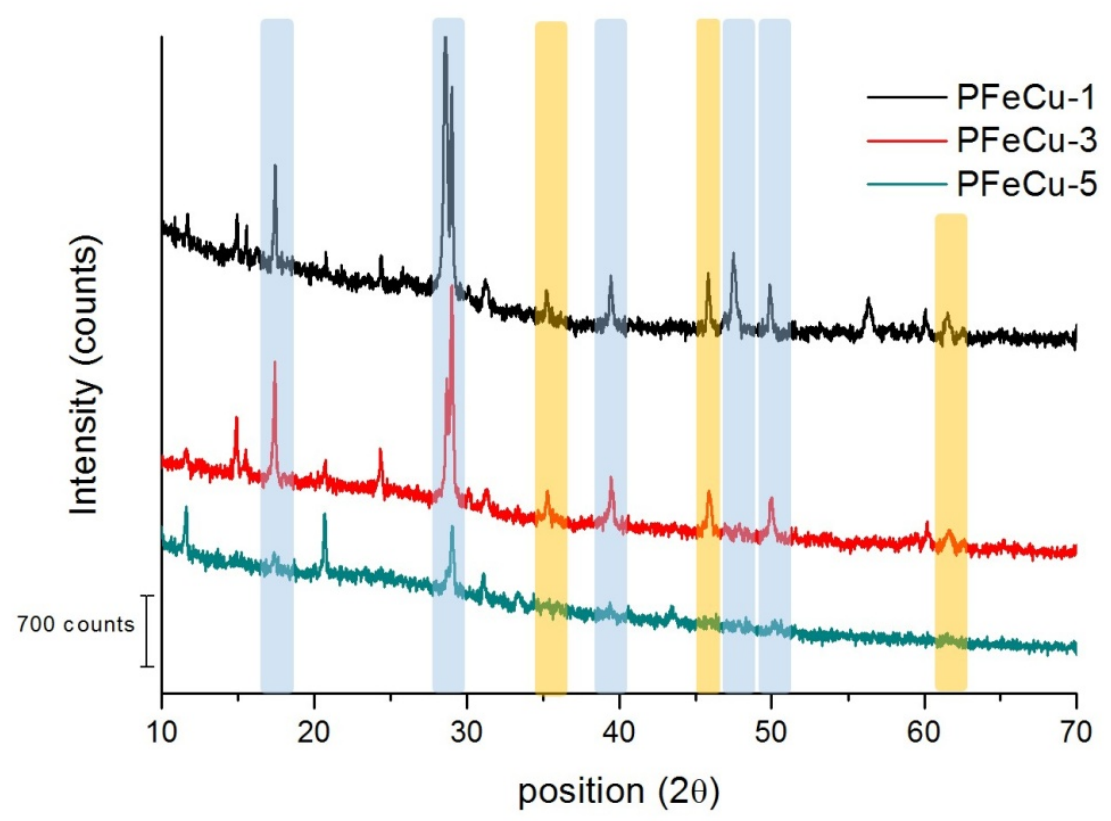

Fig. 3.1.2: $X R D$ patterns of PFeCu-1, PFeCu-3 and PFeCu-5. The main reflections are highlighted, in yellow those of $\mathrm{FeCl}_{3} \times 6 \mathrm{H}_{2} \mathrm{O}$ and in blue those of $\mathrm{CuSO}_{4}$

FT-IR spectroscopy was used to identify the organic functional groups present in the samples. Fig. 3.1.3 shows the FT-IR spectra of neat BBS and the precursors (PFeCu-1, PFeCu-3 and PFeCu-5). The interpretation of these spectra is not simple due to the complex organic matrix that characterizes the BBS. The spectrum of BBS shows a broad band in the $3700-2500 \mathrm{~cm}^{-1}$ spectral range that was assigned to $\mathrm{O}-\mathrm{H}$ and $\mathrm{N}-\mathrm{H}$ vibrations and two small bands around $2930 \mathrm{~cm}^{-1}$ and $2853 \mathrm{~cm}^{-1}$, that correspond to asymmetric/symmetric $\mathrm{C}-\mathrm{H}$ stretching of aliphatic $-\mathrm{CH}_{3}$ and $-\mathrm{CH}_{2}$. The bands in the range from 1700 to $1300 \mathrm{~cm}^{-1}$ are mainly due to the stretching of carboxylic groups, and the band at $1025 \mathrm{~cm}^{-1}$ is assigned to $\mathrm{C}-\mathrm{O}$ stretching of polysaccharides or polysaccharide-like substances (Ou et al., 2009).

Noticeably, in the precursors' spectra and by comparison to the spectrum of BBS, the stretching band of carboxylate $\mathrm{COO}^{-}$was shifted to 1620 and $1400 \mathrm{~cm}^{-1}$, indicating that carboxylate functional groups of BBSs may have complexed the metal ions. In particular, the band at $1400 \mathrm{~cm}^{-1}$ evidences the complexation between $\mathrm{COO}^{-}$of $\mathrm{BBS}$ and $\mathrm{Fe}^{3+}$. This assignment was supported by the fact that a strong absorption band at about $1400 \mathrm{~cm}^{-1}$ 
appeared when a humic acid interacted with $\mathrm{Fe}^{3+}$ to form iron-humate complexes (Carlos et al. 2014). Significant changes in the region assigned to C-O stretching bands of carbohydrates and polysaccharide-like moieties $\left(950-1125 \mathrm{~cm}^{-1}\right)$ were observed for the precursors, which suggest the interaction of these groups with $\mathrm{Fe}^{3+}$ and $\mathrm{Cu}^{2+}$. Also, two new sets of bands are developed: one comprises the signal at $1224 \mathrm{~cm}^{-1}$, that correspond to $\mathrm{SO}_{4}{ }^{2-}$ of the $\mathrm{Cu}^{2+}$ precursor salt (Cheng \& Hwang, 2009), and the other due to Fe-O vibrations (at $660 \mathrm{~cm}^{-1}, 590 \mathrm{~cm}^{-1}$ (Maity \& Agrawal, 2007)), and Cu-O (at $470 \mathrm{~cm}^{-1}$ (Konar et al., 2016). A comparison of the FT-IR spectra of the three precursors shows that the higher amount of BBS used in the synthesis, the weaker the signals obtained.

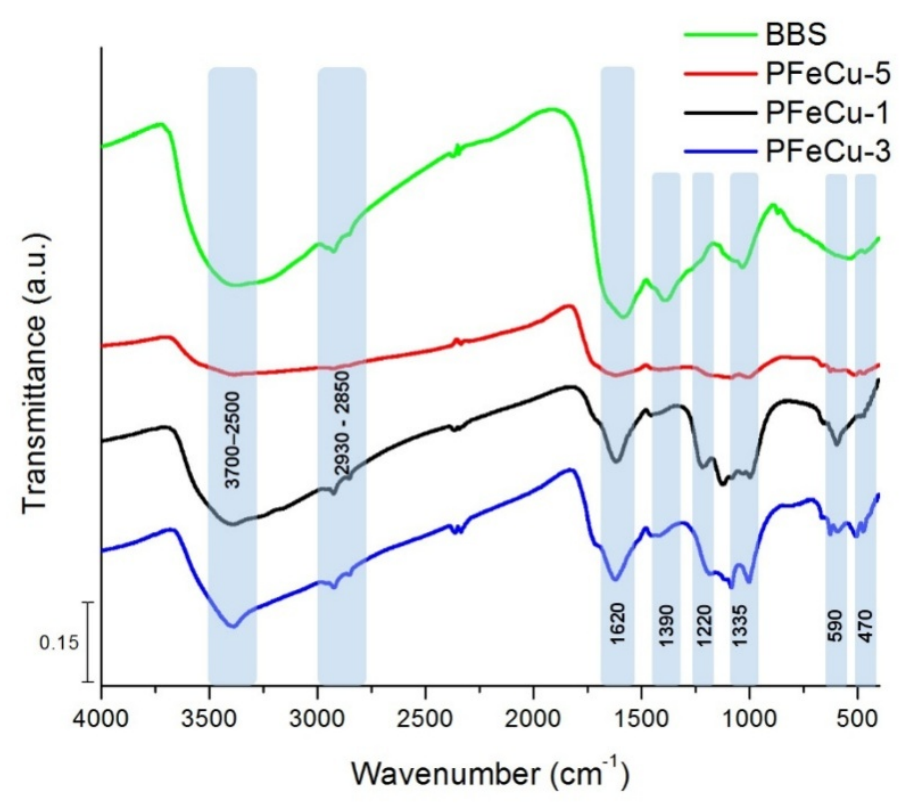

Fig. 3.1.3: FT-IR spectra of the precursors. Most remarkable bands are highlighted

In order to determine the organic matter content TGA was carried out on BBS and the three precursors (Fig. 3.1.4). The TGA curve of BBS shows a first weight loss due to water desorption up to $150{ }^{\circ} \mathrm{C}$ and a second weight loss in the range $150-600{ }^{\circ} \mathrm{C}$ assigned to the organic matter degradation. For precursors there is also another thermal event at higher temperatures, which is likely due to the formation of crystalline phases. The amounts of organic matter (OM) present in each sample were estimated from the weight 
loss in the range $150-600{ }^{\circ} \mathrm{C}$. Estimated OM values ranged between 65.4 and 72.1 wt\% (Table 3.1).

Table 3.1: Overview of the precursors composition

\begin{tabular}{cccccc}
\hline Sample & $\begin{array}{c}\mathrm{Cu} \\
\left(\mathrm{mg} \mathrm{g}^{-1}\right)\end{array}$ & $\begin{array}{c}\mathrm{Fe} \\
\left(\mathrm{mg} \mathrm{g}^{-1}\right)\end{array}$ & $\begin{array}{c}\mathrm{Fe}: \mathrm{Cu} \\
(\text { molar ratio })\end{array}$ & $\begin{array}{c}\mathrm{Fe}+\mathrm{Cu} \\
(\mathrm{wt} \%)\end{array}$ & $\begin{array}{c}\mathrm{OM}^{\mathrm{a}} \\
(\mathrm{wt} \%)\end{array}$ \\
\hline P1 & 100 & 170 & 1.9 & 27 & 65.4 \\
P3 & 42.6 & 160.4 & 4.2 & 20.3 & 68.2 \\
P5 & 51.0 & 141.2 & 3.1 & 19.2 & 72.1 \\
& & & & \\
\hline a OM organic matter, determined by TGA & &
\end{tabular}

Final contents of Fe and $\mathrm{Cu}$ in the as prepared precursors were determined by AAS as $\mathrm{mg}$ of metal cations per $\mathrm{g}$ of precursor (Table 3.1). Surprisingly the molar ratio $\mathrm{Fe}^{3+}: \mathrm{Cu}^{2+}$ in the precursors increases from 1.9 up to 4.2, indicating a preferential interaction of BBS with $\mathrm{Fe}^{3+}$. The main consequence of this phenomenon will be the presence of a limited amount of $\mathrm{Cu}$ in the final product. It is important to note that the mass balance among Fe, $\mathrm{Cu}$ and $\mathrm{OM}$ ranges from 88.5 to $92.4 \%$, which indicates that only almost $10 \%$ of the as prepared precursors may correspond to ashes that came from BBS and/or inorganic salts formed as a byproduct of the precursors' synthesis. The interaction of BBS with metals was still not fully investigated. Despite the stability constant for BBS-Fe ${ }^{3+}$ studied by fluorescence excitation-emission matrices (Ballesteros et al., 2017), no qualitative data about the interaction with different cations has been reported. By comparison with studies performed with humic acids, the complexation of $\mathrm{Fe}^{3+}$ mainly involves specific structural arrangements including carboxylic groups distributed in aliphatic domains. However, $\mathrm{Cu}^{2+}$ complexation involves singular structural arrangements including phenols (and probably substituted phenols) and O-alkyl groups inside chains of aromatic domains (Fuentes et al., 2013). Considering this, the larger amounts of carboxylic groups (1.4 mmol 
$\left.\mathrm{g}^{-1}\right)$ compared to phenolic groups $\left(0.78 \mathrm{mmol} \mathrm{g}^{-1}\right)$ in the BBS structure ((Magnacca et al., 2014)) could account for the higher amount of $\mathrm{Fe}^{3+}$ than $\mathrm{Cu}^{2+}$ observed in the precursors.
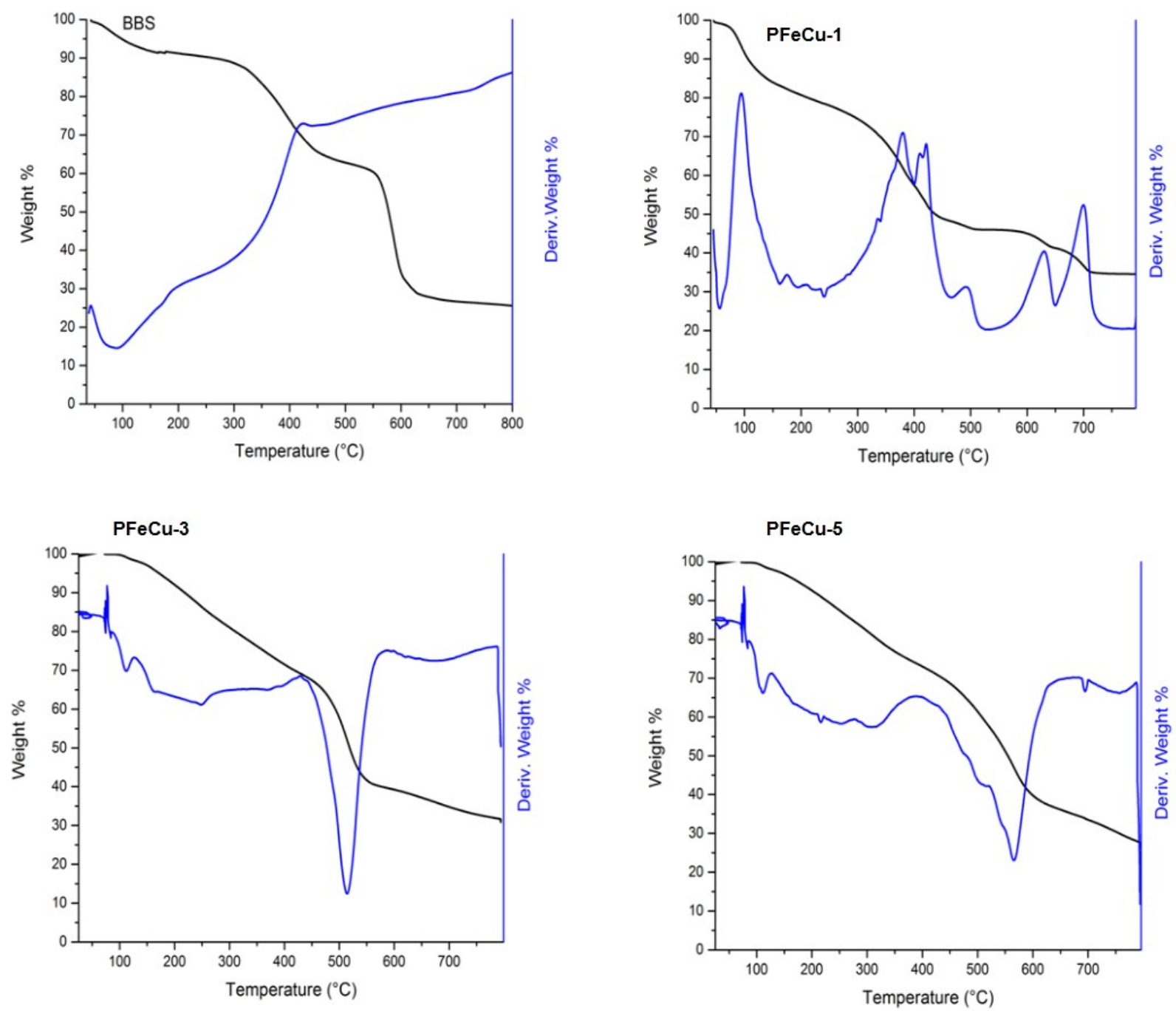

Fig. 3.1.4: TGA curves of BBS and precursors 



\section{Magnetic Nanocomposites}

In this section, the description of the different magnetic materials is presented. A deep physicochemical characterization of the nanocomposites has been performed by means of XRD, XANES/EXAFS, HR-TEM, FT-IR, TGA, VSM, BET and elemental analysis. As mentioned above, different experimental conditions were tested in the synthesis procedures, including modifications of the amount of organic matter used in the preparation of the complex precursors, the target temperature of the pyrolysis and the nature of the $\mathrm{M}^{2+}$ cation. Among the different target temperatures, it is noteworthy that the lower temperature that led to a magnetic material was $400{ }^{\circ} \mathrm{C}$. This means that when the precursor was subjected to a pyrolysis at $300{ }^{\circ} \mathrm{C}$, the obtained material showed no magnetic response. For this reason, to study the effect of the amount of organic matter, the temperature treatment of $400{ }^{\circ} \mathrm{C}$ was chosen.

\section{Effect of the amount of BBS}

The samples FeCu400/1, FeCu400/2, FeCu400/3, FeCu400/4 and FeCu400/5 were analyzed in this section. HR-TEM images of these materials are shown in Fig. 3.1.5 to Fig. 3.1.9. It can be seen small crystalline spherical-shaped particles dispersed in an amorphous carbon matrix in almost all images. Particle sizes seem to increase with the increasing of BBS content in the precursors. Nanoparticles of about $2 \mathrm{~nm}$ for the FeCu400/1 sample and $6 \mathrm{~nm}$ for FeCu400/2 and FeCu400/3 samples were evidenced. For samples FeCu400/4 and FeCu400/5 nanoparticles higher than $6 \mathrm{~nm}$ are also commonly observed. The lattice fringe patterns observed in the HR-TEM images were associated to crystalline planes of magnetite, maghemite and/or hematite phases. 


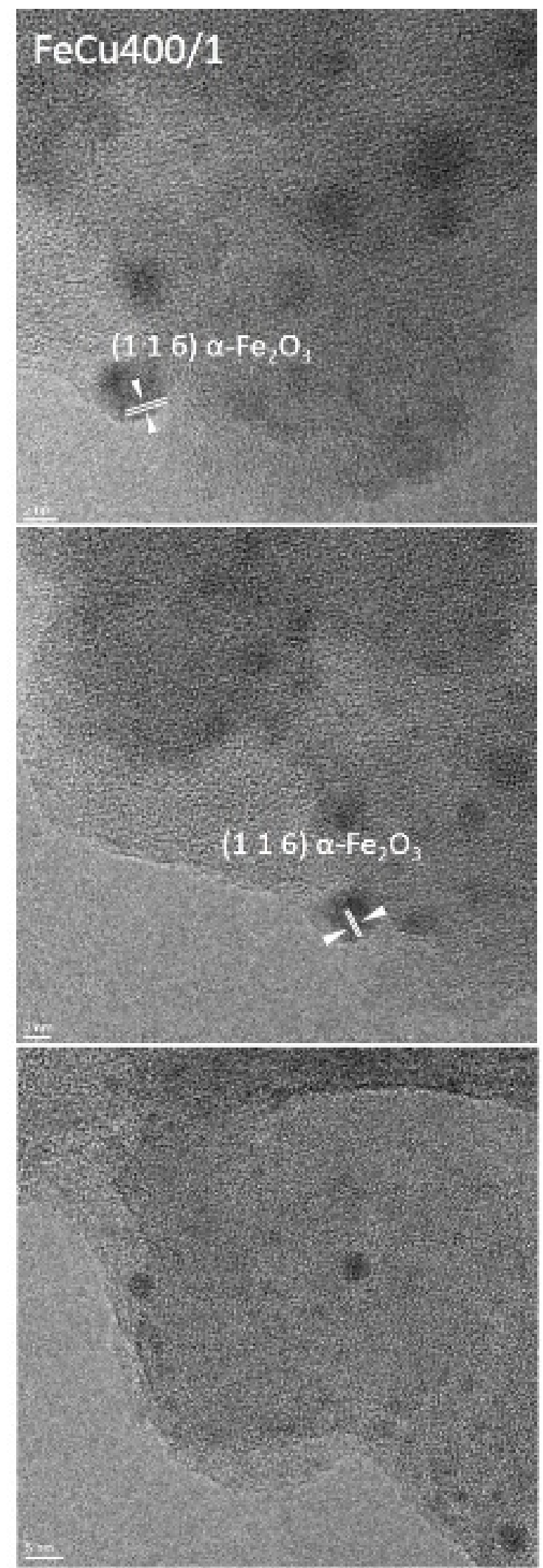

Fig. 3.1.5: HR-TEM micrograph in three different regions of FeCu400/1 sample 


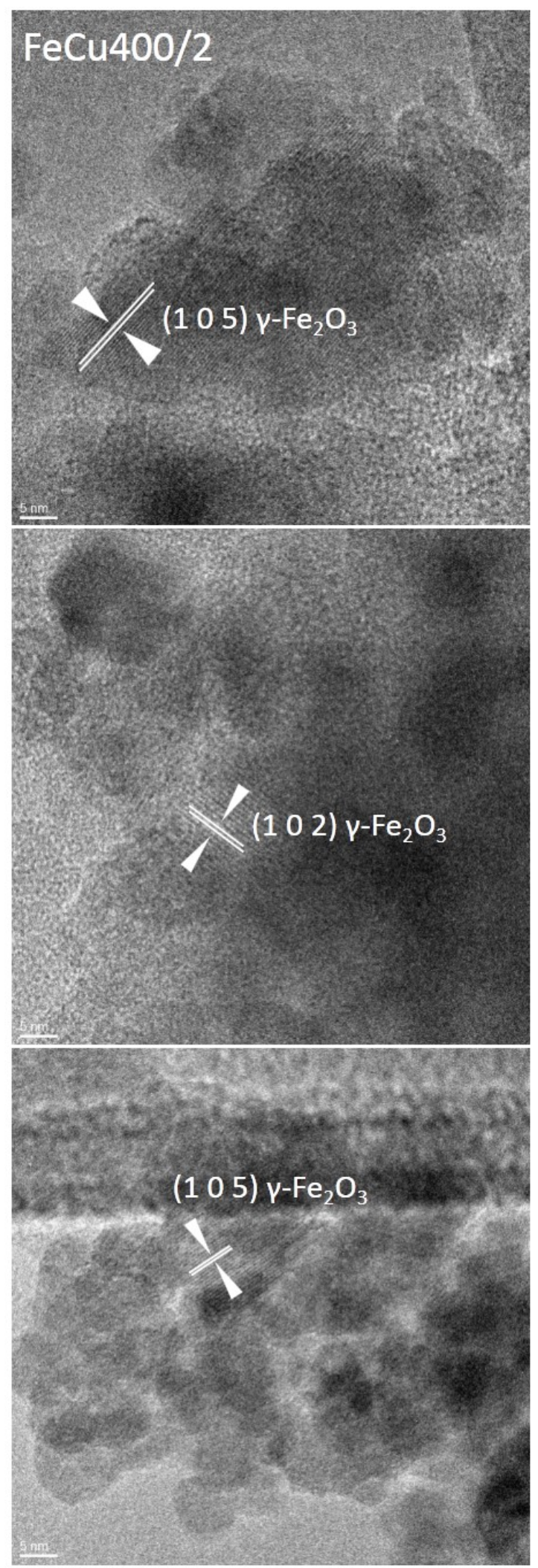

Fig. 3.1.6: HR-TEM micrograph in three different regions of FeCu400/2 sample 

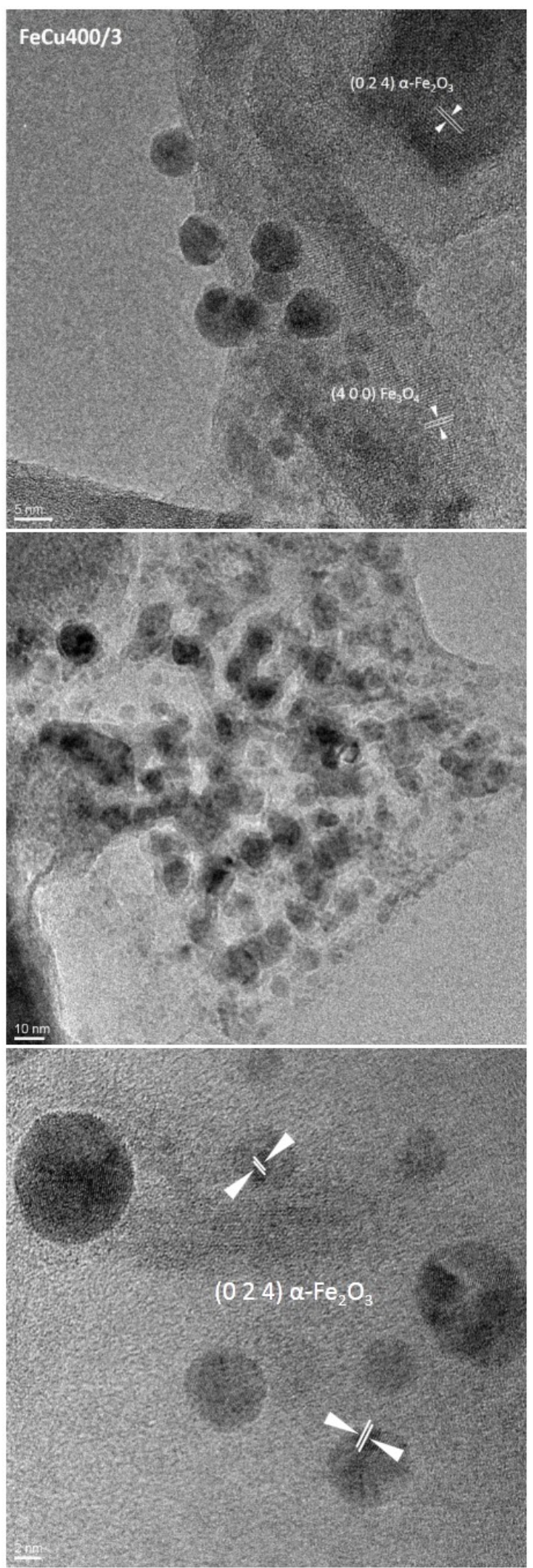

Fig. 3.1.7: HR-TEM micrograph in three different regions of FeCu400/3 sample 


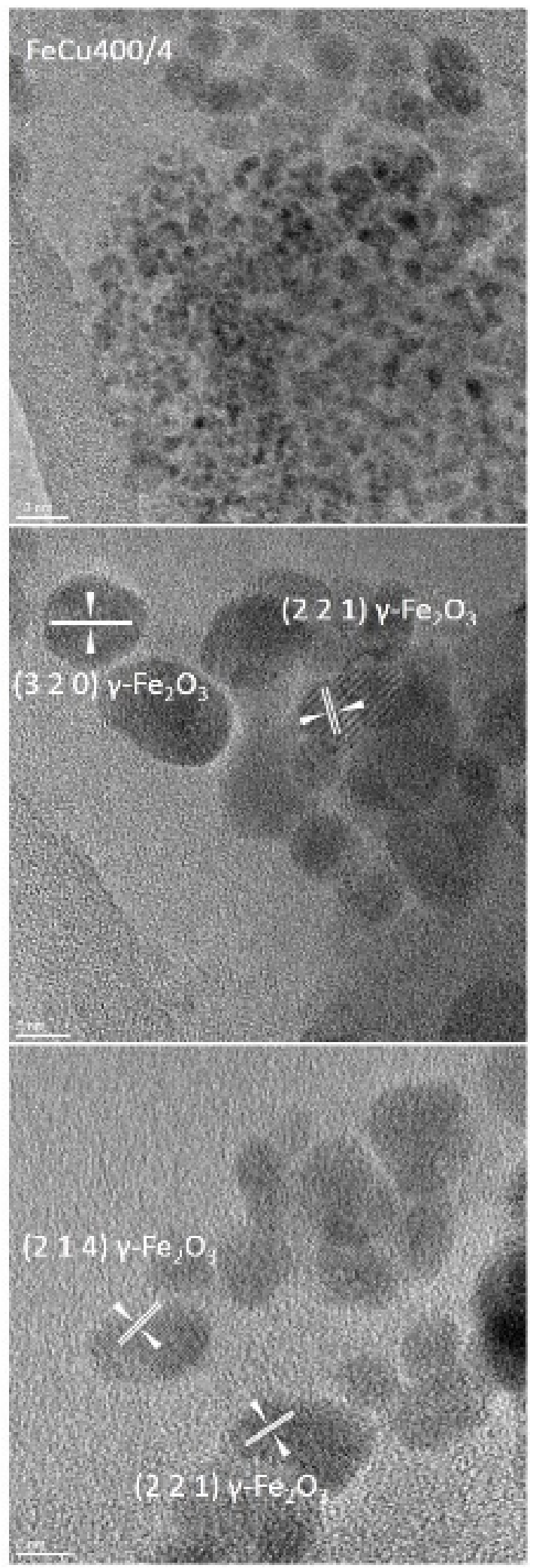

Fig. 3.1.8: HR-TEM micrograph in three different regions of FeCu400/4 sample 

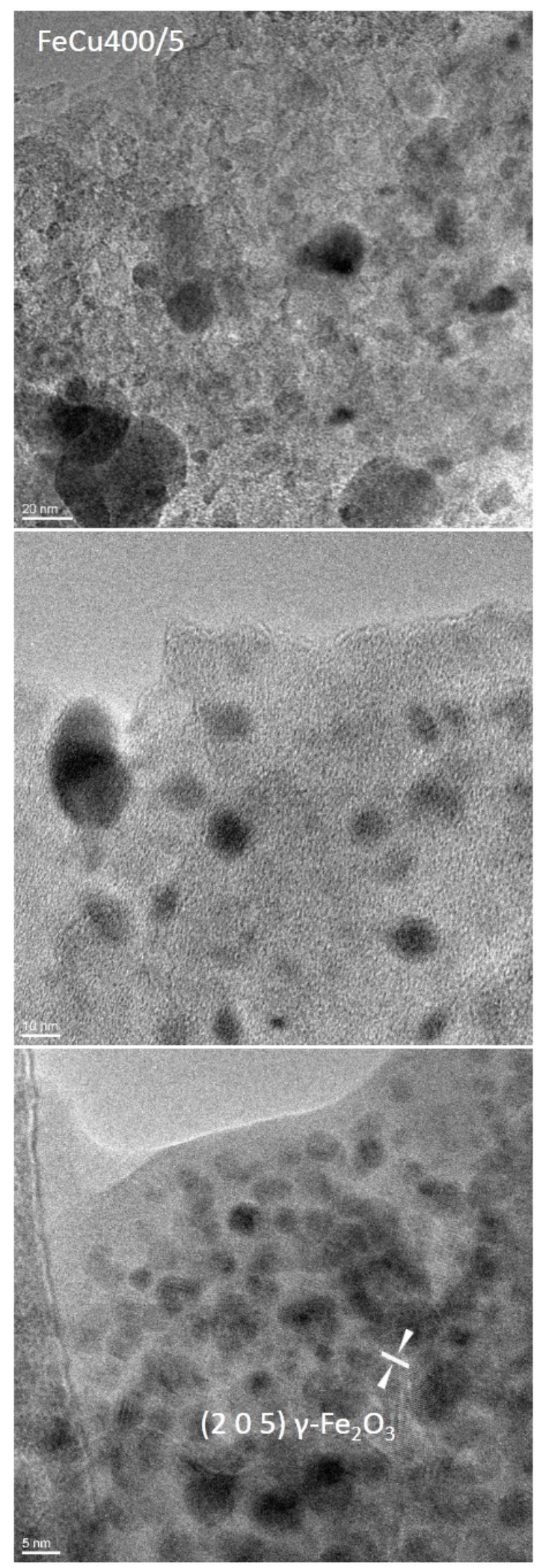

Fig. 3.1.9: HR-TEM micrograph in three different regions of FeCu400/5 sample 

The actual content of organic matter (OM) after the thermal treatment was estimated from TGA curves (Fig. 3.1.10). All samples show a similar behavior: a first weight loss at around $100{ }^{\circ} \mathrm{C}$, due to water evaporation and a second loss between $300{ }^{\circ} \mathrm{C}$ and $600{ }^{\circ} \mathrm{C}$, which corresponds to the oxidation of organic matter. The OM content present in the nanocomposites ranged between 50 and $70 \mathrm{wt} \%$. It is noteworthy that for samples with low BBS amounts (i.e. FeCu400/1, FeCu400/2 and FeCu400/3), an increasing of BBS amount results in a higher OM content. Whereas for samples with higher BBS amounts (i.e. FeCu400/3, FeCu400/4 and FeCu400/5) no difference in the total weight loss was observed, suggesting that the BBS amount exerts no influence on the final OM content of the nanocomposites. In agreement with these results, elemental analysis showed the same trend of $\mathrm{C}$ content for these samples (Table 3.2).

Nitrogen gas-volumetric tests at $77 \mathrm{~K}$ performed on the nanomaterials allow to evaluate the surface specific area (SSA). For comparison purposes, only $\mathrm{N}_{2}$ isotherms on $\mathrm{FeCu} 400 / 1, \mathrm{FeCu} 400 / 3$ and FeCu400/5 are reported in Fig. 3.11. All three samples show type II isotherms according to IUPAC classification, which is typical for non-porous and macroporous materials. At relative pressures higher than 0.4 , hysteresis can be observed due to interparticle porosity (Ursachi et al., 2011). The results of the specific surface area obtained applying the BET model are reported in Table 3.2. Low SSA values were obtained for almost all samples, except for FeCu400/1 (SSA = 33 $\left.\mathrm{m}^{2} \mathrm{~g}^{-1}\right)$. 

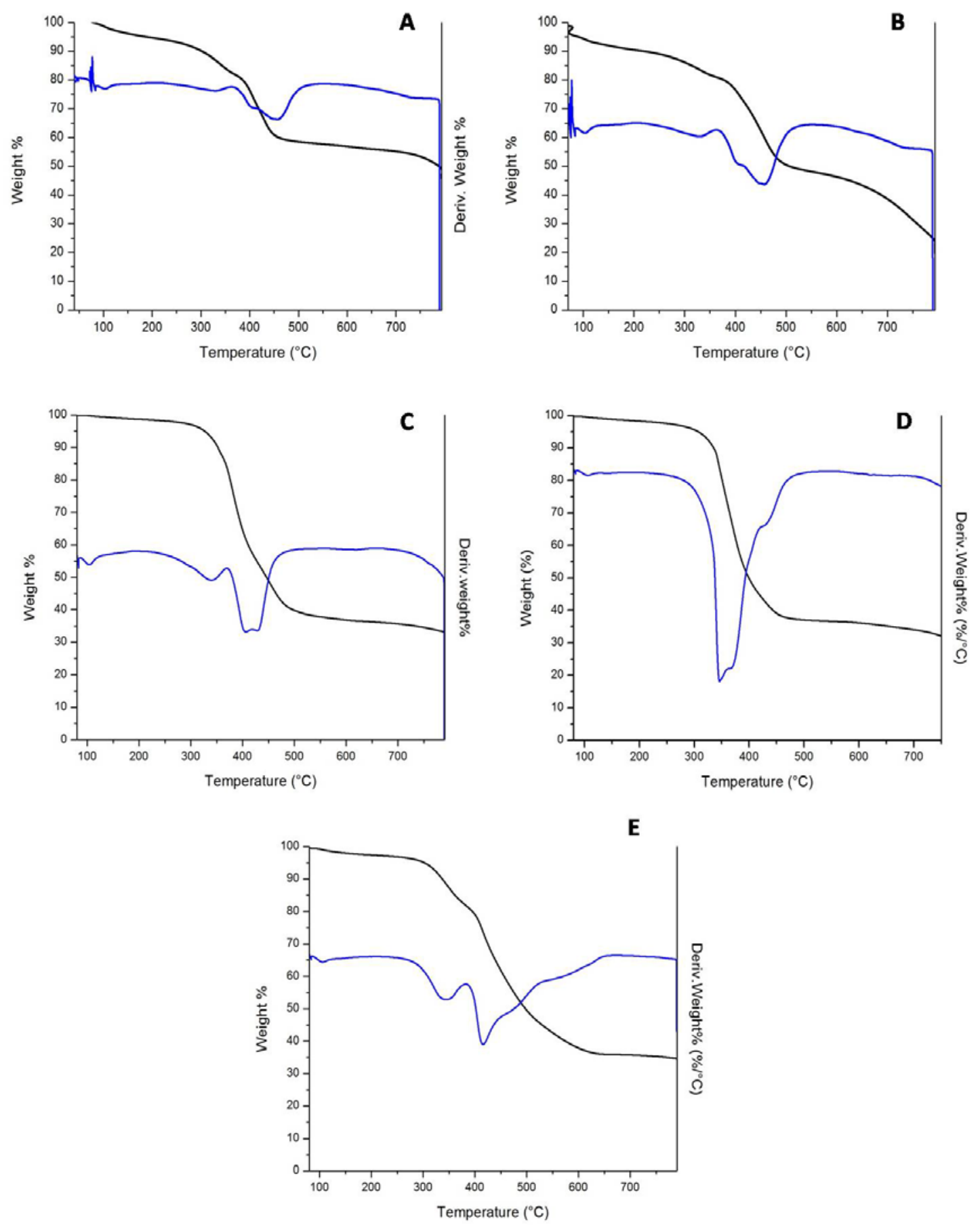

Fig. 3.1.10: TGA curves for: (A) FeCu400/1; (B) FeCu400/2; (C) FeCu400/3; (D) FeCu400/4 and (E) FeCu400/5 


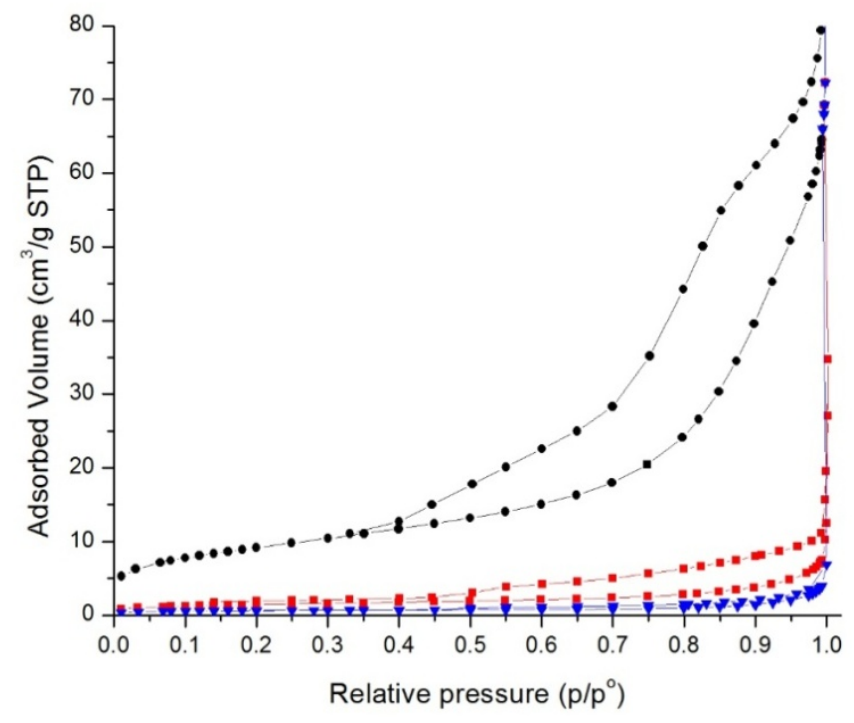

Fig. 3.1.11: Nitrogen adsorption-desorption isotherms of FeCu400/1 (black dots), FeCu400/3 (red squares) and FeCu400/5 (blue triangles).

Table 3.2: Magnetic properties, apparent specific surface area (SSA) and OM content of materials obtained by pyrolysis at $400{ }^{\circ} \mathrm{C}$

\begin{tabular}{|c|c|c|c|c|c|}
\hline Sample & $\begin{array}{c}\mathrm{SSA}^{\mathrm{a}} \\
\left(\mathrm{m}^{2} \cdot \mathrm{g}^{-1}\right)\end{array}$ & $\begin{array}{l}\mathrm{OM}^{\mathrm{b}} \\
(\mathrm{wt} \%)\end{array}$ & $\begin{array}{c}C^{c} \\
\text { (wt\%) }\end{array}$ & $\begin{array}{c}\mathrm{N}^{\mathrm{c}} \\
(\mathrm{wt} \%)\end{array}$ & $\begin{array}{c}S^{c} \\
(w t \%)\end{array}$ \\
\hline FeCu400/1 & 33 & 50.50 & 26.23 & 3.60 & 4.90 \\
\hline $\mathrm{FeCu} 400 / 2$ & 14.48 & 56.75 & 29.38 & 4.17 & 4.70 \\
\hline $\mathrm{FeCu} 400 / 3$ & $<10$ & 66.80 & 41.02 & 4.63 & 3.18 \\
\hline $\mathrm{FeCu} 400 / 4$ & $<10$ & 67.90 & 40.55 & 5.14 & 3.17 \\
\hline $\mathrm{FeCu} 400 / 5$ & $<10$ & 65.40 & 41.50 & 4.86 & 2.30 \\
\hline
\end{tabular}

FT-IR spectra of the nanocomposites FeCu400/1, FeCu400/3 and FeCu400/5 are shown in Fig. 3.1.12 to illustrate the trend among this series. It is noteworthy that even after the pyrolysis treatment, the spectra show bands related to organic functional groups: symmetric/anti-symmetric $-\mathrm{CH}$ vibrations at $2920-2850 \mathrm{~cm}^{-1},-\mathrm{COO}^{-}$at 1590 and -CO stretching at $1120 \mathrm{~cm}^{-1}$. The intensity of these bands is lower than those present in 
the spectra of the precursors. Additionally, the two small and narrow signals (3450 and $3343 \mathrm{~cm}^{-1}$ ) noticeable in the high frequency region, are assignable to structurally well defined $-\mathrm{OH}$ groups. Fe-O and $\mathrm{Cu}-\mathrm{O}$ bands are also detected at 575 and $460 \mathrm{~cm}^{-1}$, respectively.

XRD patterns are shown in Fig. 3.1.13. As indicated by peak's intensity, the crystallinity of the materials is very limited when higher amounts of organic matter were used to stabilize the complex precursors. Despite this, the signals observed at $2 \theta 30.1$, $34.4,37.1,43.0,53.4,56.9$ and $62.5^{\circ}$ can be assigned to magnetite and/or maghemite phases (since XRD is not the most suitable technique to distinguish between both phases because their XRD patterns are very similar (Sklute et al., 2018)). On the other hand, peak positions at $2 \theta 24.2,33.2,49.5$ and $64.0^{\circ}$ can be assigned to hematite phase (ICCD card number 01-073-2234). No signals associated to copper phases were observed, indicating that this element could be present in a non-crystalline phase.

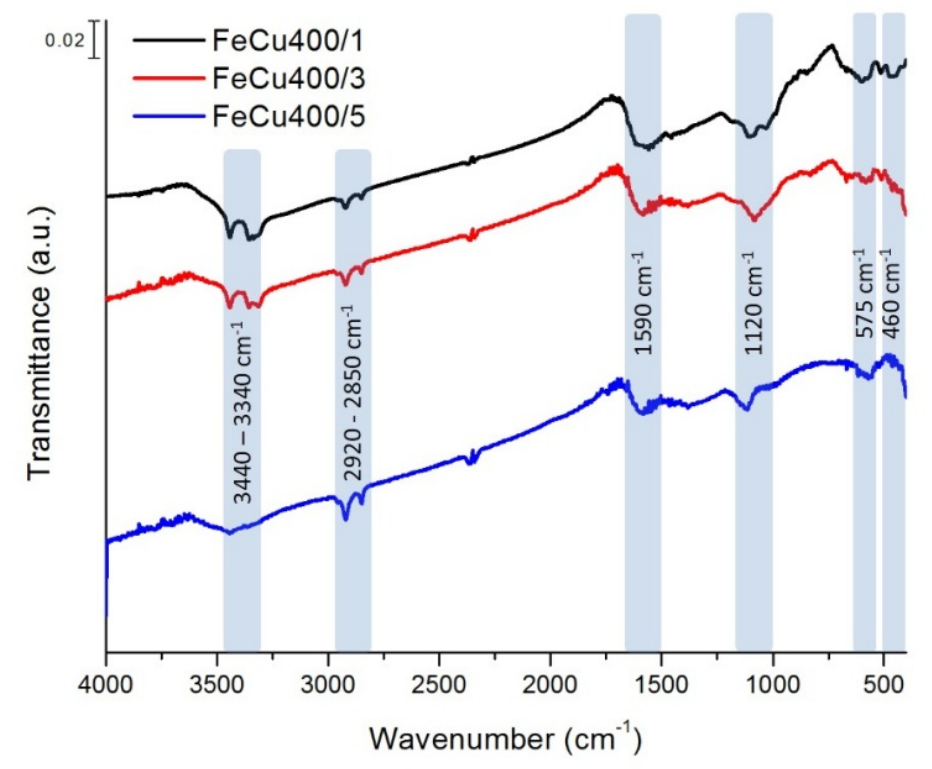

Fig. 3.1.12: FT-IR spectra of FeCu400/1, FeCu400/3 and FeCu400/5 


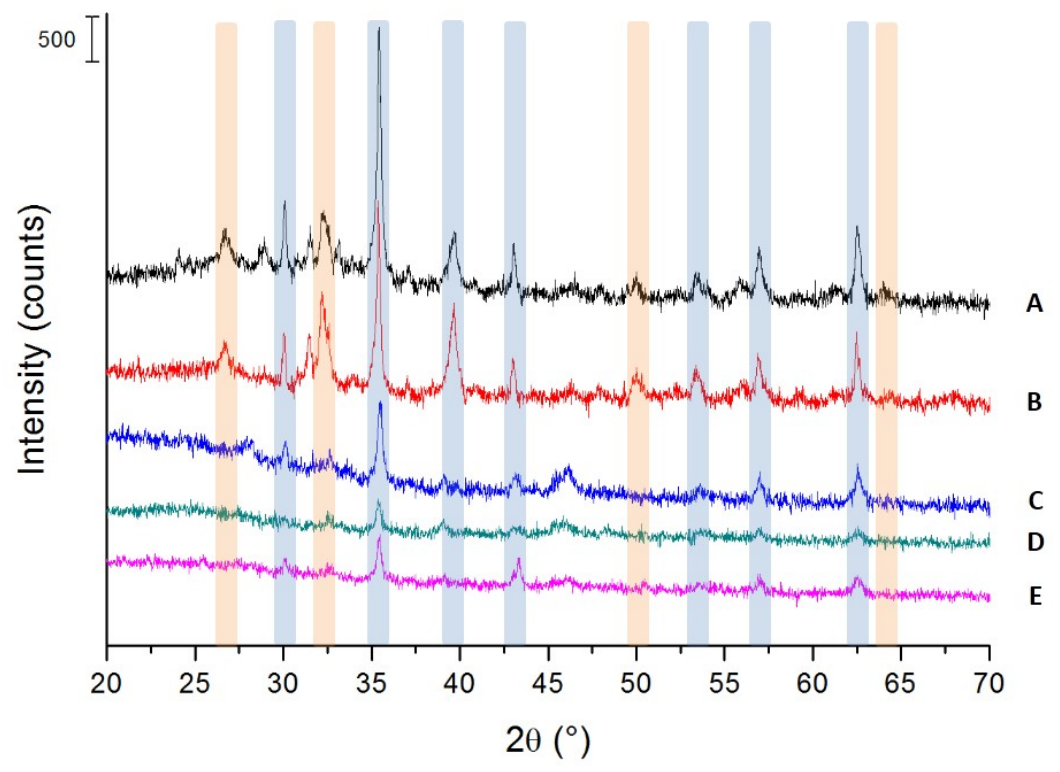

Fig. 3.1.13: XRD patterns of (A) FeCu400/1; (B) FeCu400/2; (C) FeCu400/3: (D) FeCu400/4 and (e) FeCu400/5. Peaks that correspond to $\mathrm{Fe}_{3} \mathrm{O}_{4} / \mathrm{V}-\mathrm{Fe}_{2} \mathrm{O}_{3}$ phase are shown in blue (ICCD card number 01-076-1849 and 00-025-1402), whereas those assigned to $\alpha-\mathrm{Fe}_{2} \mathrm{O}_{3}$ are shown in orange (ICCD card number 01-073-2234).

XANES/EXAFS with synchrotron radiation were performed to determine the oxidation state of copper and iron. XANES/EXAFS spectra of the K-edge of Cu and Fe for $\mathrm{FeCu} 400 / 1$ and $\mathrm{FeCu} 400 / 3$ and FeCu400/5 were all very similar, indicating analogous moieties of $\mathrm{Fe}$ and $\mathrm{Cu}$ in all three samples (Fig. 3.1.15). Comparison of the experimental spectra of the K-edge of $\mathrm{Cu}$ with those of $\mathrm{CuO}, \mathrm{Cu}_{2} \mathrm{O}, \mathrm{Cu}(\mathrm{OH})_{2}, \mathrm{Cu}$, and $\mathrm{CuFe}_{2} \mathrm{O}_{4}$ references, led to the conclusion that our samples cannot be assigned to any of these phases (Fig. 3.1.14).

To further characterize the copper moiety in the samples, a mixture of BBS and $\mathrm{CuSO}_{4}$ was prepared in a molar ratio of $\mathrm{C}: \mathrm{Cu}=0.15$ for comparison. The mixture was stirred at room temperature for $24 \mathrm{~h}$ and then centrifuged at $4000 \mathrm{rpm}$ to separate the solid. The solid was dried at $60^{\circ} \mathrm{C}$ up to constant weight. The spectrum of the Cu K-edge of this sample (named $\mathrm{Cu}^{2+}-\mathrm{BBS}$ ) resulted similar to $\mathrm{FeCu} 400 / 1, \mathrm{FeCu} 400 / 3$ and $\mathrm{FeCu} 400 / 5$ in the EXAFS region, which indicates a similar environment of $\mathrm{Cu}$ in all these samples. From this result, we can propose that the copper could be present as a cation complexed by the 
organic matter still present in the samples (indicated as BBS-CU(II) complexes). On the other hand, XANES/EXAFS allows discerning between $\mathrm{Fe}_{3} \mathrm{O}_{4}, \alpha-\mathrm{Fe}_{2} \mathrm{O}_{3}$, and $\gamma-\mathrm{Fe}_{2} \mathrm{O}_{3}$. Thus, the application of this technique made possible the estimation of the relative amounts of $\mathrm{Fe}_{3} \mathrm{O}_{4}, \alpha-\mathrm{Fe}_{2} \mathrm{O}_{3}$, and $\gamma-\mathrm{Fe}_{2} \mathrm{O}_{3}$ in our samples. Simulation of the experimental spectra with linear combinations of different contributions of those corresponding to references of $\mathrm{Fe}_{3} \mathrm{O}_{4}, \alpha-\mathrm{Fe}_{2} \mathrm{O}_{3}$, and $\gamma-\mathrm{Fe}_{2} \mathrm{O}_{3}$ showed that the best fitting is obtained for $60 \% \mathrm{Fe}_{3} \mathrm{O}_{4}, 20 \% \alpha-$ $\mathrm{Fe}_{2} \mathrm{O}_{3}$, and $20 \% \gamma-\mathrm{Fe}_{2} \mathrm{O}_{3}$ (Fig. 3.1.15). These amounts will be taken as the content of all three iron phases in our samples treated at $400{ }^{\circ} \mathrm{C}$.

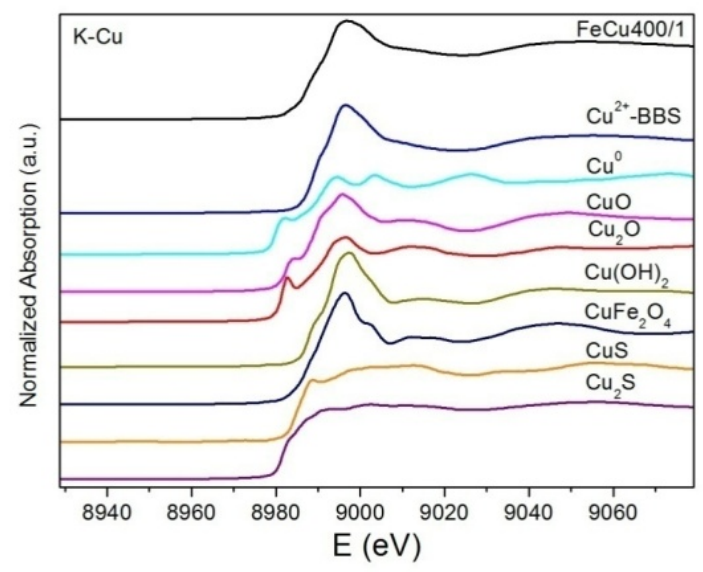

Fig. 3.1.14: K-edge of $\mathrm{Cu}$ for FeCu400/1 sample and different references measured (this sample is representative of the whole series).
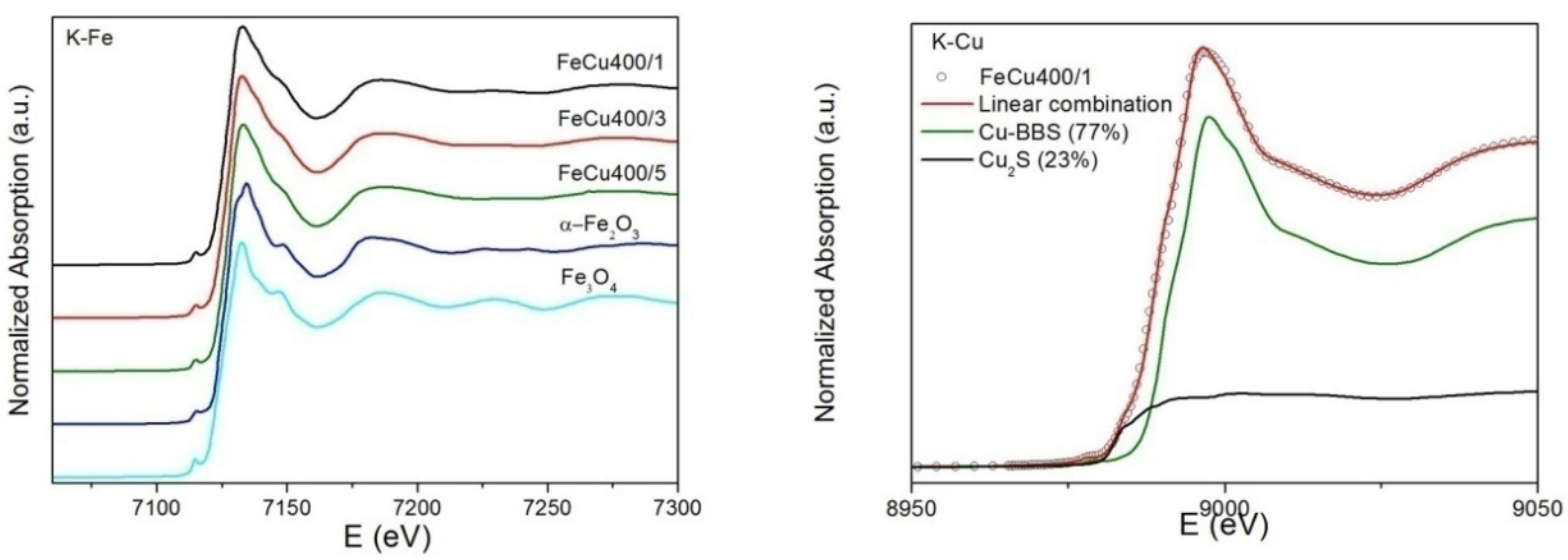

Fig. 3.1.15: K-edge of iron (left) and copper (right) for materials treated at $400^{\circ} \mathrm{C}$ and the references used. 
Magnetization measurements have shown very small values of saturation magnetization $\left(\mathrm{MS}_{\mathrm{S}}\right.$ ), between 2 and $6 \mathrm{emu}^{-1}$ (Fig. 3.1.16). This is due to the presence of high content of non-magnetic phases in the samples (organic matter, hematite and copper containing phases). As expected, $M_{S}$ is higher for FeCu400/1, whereas the same value of $M_{S}$ is obtained for FeCu400/3 and FeCu400/5. All three samples show a very small hysteresis loop, low values of coercivity (Hc) and remnant magnetization (Mr) (Table 3.3). Hysteresis loops are characteristic for ferromagnetic materials, whereas for small nanoparticles, a superparamagnetism phenomenon is usually observed. In this case, they show an intermediate behavior, possibly indicating the presence of both types of magnetic features.

Table 3.3: Magnetic properties of materials obtained by pyrolysis at $400{ }^{\circ} \mathrm{C}$

\begin{tabular}{cccc}
\hline Sample & $\begin{array}{c}\mathrm{M}_{\mathrm{S}} \\
(\text { emu.g }\end{array}$ & $\begin{array}{c}\mathrm{M}_{\mathrm{R}} \\
(\mathrm{Oe})\end{array}$ & $\begin{array}{c}\mathrm{H}_{\mathrm{C}} \\
(\mathrm{Oe})\end{array}$ \\
\hline $\mathrm{FeCu} 400 / 1$ & 6.7 & 1.4 & 199.6 \\
$\mathrm{FeCu} 400 / 3$ & 1.5 & 0.2 & 197.6 \\
$\mathrm{FeCu} 400 / 5$ & 2.2 & 0.4 & 197.6 \\
\hline
\end{tabular}

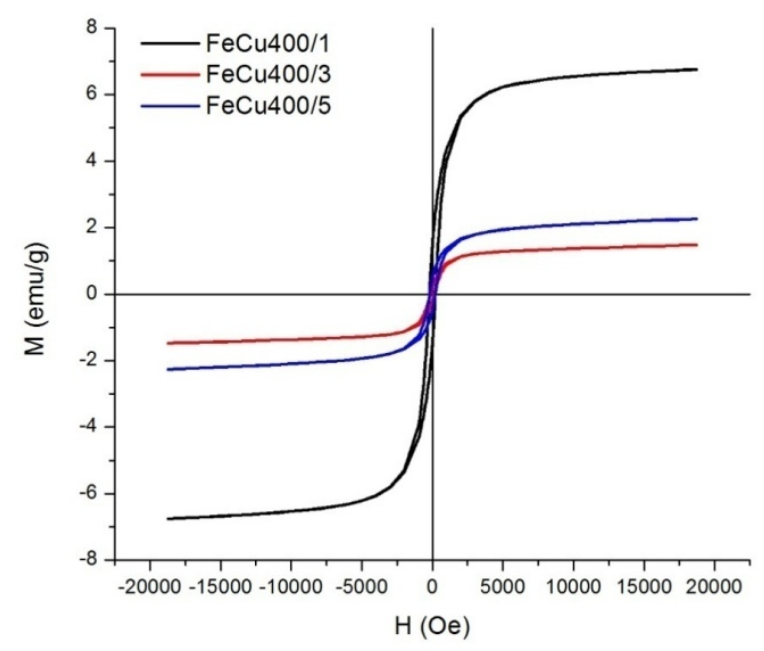

Fig. 3.1.16: Magnetization curves of materials obtained at $400^{\circ} \mathrm{C}$. 



\section{Effect of temperature}

Thermal treatments with a final temperature of 400,600 and $800{ }^{\circ} \mathrm{C}$ were studied in order to evaluate the effect of temperature on the structure of the nanocomposites. The materials obtained for this study were prepared by using the precursor PFeCu-1 (n $\left.(C) /\left(n\left(\mathrm{Fe}^{3+}\right)+n\left(\mathrm{M}^{2+}\right)\right)=1\right)$. From the analysis of the HR-TEM images it is noteworthy the difference in morphology of the samples treated at 600 and $800{ }^{\circ} \mathrm{C}$ compared to those treated at $400{ }^{\circ} \mathrm{C}$ : the higher the temperature of the pyrolysis treatment, the more sheetlike are the samples (Fig. 3.1.17 and Fig. 3.1.18). The crystalline nanoparticles seem to remain within the carbon matrix at 600 and $800^{\circ} \mathrm{C}$. 


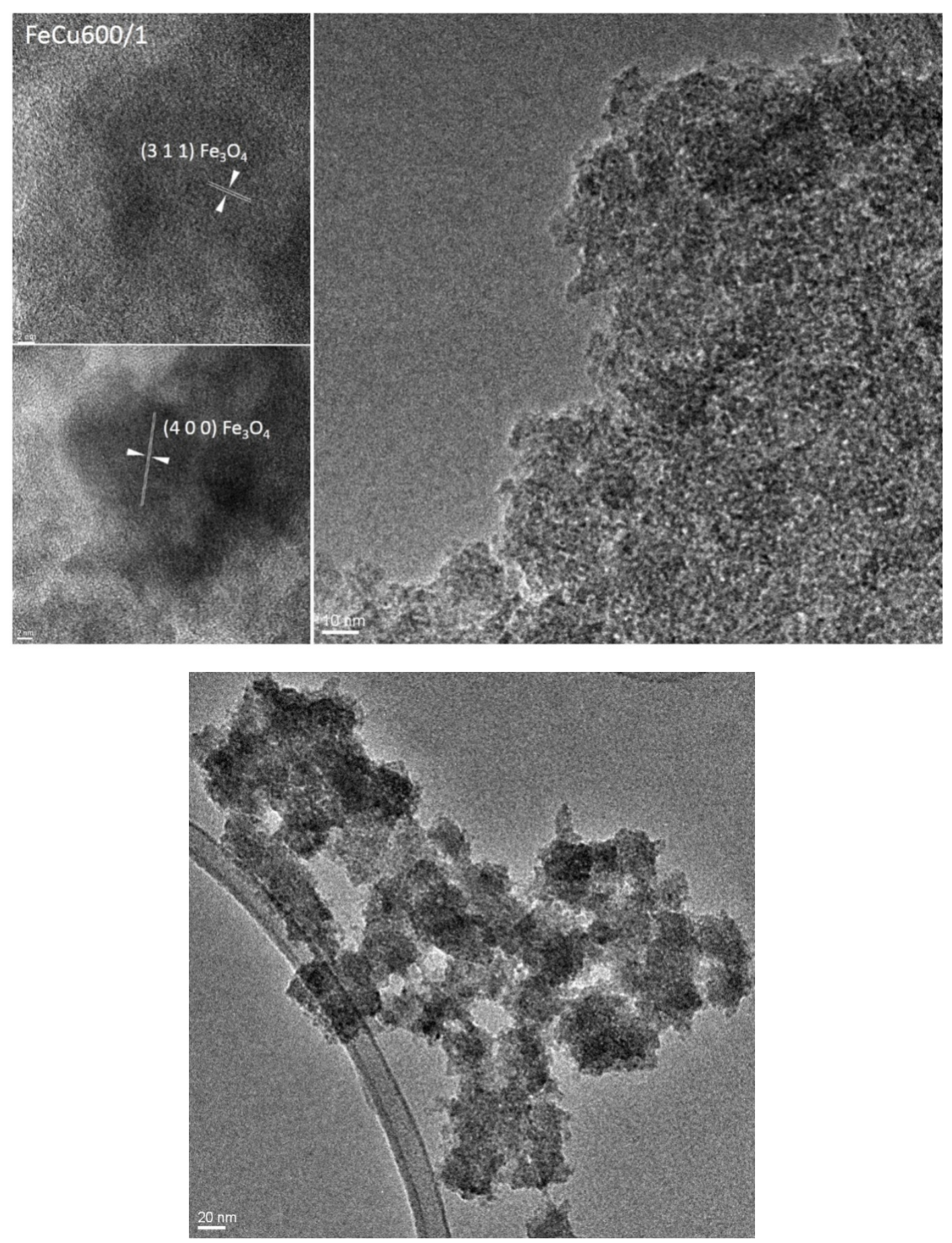

Fig. 3.1.17: HR-TEM micrograph of sample FeCu600/1. 

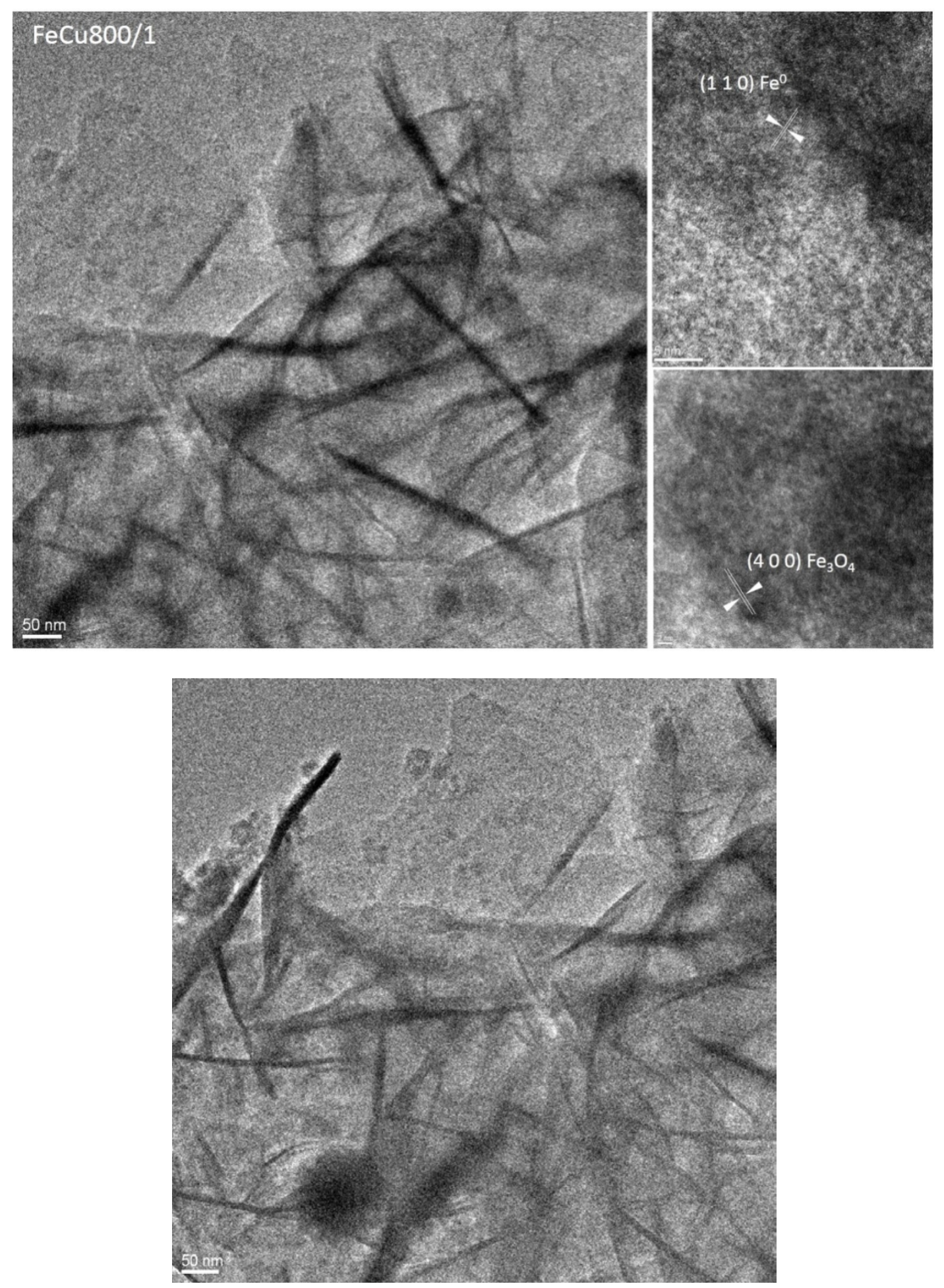

Fig. 3.1.18: HR-TEM micrograph of sample FeCu800/1. 
TGA curves showed a complex behavior of samples FeCu600/1 and FeCu800/1 (Fig. 3.1.19). Comparing to FeCu400/1, forFeCu600/1 and FeCu800/1 no water loss is observed up to $150{ }^{\circ} \mathrm{C}$. Indeed, the TGA curves remain almost constant up to $350{ }^{\circ} \mathrm{C}$, and then a slight increase of the signal, due to formation of oxidized products followed by a decrease until $700^{\circ} \mathrm{C}$ is observed for both samples. A reduction in the $\mathrm{OM}$ content of these materials compared to FeCu400/1 seems to occur. This reduction in organic matter was also confirmed by elemental analysis, since the carbon content is decreased (values are reported in Table 3.4).
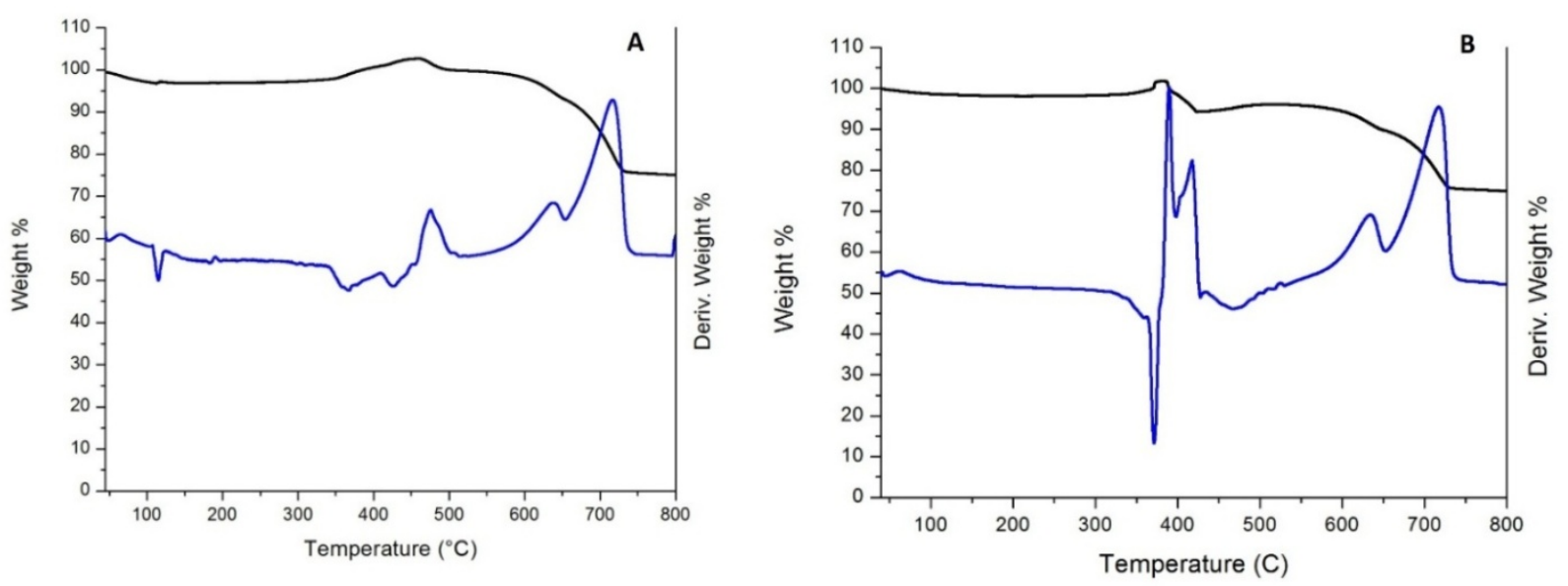

Fig. 3.1.19: TGA curves of (A) FeCu600/1 and (B) FeCu800/1.

Table 3.4: Apparent specific surface area (SSA), OM content and elemental analysis of samples treated at different temperature

\begin{tabular}{cccccc}
\hline Sample & $\begin{array}{c}\mathrm{SSA}^{\mathrm{a}} \\
\left(\mathrm{m}^{2} \cdot \mathrm{g}^{-1}\right)\end{array}$ & $\begin{array}{c}\mathrm{OM}^{\mathrm{b}} \\
(\mathrm{wt} \%)\end{array}$ & $\begin{array}{c}\mathrm{C}^{\mathrm{c}} \\
(\mathrm{wt} \%)\end{array}$ & $\begin{array}{c}\mathrm{N}^{\mathrm{c}} \\
(\mathrm{wt} \%)\end{array}$ & $\begin{array}{c}\mathrm{S}^{\mathrm{c}} \\
(\mathrm{wt} \%)\end{array}$ \\
\hline FeCu400/1 & 33 & 50.50 & 26.23 & 3.60 & 4.90 \\
FeCu600/1 & 138 & - & 9.78 & 3.38 & 11.90 \\
FeCu800/1 & 158 & - & 10.60 & 2.15 & 9.32 \\
\hline
\end{tabular}

${ }^{a}$ From $\mathrm{N}_{2}$ adsorption isotherms ${ }^{\mathrm{b}} \mathrm{TGA}^{\mathrm{c}}$ elemental analysis. 
Nitrogen adsorption isotherms are shown in Fig. 3.1.20, and the values of SSA are listed in Table 3.4. Also, in this case the samples show type II isotherms according to the IUPAC classification, which are typical for non-porous and macroporous materials. Both samples show similar hysteresis behavior due to interparticle porosity (Ursachi et al., 2011). The values of SSA are significantly higher than those reported for the samples treated at lower temperature.

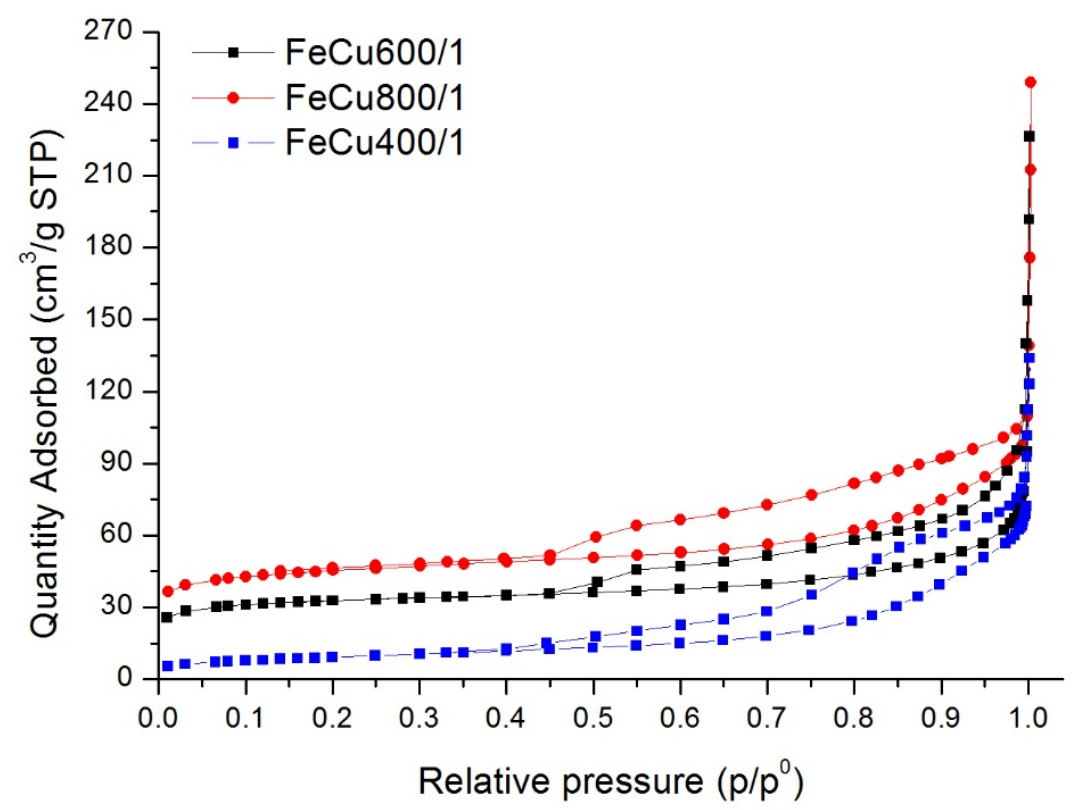

Fig. 3.1.20: Nitrogen adsorption-desorption isotherms of FeCu600/1 (black squares) and FeCu800/1 (red dots).

The FT-IR spectroscopy data showed the presence of different organic functional groups for each sample after different pyrolysis temperatures (Fig. 3.1.21). Organic carbon was observed by the absorption at 2850 and $2920 \mathrm{~cm}^{-1}$, which corresponds to aliphatic C$\mathrm{H}$ stretching vibrations, and by the absorption in the range $1700-1100 \mathrm{~cm}^{-1}$, which could correspond to aromatic $\mathrm{C}=\mathrm{C}$ vibration, aliphatic $\mathrm{HO}$ groups and epoxide groups (Magnacca, 2014). After thermal treatment at $800^{\circ} \mathrm{C}$, a significant depletion of signals due to $\mathrm{C}=\mathrm{C}$ aromatic species and the disappearance of signals due to the interaction of organic functional groups with iron oxide species were observed. However, the relative intensities of signals associated to $\mathrm{C}-\mathrm{H}$ aliphatic stretching vibrations (2850 and $2920 \mathrm{~cm}^{-1}$ ) increased 
with respect to the band of $\mathrm{C}=\mathrm{C}$ stretching. This lower $\mathrm{OM}$ content agrees with the TGA results.

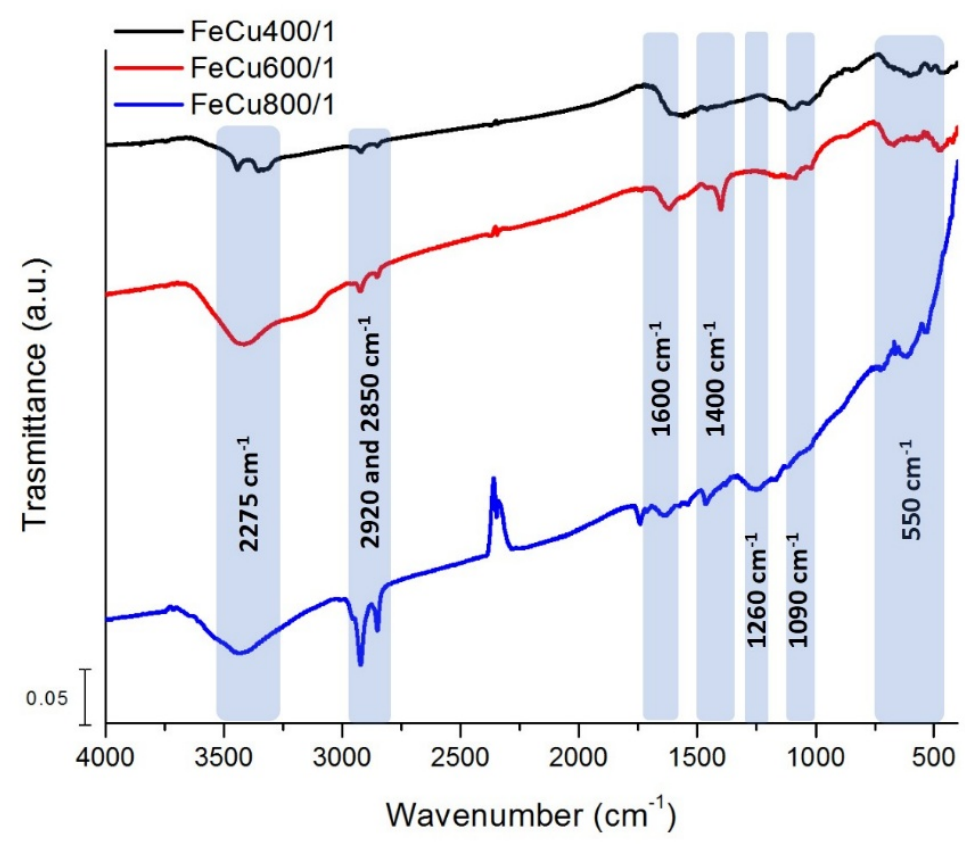

Fig. 3.1.21: FT-IR spectra of materials treated at higher temperatures. The spectrumof FeCu400/1 is also shown for comparison.

XRD patterns of FeCu600/1 and FeCu800/1 (Fig. 3.1.22) show the signals that correspond to magnetite/maghemite; no peaks were observed related to the hematite phase. For the FeCu800/1 sample, peaks that correspond to $\mathrm{Fe}^{0}$ were also observed $(2 \theta=$ 44.6 and 65.07 assigned to $\left(\begin{array}{lll}2 & 0 & 0\end{array}\right)$ and $\left(\begin{array}{lll}1 & 1 & 0\end{array}\right)$ planes, respectively). Also, a small peak at $2 \theta$ $=41.2$ matches the $\left(\begin{array}{lll}2 & 0 & 0\end{array}\right)$ plane of wüstite $(\mathrm{FeO})$. This result agrees with previous works (Cesano, 2015), where the formation of iron is postulated due to the reducing atmosphere. It was proposed that initially the reduction of maghemite $\left(\nu-\mathrm{Fe}_{2} \mathrm{O}_{3}\right)$ into the wüstite form takes place. Then, mediated by the graphitic carbon produced by BBS (and since wüstite is thermodynamically unstable above $575^{\circ} \mathrm{C}$ ), FeO disproportionates into metallic iron $\left(\mathrm{Fe}^{0}\right)$ and magnetite $\left(\mathrm{Fe}_{3} \mathrm{O}_{4}\right)$. On the other hand, for samples treated at 600 and $800{ }^{\circ} \mathrm{C}$, the observed peaks at $2 \theta=29.5,33.1$ and 47.4 seem to match the $\left(\begin{array}{lll}1 & 0 & 2\end{array}\right),\left(\begin{array}{ll}0 & 0\end{array}\right.$ 
6) and ( $\left.\begin{array}{lll}1 & 1 & 0\end{array}\right)$ crystal planes of $\mathrm{Cu}_{2} \mathrm{~S}$ phase, respectively. This could be a side-product, since the amount of sulfur arising from the sulfate salt could remain attached to the BBS matrix and evolve into copper(I) sulfide (Farhadi and Siadatnasab, 2016). This hypothesis is supported by the higher sulfur-to-carbon ratio observed for FeCu600/1 and FeCu800/1 compared to that for the materials treated at $400{ }^{\circ} \mathrm{C}$ and is also supported by the XRS results (see below).

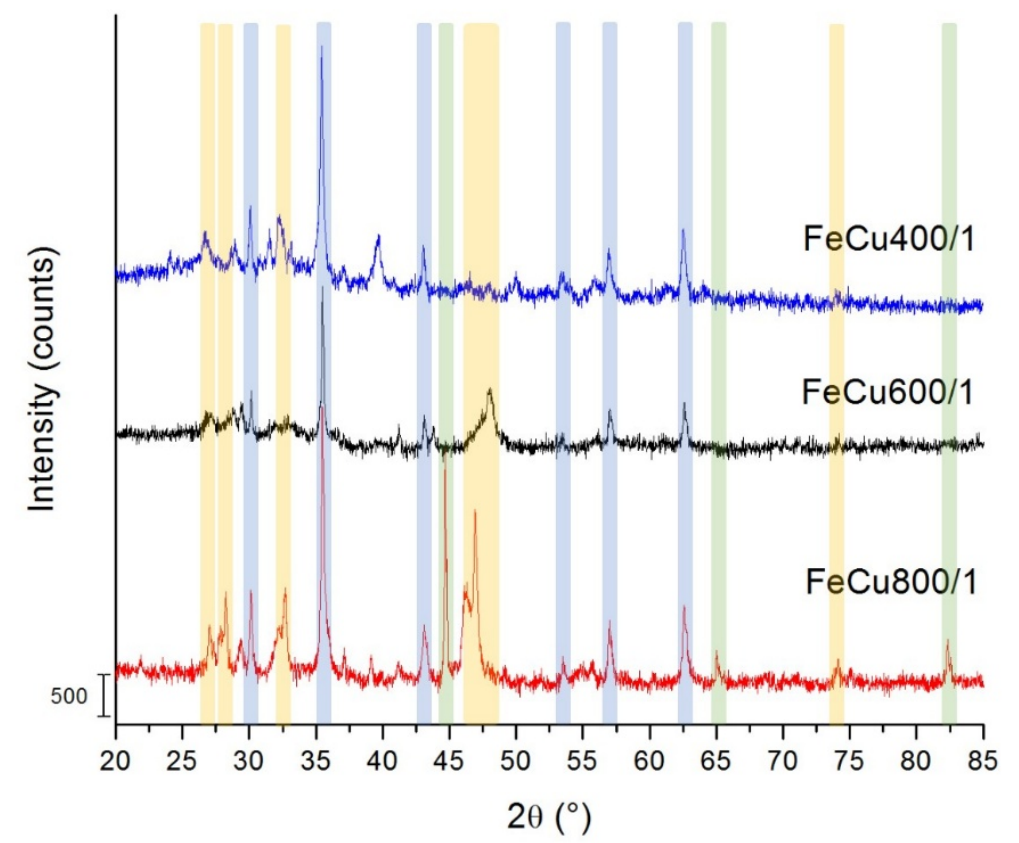

Fig. 3.1.22: XRD diffraction patterns of materials treated at higher temperatures (A) FeCu600/1 and (B) FeCu800/1. The peaks assigned to $\mathrm{Fe}_{3} \mathrm{O}_{4} / \gamma-\mathrm{Fe}_{2} \mathrm{O}_{3}$ and/or $\mathrm{CuFe}_{2} \mathrm{O}_{4}$ are highlighted in blue; in green those assigned to $\mathrm{Fe}^{0}$ and in yellow those peaks that could correspond to $\mathrm{Cu}_{2} \mathrm{~S}$.

Simulation of the experimental spectra of the K-edge of iron with linear combinations of different contributions of reference spectra shows that iron is present in $60 \%$ in the form of $\mathrm{Fe}_{3} \mathrm{O}_{4}, 30 \%$ as $\mathrm{y}-\mathrm{Fe}_{2} \mathrm{O}_{3}$ and $10 \%$ as $\alpha-\mathrm{Fe}_{2} \mathrm{O}_{3}$ for $\mathrm{FeCu600/1}$ (Fig. 3.23). No peaks assigned to hematite phase were distinguished by XRD. Therefore, the obtained linear combination of iron phases could overestimate the low amount of hematite present in the sample. For FeCu800/1 65\% is present as $\mathrm{Fe}_{3} \mathrm{O}_{4}, 20 \%$ as $\mathrm{y}-\mathrm{Fe}_{2} \mathrm{O}_{3}$ and $15 \%$ as $\mathrm{Fe}^{0}$. On the other hand, spectra of the K-edge of $\mathrm{Cu}$ are very different from that of the BBS-Cu${ }^{2+}$ 
mixture in the XANES region. But, the similarity of both spectra in the EXAFS region is indicative of an analogous $\mathrm{Cu}$ environment in FeCu600/1 and BBS-Cu(II) samples. In addition, there is also no coincidence of the spectra with those of $\mathrm{CuO}, \mathrm{Cu}_{2} \mathrm{O}, \mathrm{Cu}(\mathrm{OH})_{2}, \mathrm{Cu}$, and $\mathrm{CuFe}_{2} \mathrm{O}_{4}$ (Fig. 3.14). But by considering $\mathrm{Cu}_{2} \mathrm{~S}$ and $\mathrm{CuS}$ besides $\mathrm{Cu}$-BBs phases, an acceptable reproduction of the experimental spectrum is obtained. For FeCu600/1 sample, the main phase seems to be $\mathrm{Cu}_{2} \mathrm{~S}(52 \%)$ whereas in the FeCu800/1 sample the main phase is CuS (47\%). The reproduction of the experimental spectra, however, is not fully achieved. A possible reason for the discrepancies could be that the $\mathrm{CuS}_{2}$ and $\mathrm{Cu}_{2} \mathrm{~S}$ references were measured under different experimental conditions. Also, by XRD evidence of only the $\mathrm{Cu}_{2} \mathrm{~S}$ phase was observed. Therefore, CuS could be present in an amorphous phase.
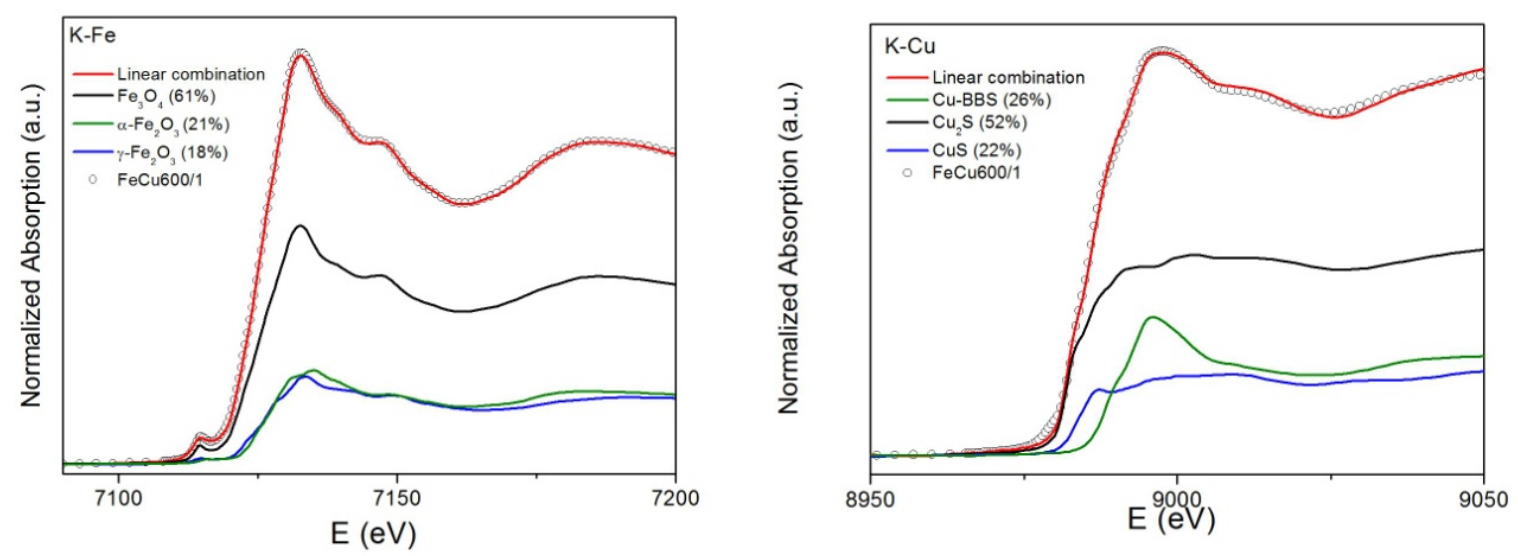

Fig. 3.1.23: Linear combination of the spectra of references measured and compared to the experimental Kedge spectra of Fe and Cu obtained for a FeCu600/1 sample. 

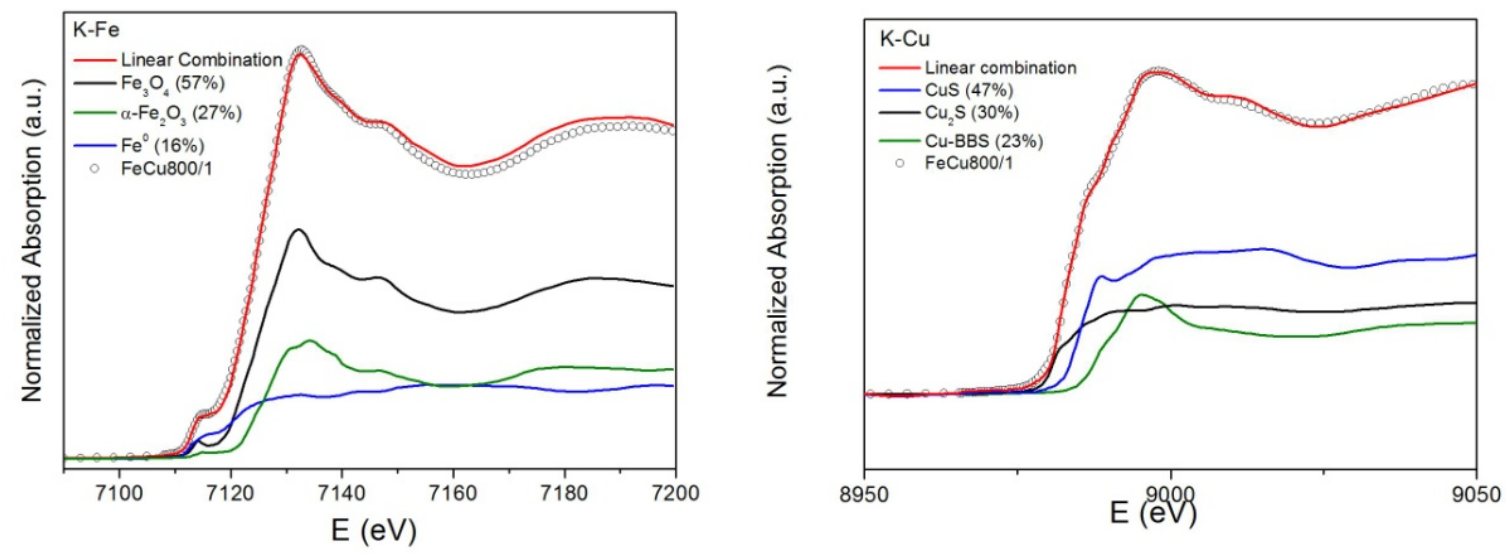

Fig. 3.1.24: Linear combination of the spectra of references measured and compared to the experimental Kedge spectra of Fe and Cu obtained for a FeCu800/1 sample.

Magnetization curves of FeCu600/1 and FeCu800/1 are compared to FeCu400/1 in Fig. 3.1.25. The magnetic properties extracted from these curves are displayed in Table 3.5. It was observed that by increasing the temperature of the thermal treatment, higher values of $M_{s}$ are obtained; the observation is in agreement with the fact that $\mathrm{Fe}^{0}$ is present in the sample FeCu800/1 since $\mathrm{Fe}^{0}$ presents higher $\mathrm{M}_{\mathrm{s}}\left(217.6 \mathrm{emu} / \mathrm{g}\right.$ ) than neat $\mathrm{Fe}_{3} \mathrm{O}_{4}$ (96.5 emu/g) at $300 \mathrm{~K}$ (Han et al., 2014). Magnetization curves (Fig. 3.1.25) display the same behavior as those treated at lower temperatures, i.e., small hysteresis loops that correspond to ferromagnetic/almost superparamagnetic materials. In this case, where a lower amount of organic matter is present compared to the samples treated at $400{ }^{\circ} \mathrm{C}$, an increase in $M_{s}$ is observed. The small magnetization saturation compared to magnetite nanomaterials with the same amount of organic matter could be due to the copper nonmagnetic phases. 


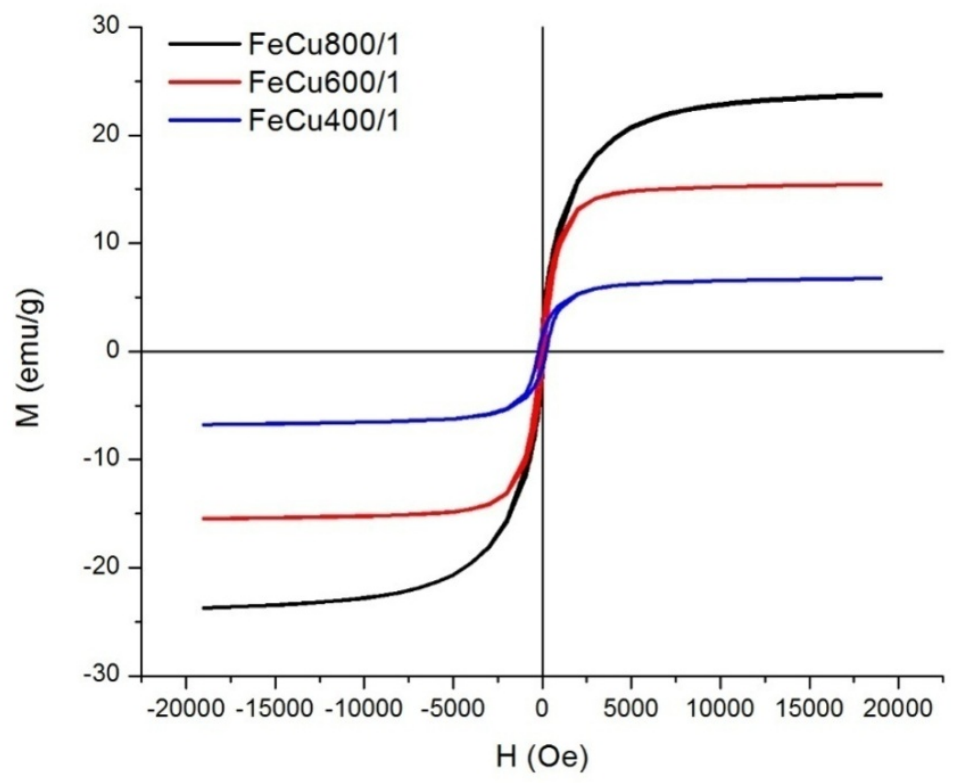

Fig. 3.1.25: Magnetization curves for materials obtained after treatment at different temperatures.

Table 3.5: Magnetic properties of materials obtained after treatment at different temperatures

\begin{tabular}{cccc}
\hline Sample & $\begin{array}{c}\mathrm{M}_{\mathrm{S}} \\
\left(\mathrm{emu} \mathrm{g}^{-1}\right)\end{array}$ & $\begin{array}{c}\mathrm{M}_{\mathrm{R}} \\
(\mathrm{Oe})\end{array}$ & $\begin{array}{c}\mathrm{H}_{\mathrm{C}} \\
(\mathrm{Oe})\end{array}$ \\
\hline FeCu400/1 & 6.7 & 1.4 & 199.6 \\
FeCu600/1 & 15.4 & 1.796 & 95.214 \\
FeCu800/1 & 23.6 & 2.188 & 113.14 \\
\hline
\end{tabular}





\section{Effect of the nature of the bivalent $\left(\mathrm{Cu}^{2+}, \mathrm{Ni}^{2+}\right.$ and $\left.\mathrm{Co}^{2+}\right)$}

Different types of materials were obtained by replacing the $\mathrm{Cu}^{2+}$ salt with $\mathrm{Ni}^{+2}$ or $\mathrm{Co}^{+2}$ salts in the preparation of the precursors. HR-TEM images of FeCo600/1 and FeNi600/1 samples are shown in Fig. 3.1.26 and Fig. 3.1.27. For the samples containing Co or Ni the TEM images show small crystalline particles dispersed in a carbonaceous matrix, as was also observed for $\mathrm{Cu}$ (sample FeCu600/1). The nanoparticle size distribution is difficult to obtain since TEM images do not clearly show the edges of the nanoparticles. However, for FeCo600/1 or FeNi600/1, nanoparticles with diameters of less than $10 \mathrm{~nm}$ are also typically observed. In addition, big regions of amorphous carbon can be noticed.

TGA analyses of these materials are displayed in Fig. 3.1.28. Results show that for the Co- and Ni- containing materials, the total organic content was ca. 23 and 35\%, respectively (Table 3.6). Compared to Cu-containing material treated at the same temperature, FeCo600/1 and FeNi600/1 present higher organic carbon content as also evidenced from TEM images. This result could be explained considering that either $\mathrm{Ni}$ and Co oxides present different magnetic properties from those of $\mathrm{Cu}$ oxides, which could help to separate more carbon content in the washing step of the nanocomposites. 



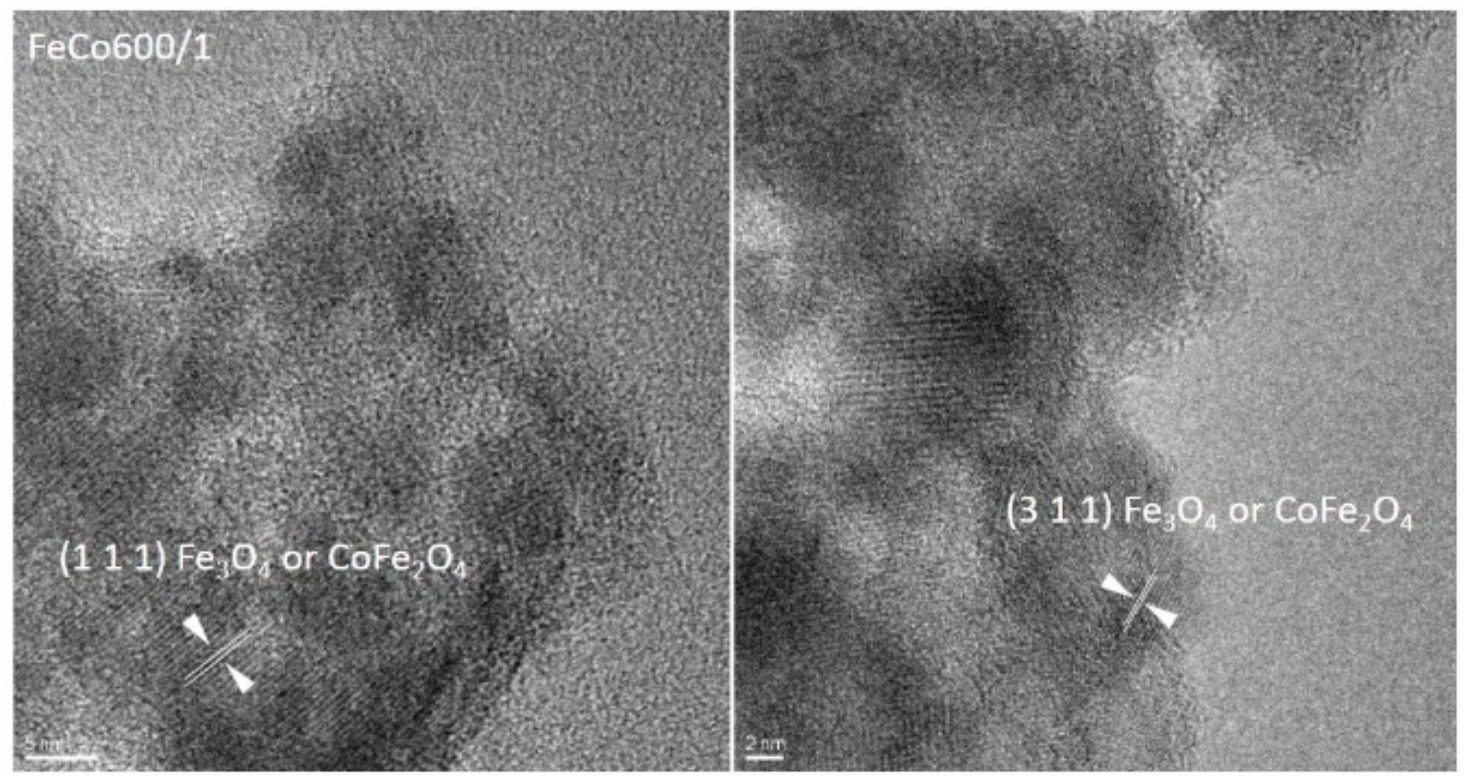

Fig. 3.1.26: HR-TEM micrograph of a FeCo600/1 sample.

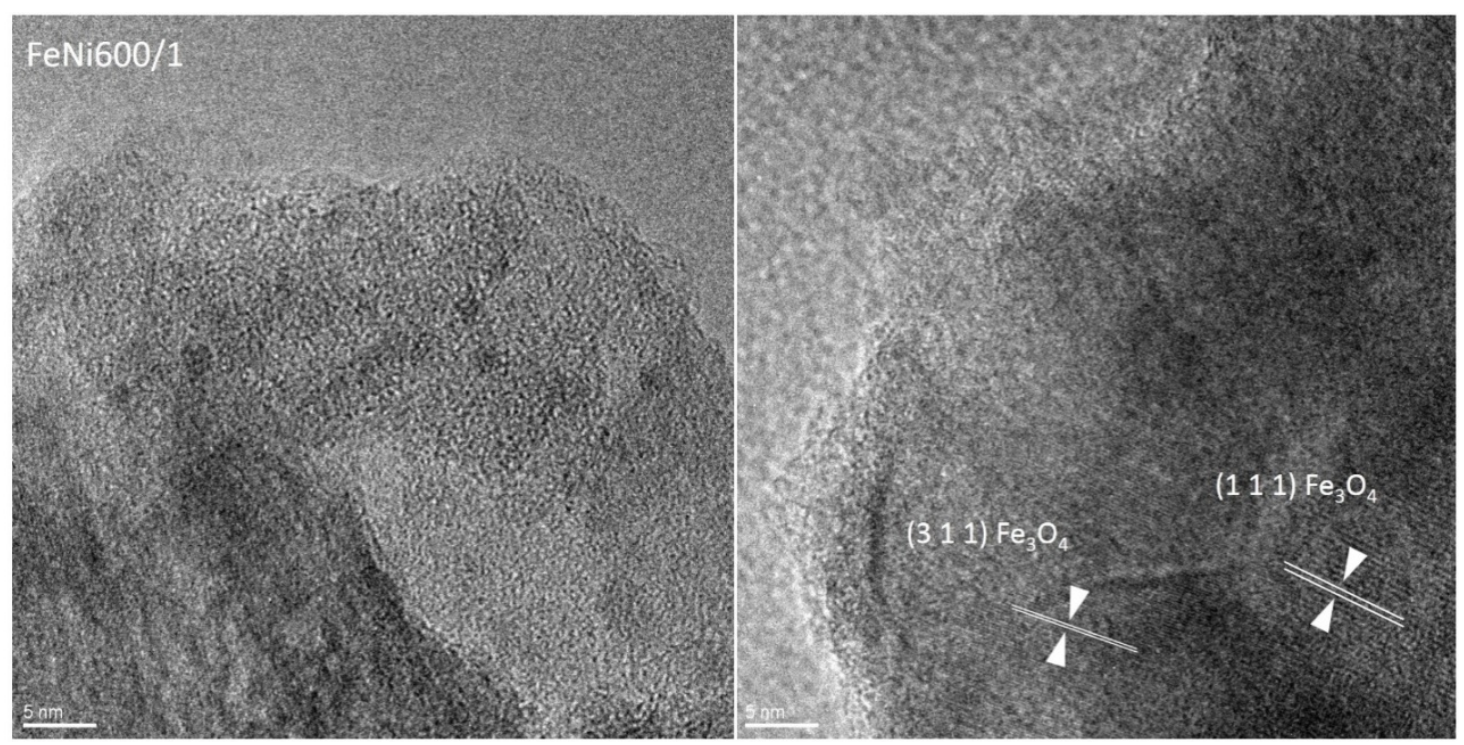

Fig. 3.1.27: HR-TEM micrograph of a FeNi600/1 sample. 


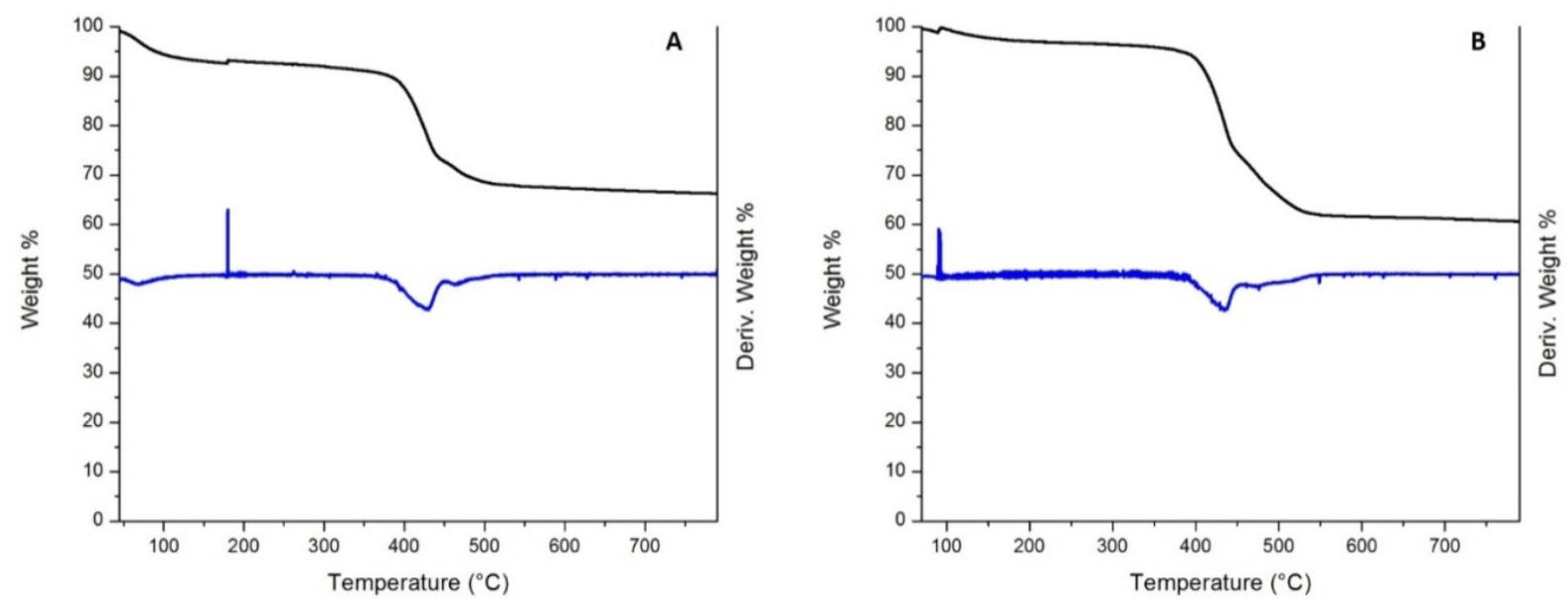

Fig. 3.1.28: TGA curves of FeCo600/1 (A) and FeNi600/1 (B).

Table 3.6: Specific surface area (SSA) and OM content of materials obtained by changing the $\mathrm{M}^{2+}$ ion

\begin{tabular}{cccccc}
\hline Sample & $\begin{array}{c}\mathrm{SSA}^{\mathrm{a}} \\
\left(\mathrm{m}^{2} \cdot \mathrm{g}^{-1}\right)\end{array}$ & $\begin{array}{c}\mathrm{OM}^{\mathrm{b}} \\
(\mathrm{wt} \%)\end{array}$ & $\begin{array}{c}\mathrm{C}^{\mathrm{c}} \\
(\mathrm{wt} \%)\end{array}$ & $\begin{array}{c}\mathrm{N}^{\mathrm{c}} \\
(\mathrm{wt} \%)\end{array}$ & $\begin{array}{c}\mathrm{S}^{\mathrm{c}} \\
(\mathrm{wt} \%)\end{array}$ \\
\hline FeCu600/1 & 138 & - & 9.78 & 3.38 & 11.90 \\
FeCo600/1 & 221 & 23 & 20.61 & 3.15 & 0.57 \\
FeNi600/1 & 212 & 35.8 & 26.72 & 3.91 & 0.69 \\
\hline
\end{tabular}

${ }^{a}$ BET model, ${ }^{b}$ TGA analysis; ${ }^{c}$ Elemental analysis.

The $\mathrm{N}_{2}$ adsorption isotherms of FeCo600/1 and FeNi600/1 are of Type II, according to IUPAC classification and show hysteresis due to interparticle porosity (Fig. 3.1.29). The SSA values are even higher than those measured for the Cu-containing materials treated at the same temperature (Table 3.6). This difference could be related to the higher organic matter content present in these samples compared to that in the Cu-containing materials. 


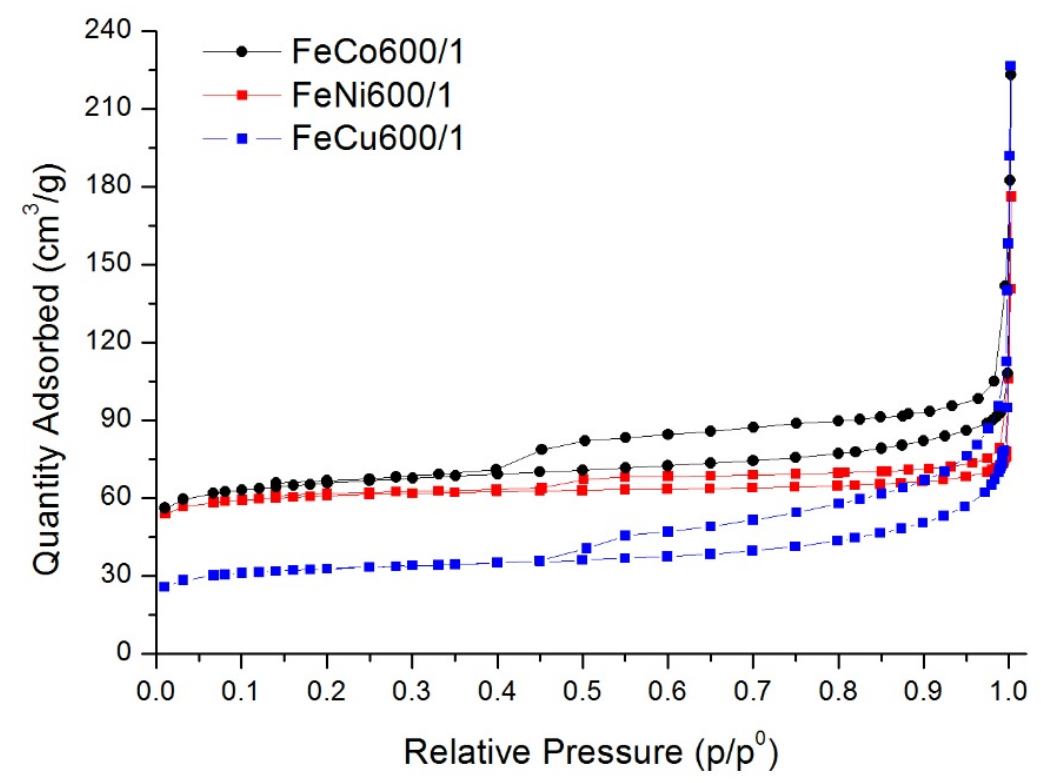

Fig. 3.1.29: Nitrogen adsorption-desorption isotherms of FeCo600/1 and FeNi600/1.

The FT-IR spectra of these samples (Fig. 3.1.30) depict the bands that correspond to $\mathrm{OH}$ groups $\left(3410 \mathrm{~cm}^{-1}\right)$; those characteristic bands of asymmetric/symmetric C-H stretching of aliphatic $-\mathrm{CH}\left(2920-2850 \mathrm{~cm}^{-1}\right)$; carboxylic groups $\left(1615 \mathrm{~cm}^{-1}\right)$ and adsorbed carbohydrates or polysaccharide-like substances (shoulder at $1090 \mathrm{~cm}^{-1}$ ). All of them are less intense than those for samples treated at $400{ }^{\circ} \mathrm{C}$ (FeCu400/1) containing higher amount of organic matter. They also show a stronger band near $575 \mathrm{~cm}^{-1}$ that corresponds to Fe-O or $\mathrm{M}^{2+}-\mathrm{O}$ bond of the spinel structure, which is higher than that observed for the sample FeCu600/1. No other bands, which could be assigned to other $\mathrm{Ni}, \mathrm{Co}$ and Fe oxides phases were detected in the FT-IR spectra. 


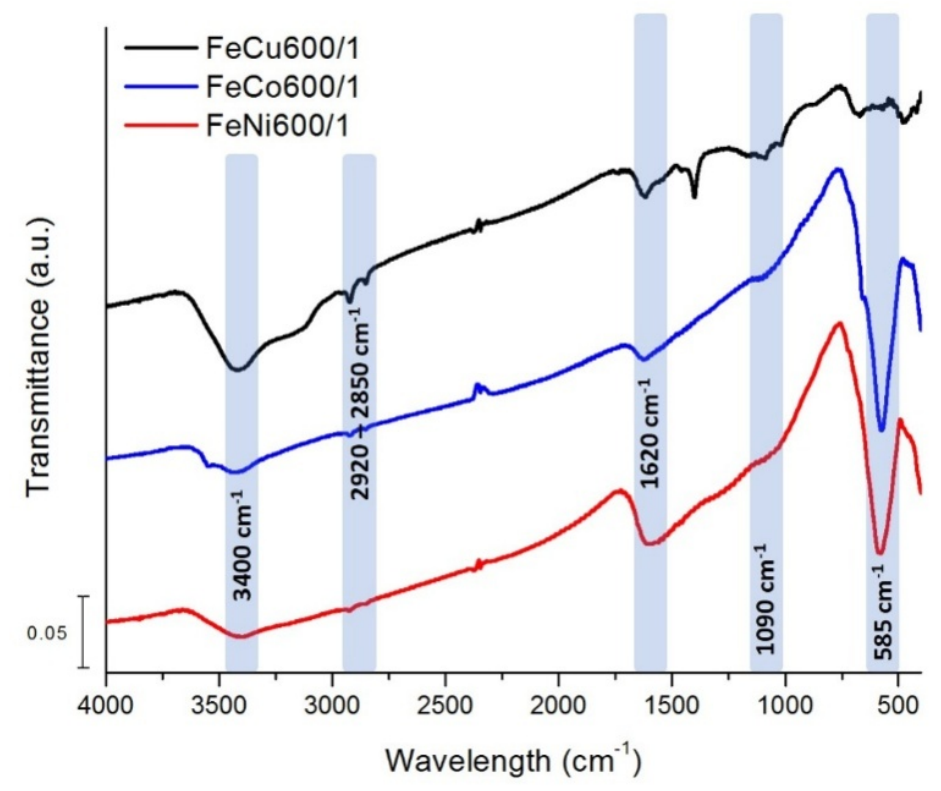

Fig. 3.1.30: FT-IR spectra of FeCo600/1 and FeNi600/1 and its assignment.

XRD patterns of the materials pyrolyzed at $600{ }^{\circ} \mathrm{C}$ are shown in Fig. 3.1.31. The position of the peaks for FeCo600/1 and FeNi600/1 are coincident with those of the $\mathrm{Fe}_{3} \mathrm{O}_{4}$, $\mathrm{CoFe}_{2} \mathrm{O}_{4}$ (for $\mathrm{FeC0600/1)} \mathrm{and} \mathrm{NiFe}_{2} \mathrm{O}_{4}$ (for FeCo600/1) phases, detailed signals are present at $2 \theta=30.17,35.45,37.15,43.17,53.57,57.11$ and $62.71^{\circ}$ associated with (2 20 ), (3 11 ),

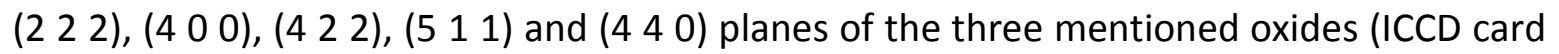
numbers 01-075-0393, 01-074-2081 and 00-001-1121).

For FeCo600/1 additional small peaks related to $\mathrm{CoO}$ were observed at $2 \theta=36.52$ (1 1 1), 42.42 (2 0 0 0), 61.55 (2 2 0) (ICCD card number 01-075-0393), whereas for FeNi600/1 additional peaks associated with NiO were found at $2 \theta=37.28$ (1 11 1), 43.25 (2 0 0) and $62.72^{\circ}$ (2 2 0)(ICCD card number 00-002-1216). In both samples low peaks associated with hematite phase were also evidenced at $2 \theta=24.12$ (0 1 2), 33.11 (1 04 ) (ICCD card number 00-024-0072). It is important to mention that when Co or Ni were used in the synthesis, the formation of its respective oxides (i.e. $\mathrm{CoO}$ and $\mathrm{NiO}$ ) after the thermal treatment at $600{ }^{\circ} \mathrm{C}$ is observed, whereas for the case of $\mathrm{Cu}$ there was no evidence of the formation of $\mathrm{CuO}$. Moreover, highlighting the differences between the materials obtained 
using $\mathrm{Cu}$ from those of $\mathrm{Ni}$ and $\mathrm{Co}$, note that the hematite phase was only found in $\mathrm{Co}$ and Ni materials.

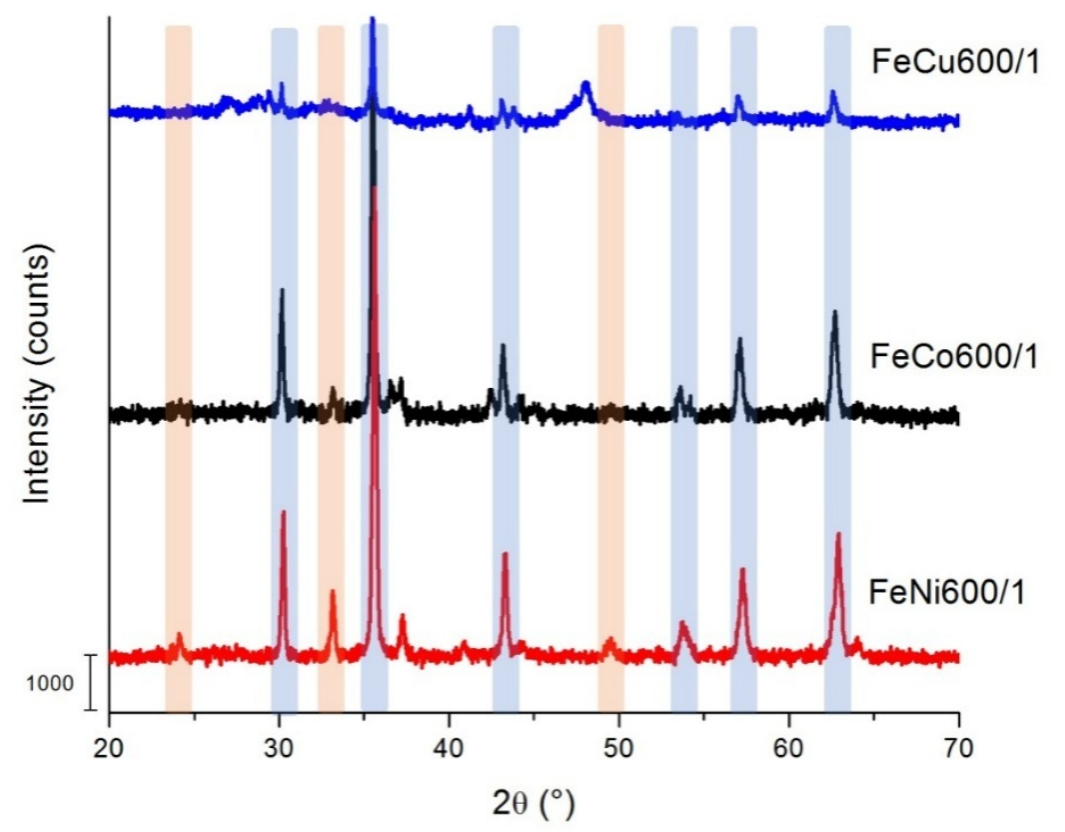

Fig. 3.1.31: XRD patterns of FeCo600/1 (A) and FeNi600/1 (B). The peaks assigned to $\mathrm{Fe}_{3} \mathrm{O}_{4}, \gamma-\mathrm{Fe}_{2} \mathrm{O}_{3}, \mathrm{CoFe}_{2} \mathrm{O}_{4}$ and $\mathrm{NiFe}_{2} \mathrm{O}_{4}$ are highlighted in blue and those that match with $\alpha-\mathrm{Fe}_{2} \mathrm{O}_{3}$ are shown in orange.

To obtain further information on the composition of the nanocomposites, again the X-rays absorption spectroscopy was used. XANES/EXAFS spectra in the K-edge of Ni show that $\mathrm{Ni}$ is mainly present in the form NiO (Fig. 3.1.32). The analysis of the XANES/EXAFS spectra in the K-edge of Fe indicate that this metal is present as a mixture of $68 \% \mathrm{Fe}_{3} \mathrm{O}_{4}$ and $30 \% \alpha-\mathrm{Fe}_{2} \mathrm{O}_{3}$. X-ray fluorescence data showed a Fe:Ni ratio of 2.2. For the Co containing material FeCo600/1, XANES spectra (Fig. 3.1.33) show the presence of CoO and a small fraction in the form of $\mathrm{CoFe}_{2} \mathrm{O}_{4}$. This latter phase cannot be discerned from magnetite with the XRD technique. The ratio Fe:Co obtained from X-rays fluorescence spectroscopy is 1.21 .

It was not possible to fit the K-edges spectra of FeCo600/1 and FeNi600/1 as a linear combination of spectra of the references (see Fig. 3.1.32 and Fig. 3.1.33). This could be due to the existence of complexes of $\mathrm{Ni}^{2+}$ and $\mathrm{Co}^{2+}$ with the organic matter still present 
in these samples, as was observed for the $\mathrm{Cu}$ containing materials obtained at $400{ }^{\circ} \mathrm{C}$. However, this is just a speculation.
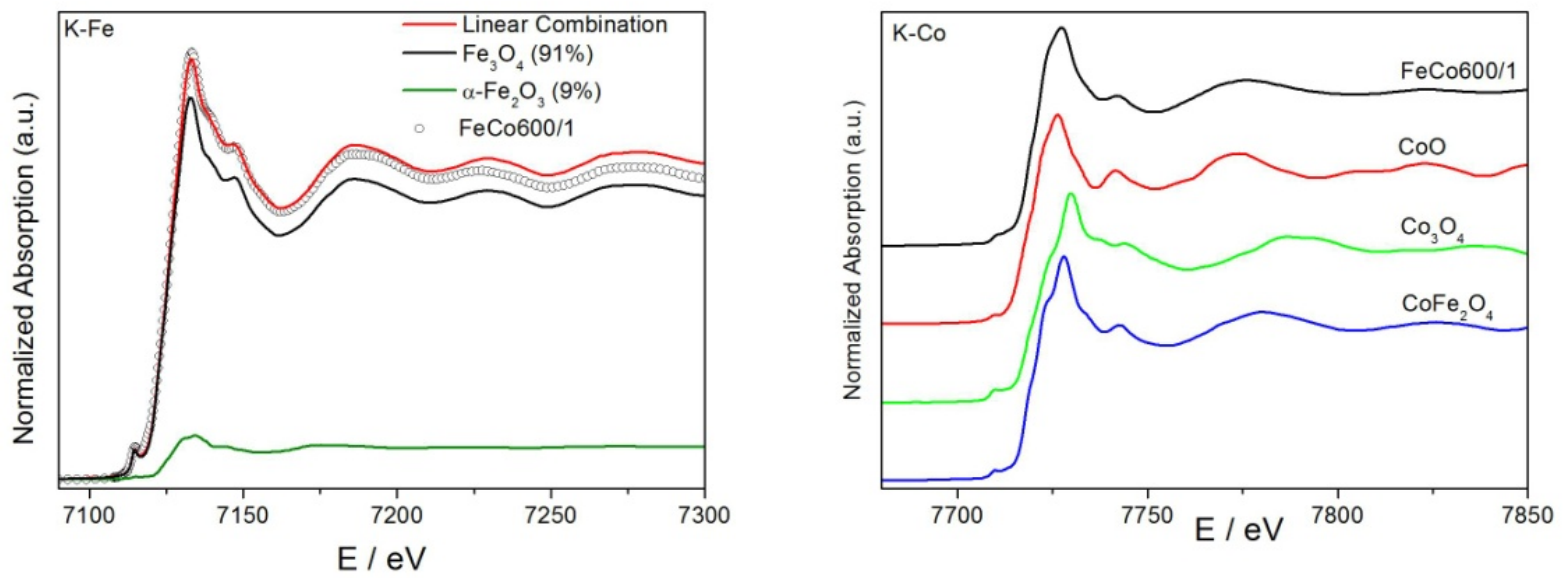

Fig. 3.1.32: K-edge spectra of Fe (left) and Co (right) measured for a FeCo600/1 sample and references.
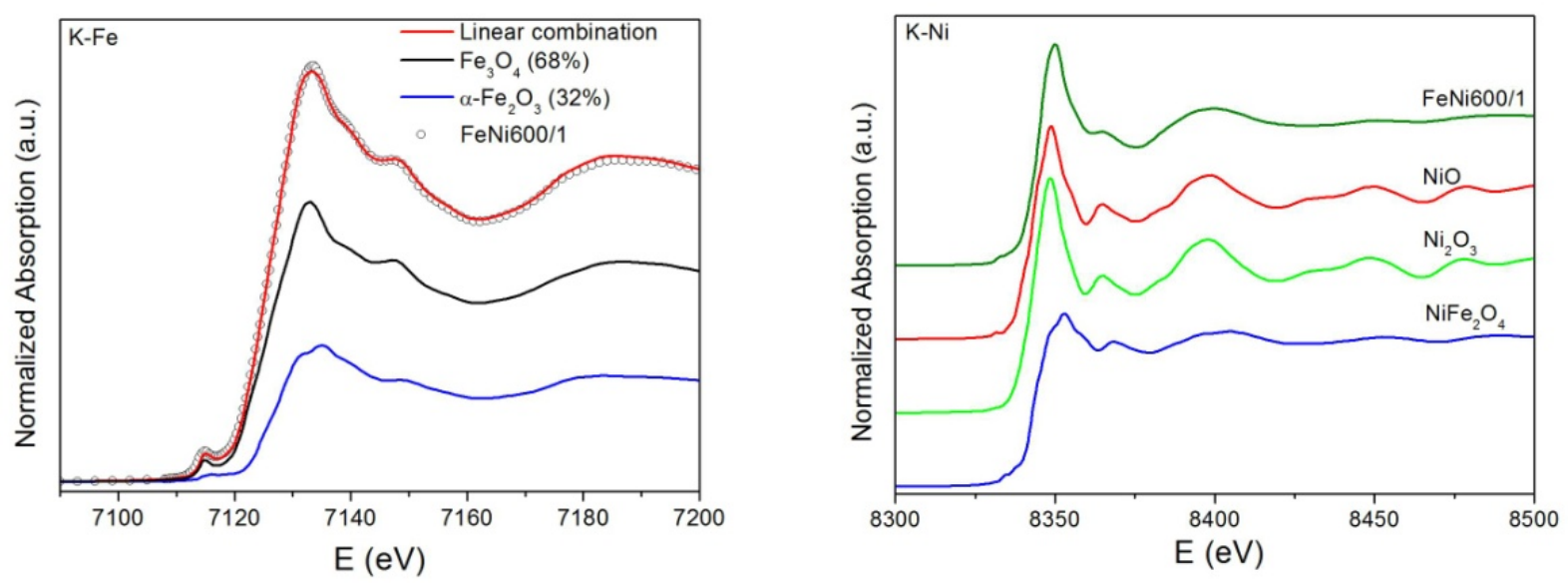

Fig. 3.1.33: K-edge spectra of Fe (left) and Ni (right) measured for a FeNi600/1 sample and references. 
Magnetization measurements show the same ferromagnetic behavior with a broader curve for the Co containing material (Fig. 3.1.34). The magnetic properties extracted from the magnetization curves are listed in the Table 3.7. Values of Ms are higher than those of the Fe-Cu nanocomposites treated at $600{ }^{\circ} \mathrm{C}$ and follow the trend $\mathrm{Co}>\mathrm{Ni}>\mathrm{Cu}$, with the higher value of coercivity $\left(\mathrm{H}_{\mathrm{c}}\right)$ for the Co containing material (638 Oe).

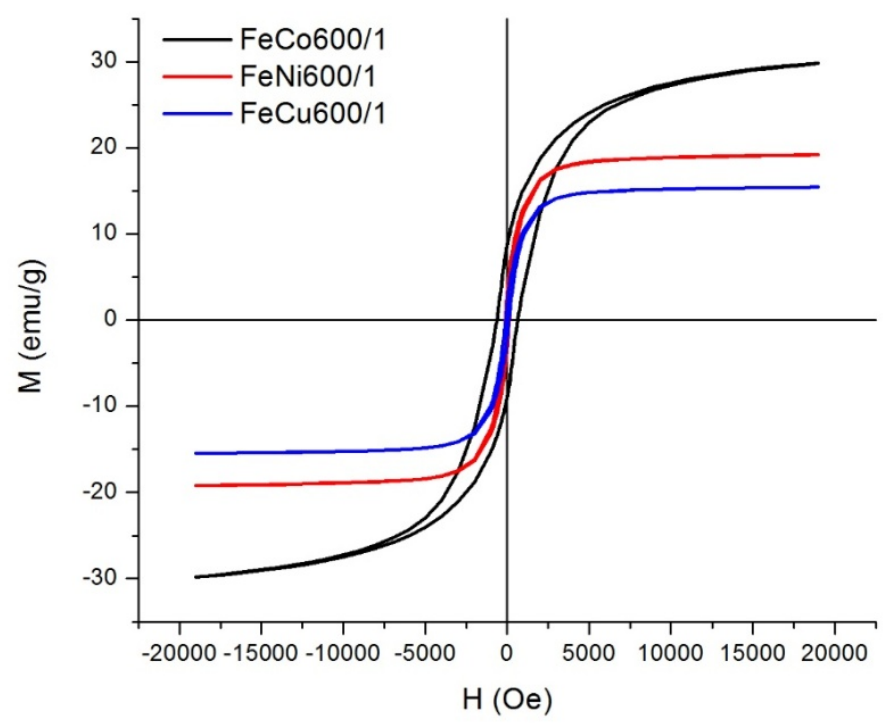

Fig. 3.1.34: Magnetization curves for FeCo600/1 and FeNi600/1.

Table 3.7: Magnetic properties of FeCo600/1, FeNi600/1, and FeCu600/1.

\begin{tabular}{cccc}
\hline Sample & $\begin{array}{c}\mathrm{M}_{\mathrm{S}} \\
\left(\mathrm{emu} \mathrm{g}^{-1}\right)\end{array}$ & $\begin{array}{c}\mathrm{M}_{\mathrm{R}} \\
(\mathrm{Oe})\end{array}$ & $\begin{array}{c}\mathrm{H}_{\mathrm{C}} \\
(\mathrm{Oe})\end{array}$ \\
\hline FeCu600/1 & 15.4 & 1.796 & 95.214 \\
FeCo600/1 & 29.75 & 8.75 & 637.99 \\
FeNi600/1 & 19.26 & 3.18 & 119.63 \\
\hline
\end{tabular}


Table3.8: Summary of the materials characterization.

\begin{tabular}{|c|c|c|c|c|c|c|c|c|}
\hline \multirow[b]{2}{*}{ Material } & \multicolumn{3}{|c|}{ Organic/carbonaceous matrix } & \multicolumn{2}{|c|}{ Metal oxides core } & \multirow[b]{2}{*}{$\begin{array}{l}\operatorname{SSA}^{f} \\
\left(\mathrm{~m}^{2} \mathrm{~g}^{-1}\right)\end{array}$} & \multirow[b]{2}{*}{$\begin{array}{c}M_{s}^{g} \\
\left(\text { emu.g } g^{-1}\right)\end{array}$} & \multirow[b]{2}{*}{$\begin{array}{l}\text { Morphological }{ }^{\mathrm{h}} \text { and } \\
\text { textural }^{\mathrm{f}} \text { properties }\end{array}$} \\
\hline & OM\% ${ }^{\mathrm{a}}$ & $\mathrm{C} \%^{\mathrm{b}}$ & $\begin{array}{l}\text { Functional } \\
\text { groups }^{c}\end{array}$ & $\begin{array}{l}\text { Crystalline } \\
\text { phases }^{d}\end{array}$ & $\begin{array}{l}\text { Non- } \\
\text { crystalline } \\
\text { phases }^{\mathrm{e}}\end{array}$ & & & \\
\hline FeCu400/1 & 50.50 & 26.23 & \multirow{5}{*}{$\begin{array}{l}-\mathrm{CH} \\
-\mathrm{COO} \\
-\mathrm{OH}\end{array}$} & \multirow{5}{*}{$\begin{array}{c}\mathrm{Fe}_{3} \mathrm{O}_{4} 60 \% \\
\alpha-\mathrm{Fe}_{2} \mathrm{O}_{3} 20 \% \\
\gamma-\mathrm{Fe}_{2} \mathrm{O}_{3} 20 \%\end{array}$} & \multirow{5}{*}{$\begin{array}{l}\text { BBS-Cu(II) } \\
\text { complexes }\end{array}$} & 33 & 6.7 & \multirow{5}{*}{$\begin{array}{c}\text { Small crystalline particles ( } 2 \\
\text { to } 10 \mathrm{~nm} \text { ) dispersed in a } \\
\text { non-porous, non-crystalline } \\
\text { organic matrix }\end{array}$} \\
\hline FeCu400/2 & 56.75 & 29.38 & & & & 14.48 & - & \\
\hline FeCu400/3 & 66.80 & 41.02 & & & & $<10$ & 1.5 & \\
\hline FeCu400/4 & 67.90 & 40.55 & & & & $<10$ & - & \\
\hline FeCu400/5 & 65.40 & 41.50 & & & & $<10$ & 2.2 & \\
\hline FeCu600/1 & - & 9.78 & $\begin{array}{c}-\mathrm{CH} \\
\text { Aromatic } \mathrm{C}=\mathrm{C} \\
\text { aliph-OH }\end{array}$ & $\begin{array}{c}\mathrm{Fe}_{3} \mathrm{O}_{4} 60 \% \\
\gamma-\mathrm{Fe}_{2} \mathrm{O}_{3} 30 \% \\
\mathrm{FeO} \\
\mathrm{Cu}_{2} \mathrm{~S} \\
\end{array}$ & $\mathrm{CuS}_{2}$ & 138 & 15.4 & $\begin{array}{l}\text { Crystalline regions not well } \\
\text { limited within organic } \\
\text { non-crystalline carbon }\end{array}$ \\
\hline FeCu800/1 & - & 10.60 & aliph-CH & $\begin{array}{c}\mathrm{Fe}_{3} \mathrm{O}_{4} 65 \% \\
\mathrm{Y}-\mathrm{Fe}_{2} \mathrm{O}_{3} 20 \% \\
\mathrm{FeO} \\
\mathrm{Fe}^{0} 15 \% \\
\mathrm{Cu}_{2} \mathrm{~S}\end{array}$ & $\mathrm{CuS}_{2}$ & 158 & 23.6 & $\begin{array}{l}\text { Crystalline regions not well } \\
\text { limitedwithin organic } \\
\text { non-crystalline } \\
\text { carbonaceousneedles/sheets }\end{array}$ \\
\hline FeCo600/1 & 23 & 20.61 & \multirow{2}{*}{$\begin{array}{l}-\mathrm{OH} \\
\text { aliph C-H } \\
-\mathrm{COO}\end{array}$} & $\begin{array}{c}\mathrm{Fe}_{3} \mathrm{O}_{4} 65 \% \\
\alpha-\mathrm{Fe}_{2} \mathrm{O}_{3} 20 \% \\
\gamma-\mathrm{Fe}_{2} \mathrm{O}_{3} 20 \% \\
\mathrm{CoO} \\
\mathrm{CoFe} 2 \mathrm{O} 4\end{array}$ & - & 221 & 29.75 & \multirow{2}{*}{$\begin{array}{c}\text { Small crystalline particles (> } \\
10 \mathrm{~nm} \text { ) dispersed in a } \\
\text { non-porous, non-crystalline } \\
\text { organic/carbonaceous } \\
\text { matrix }\end{array}$} \\
\hline FeNi600/1 & 35.80 & 26.72 & & $\begin{array}{c}\mathrm{Fe}_{3} \mathrm{O}_{4} 68 \% \\
\alpha-\mathrm{Fe}_{2} \mathrm{O}_{3} 30 \% \\
-\mathrm{Fe}_{2} \mathrm{O}_{3} 20 \% \\
\mathrm{NiO}\end{array}$ & - & 212 & 19.26 & \\
\hline
\end{tabular}

${ }^{\mathrm{a}} \mathrm{TGA} ;{ }^{\mathrm{b}}$ Elemental analysis; ${ }^{\mathrm{C}} \mathrm{FT}$-IR spectroscopy; ${ }^{\mathrm{d}} \mathrm{XRD}$ (percentages based on confirmation by XRS); ${ }^{\mathrm{e} X R S}$; ${ }^{\mathrm{f}} \mathrm{BET}$ model; ${ }^{\mathrm{g} V S M}{ }^{\mathrm{h}}{ }^{\mathrm{h}} \mathrm{HR}-\mathrm{TEM}$ 
Finally, in order to summarize the results obtained by the physicochemical characterization, Table 3.8 outlines the main features of all the samples prepared in this Thesis. 


\section{UV-Visible Light Absorption Spectroscopy}

\section{Diffuse Reflectance Spectroscopy (DRS)}

It is accepted that most of the Fe oxides are semiconductors, such as maghemite (band gap $\approx 2.0 \mathrm{eV}$ ), whereas magnetite exhibits properties closer to a conductor (band gap $\approx 0.1 \mathrm{eV}$ (Cornell \& Schwertmann, 2003). Table 3.8 reports some values of band gaps published for these oxides. Moreover, when these oxides are in the nanoscale (as nanoparticles, nanoplates, etc.) the effect of the particle size on the measured band gaps is evidenced. For instance, Kulkarni et al. (Kulkarni et al., 2014) have recently reported that the bandgap of magnetite nanoparticles increases by decreasing the mean particle size (from $1.88 \mathrm{eV}$ for nanoparticles of $35 \mathrm{~nm}$ obtained by co-precipitation, to $2.08 \mathrm{eV}$ for $20 \mathrm{~nm}$ nanoparticles obtained by the combustion technique). On the other hand, maghemite and hematite are excellent photocatalysts for oxidation reactions because of their band gap energies in the range 2.0-2.2 eV, which would allow the absorption of visible light (Tilley, et al. 2010).

Table 3.9: Reported band gaps for iron oxides (taken from Cornell \& Schwertmann, 2017)

\begin{tabular}{cc}
\hline Mineral & Band Gap (eV) \\
\hline Conductor & $\leq 0$ (overlap) \\
Magnetite $\left(\mathrm{Fe}_{3} \mathrm{O}_{4}\right)$ & 0.1 \\
Semiconductor & $0.5-3$ \\
Feroxyhyte $(\delta-\mathrm{FeOOH})$ & 1.94 \\
Maghemite $\left(\nu-\mathrm{Fe}_{2} \mathrm{O}_{3}\right)$ & 2.03 \\
Lepidocrocite $(\gamma-\mathrm{FeOOH})$ & 2.06 \\
Goethite $(\alpha-\mathrm{FeOOH})$ & 2.10 \\
Akaganeite $(\beta-\mathrm{FeOOH})$ & 2.12 \\
Hematite $\left(\alpha-\mathrm{Fe}_{2} \mathrm{O}_{3}\right)$ & 2.20 \\
Insulator & $>3$ \\
\hline
\end{tabular}


Also, several modifications of the iron oxides were used as a strategy for the improvement of electron-hole separation and catalysis enhancement. To this end, Lassoued et al. prepared pure and copper-doped hematite $\left(\alpha-\mathrm{Fe}_{2} \mathrm{O}_{3}\right)$ nanocrystals by the co-precipitation method and observed that the size of the nanoparticles decreases with Cu-doping. These authors showed by UV-Vis absorption spectroscopy that the decrease of particle size was also accompanied by a decrease in the band gap value (from $2.12 \mathrm{eV}$ for pure $\alpha-\mathrm{Fe}_{2} \mathrm{O}_{3}$ to $1.91 \mathrm{eV}$ for $8 \% \mathrm{Cu}$-doped $\alpha-\mathrm{Fe}_{2} \mathrm{O}_{3}$ ) (Lassoued, et al., 2017). Besides the doping, the coupling with other photocatalysts (either oxides or not) in composite structures is another approach aimed to increase the photocatalytic activity. In this sense several efforts have been made, with very different results. Beydoun et al. have prepared composites of the core-shell type by coating $\mathrm{TiO}_{2}$ particles onto nano-magnetite particles (Beydoun et al., 2002), and studied their photoactivity. They have found that their activity is lower than that of $\mathrm{TiO}_{2}$ and refer this behavior to the fact that a more favorable environment for electron-hole recombination is generated by the narrower band gap of the iron oxides. By choosing a semiconductor with small band gap to prepare composites of $\mathrm{SnO}_{2} / \alpha-\mathrm{Fe}_{2} \mathrm{O}_{3}$, Niu et al. (Niu et al., 2010) showed that the photo-generated electrons are transferred from the conduction band of hematite to the conduction band of the other semiconductor (i.e. $\mathrm{SnO}_{2}$ ). This led to the separation of the electrons and holes across the heterojunction

According to the XANES results shown in the previous section, some of the samples contained copper sulfides. Copper sulfides can adopt a large number of crystallographic phases depending on their stoichiometric nature, from copper-rich $\mathrm{Cu}_{2} \mathrm{~S}$ to copper-poor $\mathrm{CuS}_{2}$ phases (Mousavi-Kamazani, et al.2016). Copper(I) sulfide has a bulk band gap of 1.21 $\mathrm{eV}$, which is in the optimum range for solar-energy conversion (Brewer \& Arnold, 2014).

The Diffuse Reflectance spectra (DRS) of the nanomaterials are shown in Fig. 3.1.35. As can be seen, the shape of the spectra of all samples is very similar, and different from that expected for a semiconductor material. Instead of an increase of the reflectance in the region of higher wavelengths of the spectrum, they all have a broad band centered at around $230 \mathrm{~nm}$ (not completely shown), a smaller one centered at ca. $350 \mathrm{~nm}$, and 
then, the intensity of the reflectance decreases homogeneously from 400 up to $800 \mathrm{~nm}$. Bare hematite and magnetite were prepared $^{1}$ for comparison of their DRS spectra to those shown in Fig. 3.35. In these cases, a clear minimum of reflectance is observed at ca. $400 \mathrm{~nm}$. By applying the Kubelka-Munk (KM) expression, from a Tauc's plot treating them as direct semiconductors, the values of the band gaps of the magnetite and hematite were obtained (Fig. 3.36): $1.36 \mathrm{eV}$ for magnetite and $2.35 \mathrm{eV}$ for hematite. Preisinger et al. (Preisinger et al. , 2005) investigated the electronic structure of nanosized iron oxide by scanning tunnelling microscopy, as well as by photoelectron spectroscopy and optical spectroscopy. They concluded that the photocatalytic activity of the particles, are due to the formation of a surface band gap different from that of the volume. The existence of such a surface band gap appears to be triggered by defects within the nanoparticle.

For the materials prepared by pyrolysis of BBS-metals complexes, this approach was not possible. Due to the shape of the spectra, KM combined with Tauc's plots led to negative band gaps. To further understand this behavior, another sample (reduced graphene oxide, rGO) was prepared and its DRS spectrum measured for comparison. Surprisingly, the shape of its spectrum resulted very similar to that of the nanocomposites. These results led us to propose that the content of organic (or carbonaceous) phases could be masking the DRS spectra of the semiconductor's phases; and therefore, that this is not a suitable technique to determine their band gap energy.

\footnotetext{
${ }^{1}$ The preparation method and characterization of these materials is shown in the Appendix, at the end of this section.
} 

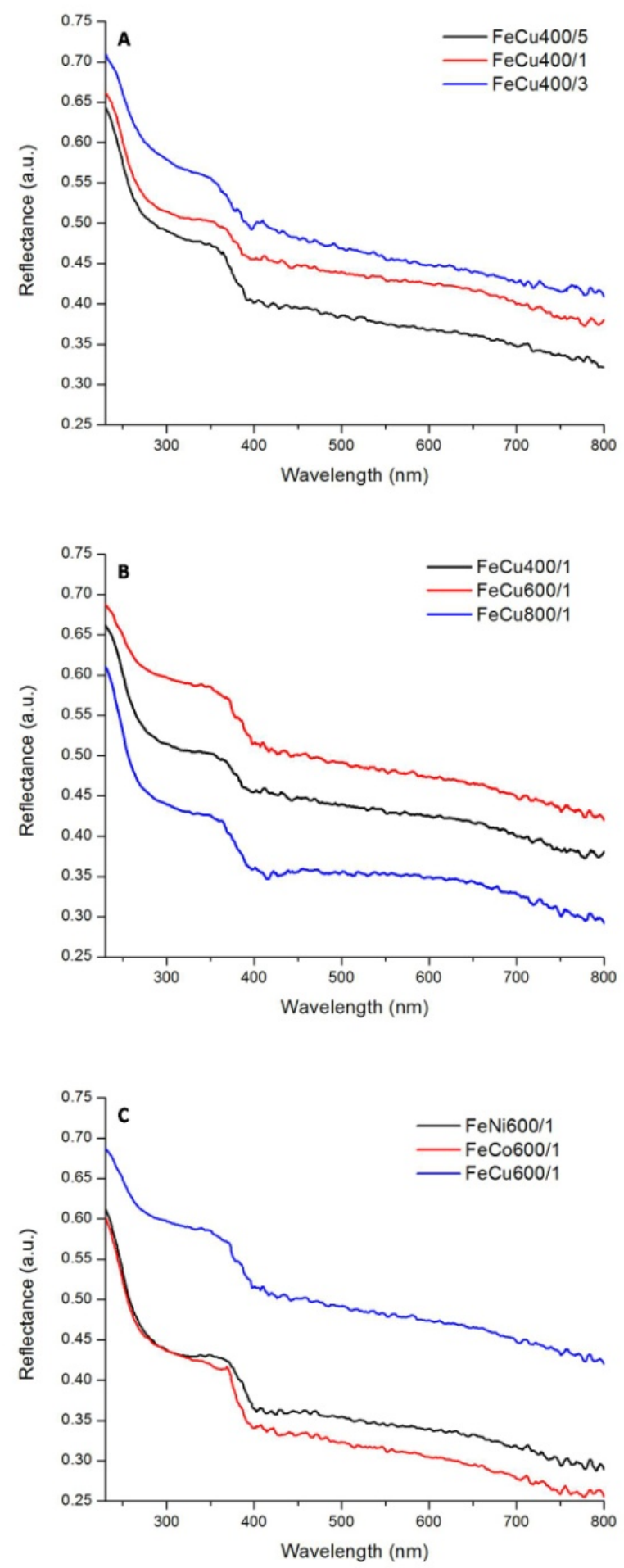

Fig. 3.1.1: DRS of materials with different amount of organic matter (A); different temperature of the pyrolysis (B); and different $\mathrm{M}^{2+}$ cation (C). 
Instead, some information regarding to the carbon structure, bonding $\left(\mathrm{sp}^{3} / \mathrm{sp}^{2}\right)$, crystallinity, and grain size of the powders could be extracted. Applin et al. studied the UV reflectance of carbonaceous materials and proposed that the electronic $\sigma-\sigma^{*}$ transitions occur near $\lambda=85 \mathrm{~nm}$, whereas the $\pi-\pi^{*}$ at $\lambda=250 \mathrm{~nm}$. These features shift to longer wavelengths (from $\lambda=241 \mathrm{~nm}$ for graphite to $\lambda=262 \mathrm{~nm}$ for some samples of amorphous carbon), become broader and increase in intensity with increasing amorphization (or decreasing long range ordering). These results indicate that the overall $\pi-\pi^{*}$ bonding distance decreases and there is a wider distribution of bonding distances with increasing amorphization, causing the $\pi-\pi^{*}$ peak to broaden and move to longer wavelengths (Applin et al., 2018). In the same work, Applin and co-workers studied a survey of silicate mineral UV reflectance spectra and they found that an inter-band due to the $\mathrm{Fe}^{2+}-\mathrm{O}$ and $\mathrm{Fe}^{3+}-\mathrm{O}$ charge transfers near $\lambda=230 \mathrm{~nm}$ occurs mainly in some Fe-bearing silicates. Among these materials, there is an effect of the grain size on the resolution of the bands assigned to $\pi-\pi^{*}$ of the carbonaceous fraction and the $\mathrm{Fe}^{2+}-\mathrm{O}$ and $\mathrm{Fe}^{3+}-\mathrm{O}$ charge transfers. The overlapping of these bands is more noticeable for the samples with higher grain size. Thus, the large reflectance at about $\lambda=230 \mathrm{~nm}$ in our materials could be due to a combination of the $\pi-\pi^{*}$ electronic transition (from carbonaceous matrices) and the $\mathrm{Fe}^{2+}-\mathrm{O}$ and $\mathrm{Fe}^{3+}-\mathrm{O}$ charge transfers from the iron oxides phases (Applin et al., 2018).

As it has been mentioned earlier, the content of carbon decreases as the temperature of the pyrolysis treatment increases. It is expected that the iron oxides phases contribute progressively more to the overall spectra as carbon concentration decreases. This could explain the change in the shape of the spectra for the materials treated at higher temperature in the region of $\lambda>400 \mathrm{~nm}$ (Fig. 3.1.35-B). Note the high reflectance in this wavelength region for $\mathrm{Fe}_{3} \mathrm{O}_{4}$ and $\alpha-\mathrm{Fe}_{2} \mathrm{O}_{3}$ (Fig. 3.1.36).

As can be seen in Fig. 3.1.35-C, for materials containing $\mathrm{Co}$ and $\mathrm{Ni}$, the spectra are almost coincident, whereas for the $\mathrm{Cu}$ containing material the intensity of the signal is significantly higher. The $\mathrm{Ni}$ - and Co- containing materials have a higher amount of carbon, and thus lower content of metal oxides, compared to the $\mathrm{Cu}$ - materials treated at the 
same temperature (see previous section). The lower reflectance of the FeNi600/1 and FeCo600/1 at $\lambda>400 \mathrm{~nm}$ could be due to the low amounts of iron oxides.
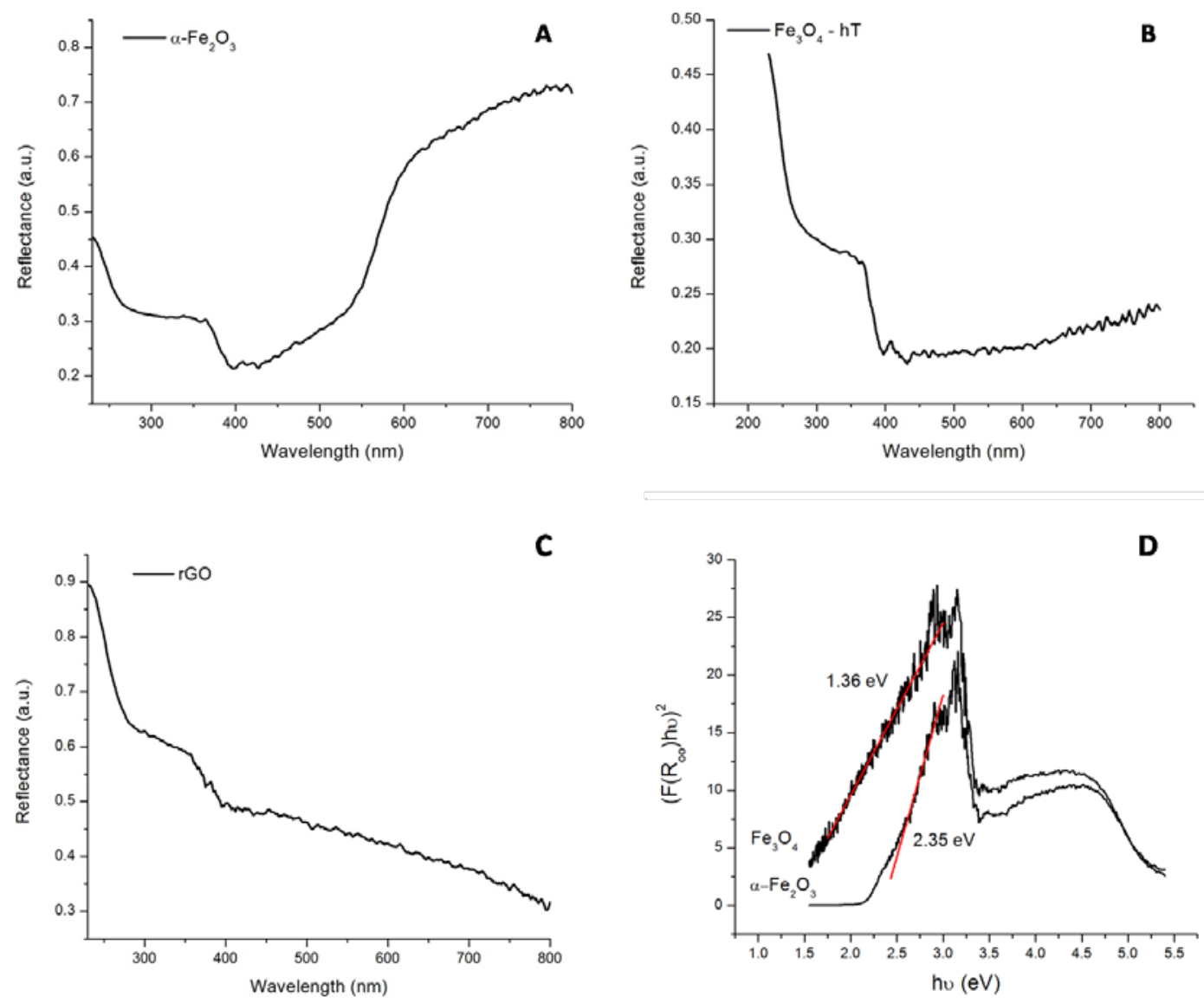

Fig. 3.1.2: Diffuse reflectance spectrum of bare hematite (A) and magnetite (B) prepared by hydrothermal synthesis, and reduced graphene oxide (C). Tauc's plots for bare hematite and magnetite and their band gap values (D). 


\section{Conclusions:}

From the study of the precursor's composition by AAS it was possible to determine that different amounts of $\mathrm{Cu}^{2+}$ and $\mathrm{Fe}^{3+}$ were taken by BBS from their solutions. This result should be considered to further design synthesis strategies by using this method.

Among the materials obtained at $400{ }^{\circ} \mathrm{C}$, by increasing the amount of BBS used, it is noteworthy the loss of effect on the final content of OM once the molar ratio $[\mathrm{nC} /(\mathrm{nFe}+$ $\mathrm{nCu})]=5.5$ was reached. It could be due to a saturation-like situation of the chelating sites. HR-TEM images show that the size of the nanocomposites varies from ca. $2 \mathrm{~nm}$ for the FeCu400/1 sample up to $6 \mathrm{~nm}$ (or even bigger) for theFeCu400/5 sample. XRD patterns have shown the magnetite, maghemite and hematite phases, and no peaks of copper containing phases were observed. The carbon present in the nanocomposites seems to be in amorphous phases as well. FT-IR spectra show organic functional groups from BBS and bands assigned to the Fe-O and/or Cu-O bond. Small specific surface values and magnetization saturation were obtained for all these materials. From XRS, the iron was determined to be present as magnetite (60\%), maghemite $(20 \%)$ and hematite (20\%). For copper it was needed to prepare a BBS-Cu${ }^{2+}$ complex sample to obtain a reference to explain the nanocomposites spectra. This led us to risk the hypothesis that copper remains more attached to organic matter, following its own fate during the pyrolysis, independent of iron.

The temperature of the pyrolysis treatment has a remarkable effect on the final materials obtained. First, the organic matrix of the materials obtained at $400{ }^{\circ} \mathrm{C}$ becomes a more graphitic matrix by increasing the temperature. This was reflected in the changes of the FT-IR spectra, where the bands assigned to organic functional groups drastically diminished. Also, the carbon content determined by elemental analysis decreases. Specific surface area and magnetic saturation values were also higher for these materials. XRD patterns have shown again peaks assigned to magnetite and maghemite phases, and in the case of $\mathrm{FeCu} 800 / 1$ sample, $\mathrm{Fe}^{0}$. In these samples, peaks assigned to $\mathrm{Cu}_{2} \mathrm{~S}$ were also observed. And as can be seen also by elemental analysis, an enrichment on the content of sulfur occurs by increasing the temperature. In addition, acceptable reproductions of the 
experimental XANES spectra were obtained by including references of $\mathrm{Cu}_{2} \mathrm{~S}$ and $\mathrm{CuS}_{2}$ phases.

By changing the $\mathrm{M}^{2+}$ ion, the materials FeNi600/1 and FeCo600/1 were obtained. They both have shown higher values of SSA and $M_{S}$ than their analogous FeCu600/1. These results encourage us to further study the complexation of cations by BBS. In addition, and since not trustworthy reproduced XANES spectra were obtained by linear combination of spectra of different references, the proposal of a different interaction between BBS and $\mathrm{Ni}^{2+}$ and $\mathrm{Co}^{2+}$ is supported.

DRS assays did not allow us to determine the value of the band gap for the materials prepared. But some hints about the graphitic-like carbonaceous matrices were found. 


\subsection{Transients Characterization and ROS generation}

\section{Transient Absorption Spectroscopy}

\section{Laser flash-photolysis (LFP) experiments performed in the absence of scavengers}

Transient techniques provide very sensitive means of understanding the charge carrier dynamics. The experiments were performed with samples FeCu400/1, FeCu600/1, and FeCu800/1 in order to investigate the effect of the temperature treatment on the semiconductor performance of the nanomaterials. LFP experiments were performed with Ar-saturated suspensions of the nanomaterials at a concentration of $2.5 \mathrm{~g} . \mathrm{L}^{-1}$. All the samples showed the decay of transient species in the whole range of analysis wavelengths (370-750 nm). Two typical signals obtained for suspensions of FeCu400/1 at 605 and 455 $\mathrm{nm}$ are shown in Fig. 3.2.1. Typically, the decay of the signals takes place in the submicrosecond time scale.
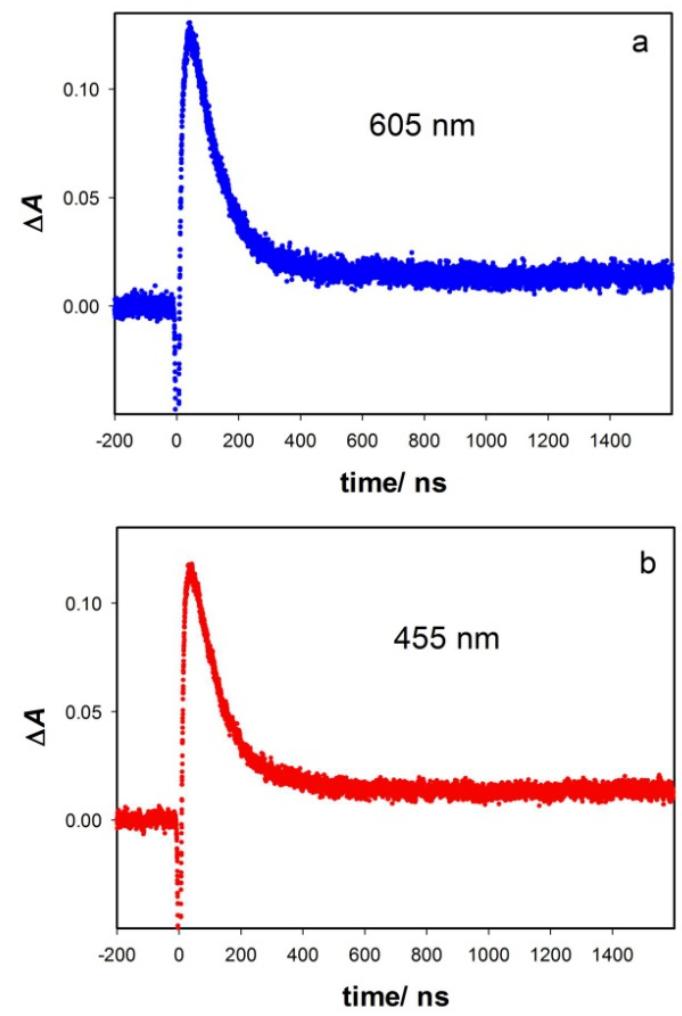

Fig. 3.2.1: Absorbance profiles obtained after laser excitation of Ar-saturated $2.5 \mathrm{gL}^{-1}$ suspensions of the FeCu400/1 at two different wavelengths of analysis: a) $605 \mathrm{~nm}$ and b) $455 \mathrm{~nm}$. 
Fig. 3.2.2 shows the absorption spectra of the observed transients at different times after the laser shot for the FeCu400/1 sample. As can be seen, there is a broad absorption band all over the range of analysis wavelength. From comparison of these spectra to those obtained upon irradiation of various families of semiconductor nanoparticles (Baldoví et al., 2014; Uchihara et al., 1998), we propose that the transients correspond to the charge-separated states of electron and holes located in different traps.
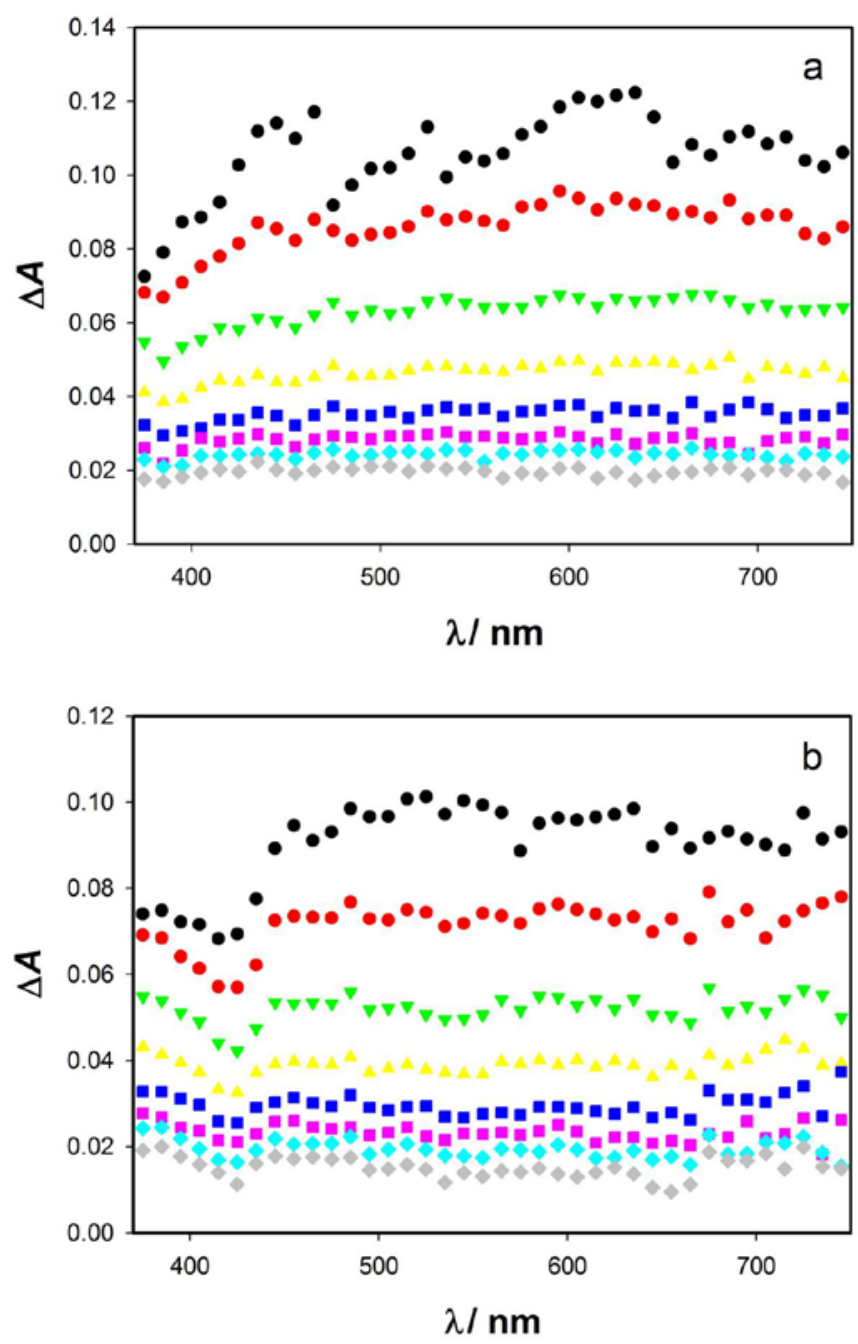

Fig. 3.2.2: Absorption spectra of the transients obtained in LFP experiments performed with Ar-saturated 2.5 $\mathrm{gL}^{-1}$ aqueous suspensions of FeCu400/1: $\mathrm{a}$ ) in the absence of KSCN and b) in the presence of $0.05 \mathrm{M} \mathrm{KSCN}$. The spectra shown in both pictures correspond from top to bottom to the following times after the laser shot: $0,40,80,120,160,200,240$, and $320 \mathrm{~ns}$ 
In order to elucidate whether more than one species contribute to the absorbance signals, a global analysis of the signals was performed with the Glotaran software. A consecutive model with two species was proposed, as shown schematically in Fig. 3.2.3.

Consecutive model for all essays:

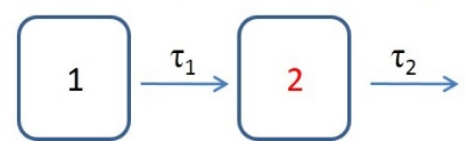

Fig. 3.2.3: Scheme of the consecutive model applied to the analysis of the data.

As can be seen in Table 3.10, for all the samples there is a fast lifetime of the same order of magnitude as the laser pulse, which can be related to the response of the detection system to light scattering. For all the samples the second component of longer lifetime is assigned to charge-separated states of electron and holes located in different traps. The DADs of both components are shown in Fig. 3.2.4. Similar results are obtained for FeCu600/1 and FeCu800/1 (data not shown).

Table 3.10: Lifetimes of the species retrieved from the Glotaran software for the LFP experiments performed with Ar-saturated suspensions of the nanomaterials in the absence and presence of $0.05 \mathrm{M}$ $\mathrm{KSCN}$.

\begin{tabular}{c|cc|cc|c}
\hline \multirow{2}{*}{ Nanomaterial } & \multicolumn{2}{|c|}{ without KSCN } & \multicolumn{2}{c|}{ with 0.05 M KSCN } & \multirow{2}{*}{$\mathbf{k}_{\mathbf{q}}\left(\mathbf{M}^{-1} \mathbf{s}^{-1}\right)$} \\
& $\tau_{1}$ (ns) & $\tau_{\mathbf{2}}$ (ns) & $\tau_{1}$ (ns) & $\tau_{2}$ (ns) & \\
\hline FeCu400/1 & 5.5 & 301 & 7.1 & 222 & $2.4 \times 10^{7}$ \\
FeCu600/1 & 7.3 & 289 & 6.9 & 261 & $2.1 \times 10^{7}$ \\
FeCu800/1 & 4.4 & 458 & 5.8 & 284 & $2.7 \times 10^{7}$ \\
\hline
\end{tabular}



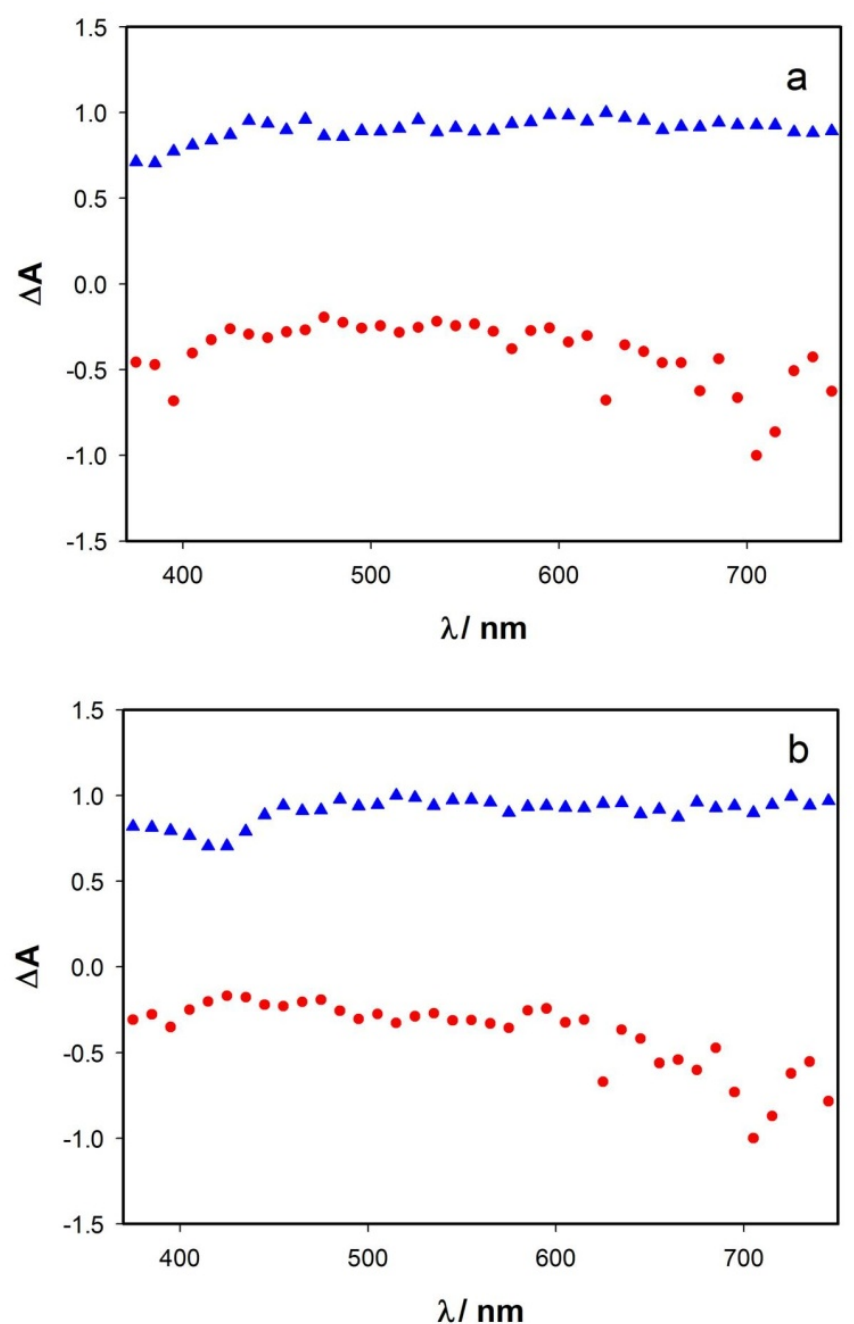

Fig. 3.2.4: Normalized DADs of the species obtained from the analysis with the Glotaran software of LFP experiments performed with $2.5 \mathrm{gL}^{-1} \mathrm{FeCu} 400 / 1$ : (a) in the absence of $\mathrm{KSCN}$ and (b) in the presence of 0.05 $\mathrm{M}$ of KSCN. Red and blue symbols show the absorption spectra of the species with shorter and longer lifetime, respectively. 


\section{LFP experiments performed in the presence of hole and electron scavengers}

The results obtained in the presence of $0.05 \mathrm{M} \mathrm{KSCN}$ are like those obtained in its absence. For the experiments performed with FeCu400/1, Fig. 3.2.2 shows the spectra taken at different times after the laser shot and Fig. 3.2.4 shows the DADs obtained from the global analysis of the experiments with the Glotaran software. Fig. 3.2.5 shows the DADs obtained for FeCu600/1 and FeCu800/1 in the presence of KSCN, which are coincident with those without KSCN (not shown).
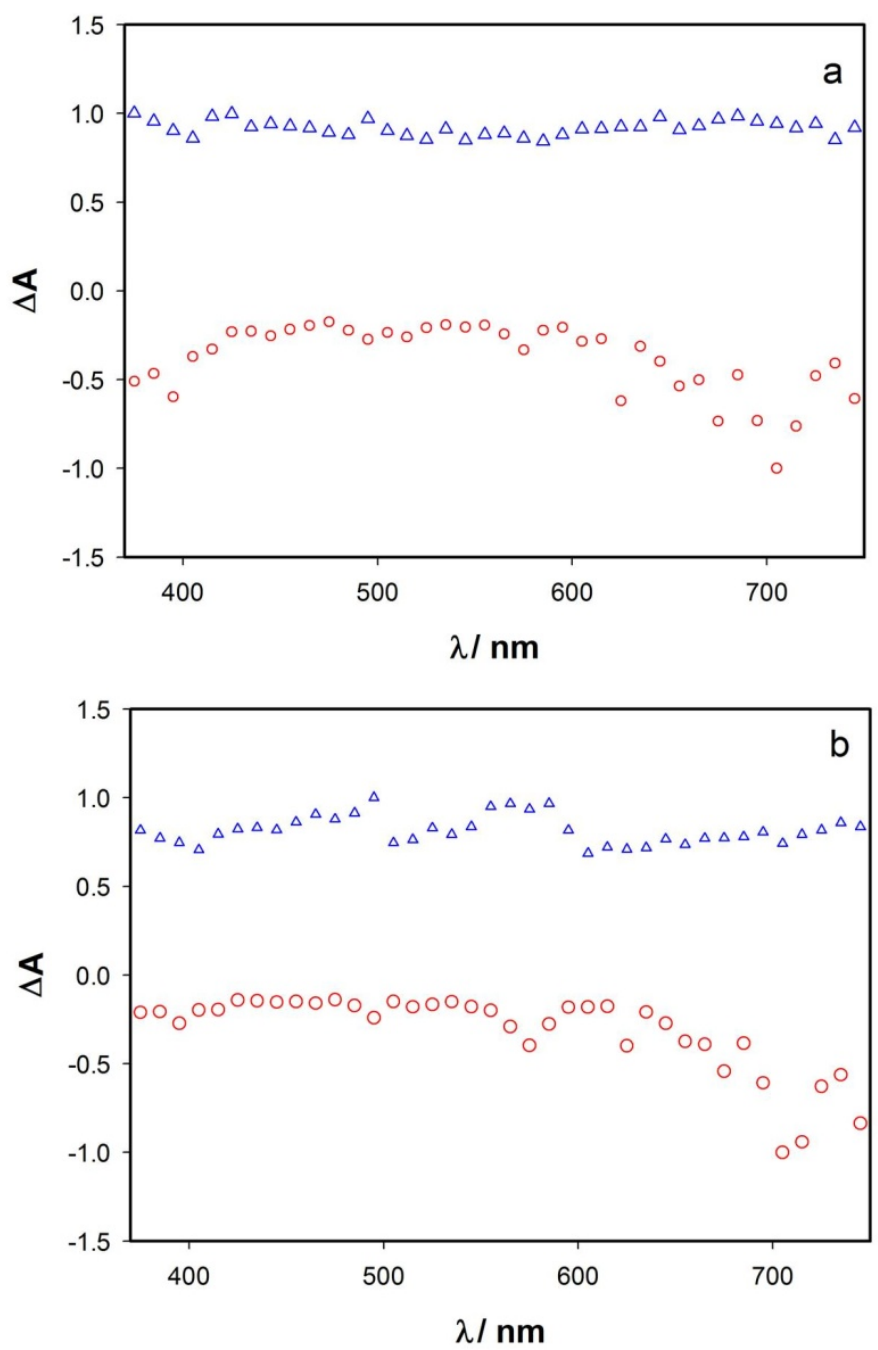

Fig. 3.2.5: Normalized DADs of the species obtained from the analysis with the Glotaran program of LFP experiments performed with $0.05 \mathrm{M} \mathrm{KSCN}$ and $2.5 \mathrm{gL}^{-1}$ of: (a) FeCu600/1 and (b) FeCu800/1. Red and blue symbols show the absorption spectra of the species with shorter and longer lifetime, respectively. 
For samples FeCu400/1, FeCu600/1 and FeCu800/1 the decay of the second species obtained from the program is faster in the presence of KSCN. Table 3.6 also shows the corresponding quenching constants $\mathrm{k}_{\mathrm{q}}$. They are all similar and are well below the diffusion-controlled limit. It is noteworthy that although there is an acceleration of the absorption decay of the charge-separated states of electron and holes located in different traps, this absorption precludes the observation of the typical band of the dithiocyanate radical anions $\left(\lambda^{\max }=475 \mathrm{~nm}\right)$, which are expected to be formed by reactions $(1)$ and (2)(Caregnatoet al., 2005).

$$
\begin{aligned}
& \text { Trapped } \mathrm{h}^{+}+\mathrm{SCN}^{-} \rightarrow \mathrm{SCN}^{-} \\
& \mathrm{SCN}^{-}+\mathrm{SCN}^{-} \leftrightarrows(\mathrm{SCN})_{2}^{--}
\end{aligned}
$$

Similar results are reported by Bahnemann et al. (Bahnemann et al., 2005). They used nanosecond flash photolysis to study hole scavenging by thiocyanate and dichloroacetate and concluded that some holes react with the adsorbed hole scavengers promptly within the duration of the laser pulse, and others react more slowly. Ultrafast pump-probe spectroscopy studies ((Cavaleri et al., 1998, D. Colombo et al., 1995 and D. P. Colombo \& Bowman, 1995)) suggest that for thiocyanate, this prompt reaction occurs on the femtosecond time scale; some holes react more slowly, and some holes do not react at all, at any concentration of the hole scavenger. Thus, the quenching observed here (Table 3.6) can be assigned to the holes reacting slowly with thiocyanate ions.

In order to achieve accumulation of electrons, 4:1 mixtures of acetonitrile and triethanolamine (TEOA) were employed as the solvent (Pellegrin \& Odobel, 2016; Rodríguez et al., 2017). Under these conditions, TEOA scavenges the holes according to reaction 3:

$$
\text { Trapped } \mathrm{h}^{+}+\text {TEOA } \rightarrow \text { TEOA }^{+}
$$

Fig. 3.2.6 shows the spectra taken immediately after the laser shot with Ar-saturated samples of FeCu400/1, FeCu600/1 and FeCu800/1 in 4:1 acetonitrile:TEOA. 
The spectra show that the intensity of the transient absorption in the longer wavelength region (> ca. $600 \mathrm{~nm}$, related to the absorption of the electrons) observed immediately after laser excitation is larger than that in the shorter wavelength region due to trapped holes. The same observation was done by Uchihara et al. (Uchihara et al., 1998) for transient spectra obtained in acetonitrile upon excitation of samples of CdS quantum dots modified with thiol groups, which act as hole scavengers.

The intensity of the absorbance immediately after the laser shot follows the trend $\mathrm{FeCu} 400 / 1>\mathrm{FeCu} 600 / 1>\mathrm{FeCu} 800 / 1$. This means that more electrons are detected for the samples treated at lower temperature.

An independent series of experiments was performed in a reduced wavelength interval of analysis ( $\lambda \geq 600 \mathrm{~nm}$ ), where the contributions of electrons to the absorption trace should be prevalent. For these samples the Glotaran program yielded only one component with lifetimes 220 ns, 138 ns, and 269 ns, for FeCu400/1, FeCu600/1 and FeCu800/1, respectively. The same trend as shown in Fig. 3.2.5 is observed for the spectra retrieved from the Glotaran program (see part b). These results should be indicative of a decrease of the semiconductor performance of the nanomaterials with increasing pyrolysis temperature. 

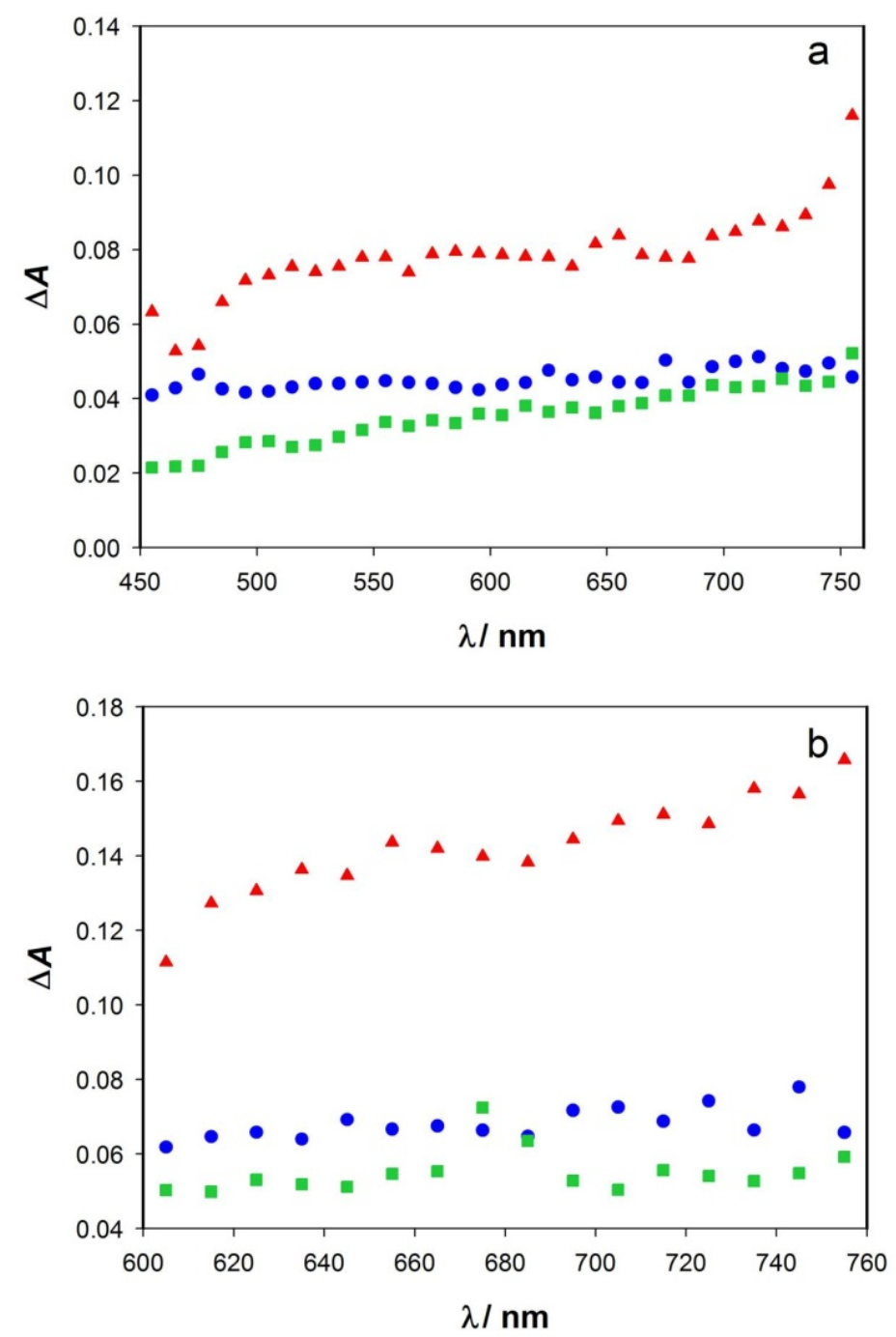

Fig. 3.2.6: a) Absorption spectra of Ar-saturated $0.25 \mathrm{gL}^{-1}$ suspensions of FeCu400/1 (red), FeCu600/1 (blue), and FeCu800/1 (green) in 4:1 acetonitrile: TEOA. b) DADs of the only species obtained from the analysis with the Glotaran program of LFP experiments obtained in a reduced wavelength region with Ar-saturated 2.5 $\mathrm{gL}^{-1}$ suspensions of FeCu400/1 (red), FeCu600/1 (blue), and FeCu800/1 (green) in 4:1 acetonitrile: TEOA.

All the experiments performed in Ar-saturated acetonitrile:TEOA samples seem to show a higher contribution of the trapped electrons on the surface of the nanomaterials. Thus, in order to verify this hypothesis, experiments were done in the presence of $\mathrm{MV}^{2+}$ as electron scavenger. LFP experiments were performed with $0.25 \mathrm{gL}^{-1} \mathrm{FeCu} 400 / 1$ sample in the absence and presence of $0.19 \mathrm{mM} \mathrm{MV}^{2+}$. The contribution of the two absorbance 
components obtained from the Glotaran program are shown in Fig. 3.2.7. The shorter lifetime (177 ns) was independent of the presence of $\mathrm{MV}^{2+}$. The longer lifetime which has a lesser contribution to the signals (less than 10\%) was about $6 \mu$ s in both cases.
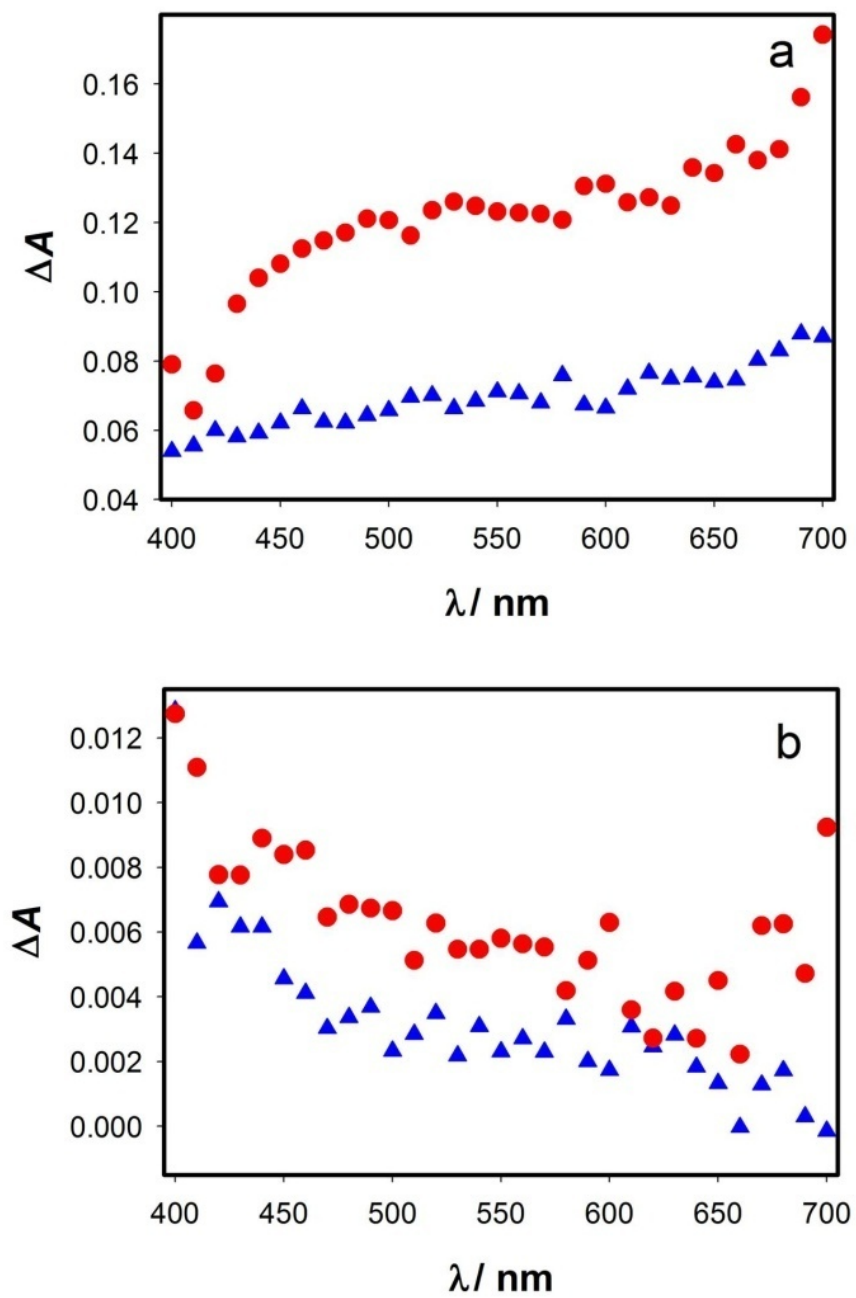

Fig. 3.2.7: a) DADs of the first component obtained from the analysis with the Glotaran program of LFP experiments obtained with Ar-saturated $0.25 \mathrm{gL}^{-1}$ suspensions of FeCu400/1 in the absence (red) and presence of $0.19 \mathrm{mM} \mathrm{MV}^{2+}$ (blue) in 4:1 acetonitrile: TEOA. b) DADs of the second component of the same experiments shown in (a). 
From Fig. 3.2.7-a, it can be seen that there is a fast quenching taking place at times shorter than the laser pulse of the trapped electrons by $\mathrm{MV}^{2+}$ according to reaction (4):

$$
\text { Trapped } \mathrm{e}^{-}+\mathrm{MV}^{2+} \rightarrow \mathrm{MV}^{\cdot}
$$

The constant decay of both components indicates the non-occurrence of slower quenching events. The reason for this behavior could be related to the adsorption of $\mathrm{MV}^{2+}$ on the surface of the nanomaterial.

Similar experiments were performed in mixtures of 4:1 acetonitrile:trimethylamine (TEA) and the results are shown in Fig. 3.2.8. In this case $\mathrm{MV}^{2+}$ and oxygen were used as electron scavengers. Oxygen can react with trapped electrons as shown in reaction (5):

$$
\text { Trapped } \mathrm{e}^{-}+\mathrm{O}_{2} \rightarrow \mathrm{O}_{2}^{--}
$$

From the data shown in Fig. 3.2.8 we can conclude that $\mathrm{MV}^{2+}$ quenches more favorably the trapped electrons than oxygen because the amplitude of the first component decreases more in the presence of $\mathrm{MV}^{2+}$ when the samples are saturated with Ar. This could be unexpected because: i) the redox potential of the $\mathrm{MV}^{2+} / \mathrm{MV}^{+}$couple is $-0.45 \mathrm{~V}$ vs. NHE (Gårdfeldt\& Jonsson, 2003), whereas that of the $\mathrm{O}_{2} / \mathrm{O}_{2}^{--}$is $1.23 \mathrm{~V}$ and ii) the concentration of $\mathrm{MV}^{2+}$ employed here is lower than that of oxygen in air-saturated solutions of acetonitrile (1.7 mM) (Wadhawanet al., 2003). This observation makes us suspect again that $\mathrm{MV}^{2+}$ is adsorbed on the surface of the nanomaterial. 

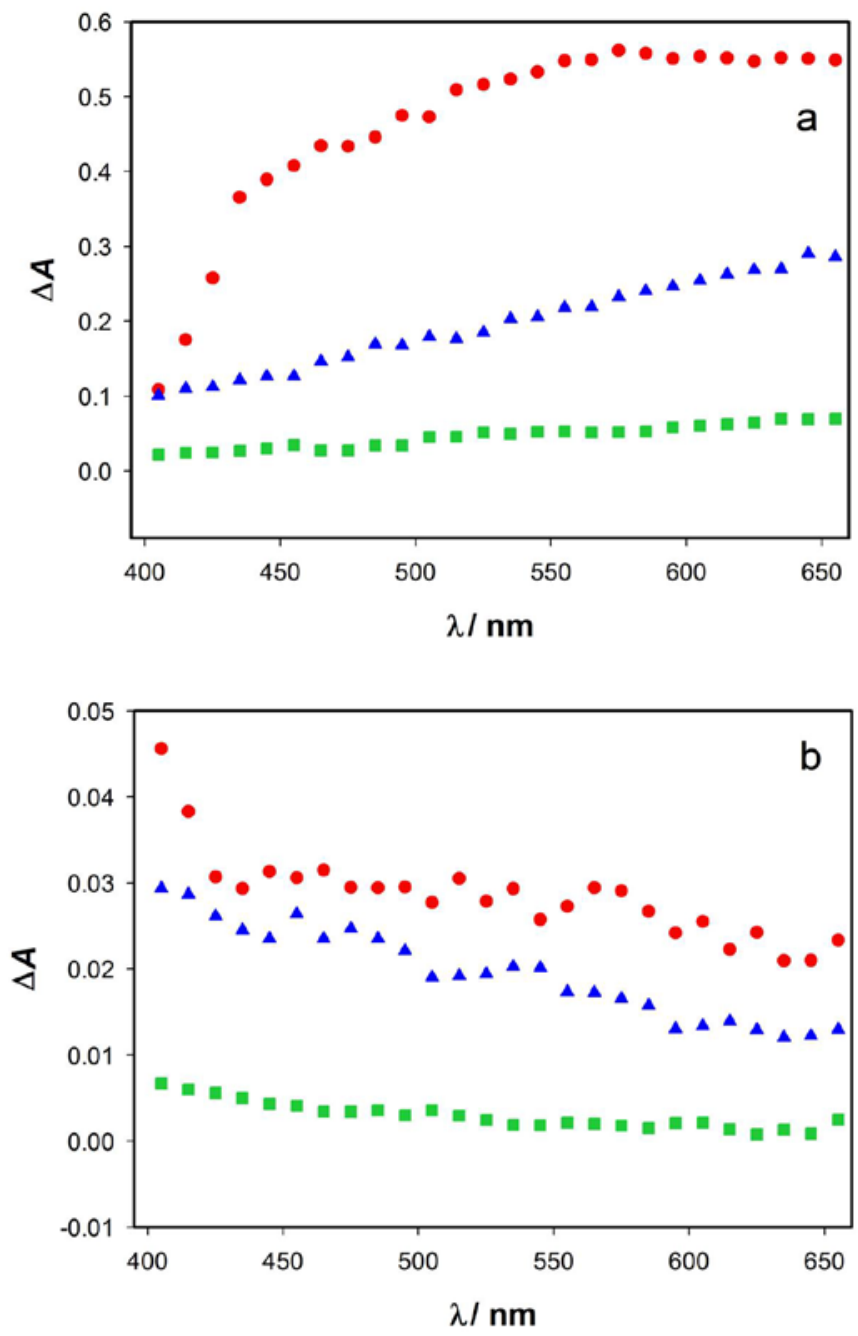

Fig. 3.2.8: a) DADs of the first component obtained from the analysis with the Glotaran software of LFP experiments obtained with $0.17 \mathrm{gL}^{-1}$ suspensions of FeCu400/1 in 4:1 acetonitrile:TEA in the absence of $\mathrm{MV}^{2+}$ under Ar-saturation (red), in the presence of $0.13 \mathrm{mM} \mathrm{MV}^{2+}$ under air-saturation (blue), in the presence of $0.13 \mathrm{mM} \mathrm{MV}^{2+}$ under Ar-saturation (green). b) DADs of the second component of the same experiments. 



\section{Electronic Paramagnetic Resonance}

By transient absorption spectroscopy we were able to characterize the absorption of the charge-separated electron and holes. Now, with EPR spectroscopy we try to detect the generation of hydroxyl radicals upon irradiation of suspensions of the nanomaterials with a solar simulator.

All EPR spectra were collected under the same experimental conditions, thus it is possible to compare the relative $\mathrm{OH}$ production by analyzing the intensity of the signals. All spectra show the typical signal of DMPO-OH spin adduct (a 1:2:2:1 quartet, with a 14.8 $\mathrm{G}$ hyperfine splitting constant). From the intensity of the signal, it is possible to estimate the number of trapped radicals. Due to the overall poor signal/noise ratio, for quantitative analysis the line showing the highest signal/noise ratio at 3470 Gauss was chosen as the analytical tool.

The direct correlation between the EPR signal intensities of the DMPO-OH and the ability of each material to generate hydroxyl radicals upon photoexcitation requires the same fraction of light absorbed by all the samples. The nanomaterials employed for the EPR assays were FeCu400/1, FeCu400/3, FeCu400/5, FeCu600/1, FeCu800/1, FeCo600/1 and FeNi600/1. The concentration of all samples was $500 \mathrm{mg} \cdot \mathrm{L}^{-1}$ and the irradiation source was a solar simulator provided with a $340 \mathrm{~nm}$ cut-off filter. The fraction of absorbed light by the samples was calculated according to the Eq.3.1:

$$
f=\frac{\sum_{i} p_{i}\left(1-10^{-A_{i}}\right)}{\sum_{i} p_{i}}
$$

where the subscript $i$ refers to small wavelength intervals. The summation was performed all over the emission range of the source $(340-800 \mathrm{~nm}) ; p_{i}$ is the probability of photonic 
emission of the simulator with the $340 \mathrm{~nm}$ cut-off filter and $A_{i}$ is the absorbance of the sample ${ }^{2}$. The values for all the samples are depicted in Table 3.11.

Table 3.11: Fraction of absorbed light of the aqueous solutions employed for the EPR assays

\begin{tabular}{c|c}
\hline Sample & $f$ \\
\hline FeCu400/1 & 0.47 \\
FeCu400/3 & 0.43 \\
FeCu400/5 & 0.55 \\
\hline FeCu600/1 & 0.49 \\
FeCu800/1 & 0.46 \\
\hline
\end{tabular}

Among the materials obtained by the treatment at $400{ }^{\circ} \mathrm{C}$, the sample FeCu400/1 has the lowest amount of organic matter (as shown in the previous section). This can explain the higher intensity of the EPR signal for this nanocomposite (Fig. 3.45), since the reaction between $\mathrm{OH}^{*}$ radical with the organic matter leads to lower amount of radical species able to react with the spin trap. This behavior was previously reported by increasing the concentration of a similar type of BBS (Bianco Prevot et al., 2011). FeCu400/1 and FeCu400/3 samples have very similar values of $f$, whereas the FeCu400/5 sample shows a slightly higher value, in line with the expected higher content of organic matter in this sample.

The values of $f$ for samples FeCu400/1, FeCu600/1 and FeCu800/1 are quite similar, and thus the intensity of the EPR signal of the adduct should reflect the ability of the nanomaterial to generate hydroxyl radicals. Fig. 3.2.10 shows the EPR spectra of materials FeCu400/1, FeCu600/1 and FeCu800/1. From these measurements it is appreciable the fact that the sample FeCu800/1 has the higher production of $\mathrm{OH}$ radical, almost twice as FeCu400/1 and FeCu600/1. On the other hand, the transient absorption spectra obtained in the LFP experiments under conditions of electrons accumulation show

\footnotetext{
${ }^{2}$ The value of Absorbance was obtained by measuring the Transmission spectra of the suspensions, with the integrating sphere accessory (data not shown).
} 
that absorption intensity in the longer wavelength region characteristic of the absorption of the electrons follow the opposite trend: FeCu400/1>FeCu600/1>FeCu800/1. This behavior can be explained by the well-known diffusion-controlled scavenging of solvated electrons by hydroxyl radicals (Elliot \& Ouehette, 1994). 

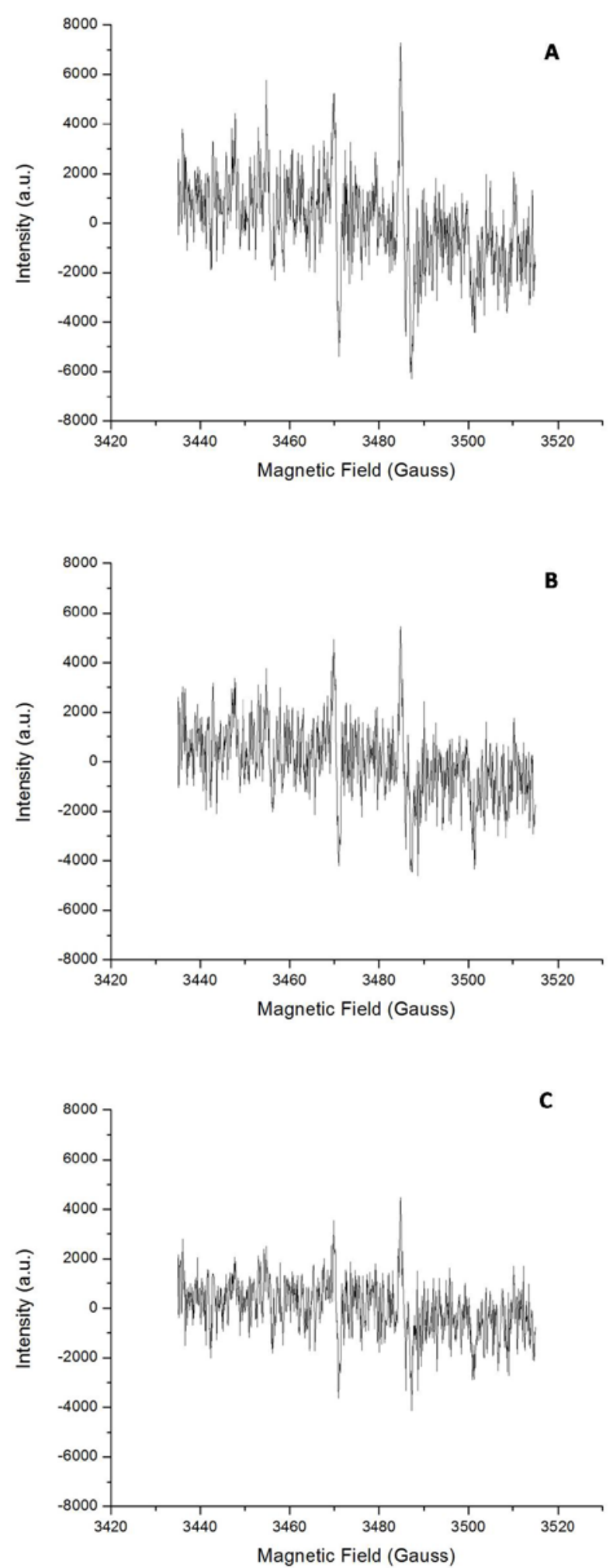

Fig. 3.2.9: EPR spectra for materials FeCu400/1 (A), FeCu400/3 (B) and FeCu400/5 (C) with a filter of $340 \mathrm{~nm}$. 

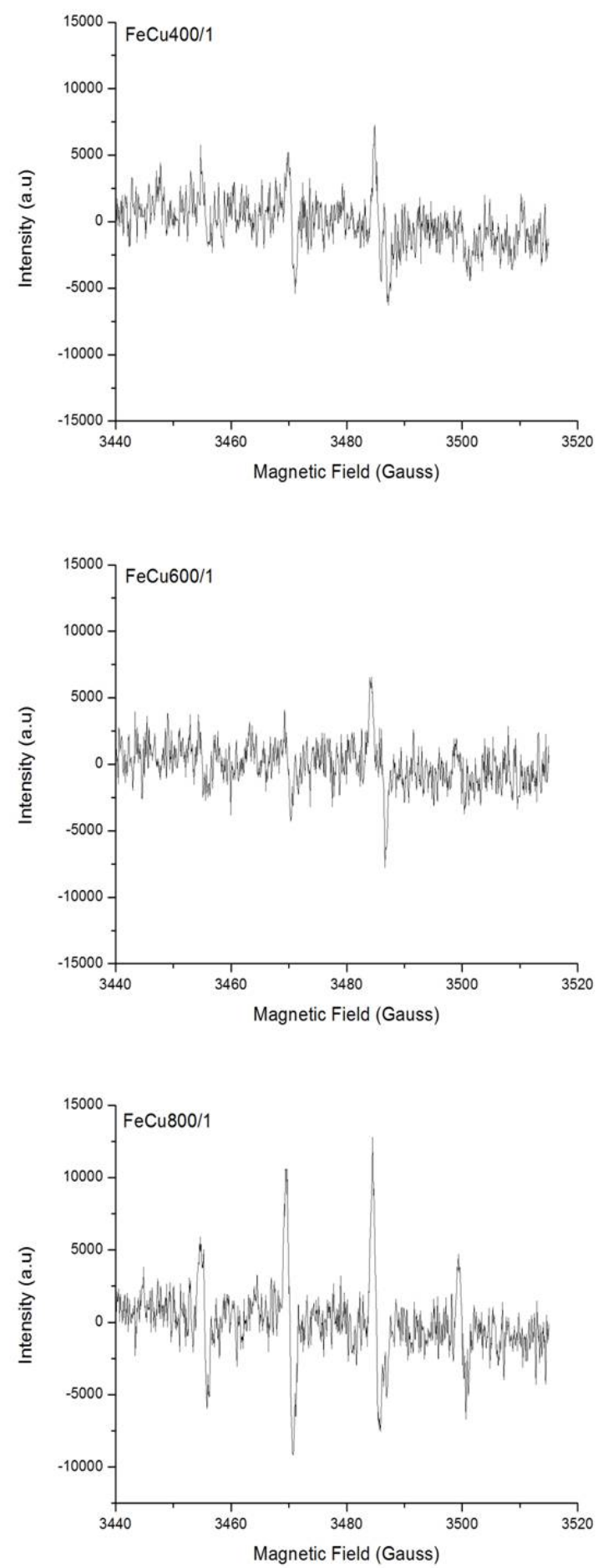

Fig. 3.2.10: EPR spectra of the hydroxyl adduct obtained upon irradiation of FeCu400/1, FeCu600/1, and FeCu800/1 samples with a solar simulator employing a $340 \mathrm{~nm}$ cut-off filter (spectrum of material $\mathrm{FeCu} 400 / 1$ is shown again for comparative purposes). 
For FeCo600/1 and FeNi600/1 the obtained spectra are shown in Fig. 3.2.11. In this case, no signals could be detected employing the same irradiation conditions as for the other samples (with the solar simulator and the $340 \mathrm{~nm}$ cut-off filter). This means that the amount of hydroxyl radical produced upon irradiation of FeCo600/1 and FeNi600/1 is lower than for the other samples.
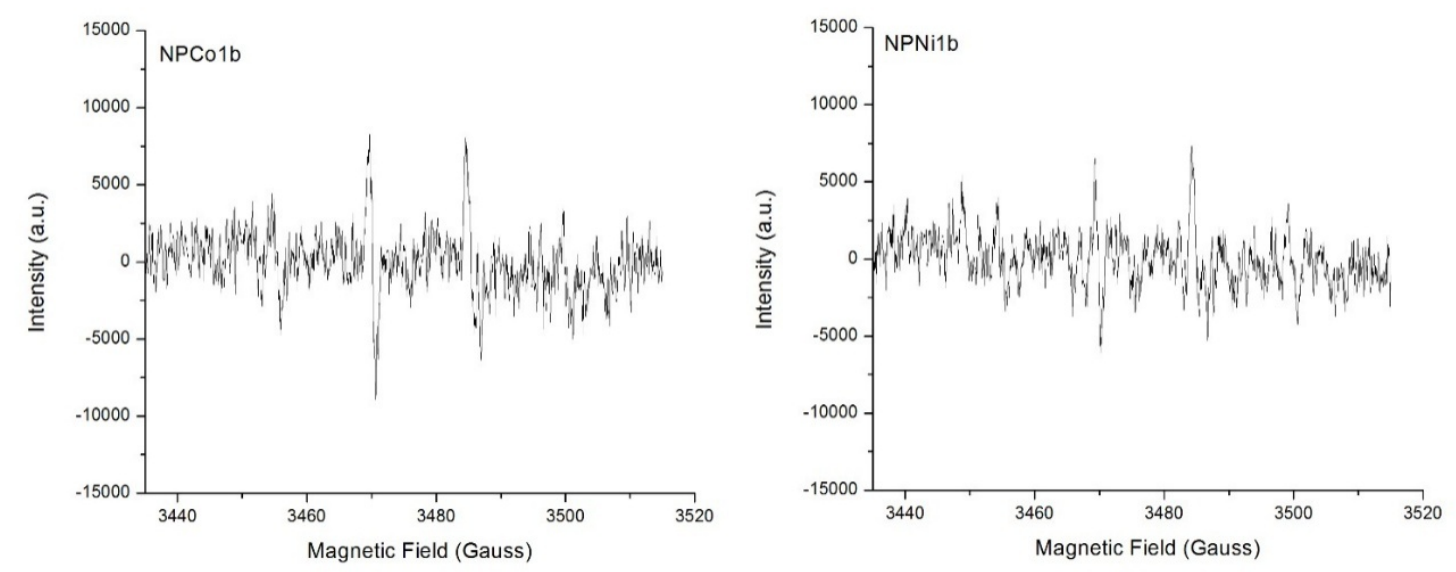

Fig. 3.2.11: EPR spectra of the hydroxyl adduct obtained upon irradiation of FeCo600/1 and FeNi600/1 samples with a solar simulator employing a $310 \mathrm{~nm}$ cut-off filter. 


\section{Conclusions}

By transient absorption spectroscopy we were able to show that: i) upon irradiation at $355 \mathrm{~nm}$, charge-separated electron and holes are formed; ii) both the electron and holes can be scavenged with appropriate substrates, and iii) according to experiments performed employing scavengers for the transient in the longer wavelength region (characteristic of the electrons) a decrease with the treatment temperature, i.e., $\mathrm{FeCu} 400 / 1$ > FeCu600/1 > FeCu800/1 was found.

The intensities of EPR signals of the DMPO-OH spin adduct obtained upon irradiation of the samples with a solar simulator employing a $340 \mathrm{~nm}$ cut-off filter follow the trend FeCu400/1 < FeCu600/1 < FeCu800/1, which can be explained by the higher content of organic matter contained in the samples treated at lower temperature and the ability of the organic matter to react with the hydroxyl radicals. Among the materials obtained at $400{ }^{\circ} \mathrm{C}$, the same trend is followed: the sample FeCu400/5 having the largest amount of organic matter yield the lowest EPR signal, whereas FeCu400/1 has the highest one. Samples FeCo600/1 and FeNi600/1 produced smaller amounts of hydroxyl radicals than the others. 



\subsection{Appendix: Preparation and characterization of auxiliary materials}

Both hematite and magnetite were prepared using a general-purpose autoclave made of stainless steel, provided with a Teflon liner of $100 \mathrm{~mL}$ capacity. For obtaining $\mathrm{Fe}_{3} \mathrm{O}_{4}$ (Deng et al., 2015), $\mathrm{FeCl}_{3}(0.0083 \mathrm{~mol}$ ) and sodium acetate trihydrate (0.0439 mole) were dissolved in $50 \mathrm{~mL}$ of etilenglycol. The mixture was placed in the reactor and kept at $200{ }^{\circ} \mathrm{C}$ for $8 \mathrm{~h}$. After cooling to RT, the black precipitate was washed with EtOH: $\mathrm{H}_{2} \mathrm{O}(4: 1)$ and dried in oven at $60^{\circ} \mathrm{C}$ until constant weight.

For the $\alpha-\mathrm{Fe}_{2} \mathrm{O}_{3}$ preparation, a modification of the method published by Keerthana et al. was used. (Keerthana et al., 2015). Briefly, ammonium hydroxide (28 \%) was added in drops to $10 \mathrm{~mL}$ of aqueous solution of anhydrous $\mathrm{FeCl}_{3}(0.8 \mathrm{M})$, until pH 9 was reached and then the mixture was stirred for $10 \mathrm{~min}$ at RT. The resulting $\mathrm{Fe}(\mathrm{OH})_{3}$ was formed as a reddish brown precipitate, which was then washed in de-ionized water repeatedly to remove excess ions until pH 7 was reached. Then, $10 \mathrm{~mL}$ of BBS solution $(0.45 \% \mathrm{w} / \mathrm{w})$ was added to the precipitate, and a final volume of $30 \mathrm{~mL}$ was reached by adding de-ionized water. The reactor was kept at $200{ }^{\circ} \mathrm{C}$ for $10 \mathrm{~h}$, to yield hematite as an orange precipitated. Both solids were characterized by XRD (Fig. 3.3.1). No contamination of other crystalline phases were observed, as can be seen by the perfect coincidence of the experimental diffraction patterns (Fig. 3.3.1, part A) with those of the references (stick patterns in part B). Moreover, no rests of the organic reducing agents used in each case (i.e. sodium acetate in magnetite and BBS in hematite synthesis) were found, as can be seen from their FT-IR spectra in Fig. 3.3.2. Highlighted bands are assigned to the stretching and bending vibrations of the hydroxyl groups and/or water molecules (broad band centered at $3430 \mathrm{~cm}^{-1}$ and sharper band at $1570 \mathrm{~cm}^{-1}$, respectively), according to Lassoued et al. (Lassoued et al., 2017). These bands could indicate the presence of not only a small amount of adsorbed water on the surface of the product, but also structural hydroxyl groups on the same surface, since the products were prepared in aqueous 
solution. In addition, there is a band at $1437 \mathrm{~cm}^{-1}$ that is assigned to the deformation of $\mathrm{CH}_{3}$, presumably due to remaining of organic moieties.
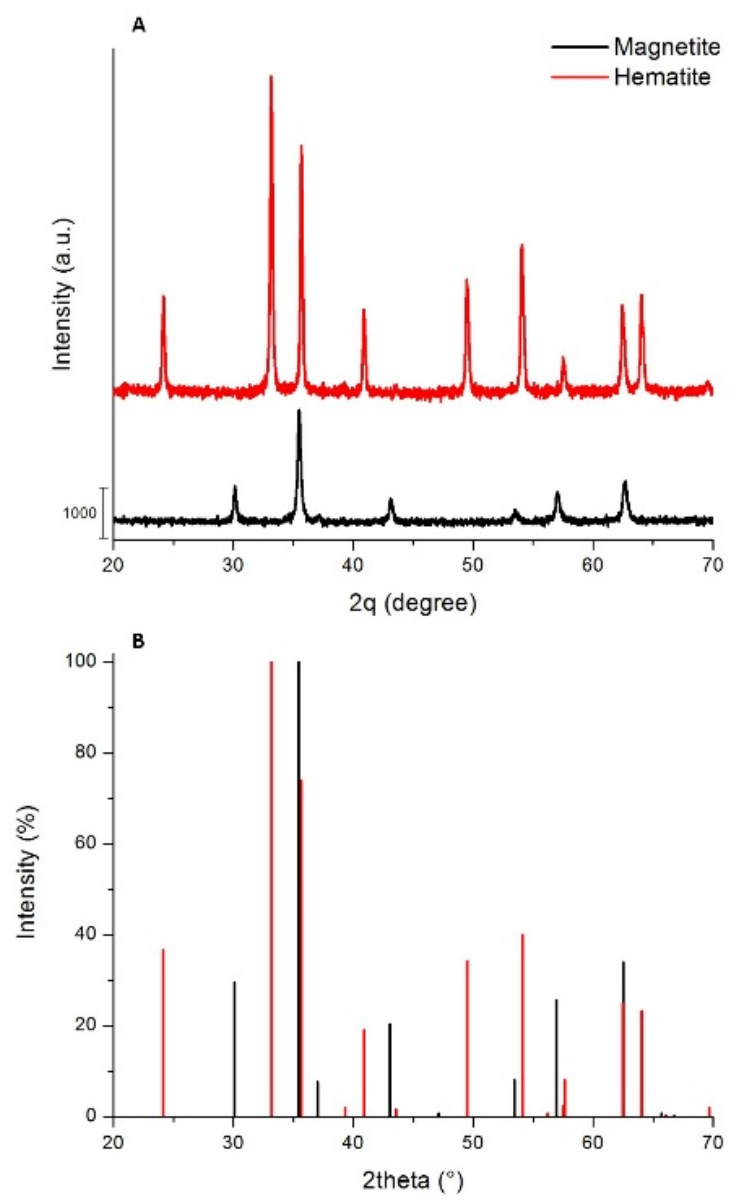

Fig. 3.3.1: XRD patterns of magnetite and hematite prepared by hydrothermal method (A). Stick patterns of magnetite (black, ICCD card number 01-076-1849), and hematite (red, ICCD card number 01-073-2234) (B). 


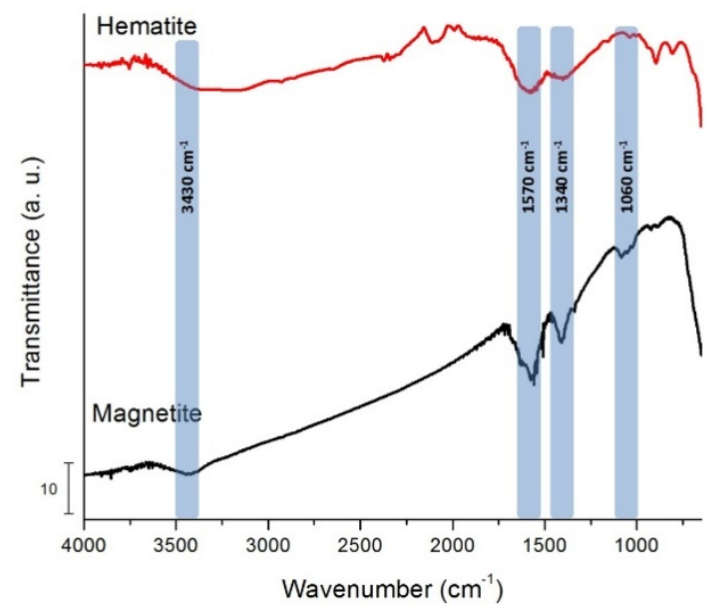

Fig. 3.3.2: FT-IR spectra of bare magnetite and hematite

Reduced graphene oxide $(\mathrm{rGO})$ was prepared by a chemical reduction of graphene oxide (GO) with hydrazine; whereas $\mathrm{GO}$ was prepared by a modification of the Hummer's method (Hummers, 1958): $4 \mathrm{~g}$ of powdered graphite and $2 \mathrm{~g}$ of $\mathrm{NaNO}_{3}$ were placed into a $500 \mathrm{~mL}$ flask and $100 \mathrm{~mL}$ of fuming $\mathrm{H}_{2} \mathrm{SO}_{4}(98 \%)$ was added, while keeping the flask into an ice-bath and with constant magnetic stirring. Then, $12 \mathrm{~g}$ of $\mathrm{KMnO}_{4}$ were slowly added; once a homogeneous mixture was obtained, the ice bath was removed, and the flask was heated to $30^{\circ} \mathrm{C}$ for $20 \mathrm{~min}$. Then, $180 \mathrm{~mL}$ of deionized water was slowly added, and the temperature increased to $90{ }^{\circ} \mathrm{C}$, for $20 \mathrm{~min}$; after that, $120 \mathrm{~mL}$ of $3 \% \mathrm{H}_{2} \mathrm{O}_{2}$ were added. The water bath was removed, and the reaction mixture was cooled to RT. The isolation was carried out by centrifugation at $4000 \mathrm{rpm}$ for 15 minutes. The supernatant was discarded, and this process was repeated three more times, until $\mathrm{pH}>2$. The black precipitate was transferred to a Petri dish and allowed to dry at room temperature for 5 days. For the chemical reduction with hydrazine (Fenget al., 2014), $100 \mathrm{~mL}$ of aqueous solution $\left(1.2 \mathrm{~g} \cdot \mathrm{L}^{-1}\right)$ of the as obtained $\mathrm{GO}$ was placed into a $250 \mathrm{~mL}$ round flask. $117.6 \mu \mathrm{L}$ of $80 \%$ hydrazine solution was added, (weight ratio $\mathrm{GO} / \mathrm{N}_{2} \mathrm{H}_{4}=0.624$ ). A reflux condenser was attached, and the solution was heated to $95^{\circ} \mathrm{C}$ and this temperature was kept for 30 minutes. After that, the mixture was cooled to RT and then filtered, washing three times 
with $\mathrm{MeOH}$. The product was transferred to a Petri dish and allowed to dry at RT until constant weight.

In Fig. 3.3.3, part A, the FT-IR spectra of GO and $\mathrm{rGO}$ are shown. The FT-IR spectrum of GO, because of its oxidation degree, shows a strong and broad $\mathrm{O}-\mathrm{H}$ stretching vibration band at $3400 \mathrm{~cm}^{-1}$, carboxyl C-O stretching band at $1720 \mathrm{~cm}^{-1}, \mathrm{O}-\mathrm{H}$ deformation vibration band at $1404 \mathrm{~cm}^{-1}$, ester carbonyl vibration band at $1225 \mathrm{~cm}^{-1}$ and C-O stretching vibration at $1035 \mathrm{~cm}^{-1}$. As expected, due to the reduction reaction by hydrazine hydrate, these characteristic bands of GO are relatively weaker or completely removed in the FT-IR spectrum of rGO. These results indicate that $r G O$ was successfully obtained after reduction reaction. Bands at $2920-2850 \mathrm{~cm}^{-1}$ corresponding to $\mathrm{C}-\mathrm{H}$ stretching vibration and at $1580 \mathrm{~cm}^{-1}$ assigned to aromatic $\mathrm{C}=\mathrm{C}$ stretching vibrations are also observed (Çiplaket al., 2015). 


\subsection{References}

Applin, D. M., Izawa, M. R. M., Cloutis, E. A., Gillis-Davis, J. J., Pitman, K. M., Roush, T. L., ... Lucey, P. G. (2018). Ultraviolet spectral reflectance of carbonaceous materials. Icarus, 307, 40-82. https://doi.org/10.1016/j.icarus.2018.02.012

Bahnemann, D., Henglein, A., Lilie, J., \& Spanhel, L. (2005). Flash photolysis observation of the absorption spectra of trapped positive holes and electrons in colloidal titanium dioxide. The Journal of Physical Chemistry, 88(4), 709-711. https://doi.org/10.1021/j150648a018

Baldoví, H. G., Ferrer, B., Álvaro, M., \& García, H. (2014). Microsecond transient absorption spectra of suspended semiconducting metal oxide nanoparticles. Journal of Physical Chemistry C, 118(17), 9275-9282. https://doi.org/10.1021/jp5018345

Ballesteros, S. G., Costante, M., Vicente, R., Mora, M., Amat, A. M., Arques, A., ... Einschlag, F. S. G. (2017). Humic-like substances from urban waste as auxiliaries for photo-Fenton treatment: a fluorescence EEM-PARAFAC study. Photochemical and Photobiological Sciences, 16(1), 38-45. https://doi.org/10.1039/c6pp00236f

Beydoun, D., Amal, R., Low, G. K.-C., \& McEvoy, S. (2002). Novel Photocatalyst: TitaniaCoated Magnetite. Activity and Photodissolution. The Journal of Physical Chemistry B, 104(18), 4387-4396. https://doi.org/10.1021/jp992088c

Bianco Prevot, A., Avetta, P., Fabbri, D., Laurenti, E., Marchis, T., Perrone, D. G., Boffa, V. (2011). Waste-derived bioorganic substances for light-induced generation of reactive oxygenated species. ChemSusChem, 4(1), 85-90.

https://doi.org/10.1002/cssc.201000237

Brewer, A. S., \& Arnold, M. S. (2014). Field-effect measurements of mobility and carrier concentration of $\mathrm{Cu} 2 \mathrm{~S}$ colloidal quantum dot thin films after ligand exchange. Thin Solid Films, 567, 91-95. https://doi.org/10.1016/j.tsf.2014.07.015

Caregnato, P., Bertolotti, S. G., Gonzalez, M. C., \& Mártire, D. O. (2005). Water/Silica Nanoparticle Interfacial Kinetics of Sulfate, Hydrogen Phosphate, and Dithiocyanate $\begin{array}{llll}\text { Radicals. } & \text { Photochemistry and Photobiology, } & \end{array}$ 
https://doi.org/10.1562/2005-07-07-ra-603

Cavaleri, J. J., Colombo, D. P., \& Bowman, R. M. (1998). Ultrafast Charge Carrier Dynamics of SnO 2 Nanoclusters: A Refined Interpretation of the. J. Phys. Chem. B, 102(8), 1341-1346.

Cesano, F., Fenoglio, G., Carlos, L., \& Nisticò, R. (2015). One-step synthesis of magnetic chitosan polymer composite films. Applied Surface Science, 345, 175-181. https://doi.org/10.1016/j.apsusc.2015.03.154

Cheng, M. Y., \& Hwang, B. J. (2009). Control of uniform nanostructured alpha-Ni(OH)2 with self-assembly sodium dodecyl sulfate templates. Journal of Colloid and Interface Science, 337(1), 265-271. https://doi.org/10.1016/j.jcis.2009.05.008

Çiplak, Z., Yildiz, N., \& Cąlimli, A. (2015). Investigation of graphene/Ag nanocomposites synthesis parameters for two different synthesis methods. Fullerenes Nanotubes and Carbon Nanostructures, 23(4), 361-370. https://doi.org/10.1080/1536383X.2014.894025

Colombo, D. P., \& Bowman, R. (1995). Femtosecond Diffuse Reflectance Spectroscopy Of Tio2 Powders. Journal of Physical Chemistry, 99(30), 11752-11756.

Colombo, D., Roussel, K., Saeh, J., Skinner, Jj, C., \& Rm, B. (1995). Femtosecond Study Of the Intensity Dependence Of Electron Hole Dynamics In Tio2 Nanoclusters. Chemical Physics Letters, 232(3), 207-214.

Cornell, R. M., \& Schwertmann, U. (2003). The iron oxides. The iron oxides (2nd ed.). wileyVCH Verlag GmbH \& Co. KGaA, Weinheim. https://doi.org/10.4324/9780203221815

Cornell, R. M., \& Schwertmann, U. (2017). The iron oxides. The iron oxides. https://doi.org/10.4324/9780203221815

Deng, Y., Qi, D., Deng, C., Zhang, X., \& Zhao, D. (2015). Adsorption of bovine serum albumin on superparamagnetic composite microspheres with a $\mathrm{Fe} 3 \mathrm{O} 4$ / $\mathrm{SiO} 2$ core and mesoporous SiO 2 shell. RSC Advances, 5(126), 103760-103766. https://doi.org/10.1039/c5ra21773c

Elliot, A. J., \& Ouehette, D. C. (1994). Temperature dependence of the rate constant for the reaction e aq- $+\mathrm{OH}$ in water up to $150^{\circ} \mathrm{C}$. J. Chem Soc. Faraday Trans., 90(6), 837- 
841.

Farhadi, S., \& Siadatnasab, F. (2016). Copper(I) sulfide (Cu2S) nanoparticles from Cu(II) diethyldithiocarbamate: Synthesis, characterization and its application in ultrasoundassisted catalytic degradation of organic dye pollutants. Materials Research Bulletin, 83(I), 345-353. https://doi.org/10.1016/j.materresbull.2016.06.030

Feng, Y., Zhao, J., Yan, X., Tang, F., \& Xue, Q. (2014). Enhancement in the fluorescence of graphene quantum dots by hydrazine hydrate reduction. Carbon, 66, 334-339. https://doi.org/10.1016/j.carbon.2013.09.008

Fuentes, M., Olaetxea, M., Baigorri, R., Zamarreño, A. M., Etienne, P., Laîné, P., ... GarciaMina, J. M. (2013). Main binding sites involved in Fe(III) and $\mathrm{Cu}(\mathrm{II})$ complexation in humic-based structures. Journal of Geochemical Exploration, 129, 14-17. https://doi.org/10.1016/j.gexplo.2012.12.015

Gårdfeldt, K., \& Jonsson, M. (2003). Is bimolecular reduction of $\mathrm{Hg}(\mathrm{II})$ complexes possible in aqueous systems of environmental importance. Journal of Physical Chemistry A. https://doi.org/10.1021/jp0275342

Han, R., Li, W., Pan, W., Zhu, M., Zhou, D., \& Li, F. S. (2014). 1D magnetic materials of Fe304 and Fe with high performance of microwave absorption fabricated by electrospinning method. Nature Scientific Reports, 4, 7493. https://doi.org/10.1038/srep07493

Hummers, W. S., \& Offeman, R. E. (1958). Preparation of Graphitic Oxide. Journal of the American Chemical Society, 80(6), 1339. https://doi.org/10.1021/ja01539a017

Keerthana, D. S., Namratha, K., Byrappa, K., \& Yathirajan, H. S. (2015). Facile one-step fabrication of magnetite particles under mild hydrothermal conditions. Journal of Magnetism and Magnetic Materials, 378, 551-557. https://doi.org/10.1016/j.jmmm.2014.10.176

Konar, S., Kalita, H., Puvvada, N., Tantubay, S., Mahto, M. K., Biswas, S., \& Pathak, A. (2016). Shape-dependent catalytic activity of CuO nanostructures. Journal of Catalysis, 336, 11-22. https://doi.org/10.1016/j.jcat.2015.12.017

Kulkarni, S. A., Sawadh, P. S., Palei, P. K., \& Kokate, K. K. (2014). Effect of synthesis route 
on the structural, optical and magnetic properties of Fe304nanoparticles. Ceramics International, 40(1 PART B), 1945-1949.

https://doi.org/10.1016/j.ceramint.2013.07.103

Lassoued, A., Dkhil, B., Gadri, A., \& Ammar, S. (2017). Control of the shape and size of iron oxide ( $\alpha$-Fe2O3) nanoparticles synthesized through the chemical precipitation method. Results in Physics, 7, 3007-3015. https://doi.org/10.1016/j.rinp.2017.07.066 Lassoued, A., Lassoued, M. S., Dkhil, B., Gadri, A., \& Ammar, S. (2017). Structural, optical and morphological characterization of Cu-doped $\alpha$-Fe2O3nanoparticles synthesized through co-precipitation technique. Journal of Molecular Structure, 1148, 276-281. https://doi.org/10.1016/j.molstruc.2017.07.051

Magnacca, G., Allera, A., Montoneri, E., Celi, L., Benito, D. E., Gagliardi, L. G., \& Carlos, L. (2014). Novel magnetite nanoparticles coated with waste sourced bio- based substances as sustainable and renewable adsorbing materials. ACS Sustainable Chemistry and Engineering, 2(6), 1518-1524. https://doi.org/10.1021/sc500213j

Maity, D., \& Agrawal, D. C. (2007). Synthesis of iron oxide nanoparticles under oxidizing environment and their stabilization in aqueous and non-aqueous media. Journal of Magnetism and Magnetic Materials, 308(1), 46-55. https://doi.org/10.1016/j.jmmm.2006.05.001

Mousavi-Kamazani, M., Zarghami, Z., \& Salavati-Niasari, M. (2016). Facile and Novel Chemical Synthesis, Characterization, and Formation Mechanism of Copper Sulfide (Cu2S, Cu2S/CuS, CuS) Nanostructures for Increasing the Efficiency of Solar Cells. Journal of Physical Chemistry C, 120(4), 2096-2108. https://doi.org/10.1021/acs.jpcc.5b11566

Niu, M., Huang, F., Cui, L., Huang, P., Yu, Y., \& Wang, Y. (2010). Hydrothermal Synthesis, Structural Characteristics, and Enhanced Photocatalysis of SnO2/alpha-Fe2O3 Semiconductor Nanoheterostructures. ACS Nano, 4(2), 681-688.

Ou, X., Chen, S., Quan, X., \& Zhao, H. (2009). Photochemical activity and characterization of the complex of humic acids with iron (III). Journal of Geochemical Exploration, 102(2), 49-55. https://doi.org/10.1016/j.gexplo.2009.02.003 
Pellegrin, Y., \& Odobel, F. (2016). Sacrificial electron donor reagents for solar fuel production. Comptes Rendus Chimie, 20(3), 283-295.

https://doi.org/10.1016/j.crci.2015.11.026

Preisinger, M., Krispin, M., Rudolf, T., Horn, S., \& Strongin, D. R. (2005). Electronic structure of nanoscale iron oxide particles measured by scanning tunneling and photoelectron spectroscopies. Physical Review B - Condensed Matter and Materials Physics, 71, 165409-1. https://doi.org/10.1103/PhysRevB.71.165409

Rodríguez, N. A., Savateev, A., Grela, M. A., \& Dontsova, D. (2017). Facile Synthesis of Potassium Poly(heptazine imide) (PHIK)/Ti-Based Metal-Organic Framework (MIL125-NH2) Composites for Photocatalytic Applications. ACS Applied Materials and Interfaces, 9(27), 22941-22949. https://doi.org/10.1021/acsami.7b04745

Sklute, E. C., Kashyap, S., Dyar, M. D., Holden, J. F., Tague, T., Wang, P., \& Jaret, S. J. (2018). Spectral and morphological characteristics of synthetic nanophase iron (oxyhydr)oxides. Physics and Chemistry of Minerals, 45(1), 1-26. https://doi.org/10.1007/s00269-017-0897-y

Tilley, S. D., Cornuz, M., Sivula, K., \& Grätzel, M. (2010). Light-inducedwater splitting with hematite: Improved nanostructure and iridium oxide catalysis. Angewandte Chemie International Edition, 49(36), 6405-6408. https://doi.org/10.1002/anie.201003110

Uchihara, T., Oshiro, H., \& Kinjo, A. (1998). Subpicosecond studies of primary photochemical events of CdS particles with surface modified by various capping agents. Journal of Photochemistry and Photobiology A: Chemistry, 114(3), 227-237. https://doi.org/10.1016/S1010-6030(98)00225-1

Ursachi, I., Vasile, A., Chiriac, H., Postolache, P., \& Stancu, A. (2011). Magnetic properties of magnetite nanoparticles coated with mesoporous silica by sonochemical method. Materials Research Bulletin, 46(12), 2468-2473.

https://doi.org/10.1016/j.materresbull.2011.08.033

Wadhawan, J. D., Welford, P. J., McPeak, H. B., Hahn, C. E. W., \& Compton, R. G. (2003). The simultaneous voltammetric determination and detection of oxygen and carbon dioxide: A study of the kinetics of the reaction between superoxide and carbon 
dioxide in non-aqueous media using membrane-free gold disc microelectrodes. Sensors and Actuators, B: Chemical, 88(1), 40-52. https://doi.org/10.1016/S09254005(02)00307-6 
4 Carbamazepine Photodegradation 

As was already mentioned in the Introduction, the EP chosen in this Thesis is the psychiatric drug carbamazepine (CBZ). This compound has approximately $7 \%$ removal rate in sewage treatment plants and is commonly detected in the environment (Santos et al., 2010). The occurrence of CBZ in the environment may have a serious threat, as this compound is reported to be carcinogenic to rats. Additionally, this drug was shown to be fatal to zebrafish and subfatal to daphnia species at concentrations of 43 and $92 \mu \mathrm{g} \mathrm{L}^{-1}$, respectively (Santos et al., 2010).

The removal of CBZ has been widely investigated using different AOPs in recent literature (Alharbi \& Price, 2017). Direct UV photolysis at $254 \mathrm{~nm}$ or $365 \mathrm{~nm}$ has proven to be ineffective. However, the combination of UV photolysis with $\mathrm{H}_{2} \mathrm{O}_{2}$ was shown to be effective in achieving higher CBZ removal (Alharbi et al., 2017; Lee, et al., 2014). Mohapatra et al. have used different types of $\mathrm{TiO}_{2}$ and $\mathrm{ZnO}$ nanoparticles as photocatalysts for the photodegradation of CBZ using irradiation centered at $254 \mathrm{~nm}$ (Mohapatra et al., 2014). These authors prepared $\mathrm{TiO}_{2}$ and $\mathrm{ZnO}$ nanoparticles on a composite thin film in the presence and absence of whey proteins. Their results show that, after $2 \mathrm{~h}$ of UV irradiation, about 65 and 100\% of the initial CBZ concentration (295 $\mathrm{ng} \mathrm{L}{ }^{-1}$ ) were removed by $\mathrm{TiO}_{2}$ and whey- $\mathrm{TiO}_{2}$ nanoparticles, respectively. By contrast, $\mathrm{ZnO}$ and whey-ZnO nanoparticles removed about 60 and 92\% of the initial CBZ concentration, respectively.

In the next sections we show the results of the experiments of CBZ degradation performed with the aim of testing the photocatalytic performance of the materials prepared. 


\section{Carbamazepine (CBZ) Photodegradation}

Photodegradation experiments of $C B Z\left(2 \mathrm{mg} \mathrm{L} \mathrm{L}^{-1}\right)$ in the presence of nanocomposites $\left(0.625 \mathrm{~g} \mathrm{~L}^{-1}\right)$ prepared with different amounts of OM were performed. Degradation profiles of CBZ are shown in Fig. 4.1 . The more efficient degradation, $30 \%$ after $6 \mathrm{~h}$ of UV irradiation, was reached with the sample FeCu400/1 (i.e. the one with the lowest content of $\mathrm{OM})$. In order to enhance the degradation degree, further batch experiments with higher concentration of nanocomposites were performed. Fig. 4.2 shows results from $C B Z$ degradation achieved by using $1.25 \mathrm{~g} \mathrm{~L}^{-1}$ of the nanomaterials under UV irradiation. In this case, ca. 60-70\% degradation was reached after $6 \mathrm{~h}$ of irradiation when FeCu400/1, FeCu400/2 or FeCu400/3 are employed. Lower degradations rates are obtained with the nanomaterials with higher contant of organic matter (FeCu400/4 and FeCu400/5).

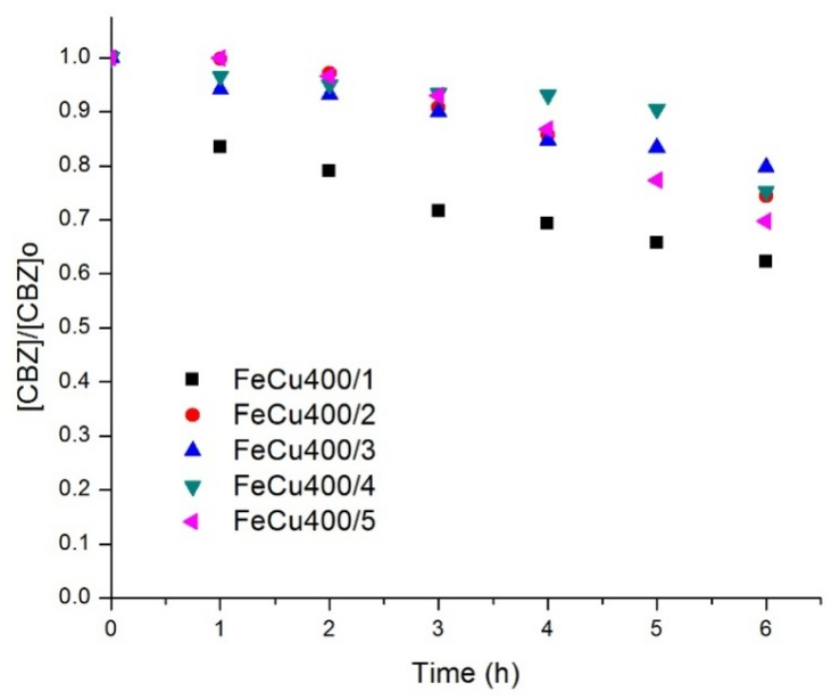

Fig. 4.1: Degradation profile of CBZ (initial concentration $2 \mathrm{mg} \cdot \mathrm{L}^{-1}$ ) obtained with the materials treated at 400 ${ }^{\circ} \mathrm{C}$ (initial concentration: $0.625 \mathrm{~g} \cdot \mathrm{L}^{-1}$ ) irradiated with $300 \mathrm{~nm}$, at RT and pH 5 . 


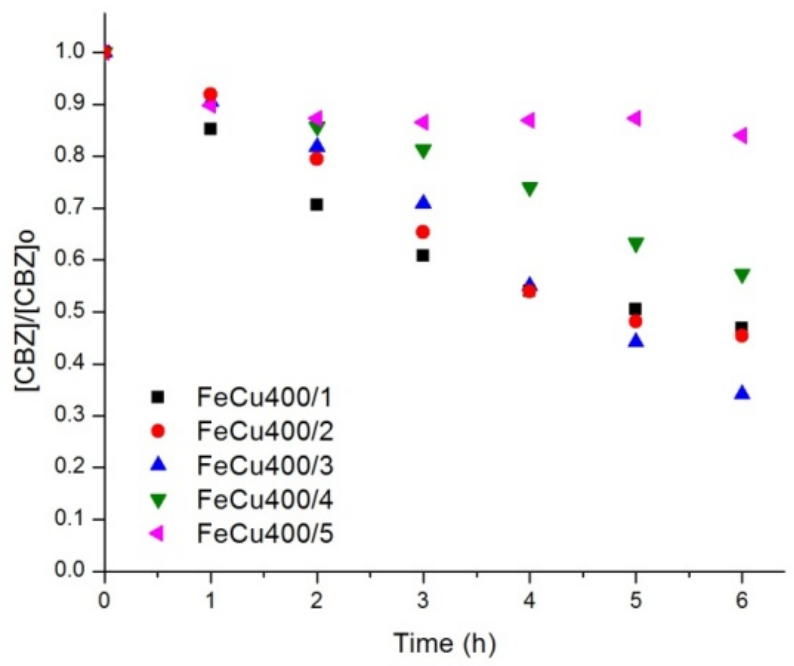

Fig. 4.2: Degradation profile of $C B Z$ (initial concentration $2 \mathrm{mg} \cdot \mathrm{L}^{-1}$ ) obtained with the materials treated at 400 ${ }^{\circ} \mathrm{C}$ (initial concentration: $1.25 \mathrm{~g} . \mathrm{L}^{-1}$ ) irradiated with $300 \mathrm{~nm}$ lamps at $\mathrm{pH} 5$ and RT.

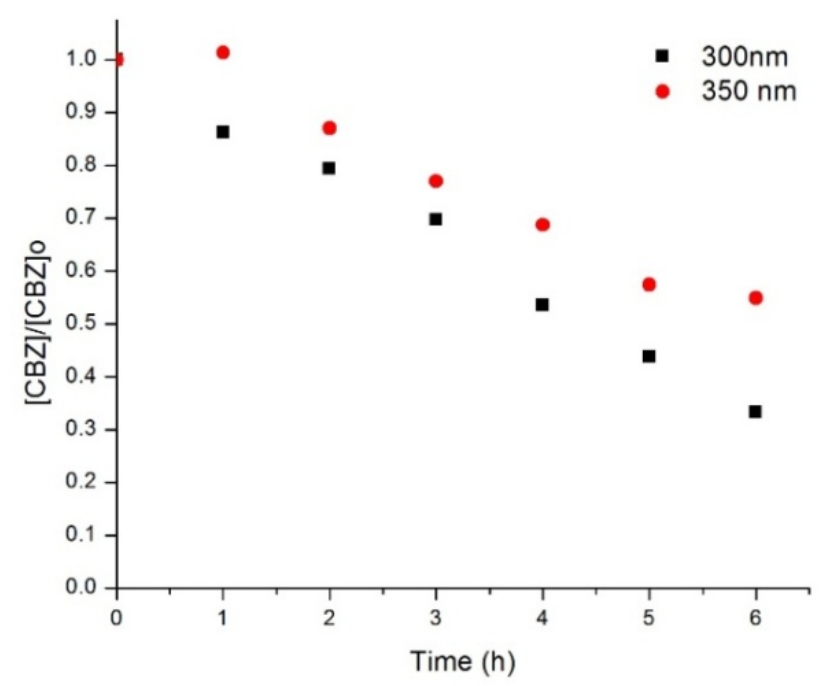

Fig. 4.3: Degradation profiles of CBZ (initial concentration $2 \mathrm{mg}^{-1} \mathrm{~L}^{-1}$ ) obtained with FeCu400/3 sample (initial

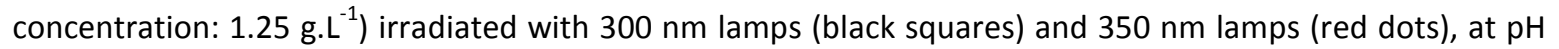
$5, \mathrm{RT}$ 
On the other hand, photochemical experiments using lamps with emission centered at $350 \mathrm{~nm}$, closer to the visible region, were also performed. A comparison between the CBZ kinetic profiles obtained in the presence of FeCu400/3 under irradiation with lamps centered at 300 and $350 \mathrm{~nm}$ are shown in Fig. 4.4. As expected from the absorption spectra of the samples, higher degradation rates were observed for the experiment performed with the $300 \mathrm{~nm}$ lamps. However, it is important to mention that under irradiation with $350 \mathrm{~nm}$ lamps a high degradation degree is still observed, which indicates that these nanocomposites could be used also in solar-driven photocatalysis.

In order to avoid a misinterpretation of the data and to quantify the effect of the direct photolysis of CBZ and the adsorption of CBZ on the nanocomposites surfaces, control experiments were performed in the absence of photocatalyst and, independently, without irradiation. Fig. 4.4 shows CBZ profiles obtained from experiments performed in the absence of photocatalysts at two irradiation systems (300 and $350 \mathrm{~nm}$ lamps). CBZ degradations lower than $5 \%$ is evidenced under both irradiation conditions, indicating that the nanocomposites are the responsible for the photocatalytic degradation of CBZ.

Adsorption experiments of CBZ were performed in the presence of FeCu400/1, FeCu400/3 and FeCu400/5. The CBZ profiles were obtained by allowing the contact (under constant stirring) of nanomaterials and CBZ, without irradiation. A removal of near $25 \%$ was reached for both FeCu400/1 and FeCu400/3 and $10 \%$ for FeCu400/5 after 6 h of contact (Fig. 4.5). These results indicate that, for FeCu400/5, the CBZ removal under irradiation takes place through an adsorption mechanism instead of degradation. For FeCu400/1 and FeCu400/3, by comparing the adsoprtion results with those obtained under irradiation, the photocatalytic pathway represents the larger contribution to the CBZ removal. Therefore, it can be inferred that the organic matter present in the samples plays a significant role in the photocatalytic properties of this type of materials: the higher OM content, the lower the photocatalytic activity. These results also agree with those found from the EPR analysis. 


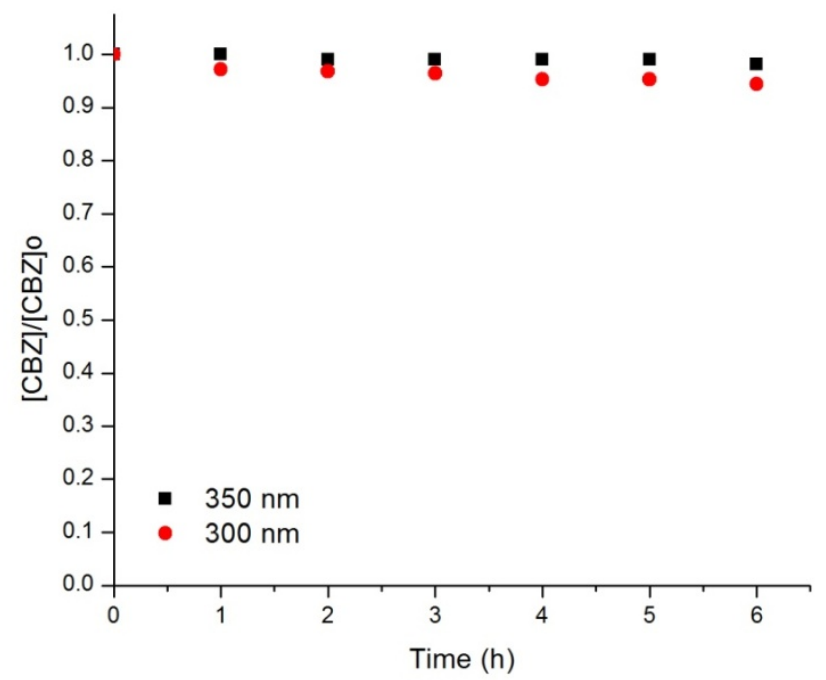

Fig. 4.4: Irradiation of CBZ solution (2 $\mathrm{mg}^{-\mathrm{L}^{-1}}$ ) in the absence of the nanocomposites (direct photolysis), at $\mathrm{pH}$ 5 and RT

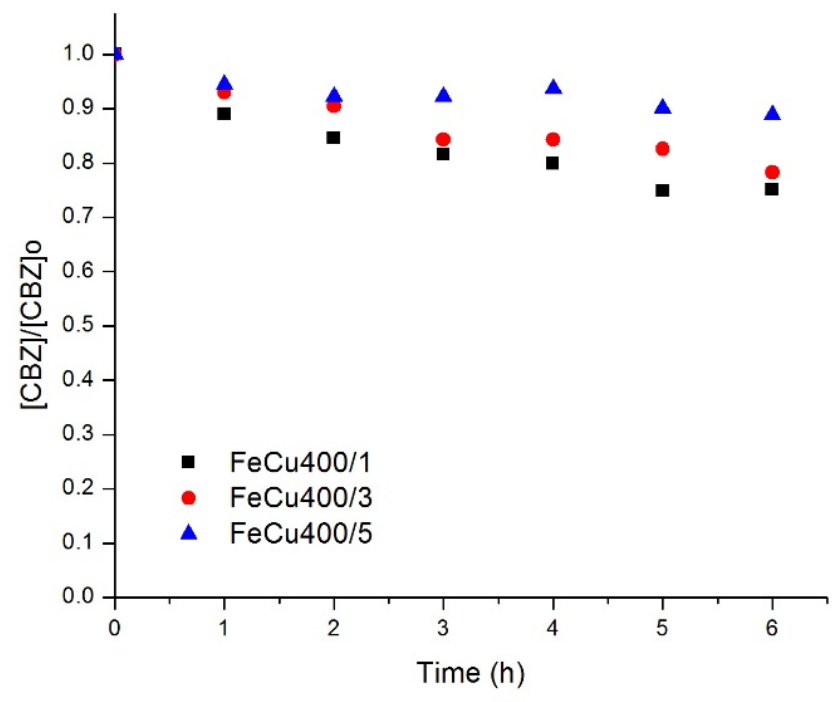

Fig. 4.5: Removal of CBZ from solutions $\left(2 \mathrm{mg}^{-L^{-1}}\right)$ in contact with the different nanocomposites $\left(0.625 \mathrm{~g} . \mathrm{L}^{-1}\right)$ without irradiation, at $\mathrm{pH} 5$ and $\mathrm{RT}$.

Fig. 4.6 shows the CBZ degradation profiles obtained with nanocomposites pyrolized at different temperatures (FeCu400/1, FeCu600/1 and FeCu800/1) under irradiation with $300 \mathrm{~nm}$ lamps. As can be seen, the sample pyrolized at $600{ }^{\circ} \mathrm{C}$ yields a 
total abatement of the carbamazepine after $4 \mathrm{~h}$ of irradiation; whereas for the material obtained by pyrolysis at $800^{\circ} \mathrm{C}$, a degradation higher than $90 \%$ was reached after $6 \mathrm{~h}$.

The control experiments without irradiation show almost the same CBZ removal for the three nanocomposites (ca. $30 \%$ ) (Fig. 4.7). This indicates that, under these conditions, samples FeCu600/1 and FeCu800/1 have photocatalytic activity much higher than FeCu400/1. The photocatalytic performance of FeCu800/1 is in line with the fact that the highest EPR signal of the hydroxyl adduct was recorded for this nanocomposite (see previous section).

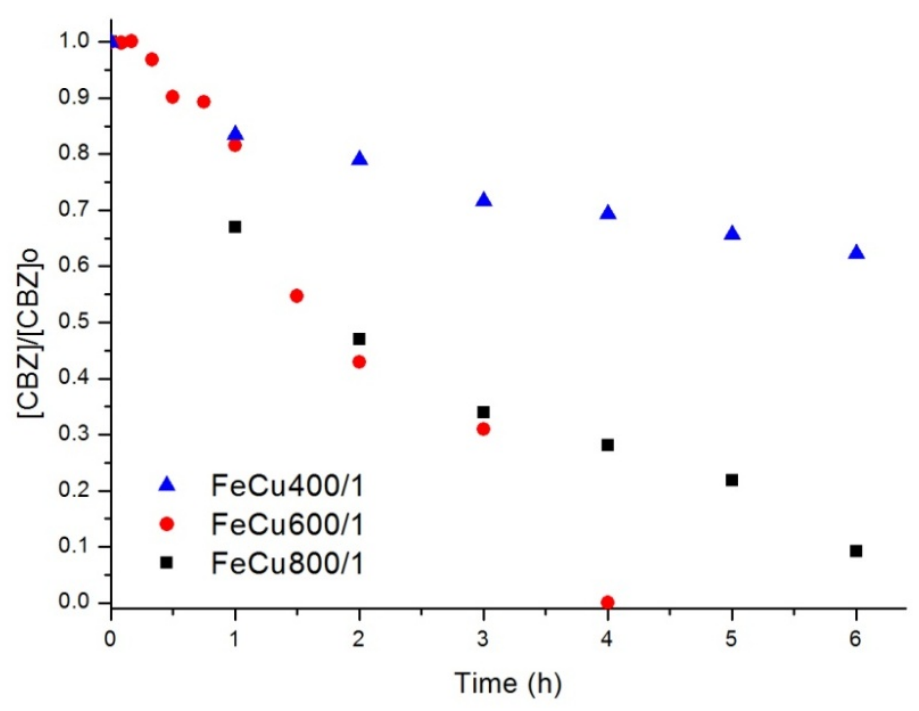

Fig. 4.6: CBZ (2 mg. $\left.\mathrm{L}^{-1}\right)$ degradation profiles obtained with FeCu600/1 and FeCu800/1 samples $\left(0.625\right.$ g. $\left.\mathrm{L}^{-1}\right)$, by irradiation with $300 \mathrm{~nm}$ lamps.

The effect of the $\mathrm{pH}$ on the CBZ photodegradation was also tested among the materials treated at different temperatures. The degradation profiles obtained with each material at $\mathrm{pH} 3,5$ and 7 are shown in Fig. 4.7 to 4.8 . In this $\mathrm{pH}$ range, there is no speciation of the CBZ, it prevails in its neutral form (Jones et al., 2002). As can be seen, at $\mathrm{pH} 3$ and 5 the degradation profiles were the same; whereas at $\mathrm{pH} 7$ the degradation was drastically diminished in the experiments performed with the three nanomaterials. The same behavior was reported by Haroune et al. (Haroune et al., 2014). These authors tested the influence of $\mathrm{pH}$ on the photodegradation of $\mathrm{CBZ}$ in presence of $\mathrm{TiO}_{2}$ and $\mathrm{ZnO}$ 
nanoparticles and found that low $\mathrm{pH}$ values favored the photodegradation independently of the type of the photocatalyst used.

Besides that, iron leaching from the nanomaterials could be the responsible for the pH dependent photodegradation. Moztahida et al. (Moztahida et al., 2019) used $\mathrm{Fe}_{3} \mathrm{O}_{4} @ r G O$ as photocatalyst and found that the leached iron complexes organic acids (intermediates of the photodegradation reaction). These complexes can be further activated by solar light, resulting in decarboxylation of the Fe-carboxylic acid complexes and a readsorption of the $\mathrm{Fe}(\mathrm{II})$ on the catalyst surface, which leads to the next photocatalytic cycle under visible light (Adán et al., 2009 and 2011). Therefore, the higher CBZ degradation at acidic pHs could be due to the more re-adsorption of the leached $\mathrm{Fe}(\mathrm{II})$, resulting in the restoration of the photocatalytic activity of the material (Moztahida et al., 2019).

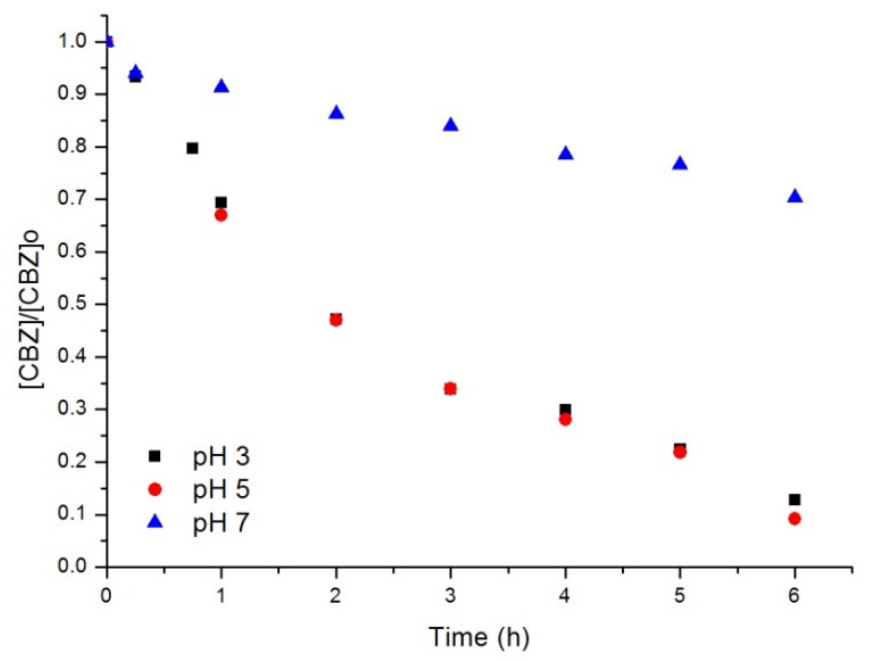

Fig. 4.7: $\mathrm{CBZ}\left(2 \mathrm{mg} \cdot \mathrm{L}^{-1}\right)$ degradation profiles obtained by irradiating with $300 \mathrm{~nm}$ lamps in suspensions of 0.625 g. $\mathrm{L}^{-1}$ of FeCu400/1 nanocomposite at different $\mathrm{pH}$ values. 


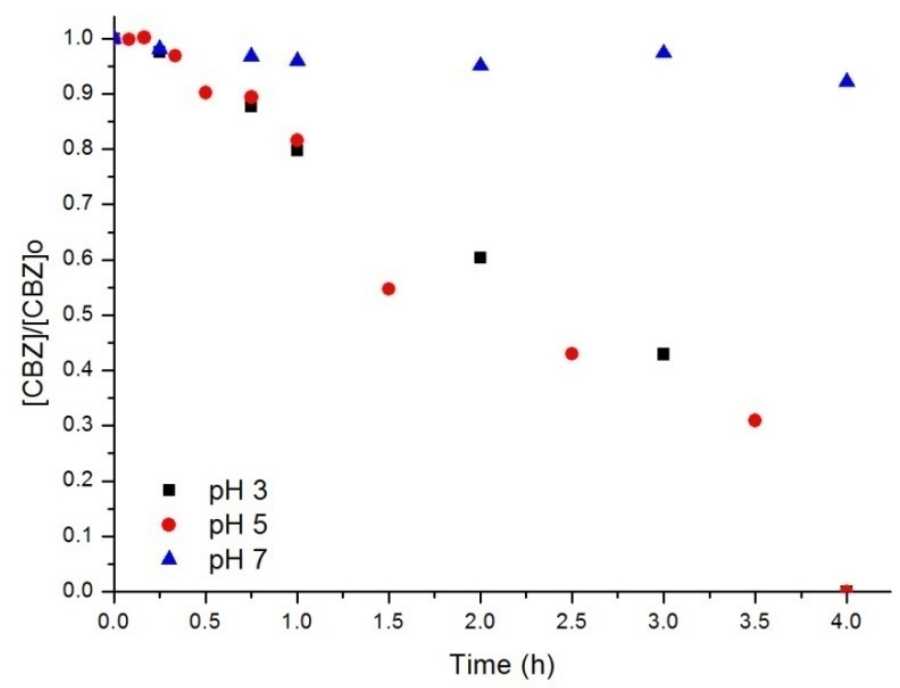

Fig. 4.8: $\mathrm{CBZ}\left(2 \mathrm{mg} \cdot \mathrm{L}^{-1}\right)$ degradation profiles obtained by irradiating with $300 \mathrm{~nm}$ lamps in suspensions of $0.625 \mathrm{~g} . \mathrm{L}^{-1}$ of FeCu600/1 nanocomposite at different $\mathrm{pH}$ values.

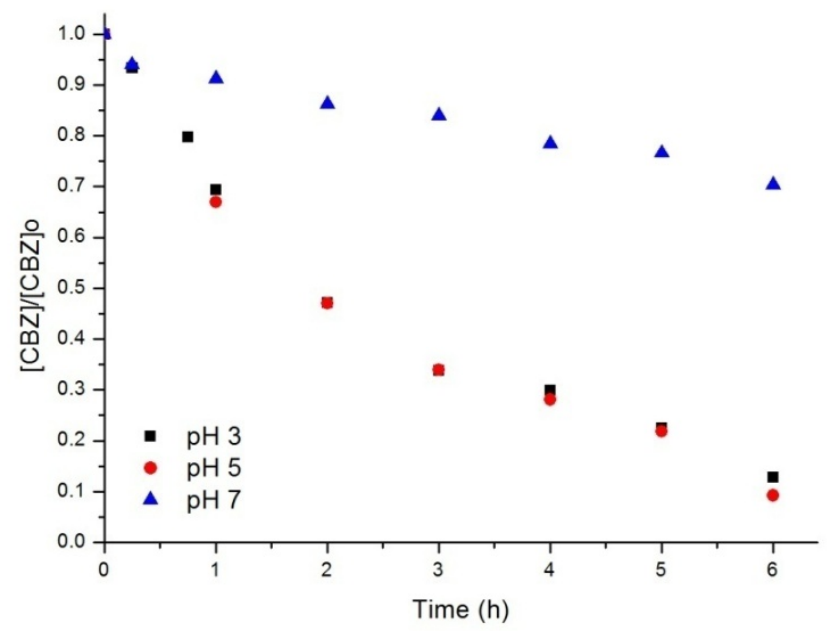

Fig. 4.9: $C B Z$ ( $2 \mathrm{mg} \cdot \mathrm{L}^{-1}$ ) degradation profiles obtained by irradiating with $300 \mathrm{~nm}$ lamps in suspensions of $0.625 \mathrm{~g} . \mathrm{L}^{-1}$ of FeCu600/1 nanocomposite at different $\mathrm{pH}$ values.

To identify the species responsible for the degradation of CBZ, photochemical experiments with FeCu400/1, FeCu600/1 and FeCu800/1 were carried out in the presence of $10 \mathrm{mM}^{2}$-propanol, an $\mathrm{HO}^{\circ}$ radical scavenger, $\mathrm{NaN}_{3}(10 \mathrm{mM})$, a singlet oxygen and $\mathrm{HO}^{\bullet}$ radical scavenger (Rubio et al., 1992) and furfuryl alcohol (1 mM) a singlet oxygen 
scavenger (Bosio et al., 2008). Results obtained from these experiments are shown in Fig. 4.10 to Fig. 4.12. According to the reaction constants shown in Table 4.1, it can be seen that 2-propanol is a scavenger specific for the detection of the $\mathrm{OH}^{*}$ radicals. On the other hand, furfuryl alcohol and $\mathrm{NaN}_{3}$ react with both $\mathrm{OH}^{\cdot}$ radicals and singlet oxygen. However, due to the much longer lifetime of singlet oxygen compared to the hydroxyl radical, the effect on this reactive species is expected to be more relevant.

Table 4.1: Reaction constant between scavengers and ROS

\begin{tabular}{|c|c|c|}
\hline scavenger & ${ }^{1} \mathrm{O}_{2}$ & $\mathrm{OH}^{\circ}$ \\
\hline Sodium azide & $\begin{array}{l}\qquad 3 \times 10^{8} \mathrm{M}^{-1} \mathrm{~s}^{-1} \\
\text { (Rubio et al., 1992) }\end{array}$ & $1.4 \times 10^{10} \mathrm{M}^{-1} \mathrm{~s}^{-1}$ (NIST, 2002) \\
\hline $\begin{array}{l}\text { Furfuryl } \\
\text { alcohol }\end{array}$ & $\begin{array}{c}1.2 \times 10^{8} \mathrm{M}^{-1} \mathrm{~s}^{-1} \\
\text { (Haag \& Hoigné, 1986) }\end{array}$ & $\begin{array}{c}1.5 \times 10^{10} \mathrm{M}^{-1} \mathrm{~s}^{-1} \\
\text { (Richard \& Lemaire, 1990) }\end{array}$ \\
\hline 2-propanol & $<10^{5} \mathrm{M}^{-1} \mathrm{~s}^{-1}$ & $\begin{array}{c}2 \times 10^{9} \mathrm{M}^{-1} \mathrm{~s}^{-1} \\
\text { (Richard \& Lemaire, 1990) }\end{array}$ \\
\hline
\end{tabular}

For the material FeCu400/1, the degradation profiles obtained in the presence of 2-propanol are much slower than in its absence. This result supports the participation of the hydroxyl radicals in the consumption of CBZ. Experiments performed with FFA and $\mathrm{NaN}_{3}$ yielded lower degradation degree than in the presence of 2-propanol. This led to the assumption that singlet oxygen is also involved in the photoreaction of the drug when FeCu400/1 material is used as photocatalyst. The generation of this reactive species should arise from the organic matter still present.

Otherwise, for the materials FeCu600/1 and FeCu800/1 the CBZ removal significantly decreased in the presence of the scavengers to values close to those obtained from the adsorption experiments. Similar effects of 2-propanol, FFA and $\mathrm{NaN}_{3}$ were observed, which indicates that $\mathrm{HO}^{\circ}$ radicals are the responsible species for the 
degradation of $\mathrm{CBZ}$, and in these cases, the role of singlet oxygen seems to be non-relevant.

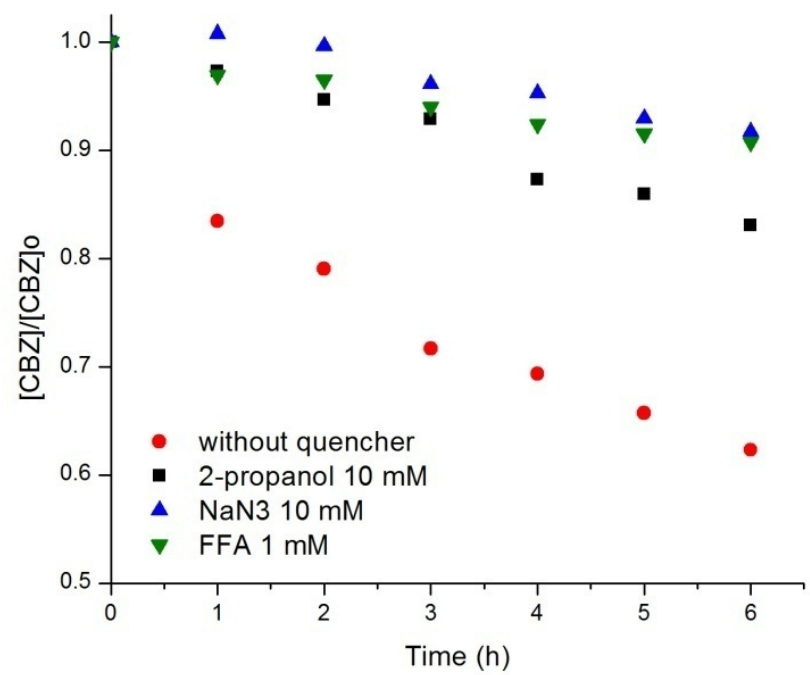

Fig. 4.10: Effect of FFA, $\mathrm{NaN}_{3}$ and 2-propanol on $\mathrm{CBZ}$ degradation profile when using FeCu400/1 sample ( $\left.0.625 \mathrm{~g} \cdot \mathrm{L}^{-1}\right)$ on the degradation profile of $\mathrm{CBZ}$ solutions $\left(2 \mathrm{mg} \cdot \mathrm{L}^{-1}\right)$

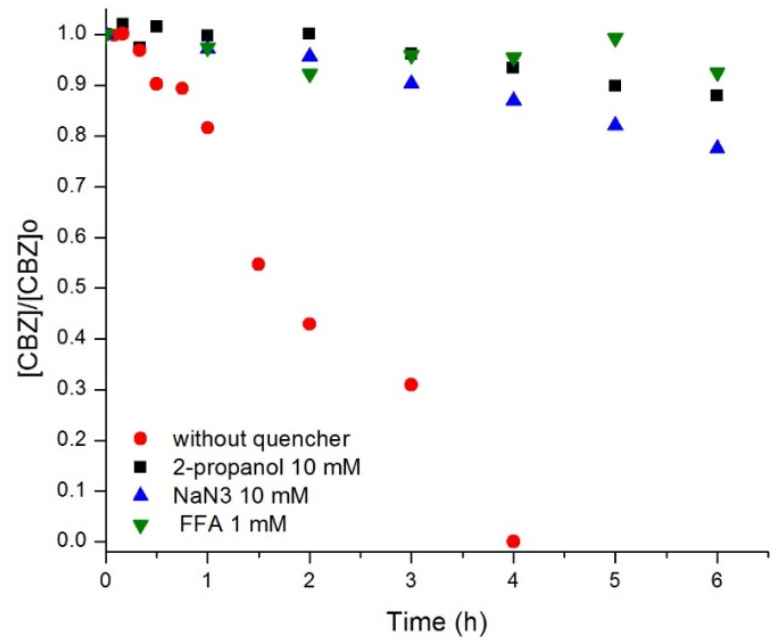

Fig. 4.11: Effect of FFA, $\mathrm{NaN}_{3}$ and 2-propanol on $\mathrm{CBZ}$ degradation profile when using FeCu600/1 sample (0.625 g.L $\left.{ }^{-1}\right)$ on the degradation profile of CBZ solutions $\left(2 \mathrm{mg}^{-1} \mathrm{~L}^{-1}\right.$. 


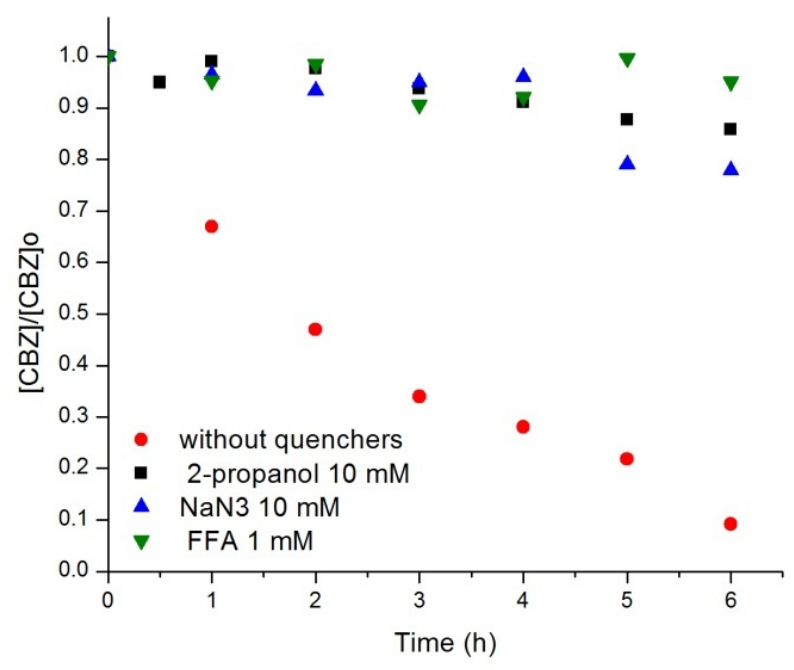

Fig. 4.12: Effect of FFA, $\mathrm{NaN}_{3}$ and 2-propanol on $\mathrm{CBZ}$ degradation profile when using FeCu800/1 sample (0.625 g. $\left.\mathrm{L}^{-1}\right)$ on the degradation profile of CBZ solutions $\left(2 \mathrm{mg} \cdot \mathrm{L}^{-1}\right)$.

The effect of the nature of the divalent metal cation used in the synthesis of the nanocomposites on the degradation of CBZ was also studied. Photochemical experiments in the presence of FeCu600/1, FeNi600/1 and FeCo600/1 were carried out with and without irradiation (Fig. 4.13 and 4.14). High percentage of CBZ removal was achieved with all samples under irradiation. FeCu600/1 yielded higher CBZ degradation than the other nanocomposites obtained at the same pyrolysis temperature. One explanation of the observed results could be the higher OM content present in FeNi600/1 and FeCo600/1 with respect to $\mathrm{FeCu600/1;} \mathrm{since} \mathrm{OM} \mathrm{plays} \mathrm{a} \mathrm{negative} \mathrm{role} \mathrm{on} \mathrm{the} \mathrm{photocatalytic}$ performance of the nanocomposites. This trend also agrees with that found from EPR measurements (see previous chapter). 


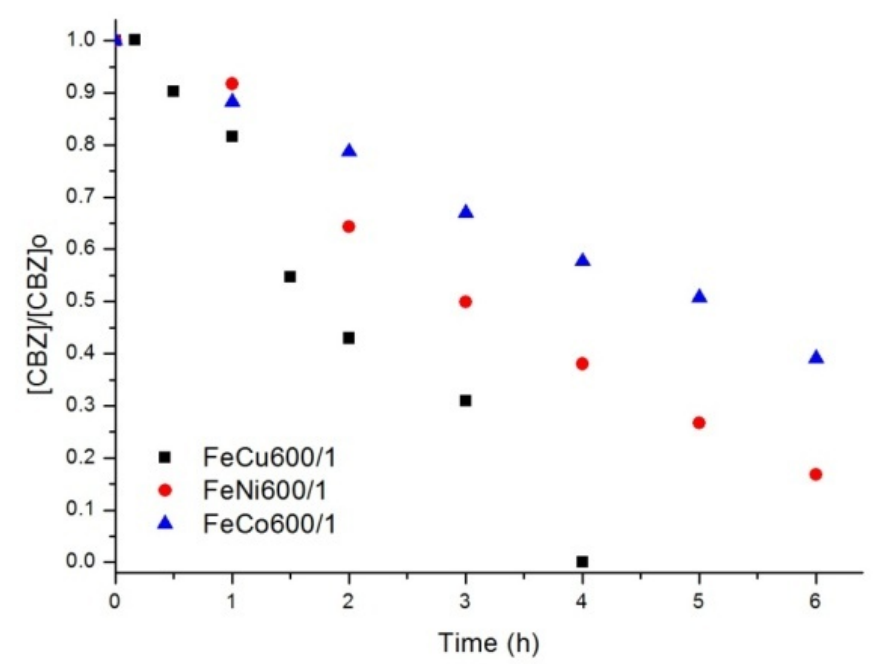

Fig. 4.13: Degradation profiles of CBZ solutions $\left(2 \mathrm{mg} \cdot \mathrm{L}^{-1}\right)$ and FeCo600/1 or FeNi600/1 samples (0.615 g. $\mathrm{L}^{-1}$ ) under irradiation with $300 \mathrm{~nm}$ lamps at pH 5 and RT. (The degradation profile obtained with FeCu600/1 sample in the same experimental conditions is shown for comparison).

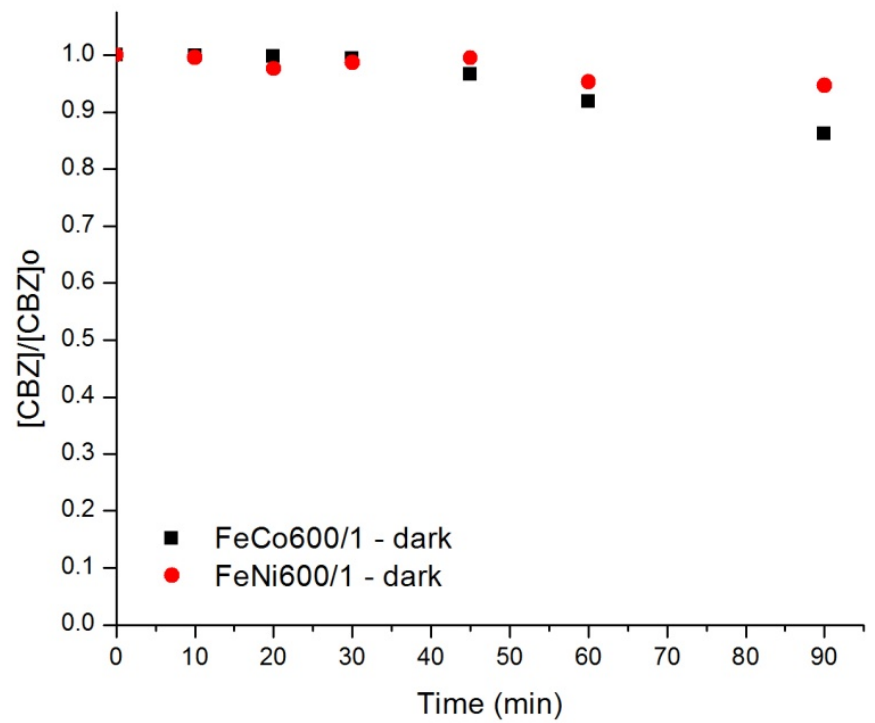

Fig. 4.14: Removal of CBZ solutions (2 mg. $\mathrm{L}^{-1}$ ) obtained with FeCo600/1 and FeNi600/1 samples (0.615 g. $\mathrm{L}^{-1}$ ) without irradiation at $\mathrm{pH} 5$ and $\mathrm{RT}$. 
The results of the photodegradation experiments obtained with all the materials in different experimental conditions are summarized in Table 4.2. The apparent rate constant $\left(k_{a p p}\right)$ resulting from a pseudo-first order fit is also included. Even if this model does not consider the complexity involved in these types of photoreactions, it can be used as a tool for comparison purposes.

Table 4.2: Results of the degradation of CBZ when using the different materials as photocatalyst and/or adsorbent materials

\begin{tabular}{|c|c|c|c|c|c|c|}
\hline material & $\lambda$ emission & $\begin{array}{c}\text { concentration } \\
\left(\mathrm{mg} \mathrm{L}^{-1}\right)\end{array}$ & $\mathrm{pH}$ & $\begin{array}{c}\% \text { CBZ } \\
\text { phodegradation }^{a}\end{array}$ & $k_{\text {app }}\left(h^{-1}\right)$ & $\begin{array}{c}\text { \% CBZ } \\
\text { darkness }^{\mathrm{b}}\end{array}$ \\
\hline \multirow{4}{*}{ FeCu400/1 } & \multirow{4}{*}{$300 \mathrm{~nm}$} & \multirow{3}{*}{0.625} & 3 & 47 & 0.092 & - \\
\hline & & & 5 & 48 & 0.118 & 25 \\
\hline & & & 7 & 23 & 0.043 & - \\
\hline & & 1.250 & 5 & 43 & 0.168 & - \\
\hline \multirow{2}{*}{$\mathrm{FeCu} 400 / 2$} & \multirow{2}{*}{$300 \mathrm{~nm}$} & 0.625 & 5 & 26 & 0.025 & \\
\hline & & 1.250 & 5 & 55 & & - \\
\hline \multirow{3}{*}{$\mathrm{FeCu} 400 / 3$} & \multirow{2}{*}{300 nm } & 0.625 & 5 & 20 & 0.037 & 22 \\
\hline & & 1.250 & 5 & 66 & 0.121 & - \\
\hline & $350 \mathrm{~nm}$ & 1.250 & 5 & 45 & 0.077 & - \\
\hline \multirow{2}{*}{$\mathrm{FeCu} 400 / 4$} & \multirow{2}{*}{$300 \mathrm{~nm}$} & 0.625 & 5 & 25 & 0.024 & - \\
\hline & & 1.250 & 5 & 53 & 0.067 & - \\
\hline \multirow{2}{*}{$\mathrm{FeCu} 400 / 5$} & \multirow{2}{*}{$300 \mathrm{~nm}$} & 0.625 & 5 & 30 & 0.021 & 12 \\
\hline & & 1.250 & 5 & 26 & 0.058 & - \\
\hline \multirow{3}{*}{ FeCu600/1 } & \multirow{3}{*}{$300 \mathrm{~nm}$} & \multirow{3}{*}{0.625} & 3 & total & 0.203 & - \\
\hline & & & 5 & Total & 0.179 & 7 \\
\hline & & & 7 & 8 & 0.044 & - \\
\hline \multirow{3}{*}{$\mathrm{FeCu} 800 / 1$} & \multirow{3}{*}{$300 \mathrm{~nm}$} & \multirow{3}{*}{0.625} & 3 & 90 & 0.363 & - \\
\hline & & & 5 & 91 & 0.368 & 29 \\
\hline & & & 7 & 30 & 0.066 & - \\
\hline FeCo600/1 & $300 \mathrm{~nm}$ & 0.625 & 5 & 62 & 0.128 & 14 \\
\hline FeNi600/1 & $300 \mathrm{~nm}$ & 0.625 & 5 & 83 & 0.218 & 5 \\
\hline
\end{tabular}

${ }^{a}$ abatement in photodegradation experiments after $6 \mathrm{~h}$ irradiation. ${ }^{\mathrm{b}}$ abatement in darkness control after $6 \mathrm{~h}$ of contact 



\section{Conclusions}

The nanocomposites prepared in this Thesis showed to be good candidates to be used as photocatalysts for the degradation of the organic pollutant Carbamazepine, both upon $300 \mathrm{~nm}$ and $350 \mathrm{~nm}$ excitation.

From comparison of the performance as photocatalysts and adsorbent materials of FeCu400/1 and FeCu400/3 and FeCu400/5, it can be concluded that the removal of CBZ with FeCu400/5 takes place mainly through an adsorption mechanism, whereas for $\mathrm{FeCu} 400 / 1$ and FeCu400/3 the photocatalytic pathway represents the main contribution to the CBZ removal. These results indicate that the higher the OM content, the lower the photocatalytic capacity. This behavior completely agrees with the results of the EPR analysis.

Photodegradation results obtained in the presence of scavengers confirm the participation of the hydroxyl radical as the main species responsible for the photocatalytic degradation of CBZ. In addition, the FeCu400/1 catalyst, the participation of singlet oxygen in the degradation of the pollutant cannot be neglected.

Comparative photocatalytic experiments performed with nanocomposites pyrolized at different temperatures (FeCu400/1, FeCu600/1 and FeCu800/1) under irradiation at $300 \mathrm{~nm}$ showed a much better performance for the nanomaterials pyrolyzed at higher temperature. The excellent photocatalytic performance of FeCu800/1 is in line with the fact that the highest EPR signal of the hydroxyl adduct was recorded for this nanocomposite.

The $\mathrm{pH}$ effect on the CBZ photodegradation is similar for the three nanocomposites tested (i.e. FeCu400/1, FeCu600/1 and FeCu800/1): there is an increase of the photodegradation rate at lower values of $\mathrm{pH}$. As was proposed by other authors, this could be due to the iron leaching, followed by its re-adsorption onto the photocatalyst surface leading to a regeneration of the photocatalytic activity. Further evidence is needed to clarify this mechanism. 



\subsection{References}

Adán, C., Carbajo, J., Bahamonde, A., Oller, I., Malato, S., \& Martínez-Arias, A. (2011). Solar light assisted photodegradation of phenol with hydrogen peroxide over iron-doped titania catalysts: Role of iron leached/readsorbed species. Applied Catalysis B: Environmental, 108-109, 168-176. https://doi.org/10.1016/j.apcatb.2011.08.026

Adán, Cristina, Martínez-Arias, A., Malato, S., \& Bahamonde, A. (2009). New insights on solar photocatalytic degradation of phenol over Fe-TiO2 catalysts: Photo-complex mechanism of iron lixiviates. Applied Catalysis B: Environmental, 93(1-2), 96-105. https://doi.org/10.1016/j.apcatb.2009.09.017

Alharbi, S. K., Kang, J., Nghiem, L. D., van de Merwe, J. P., Leusch, F. D. L., \& Price, W. E. (2017). Photolysis and UV/H2O2of diclofenac, sulfamethoxazole, carbamazepine, and trimethoprim: Identification of their major degradation products by ESI-LC-MS and assessment of the toxicity of reaction mixtures. Process Safety and Environmental Protection, 112, 222-234.

https://doi.org/10.1016/j.psep.2017.07.015

Alharbi, S. K., \& Price, W. E. (2017). Degradation and Fate of Pharmaceutically Active Contaminants by Advanced Oxidation Processes. Current Pollution Reports, 3(4), 268-280. https://doi.org/10.1007/s40726-017-0072-6

Bosio, G. N., Gara, P. D., Garcı, F. S., Gonzalez, C., Panno, D., \& Ma, D. O. (2008). Photodegradation of Soil Organic Matter and its Effect on Gram-negative Bacterial Growth. Photochemestry and Photobiology, 84, 1126-1132. https://doi.org/10.1111/j.1751-1097.2007.00274.x

Haag, W. R., \& Hoigné, J. (1986). Singlet Oxygen in Surface Waters. 3. Photochemical Formation and SteadyState Concentrations in Various Types of Waters. Environmental Science and Technology, 20(4), 341348. https://doi.org/10.1021/es00146a005

Haroune, L., Salaun, M., Ménard, A., Legault, C. Y., \& Bellenger, J. P. (2014). Photocatalytic degradation of carbamazepine and three derivatives using $\mathrm{TiO}_{2}$ and $\mathrm{ZnO}$ : Effect of $\mathrm{pH}$, ionic strength, and natural organic matter. Science of the Total Environment, 475, 16-22.

https://doi.org/10.1016/j.scitotenv.2013.12.104

Jones, O. A. H., Voulvoulis, N., \& Lester, J. N. (2002). Aquatic environmental assessment of the top 25 English prescription pharmaceuticals. Water Research, 36(20), 5013-5022. https://doi.org/10.1016/S00431354(02)00227-0

Lee, H. J., Lee, H., \& Lee, C. (2014). Degradation of diclofenac and carbamazepine by the copper(II)-catalyzed dark and photo-assisted Fenton-like systems. Chemical Engineering Journal, 245, 258-264. https://doi.org/10.1016/j.cej.2014.02.037

Mohapatra, D. P., Brar, S. K., Daghrir, R., Tyagi, R. D., Picard, P., Surampalli, R. Y., \& Drogui, P. (2014). Photocatalytic degradation of carbamazepine in wastewater by using a new class of whey-stabilized nanocrystalline TiO2 and ZnO. Science of the Total Environment, 485-486(1), 263-269. https://doi.org/10.1016/j.scitotenv.2014.03.089

Moztahida, M., Jang, J., Nawaz, M., Lim, S. R., \& Lee, D. S. (2019). Effect of rGO loading on Fe 304 : A visible light assisted catalyst material for carbamazepine degradation. Science of the Total Environment, 667, 741-750. https://doi.org/10.1016/j.scitotenv.2019.02.376 
NIST. (2002). Solution Kinetic Database. Retrieved from https://kinetics.nist.gov/solution/

Richard, C., \& Lemaire, J. (1990). Analytical and kinetic study of the phototransformation of furfuryl alcohol in aqueous ZnO suspensions. Journal of Photochemistry and Photobiology, A: Chemistry, 55(1), 127134. https://doi.org/10.1016/1010-6030(90)80025-S

Rubio, M. A., Mártire, D. O., Braslavsky, S. E., \& Lissi, E. A. (1992). Influence of the ionic strength on O2(1 $\Delta \mathrm{g})$ quenching by azide. Journal of Photochemistry and Photobiology, A: Chemistry, 66(2), $153-157$. https://doi.org/10.1016/1010-6030(92)85209-D

Santos, L. H. M. L. M., Araújo, A. N., Fachini, A., Pena, A., Delerue-Matos, C., \& Montenegro, M. C. B. S. M. (2010). Ecotoxicological aspects related to the presence of pharmaceuticals in the aquatic environment. Journal of Hazardous Materials, 175, 45-95.

https://doi.org/10.1016/j.jhazmat.2009.10.100 


\section{General Conclusions}



A new use for the BBS was successfully presented: they were proved to be able to complex metal ions, which then by pyrolysis lead to the development of crystalline phases. Regarding to the complexation itself, it is noteworthy the lack of studies of these reactions with these particular materials. There is only a report on the determination of the constant of complexation of BBS with $\mathrm{Fe}^{3+}$, (García-Ballesteros et al.). By the similarity of their physicochemical properties to those of humic acids, it is expected that they will present a similar behavior. Different affinity of $\mathrm{BBS}$ for $\mathrm{Cu}^{2+}$ and $\mathrm{Fe}^{3+}$ was evidenced in the final composition of the complex precursors under the experimental conditions studied. This is an interesting result, which could open a new line of research since more information of these interactions could be obtained by studying the effect of different parameters (such as $\mathrm{pH}$, metals concentration, ionic strength, etc.). The counter-ion of the metal salts could also be a variable of interest. Sulfate ions are still present in the precursors and are responsible for developing copper sulfides phases during the pyrolysis, whereas the nitrogen precursors (nitrates) seem to be lost by volatilization.

Magnetic nanocomposites were obtained by submitting the complex-precursors to different target temperatures, being $400{ }^{\circ} \mathrm{C}$ the lowest temperature that led to the development of crystalline magnetic phases (maghemite, magnetite and hematite). By increasing the pyrolysis temperature, the crystallinity of the materials also increased. For the material treated at $800{ }^{\circ} \mathrm{C}$ formation of $\mathrm{FeO}$ was observed. The magnetic response was also affected by the temperature of pyrolisys, presumably due to the reduction of the organic matter present in the samples. Also, the specific surface area increased by increasing the temperature of the treatment. These changes in the nature of the carbonaceous matrices are confirmed by FT-IR spectroscopy, which shows a clear reduction of the intensity of the bands assigned to organic functional groups.

Since the magnetite/maghemite/hematite phases were developed at the expense of the organic matter, the way the oxide surfaces interact with remnant organic matter seems to be different from the interaction that takes place when the particles are first formed and their surfaces modified in a second step (like in the co-precipitation synthesis). This can be suggested by the differences observed in FT-IR spectra of our 
materials with respect to those obtained by co-precipitation, especially in the signals assigned to the interaction between metal atoms and oxygen atoms from the organic matrix.

By XANES it was possible to confirm the presence of $\mathrm{Cu}$ in the nanocomposites, as copper sulfides $\left(\mathrm{Cu}_{2} \mathrm{~S}\right.$ and $\left.\mathrm{CuS}_{2}\right)$ and bonded to BBS in some extent. However, the reproduction of the experimental spectra by linear combination of those of different references was not completely successful. Thus, some information is still missing and efforts should be done to further understand the mechanism of formation of these phases.

The uptake of $\mathrm{Ni}^{2+}$ and $\mathrm{Co}^{2+}$ ions by contact with BBS solutions was also achieved. In the case of the cobalt containing material, some evidence for the formation of the cobalt ferrite was found (by XANES and XRD), but in general cobalt and nickel seemed to follow their own pathway of oxides formation, besides from the iron oxides formation. Doped magnetite or $\mathrm{MFe}_{2} \mathrm{O}_{4}$ ferrites were not easily obtained; further studies will be needed to design proper synthesis strategies if BBS will be employed in the procedures.

The complexity and inhomogeneity of BBS help us to explain the polydispersity and microheterogeneity of the resulting materials.

Since these materials are proposed to be used as photocatalysts, characterization of their band gap energy was intended by DRS. Contrary to our expectations, the spectra were very different from those of semiconductors and resembled to those of carbonaceous materials. Thus, it was not possible to obtain their band gaps from Tauc's plots. However, the production of hydroxyl radical was unambiguously shown by EPR spectroscopy and LFP gave us evidence for the electron/hole pair formation upon irradiation. Moreover, the removal of the psychiatric drug carbamazepine by irradiation of solutions in the presence of the nanocomposites was found to be successfull. Thus, the potential application of these nanomaterials in the treatment of contaminated waters revalorizes solid urban wastes as the carbon sources necessary for their synthesis. 
6 Complementary activities 



\section{Participation in Scientific Events}

- II Congreso Internacional de Ciencia y Tecnología Ambiental, II Congreso Nacional de la Sociedad Argentina de Ciencia y Tecnología Ambiental. Sociedad Argentina de Ciencia y Tecnología Ambiental (SACYTA). Buenos Aires, 2015. Oral Presentation“Fotodegradación de contaminantes por nanopartículas magnéticas". Francisca Aparicio, Luciano Carlos, Daniel Mártire

- I Jornadas de Tesistas de la Facultad de Ciencias Exactas, UNLP. Facultad de Ciencias Exactas UNLP. La Plata, 2015 Poster presentation: “Generación de Nanopartículas Magnéticas como materiales adsorbentes y fotosensibilizadores de bajo costo para tratamiento de aguas" Francisca Aparicio, Luciano Carlos, Daniel Mártire.

- XVI Encuentro de Superficies y Materiales Nanoestructurados. FCEyN - UBA Bs. As. Argentina, May, 2016. Presentación formato póster: Fotocatálisis con nanopartículas magnéticas de $\mathrm{Fe}-\mathrm{Cu}$ recubiertas con materia orgánica proveniente de residuos sólidos urbanos". Francisca Aparicio, Luciano Carlos, Daniel Mártire

- Simposio Materiales y Tecnologías para la Industria Metalmecánica y Aeroespacial. UNC Córdoba, Argentina, November22nd to 25th, 2016. Poster presentation: "Estudio de la actividad fotocatalítica de óxidos de Zn recuperados de pilas agotadas". M. Victoria Gallegos; Francisca Aparicio, Andrés Peluso, Jorge Sambeth, Horacio Thomas.

- XX Congreso Argentino de Fisicoquímica y Química Inorgánica (CAFQI). UNRC - Córdoba, Argentina, May16thto 19th 2017. Oral presentation: Materiales Magnéticos obtenidos a partir de residuos sólidos urbanos: estudio de sus propiedades y variables de síntesis". Francisca Aparicio, Luciano Carlos, Daniel Mártire, GiulianaMagnacca.

- XIII Encuentro Latinoamericano de Fotoquímica y Fotobiología (ELAFOT). October 23rd to 27th, 2017. Villa Carlos Paz, Córdoba, Argentina. Poster presentation: "Magnetic composites as photocatalyts for Carbamazepine defradation". Francisca Aparicio, Luciano Carlos, Daniel Mártire, GiulianaMagnacca.

\section{Research Stays}

Institution: Dipartimento di Chimica - UniversitàdegliStudi di Torino (UNITO) - Torino, Italia

Period: October - December 2015

Direction: Dr. Giuliana Magnacca

Institution: Instituto de Investigación y Desarrollo en Ingeniería de Procesos, Biotecnología y Energías Alternativas (PROBIEN), Universidad Nacional del Comahue - CONICET - Neuquén, Argentina

Period: February 10thto 17th, 2016

Supervisor: Dr. Luciano Carlos 
Institution: Dipartimento di Chimica - UniversitàdegliStudi di Torino (UNITO) - Torino, Italia Period: October toDicember, 2016

Supervisor: Dra. GiulianaMagnacca

Institución: Dipartimento di Chimica - UniversitàdegliStudi di Torino (UNITO) - Torino, Italia Period: September to November, 2017

Supervisor: Dra. Giuliana Magnacca

\section{PhD courses}

Title: Experimental Techniques for gas-solid adsorption studies

Duration: 15 hours over a 1 week

Institution:Dipartimento di Chìmica - UNITO, Torino, Italia

Title: Especies Reactivas del Oxígeno y su aplicación en la degradación de contaminantes acuosos Duration: 40 hoursover a week

Institution: Departamento de Química - Fac. Cs. Exactas Fisicoquímicas y Naturales - Universidad Nacional de Río Cuarto, Córdoba, Argentina

Title:Nanomateriales y Microdispositivos: Síntesis, Fabricación y Caracterización de Sistemas

Duration: 45 hours

Institution:InstitutoSábato- CNEA

Title: Especies reactivas involucradas en tratamientos fotoquímicos de aguas

Duration: 40 hours

Institution: Facultad de Ingeniería -UNCo

Title: Curso Básico de Análisis de Imágenes: ImageJ

Duration: 15 hours

Institution: CCT CONICET Mendoza

Title: Ciencia, Tecnología y Sociedad

Duration: 45 hours 
Institution: FCE - UNLP

Title: Fisicoquímica de las Interfaces

Duration: 60 hours

Institution: FCE - UNLP

Title: Fundamentos y Aplicaciones de Espectroscopias Vibracionales FT-IR y Raman

Duration: 50 hours

Institution: FCE - UNLP 
